VNIVVERSİDAD DE SALAMANCA

FACVLTAD DE EDVCACIÓN

DEPARTAMENTO DE DIDÁCTICA DE LA MATEMÁTICA

Y DIDÁCTICA DE LAS CIENCIAS EXPERIMMENTALES

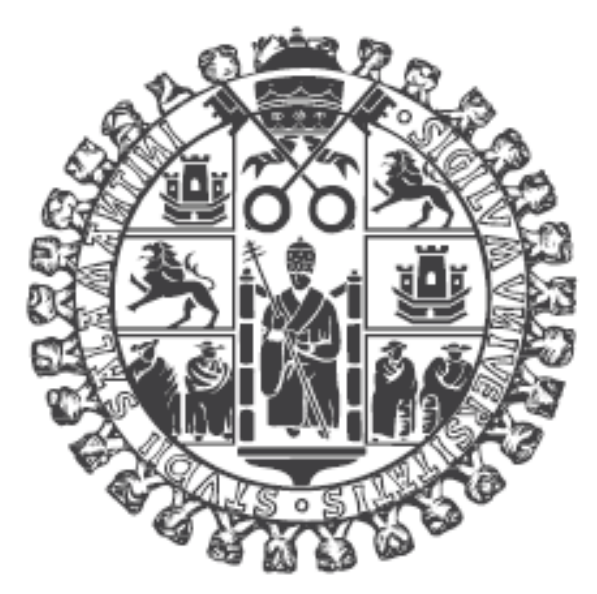

\title{
TESIS DOCTORAL \\ Historia de Vida y Metodología de Enseñanza de la Matemática de Jaime Alfonso Escalante Gutiérrez
}

\author{
Autor: Abdón Pari Condori \\ Director: Dr. D. Modesto Sierra Vázquez
}

Salamanca 2011 

VNIVERSIDAD DE SALAMANCA

FACVLTAD DE EDVCACIÓN

DEPARTAMENT@ DE DIDÁCTICA DE LA MATEMÁTICA

Y DIDÁCTICA DE LAS CIENCIAAS EXPERIMMENTALES

\section{TESIS DOCTORAL \\ Historia de Vida y Metodología de Enseñanza de la Matemática de Jaime Alfonso Escalante Gutiérrez}

Esta investigación ha sido realizada en el marco del Programa de Doctorado en Educación Matemática de la Universidad de Salamanca por Abdón Pari Condori, bajo la dirección del Dr. D. Modesto Sierra Vázquez.

Dr. D. Modesto Sierra Vázquez Abdón Pari Condori 



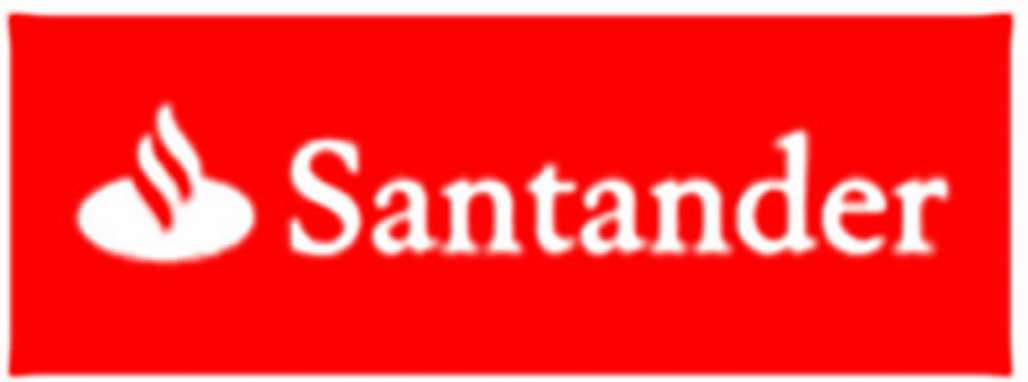

ESTE PROYECTO FUE FINANCIADO PARCIALMENTE POR LA BECA DEL GRUPO SANTANDER DESTINADA A ESTUDIANTES IBEROAMERICANOS PARA REALIZAR ESTUDIOS DE TERCER CICLO Y DOCTORADO EN LA UNIVERSIDAD DE SALAMANCA, 2005/2006, 2006/2007 Y 2007/2008. 



\section{DEDICATORIA}

Esta investigación, culminación del Programa de Doctorado en Educación Matemática y las implicaciones que han tenido en mi desarrollo personal y profesional, no hubiese sido posible sin el apoyo moral y afectivo de quienes han creído en mí y me han apoyado y acompañado siempre.

A Aylín Silvia, mi esposa y compañera de toda la vida, por su incondicional apoyo compartiendo conmigo sueños, ilusiones, así como pequeños y grandes logros. Por el cuidado y cariño prodigado a nuestros hijos, y sobre todo, por hacerme sentir cada día un hombre afortunado.

A mis queridos hijos Jaime Abdón, Liz Aylín y José Daniel, por ser mi alegría, felicidad y razón de ser, por enseñarme a ser padre; por mantener mi capacidad de asombro; por ser la fuerza que me impulsa a superarme en todos los ámbitos de la vida y por ser la esperanza de un mundo mejor.

A mis padres José Manuel y Modesta, a mis suegros Elías y Victoria, que me han dado todo a cambio de poco, porque de ellos he aprendido los valores fundamentales de la vida.

A toda mi familia, por su apoyo incondicional, arrimando el hombro siempre que lo hemos necesitado, por privarnos mutuamente durante todo este tiempo de la alegría de compartir la cotidianidad.

A mi amigo y maestro Dr. Modesto Sierra Vázquez y de quien he recibido todo el apoyo desde el día en que nos encontramos. Por la confianza y fe que siempre ha depositado en mi. Por alentar el deseo de superación profesional de quienes hemos tenido el privilegio de conocerlo y de trabajar con él. Por enseñarnos a ser profesionales reflexivos y fomentar nuestro compromiso con la educación matemática.

A un grupo de colegas y amigos con los que he tenido la oportunidad de trabajar y que han influido, en diferentes momentos, en mi desarrollo profesional: Miriam de Rodríguez, Benigno Godoy, Oscar Rojo, Santiago Sologuren, Hugo Marca, Juan Mascaros, Álvaro Garcia y Emilio Sanpedro.

A todos mis amigos de aquí y de allá; por mantenernos en su mente y corazón a pesar del tiempo y la distancia. 



\section{AGRADECIMIENTOS}

- A Dios en primer lugar, por concederme esta gran oportunidad, por su cuidado tanto de mi familia como de mi persona. Además, me puso las personas más agradables en mi estancia en Salamanca, tanto dentro del ámbito académico como fuera de él. Sólo me queda decir Gracias Señor, tu eres Fuerte y Todopoderoso.

- A mi familia; el apoyo moral y económico de mi esposa ha sido fundamental para este camino que llega a su final, y la paciencia y el apoyo que recibí de mis hijos, por sus palabras de ánimo y especialmente de José Daniel, que colaboró en el contacto con el profesor Jaime Escalante.

- Al Profesor Dr. Modesto Sierra Vázquez, por el apoyo incondicional, por sus orientaciones en el proceso de la investigación, por la paciencia y la capacidad que lo caracteriza como uno de los docentes comprometidos con la educación, específicamente con la educación matemática. Es mi maestro, profesor ejemplar.

- Agradezco también a todos mis docentes del Programa del Doctorado en Educación Matemática: Dr. Modesto Sierra Vázquez, director del Programa; Dra. María Teresa González Astudillo, Dr. José María Chamoso Sánchez, Dr. Ricardo López Fernández, Dr. José Ángel Domínguez Pérez, Dra. Carmen Azcárate Jiménez (Universidad de Barcelona); Dr. Salvador Llinares Císcar (Universidad de Alicante), y Dr. Tómas Ortega del Rincón (Universidad de Valladolid).

- A la Universidad de Salamanca y al Grupo Santander, por haberme concedido la beca por tres años consecutivos, sin la cual hubiera sido imposible mi estancia en la ciudad de Salamanca.

- Al profesor Jaime Escalante, que ha llevado su discurso a todos cuantos le han querido escuchar, y que tenía la simpleza de los genios que hacen sencillo lo que parece tan difícil. Quien me motivó a comenzar el doctorado y sin saber que yo terminaría haciendo la tesis sobre su historia de vida y su metodología de enseñanza de la matemática. Además, me proporcionó toda la documentación necesaria, aunque no suficiente, para la elaboración de este trabajo de investigación, ya que desde que se le diagnosticó el cáncer en la vejiga, la prioridad era su salud.

- A mis padres, que me dieron la vida y me enseñaron a seguir adelante a pesar de las dificultades y a poner mi confianza en Dios. 



\section{INDICE}

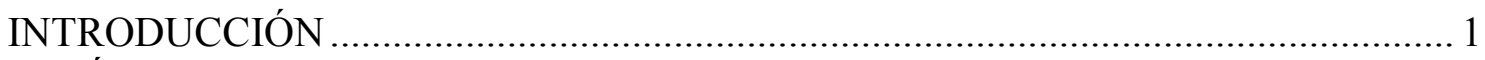



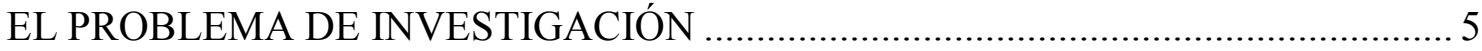



1.2 Planteamiento del problema y justificación.......................................................... 12

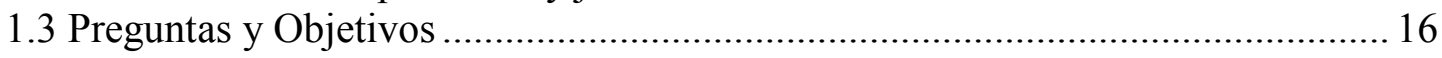

CAPITULO II ............................................................................................... 19

MARCO DE REFERENCIA CONCEPTUAL …………………………….......... 19

2.1 Historias de vida ....................................................................................... 19

2.2 Origen del término "historia de vida" .................................................................... 22

2.3 Términos afines a la historia de vida .................................................................. 26



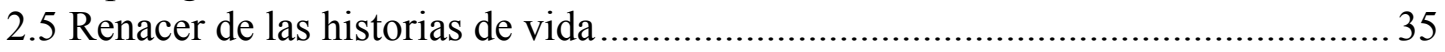

2.6 Las Historias de vida en ciencias sociales y humanas ............................................. 38

2.7 Historias de vida en investigación educativa........................................................4 42

2.8 Historias de vida en educación matemática .............................................................. 46

2. 9 Concepciones y creencias de profesores de matemáticas ......................................4 47

2.10 Caracterización de concepciones y creencias ……………………………….......51

2.11 Concepciones sobre las matemáticas ………………………………………….....5

2.12 Concepciones sobre la enseñanza y aprendizaje de las matemáticas ...................60 60

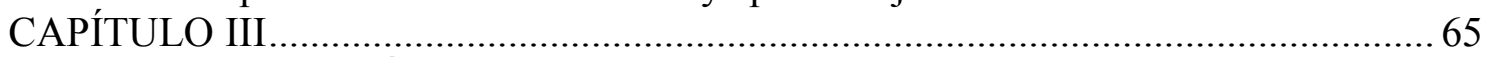

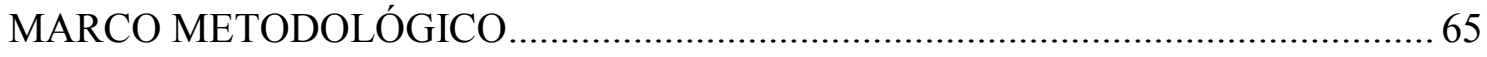

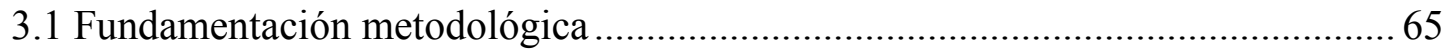

3.2 El método biográfico .................................................................................. 72

3.3 Técnicas de investigación ............................................................................... 75



3.5 Estrategias de análisis de información ............................................................... 94



HISTORIA DE VIDA DE JAIME ESCALANTE ......................................................97

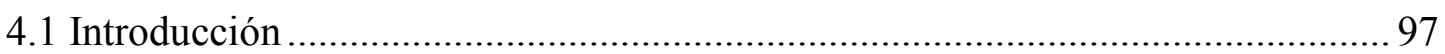

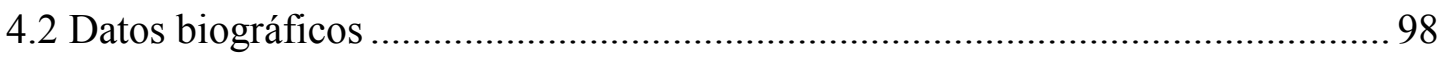

4.3 Primera etapa: Jaime Escalante en Bolivia (1930 a 1963)................................. 101

4.4 Segunda etapa: Jaime Escalante en los Estados Unidos (1964-1998) ................. 133

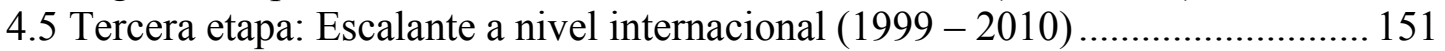

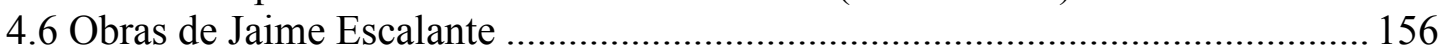

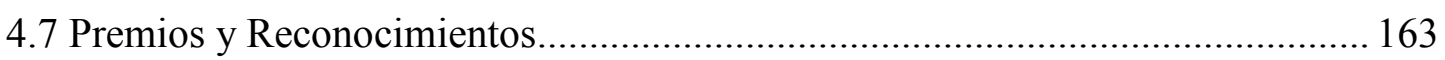

4.8 Escalante en la opinión de otros ..................................................................... 165

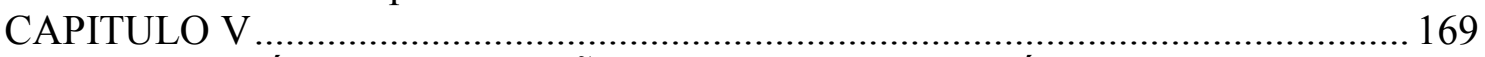

METODOLOGÍA DE LA ENSEÑANZA DE LA MATEMÁTICA ………………............ 169

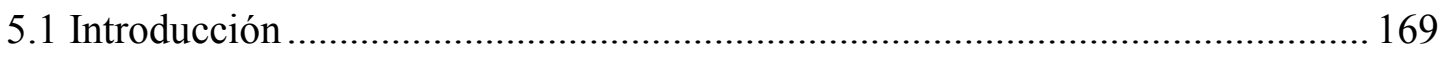

5.2 Enriquecimiento Matemático - Método Escalante............................................... 170

5.3 Concepciones y creencias sobre la matemática ................................................. 174

5.4 Concepciones y creencias sobre la matemática como objeto de enseñanza ........ 186

5.5 Concepciones sobre el aprendizaje de la matemática …………………………..... 199

5.6 Estrategias de la enseñanza de la matemática.....................................................209

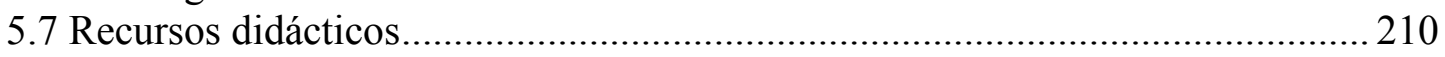




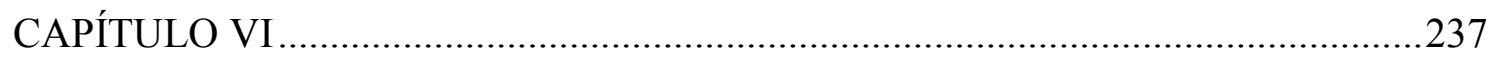

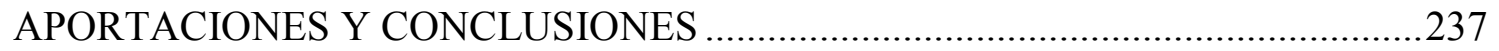

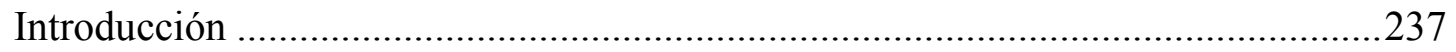

6.1 Consecución de los objetivos de investigación ...............................................240

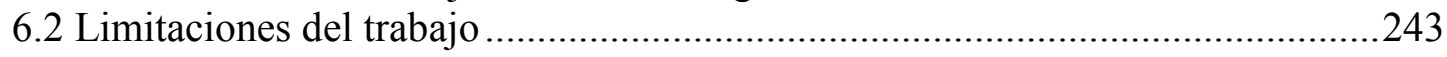

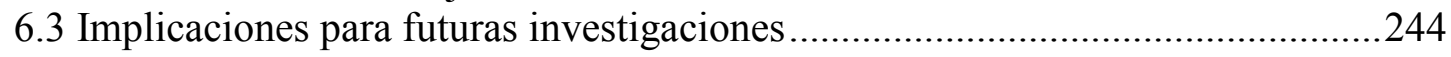

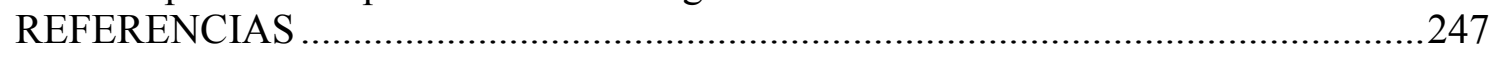



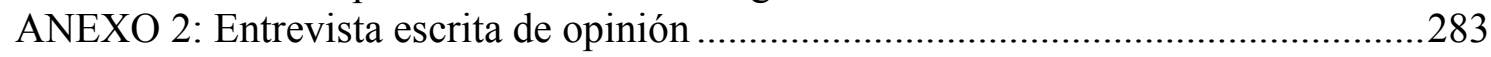

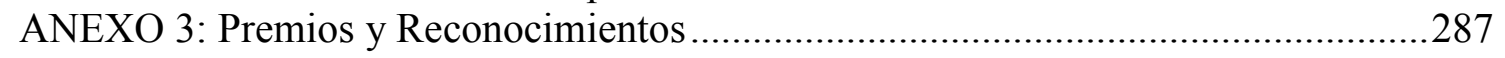

ANEXO 4: Diplomas de Doctor Honoris Causa........................................................2. 289

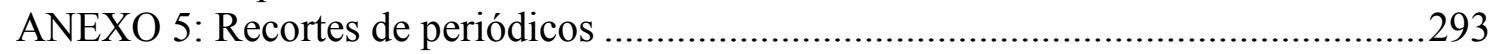



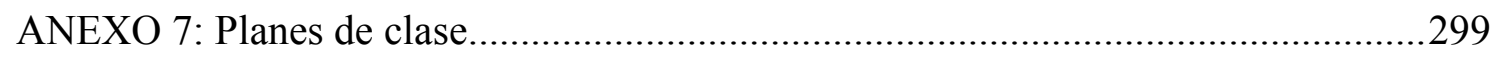

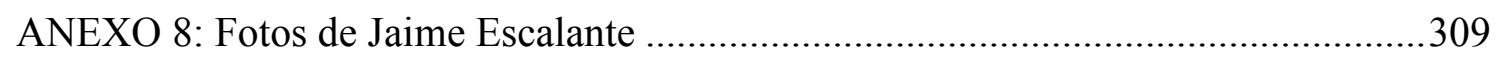




\section{INTRODUCCIÓN}

Este documento presenta el informe de investigación "Historia de vida y metodología de enseñanza de la matemática de Jaime Alfonso Escalante Gutiérrez", desarrollada en el marco del Programa de Doctorado del Departamento de la Matemática y de las Ciencias Experimentales de la Universidad de Salamanca para la obtención del grado de Doctor. El estudio consiste en una historia de vida temática de relato único de un profesor de matemáticas de origen boliviano, que se convirtió en un referente de la educación en Estados Unidos en la década de los 80 del siglo pasado.

El trabajo tiene como propósito fundamental facilitar el acceso de profesores, estudiantes, políticos e investigadores a la vida y metodología de la enseñanza de las matemáticas del profesor, ingeniero, matemático educador, Jaime Escalante (1930 - 2010), e indagar sus concepciones y creencias sobre las matemáticas como disciplina científica, su enseñanza y su aprendizaje.

El desarrollo de esta investigación está organizado en seis capítulos y estructurado de la manera siguiente:

- Capítulo I: Planteamiento del problema de investigación.

- Capítulo II: Marco de referencia conceptual.

- Capítulo III: Marco Metodológico.

- Capítulo IV: Historia de vida y obras de Jaime Alfonso Escalante Gutiérrez.

- Capítulo V: Metodología, concepciones y creencias sobre la matemática, su enseñanza y aprendizaje, y descripción de recursos didácticos.

- Capítulo VI: Aportaciones y Conclusiones.

Damos a continuación una visión general de cada capítulo, presentando para ello sus aspectos más identificativos.

En el capítulo I se presenta el objeto de estudio a través de la descripción de los antecedentes, el planteamiento y la justificación del problema, así como las preguntas y objetivos de investigación. La investigación tiene como antecedentes más cercanos a dos documentos: El libro de Mathews 
(1988), Escalante: Best Teacher in America y la película Stand and Deliver (Menéndez y Musca, 1988).

Como justificación de la investigación, partimos del principio de que cada generación recibe un caudal de ideas, conocimientos, saberes, prácticas y valores que si no se reelaboran y se asimilan, se pierden; simplemente se olvidan y desaparecen. Una historia de vida es el eco del pasado y la ventana del futuro que nos permite comprender el presente para proyectarnos al futuro. En ese sentido coincidimos ampliamente con Fernando Hernández de la Universidad de Barcelona, como señala en el prólogo del libro de Goodson (2004), Historia de vida del profesorado: "Las historias de vida como una estrategia de visualización y generación del saber pedagógico." Además, las historias de vida de los profesores de matemáticas es una nueva línea de investigación dentro de la Didáctica de la Matemática.

Este estudio ha partido de las siguientes preguntas: ¿Cuál es la vida y obra del profesor Jaime Alfonso Escalante Gutiérrez? ¿Qué creencias posee sobre la matemática como disciplina? ¿Qué concepciones sostiene sobre la enseñanza de la matemática? ¿Qué concepciones tiene acerca de cómo aprenden los alumnos? ¿Qué recursos didácticos ha implementado para la enseñanza y aprendizaje de las matemáticas en el nivel secundario? Estas preguntas han constituido las líneas de orientación de la investigación, desde la adopción del enfoque, el método, las técnicas de recogida de información, hasta la elaboración de la historia de vida.

En el capítulo II se hace una amplia presentación del marco referencial conceptual de la investigación en el que se abordan dos temas: las historias de vida, y las concepciones y creencias. Al final de esta parte, a manera de posicionamiento, se presenta una síntesis de las ideas más relevantes del marco de referencia, y se define el sentido dado a aquellos conceptos que se consideran fundamentales para la investigación realizada. Este posicionamiento conceptual ha servido de base para formular las preguntas de investigación, elaborar los instrumentos de recogida de información, su análisis, interpretación, y finalmente la elaboración de la historia de vida. 
Se hace una delimitación del término "historia de vida", después de considerar la polisemia y los términos afines. Además, se comparte "la distinción realizada por N. Denzin entre life story, como narración biográfica y life history, como construcciones narradas de la vida de alguna persona realizadas por investigadores (Tójar, 2006, p. 258), y secundado entre otros por el francés D. Bertaux, La life story (en francés récit de vie) corresponde a la historia de una vida tal como la persona que ha vivido la cuenta mientras que life history (En frances histoire de vie), que se refiere al estudio de caso referido a una persona dada, comprendiendo no sólo su life story, sino cualquier otro tipo de información o documento adicional que permite la reconstrucción de dicha biografía más exhaustiva y objetiva posible. Pujadas (2002, pp. 13-14), propone en español: "Relatos de vida para referirse al primer concepto y historias de vida al segundo". Para fines de esta investigación la historia de vida es como Life history en inglés, o Histoire de vie en francés. Y coincidimos ampliamente con el sociólogo italiano de reconocimiento internacional Franco Ferrarotti (1988), cuando señala que la historia de vida se convierte en un enfoque de investigación cuando el interés del estudio se centra en una sola persona. En la misma línea, Bolívar (2002), señala que la historia de vida es una nueva perspectiva de la investigación educativa. En relación al término de concepciones y creencias de ésta, se ha tomado como base las definiciones de Ernest (1991, 1989, 1996), Thompson (1992), Flores (1998), Martínez (2003), Ponte y Chapman (2006), Gil y Rico (2003).

En el capitulo III abordamos la fundamentación metodológica, el método biográfico, las técnicas interactivas y no interactivas y los instrumentos utilizados en la investigación. El estudio se enmarca dentro del enfoque cualitativo, específicamente en la historia de vida, y comparte los principios de la investigación interpretativa. Para elaborar esta historia de vida se utiliza el método biográfico que emplea tres técnicas: la entrevista biográfica, la observación y la documentación; y las tres fueron utilizadas a manera de comprobación y complementación. El análisis e interpretación de este estudio se basa en el esquema del árbol, y los hechos cronológicos son el hilo conductor. 
En el capítulo IV del informe se presenta un amplio recorrido del profesor Jaime Escalante, dividiéndose en tres etapas: La primera, que es la etapa inicial, abarca desde su nacimiento hasta su emigración a los Estados Unidos. La segunda, etapa que comprende desde su llegada a Los Ángeles, California, (Estados Unidos), hasta que se retira del sistema educativo americano. Y la tercera y última etapa, incluye el periodo de vida tras la jubilación hasta su muerte.

En el capitulo $\mathrm{V}$ se hace una aproximación a las concepciones y creencias sobre la matemática, su enseñanza y aprendizaje del profesor Jaime Escalante Gutiérrez a partir de las entrevistas verificadas con los documentos y la observación en el aula.

Finalmente, el capitulo VI está dedicado a las conclusiones generales y las aportaciones y tareas de futuras investigaciones.

Después de los capítulos, se incluye la referencia bibliográfica, haciendo notar que hemos optado por escribir sólo la que ha sido citada en la memoria, dado que es la que, en su mayoría, ha influido directamente en el trabajo; lo cual no representa en su totalidad todos los artículos, libros y capítulos que han sido leídos y trabajados.

En cuanto a los Anexos, tiene el siguiente orden:

- La transcripción de las entrevistas grabadas en enero de 2007.

- La entrevista escrita de 2008.

- Constancias de premios y reconocimientos.

- Fotocopias de Diplomas de Doctor Honoris Caausa.

- Algunos recortes de periodicos.

- Algunos manuscritos.

- Transcripción de planes de clases y conferencias

- Fotografías. 
Este capítulo presenta el plateamiento del problema de investigación, partiendo de los antecedentes que permiten la ubicación en el tiempo y el espacio, la justificación de la importancia y la pertinencia del estudio, las preguntas que se pretenden contestar y los objetivos que se esperan alcanzar.

\section{CAPÍTULO I}

\section{EL PROBLEMA DE INVESTIGACIÓN}

\subsection{Antecedentes}

El interés por la investigación en el campo de la didáctica de la matemática tiene su origen cuando trabajaba en Bolivia, como Director General del Instituto Normal Superior Adventista, (INSA), adscrito a la Universidad Adventista de Bolivia (UAB), con Resolución Ministerial No. 452/1999. Una institución responsable de la formación inicial y permanente de profesores de educación infantil, primaria y secundaria del sistema de la educación boliviana, siendo también profesor de matemáticas en la Facultad de Educación de la misma universidad.

En Bolivia, al igual que en la mayoría de los países, se transita por una serie de reformas educativas carentes de visión, entusiasmo y metas. Por ejemplo, el diseño de la reforma educativa que comenzó con el gobierno de Jaime Paz Zamora a finales de la década de los 80 y principios de los 90 del siglo pasado, y se ejecutó con el de Gonzalo Sánchez de Lozada, promulgando la "Ley de la Reforma Educativa 1560" de 1994. En opinión del periodista y expresidente Carlos De Mesa: "el sistema educativo nacional estaba en el límite del colapso por su ineficiencia, burocratización y sobre todo por los pésimos resultados académicos" (Mesa et al, 2003). Esta reforma educativa buscó mejorar la calidad de la educación, fortaleciendo el sector público. Introdujo la educación intercultural y bilingüe. El otro objetivo era proporcionar la 
participación de la comunidad en la educación. Se crearon núcleos piloto, se rompió el concepto tradicional de los niveles y grados inflexibles, se buscó la supresión del examen tal como se conocía y se invirtió en millones de textos escolares.

Estos espacios nos han permitido comprender la complejidad de la función docente, la enseñanza y el aprendizaje, y motivado la búsqueda de alternativas de capacitación. Además, la "Ley de la Reforma Educativa 1560" de 1994, creó núcleos piloto de prueba y un cuerpo de Asesores Pedagógicos, asignados o distribuidos por Distritos Escolares. Éstos, a su vez, organizaban cursos de capacitación docente para sus Distritos Escolares.

En una ocasión me invitaron a participar como ponente en un SeminarioTaller para profesores de matemática. Acepté esta invitación que venía de tres Asesores Pedagógicos del Distrito Escolar de Cochabamba: Elba Medrano, Teresa Gonzáles y María Luisa Solís.

De acuerdo con la programación de los organizadores del evento, el profesor Jaime Escalante era otro de los ponentes. Yo había leído algunos bocetos biográficos sobre él y también había visto en alguna ocasión la película Stand and Deliver (Menéndez y Musca, 1988), y pensaba que era uno de tantos profesores. En esa ocasión tuve la oportunidad de conocerlo personalmente, conversar un poco y tomar nota de sus datos. En ese corto espacio de tiempo, conversamos sobre algunos temas de la educación matemática en Bolivia. Además, tuve la oportunidad de observar, de forma directa, una de sus clases para profesores de matemáticas. (Cochabamba, 2003).

El profesor Escalante, con términos sencillos y una explicación emotiva, dinámica y didáctica, captó la atención de los asistentes. La clase debía haber terminado a las 12:00, pero se pasó 50 minutos. Los alumnos continuaban en sus pupitres y nadie parecía quejarse de la hora. No había duda de que este profesor de matemáticas tenía algo diferente a los demás.

Este incidente despertó en mí el deseo de indagar en su estilo de enseñanza, su trayectoria y los recursos didácticos que utilizaba para la enseñanza de las matemáticas. En esa búsqueda de fuentes documentales 
que permitieran el acceso a su metodología de la enseñanza de las matemáticas, descubrí la escasa existencia de documentos en ingles, y completamente inexistente en español.

Por otro lado, desde que llegó Evo Morales a la presidencia del país, Bolivia atraviesa por varios conflictos y ajustes. El sistema educativo no es ajeno a estos problemas político-sociales. Esto se ve reflejado en el proyecto inconcluso de la nueva ley de educación, denominada "Avelino Siñani y Elizardo Pérez," que se debate hasta el día de hoy. A causa de esta situación de incertidumbre, surgen en los docentes del país ciertas necesidades didácticas innovadoras que les permitan alcanzar sus expectativas en la enseñanza de la matemática. Esta necesidad de contar con documentos que faciliten el acceso a la vida y metodología del profesor Jaime Escalante, no es simplemente percibida por el investigador, sino también es manifestada por parte de los profesores en general, y los profesores de matemáticas en particular. Este hecho impulsó la recopilación de información y documentación.

Al incorporarme al Programa de Doctorado en Educación Matemática de la Universidad de Salamanca, entré en contacto con diferentes investigadores en el campo de la Didáctica de la Matemática. Algunos fueron mis profesores del periodo de docencia, como Salvador Llinares, Modesto Sierra, María Teresa González, entre otros. Mientras que a los demás los he conocido en algunos eventos, como el Congreso Internacional de Matemáticos (ICM-2006), celebrado en Madrid, y el X Simposio de la Sociedad Española de Investigación en Educación Matemática (SEIEM), celebrado en Lleida. Salvador Llinares atrajo mi interés de investigación sobre el profesorado y Modesto Sierra sobre la historia de la educación matemática (Sierra, 1989, Rico y Sierra, 1994).

En base a estos acontecimientos se fue definiendo el campo de estudio sobre el profesor Jaime Alfonso Escalante Gutiérrez, aunque carente de un enfoque y una metodología. Se inició el estudio desde la historia de la educación matemática, hasta que encontramos el documento de Bolívar (2002), que nos ayudo a definir el enfoque. Sarabia (1985), Pujadas (2002), Valles (2000), nos ayudó a definir la metodología. Esto se fue consolidando en el campo de la educación en base al libro de Bolívar, Domingo y Fernández 
(2001), La investigación biográfico-narrativa en educación. Y en el área del profesor, el libro de Goodson, (2004): Historias de vida del profesorado, y de Smith (2001), "Life History as a Key Factor in Understanding Teacher Collaboration and Classroom Practice." Nos motivó a indagar a través de la historia de vida las concepciones y creencias del profesor sobre las matemáticas, su enseñanza y aprendizaje.

En el campo de la investigación en creencias y concepciones sobre la matemática, su enseñanza y aprendizaje, partí del documento de Thompson, (1992): "Teacher's beliefs and conception: a síntesis of research", en el que se presenta una síntesis de las investigaciones realizadas en la década de los ochenta, en el campo de las creencias y concepciones de los profesores sobre la naturaleza de las matemáticas su enseñanza y aprendizaje. Asímismo, nos apoyamos, en la parte teórica, en el documento de Ernest (1989), titulado: "The impact of beliefs on the teaching of mathematics", en el que presenta las diferentes filosofías personales de los profesores sobre la naturaleza de la matemática, su enseñanza y aprendizaje.

Para situar el problema de la investigación existen dos documentos base sobre la vida del profesor Jaime Escalante: La película Stand and Deliver (Menéndez y Musca, 1988), protagonizada por Edward James Olmos, como el profesor de matemáticas. Esta película narra la historia real del profesor Jaime Escalante, comprometido con la promoción de jóvenes sin futuro y la ejemplar superación de una generación latina radicada en los Estados Unidos. Este profesor consiguió un hito: por primera vez un instituto de baja extracción social se situaba entre los mejores en las pruebas del Cálculo Superior para acceder a la Universidad. En 1974, el profesor Jaime Escalante llega a impartir clases de matemáticas en Garfield High School, en Los Ángeles, California. Se encuentra con estudiantes totalmente problemáticos, que ni siquiera aspiran a llegar a la universidad a causa de sus estructuras mentales y sociales, la falta del manejo del idioma inglés y la falta del apoyo de los padres por sus condiciones económicas. El profesor Jaime Escalante tuvo que hacerles cambiar de actitud y les exigió fuertes sacrificios. Objetivo que consiguió pese a los graves riesgos para su salud a causa del exceso de trabajo al que se 
sometió. Llegó a desafiar la dinámica mediocre de los profesores y autoridades de la secundaria Garfield, que le señalaban con cinismo que causaba falsas expectativas en los estudiantes, pues le aseguraban que iban a ser unos frustrados, porque -según ellos- no alcanzarían tales metas. El profesor introdujo a los alumnos en una dinámica de disciplina, responsabilidad y entusiasmo. Se preocupó, dialogó con ellos, les exigió como a un amigo, provocó en ellos la inquietud por desafiar su futuro determinado por las circunstancias porque podía ser cambiado, diseñando mediante un cambio de actitud, generando un compromiso por sí mismo, por su familia, por su clase social. Atrajo a los padres de familia y trató de influir en ellos para que dejaran de lado actitudes del machismo tradicional, y así impulsar a sus hijas a que se superaran. O les asesoró en cómo formar las herramientas básicas de la determinación, disciplina y trabajo fuerte.

En un primer momento, el objetivo fue logrado, los alumnos de Jaime Escalante respondieron a los estímulos y a la dinámica planteada por él. Fue entonces cuando Jaime Escalante propuso pasar de álgebra al cálculo. Los demás profesores y autoridades de la secundaria estallaron en ira, señalaban que era un error exigir eso a los alumnos. El reto se hizo, los alumnos tomaron clases aún en vacaciones de verano, bajo el calor intenso en las aulas; el sudor y los números recorrían el ambiente. Se acercaba la evaluación sobre cálculo que se imparte a la red de secundaria. Sólo un porcentaje bajo de latinos que lo presentaban habían podido pasarlo (Jessness, 2002).

El día del examen llegó, y los entusiastas muchachos lo presentaron. Los resultados fueron asombrosos. Pero, ¿que pasó? Los pocos errores que tuvieron fueron muy similares. El examen fue invalidado. Se dudó de la preparación de los alumnos y se les calificó de tramposos. Pues, ¿cómo era posible que todos hubieran pasado satisfactoriamente el examen de cálculo, y con los mismos errores? Seguramente se copiaron.

Los ánimos decayeron, las autoridades de la secundaria estaban preocupadas por la imagen de la misma, y no por la credibilidad de los alumnos y del profesor. Sin embargo, la relación de responsabilidad y el cariño de los alumnos le llevaron a enfrentarse con las autoridades centrales de evaluación 
de secundaria en cálculo. Les reclamó y hasta tuvo un enfrentamiento con ellos, pero no dio resultado. El otro camino fue presentar de nuevo el examen. Se dispusieron a llamar por teléfono y ver la convocatoria del siguiente examen. Sorpresa: sólo tenían dos días para prepararse. Se dispusieron a dar un repaso general en tan sólo 48 horas. Los ánimos andaban alteradísimos. El día del segundo examen: dos autoridades aplicaban la prueba en un ambiente tenso. Este examen fue más riguroso que el anterior. Los alumnos fueron minuciosamente observados. Finalmente, el día ansiado de los resultados, el profesor Jaime Escalante esperó en Garfield. El Director de Garfield solicitó por teléfono los resultados, y todos aprobaron incluso con mejores notas que el anterior.

Esta película ya es un gran esfuerzo para documentar la vida del profesor Jaime Escalante, pero sólo registra parte de su experiencia en Garfield, que va desde 1974 a 1982. Según Escalante (2007), en la película, el $90 \%$ es verdad y el $10 \%$ es cine, y se muestra muy pocas escenas de matemáticas.

Otro documento del que se parte, es el libro: Escalante: The Best Teacher in America, escrito por el periodista Jay Mathews, publicado en 1988 por Henry Holt and Company, Inc. El autor leyó una nota en el periódico Los Angeles Times, en la sección local: "14 students retake test after scores are diputed - principal charges minority bias", porque de 18 estudiantes que habían tomado el examen de cálculo avanzado, 14 habían sido acusados de copiar. El autor se centra en la sorpresa que causaron estos jóvenes estudiantes que no tienían ningún futuro y ninguna esperanza, y superaron las pruebas más difíciles, ¿cómo éstos han llegado a tener ese amor, ese cariño y esa responsabilidad? Y, ¿qué personalidad tenía este profesor para cambiarles?

Aunque el libro lleva el nombre de Escalante, se concentra en Garfield, por lo que se registra la historia de dos profesores: Henry Gradillas y Benjamin Jiménez, y los estudiantes de Garfield, además de Escalante. El libro describe desde la infancia de Escalante en Bolivia, su formación y su inicio en Estados Unidos, y la experiencia en Garfield con los alumnos hasta 1987. En este documento se habla muy poco de matemáticas porque el autor lo analiza 
desde su propia perspectiva. Además, a partir de la fecha anterior en adelante hasta su muerte, no hay registros de su vida.

De acuerdo a Sorando (2005), la película Stand and Deliver, se pudo ver en España por TV como Lecciones inolvidables. José María Sorando ha indicado en un artículo publicado en la Suma, 49, junio 2005, que el año 2000, Año mundial de las Matemáticas, Televisión Española produjo el Universo Matemático, excelente serie documental de 10 programas sobre la historia de las matemáticas, galardonada internacionalmente, dirigida y presentada por Antonio Pérez. Uno de ellos es exactamente Lecciones Inolvidables. El mismo autor dice: "Lamentablemente, no esta comercializado en video" (Suma 49, p. 135).

Otros documentos que toman parte en este estudio son Schoenfeld (2000), que presenta los propósitos y métodos de investigación en educación matemática, Cohen y Manion (2002), que señalan: "la investigación histórica en educación se puede preocupar de un individuo, un grupo, un movimiento, una idea o una institución", aunque los autores aclaran que no se puede considerar aislados de esos objetos de interés y observación históricos, lo que indica, que estos elementos siempre están interrelacionados. Los mismos autores indican que "una de las formas más comunes de la investigación histórica en educación es la biografía: un estudio de vida, enseñanza y subsiguiente influencia de alguno de los grandes educadores". Otro documento es el Shulman (1987, p. 1), que dice: "las descripciones pormenorizadas del profesor experto son escasas". Esto nos muestra la necesidad de realizar estudios sobre las experiencias de algunos profesores que hayan sido considerados como figuras destacadas en el campo de la educación. Es cierto que no podremos realizar el estudio de todos los profesores pero, por lo menos, nos acercaremos a través de algunos.

Por otro lado, los intentos de mejorar la enseñanza de la matemática se han centrado en los diferentes aspectos: cambios de contenido, reestructuración de los planes de estudios, etc. Otras veces han sido los alumnos el centro de la atención. Llinares y Sánchez (1990), señalan que, hoy en día, nadie duda que haya otras variables fundamentales en todos los 
procesos de enseñanza y aprendizaje. Así, en un contexto de enseñanza específico, junto a los alumnos y la materia a enseñar, hay un tercer componente: el profesor.

Bajo este contexto, considerando las necesidades y expectativas de la comunidad de educadores matemáticos (Rico y Sierra, 1991), se plantea la presente investigación sobre el profesor Jaime Alfonso Escalante Gutiérrez.

\subsection{Planteamiento del problema y justificación}

Algunas personas no se interesan por la historia, a muchos les gustan los buenos relatos o historias de vida, pero cada pueblo tiene narraciones que explican su origen, valores y cultura. Además, cada generación recibe un caudal de ideas y conocimientos que si no se reelaboran, se pierden 0 simplemente se olvidan. En la edad moderna, el arte de contar historias fue despreciado, la gente buscaba explicaciones científicas, (enfoque positivista) sobre la vida. Pero estas no pudieron responder las preguntas más importantes de la humanidad, y en particular, de la educación. Hoy, una generación nueva, la "posmoderna", ha redescubierto el poder de las historias de vida (Bertaux, 1980 y 1993; Ferrarotti, 1981, 1988, 2005 y 2007; Sarabia, 1985; Pujadas, 2000, 2002; Saltalamacchia, 1992; Goodson, 2003, 2004; Smith, 2001; Kaasila, 2007). La historia de vida es el eco del pasado y la ventana del futuro que nos permite comprender el presente. La historia de vida propicia una visualización y generación de saber pedagógico y como una contribución esencial a la memoria histórica de la educación en general y particularmente a la educación matemática.

Por otro lado, en los últimos años estamos viviendo transformaciones decisivas que están alterando radicalmente los diferentes sectores de la vida humana. Asistimos a un panorama de globalización inevitable a escala planetario (González, 2008/2009). La globalización es un proceso económico, tecnológico, social y cultural a gran escala, que consiste en la creciente comunicación e interdependencia entre los distintos países del mundo, unificando sus mercados, sociedades y culturas a través de una serie de transformaciones económicas, sociales y políticas que les dan un carácter 
global. En la economía, presenciamos nuevas formas de producción, distribución y consumo. Las nuevas formas de organización de todo el ciclo económico, apoyadas en las tecnologías de la información, han revolucionado las concepciones tradicionales relativas a las relaciones laborales. Retratados en los empleos precarios, la inseguridad laboral y los bajos salarios. En la esfera política, en los últimos años hemos visto la pérdida de legitimidad de la democracia representativa, el surgimiento de nuevos focos de conflicto y violencia, y la agudización de la pobreza. Otro fenómeno importante, que tiene dimensiones a la vez económicas, políticas y culturales, es el aumento de las migraciones. Finalmente, mencionamos el fenómeno del calentamiento global, que está relacionado con el cambio climático. La educación no puede ser de otra manera, también ha sufrido los embates de la globalización y los otros fenómenos de una manera intensa. Esta situación ha aumentado las desigualdades educativas en el interior del país y a nivel internacional, como señala Jaime Escalante: "la educación para unos es un privilegio y para otros es un castigo" (Escalante, 2007).

La enseñanza de la matemática no es ajena a estas reformas. La edición el Informe Cockcroft (1985) en Gran Bretaña y la posterior publicación de los estándares profesionales, por el NCMT, en los Estados Unidos (1991), ha supuesto el comienzo de la actual reforma en educación matemática.

En el caso específico de Bolivia, a más de una década de la reforma educativa, por medio de la cual se pretendió impactar principalmente sobre la educación básica, se tiene pocas evidencias del cambio que se ha dado en la enseñanza y aprendizaje en general y de las matemáticas en particular.

La investigación en Didáctica de la Matemática en Bolivia es casi inexistente, excepto algunos trabajos a nivel de licenciatura. La muestra de esto, es que los Programas de Doctorado que ofrecen algunas universidades están orientados en Educación en General y no existe en Didáctica de la Matemática.

En consecuencia enfrentamos una carencia de documentación de experiencias prácticas cualificadas como es el caso del profesor Jaime Escalante, considerado un referente de la enseñanza de la matemática en 
Estados Unidos por su sistema que impartió en Garfield, pero es casi desconocido en su país de origen, ni existen documentos que faciliten el acceso en el idioma nacional.

En la actualidad el sistema de la educación boliviana sufre una serie de conflictos y ajustes, para direccionar sus políticas educativas es necesario mirar algunos referentes nacionales e internacionales. Por consiguiente, es pertinente la necesidad de contar con experiencias prácticas innovadoras.

Según Mesa et al (2003), la reforma educativa de 1994 fue el mayor cambio desde la aprobación del código de la educación de 1955. Esto muestra que en cuatro décadas no hubo cambios sustanciales en la educación boliviana.

Las reformas educativas dependen en gran medida de las reformas institucionales: del cambio conjunto del currículum de la matemática. Ellos dependen esencialmente del cambio individual del profesor hacia la enseñanza de la matemática (Ernest, 1989).

También se despertó el interés sobre la vida y obra de Jaime Escalante entre los estudiantes de magisterio, profesores en ejercicio docente, administradores, diseñadores y gestores del sistema educativo boliviano. A su vez, se encuentran con el mismo problema ya mencionado: la escasa existencia de documentación sobre su historia de vida, su experiencia en la enseñanza de la matemática, desarrollo personal y profesional, sus perspectivas educativas, su modelo pedagógico y su práctica educativa, etc., especialmente en español.

Esta investigación se justifica por las siguientes razones:

- Este estudio es una aportación original a la historia de la educación matemática en Bolivia, por cuanto el profesor Jaime Escalante es una figura muy destacada en el panorama educativo de ese país por sus logros en la educación matemática.

- El informe documenta la vida y obra del profesor Jaime Escalante, de esta manera facilita el acceso a estudiantes, profesores, líderes comunitarios, administrativos educativos y responsables del sistema educativo. 
- Intenta satisfacer las necesidades y expectativas de los profesores del sistema de la educación boliviana para no sufrir el error calamitoso como señala Shulman (1987):

Para no sufrir este error calamitoso, es importante la asimilación o reelaboración de estas experiencias para evitar una de las frustraciones de la docencia como quehacer y profesión que sufre la profunda amnesia individual y colectiva, la frecuencia con que las mejores creaciones de quienes se dedican a esta actividad se pierden de modo que no están disponibles para sus colegas actuales y futuros. A diferencia de otras disciplinas como la arquitectura (que conserva sus creaciones tanto en planos como edificios), el derecho (que crea una jurisprudencia compuesta de sentencias e interpretaciones), la medicina (con sus historiales y estudios de caso), la enseñanza no se imparte frente a un auditorio compuesto por colegas por lo que carece de un historial práctico. (Shulman, 1987, p. 11).

Esto muestra que existen pocas investigaciones sobre la experiencia de profesores expertos a nivel nacional e internacional. Por lo que se justifica la elaboración de una historia de vida sobre el profesor de matemáticas de origen boliviano y aclamado en los Estados Unidos por su estilo único de enseñanza.

Este problema de investigación se inscribe dentro de la investigación en educación matemática y no en la disciplina de la matemática, como es señalada y explicada de una manera acertada por Rico, Sierra y Castro (2000), la diferencia entre los problemas matemáticos y los problemas de la educación.

Los problemas matemáticos son problemas dentro de una ciencia, que surgen en gran parte dentro de esta misma ciencia o de otras ciencias. Los problemas de la educación son problemas de la vida que surgen de necesidades que varían, modos y caprichos de una sociedad cambiante.

Desde tiempos antiguos los matemáticos se han pasado los problemas unos a otros, tanto los principales como los secundarios: aquí está el problema, resuélvelo; si puede, cuéntenoslo; escucharé para comprobar si es una solución. En educación, la solución del problema no es una discusión sino un proceso educativo. En educación los problemas son resueltos adecuadamente por los participantes del proceso educativo, por aquellos que educan y aquellos que son educados. (Freudenthal, 1981; citado por Rico, Sierra y Castro, 2000). 
En este contexto las instituciones educativas encargadas de formación de maestros, facultades de Educación de las diferentes universidades y los docentes universitarios son responsables de la solución y problemas educativos que enfrenta el sistema de la educación boliviana.

Esta investigación no pretende probar si Jaime Escalante fue el mejor profesor de América o no. Pero, representó a un sinnúmero de valientes maestros en todo el país.

\subsection{Preguntas y Objetivos}

En base a la justificación de este trabajo de investigación formulamos algunas preguntas y objetivos de investigación que orientan la dirección del presente estudio denominada "Historia de vida y metodología de la enseñanza de la matemática de Jaime Alfonso Escalante Gutiérrez".

\section{Preguntas}

En base al problema de estudio de esta investigación nos planteamos las siguientes preguntas:

1. ¿Cuál es la vida y obra del profesor Jaime Alfonso Escalante Gutiérrez?

2. ¿Qué creencias posee sobre la matemática como disciplina científica?

3. ¿Qué concepciones sostiene sobre la matemática como saber transmisible, es decir, concepciones sobre la enseñanza de la matemática?

4. ¿Qué concepciones tiene acerca de cómo los estudiantes aprenden matemáticas?

5. ¿Qué recursos didácticos ha implementado para la enseñanza aprendizaje de las matemáticas en el nivel secundario? 


\section{Objetivos}

Para responder estas preguntas de investigación nos planteamos los siguientes objetivos generales y específicos.

\section{Objetivo general}

Elaborar una historia de vida describiendo la experiencia pedagógica del profesor Jaime Alfonso Escalante Gutiérrez en la enseñanza de la matemática en el nivel secundario.

\section{Objetivos específicos}

1. Describir la vida y obra del profesor Jaime Escalante.

2. Establecer las creencias del profesor Escalante sobre la matemática como disciplina científica.

3. Analizar las concepciones acerca de la matemática como saber transmisible, es decir concepciones sobre la enseñanza de la matemática.

4. Analizar las concepciones acerca de cómo los estudiantes aprenden matemáticas.

5. Describir y analizar los recursos didácticos implementados para la enseñanza - aprendizaje de las matemáticas en el nivel secundario.

A contestar estas preguntas y conseguir estos objetivos se derige el presente trabajo de investigación. 

Este capítulo ofrece una ubicación contextual de las historias de vida para entender la revalorización en el campo de la investigación educativa, la aclaración de los términos afines, las tipologías y los diferentes usos, ya sea como intrumento, método o enfoque de investigación. También se hace una breve caraterización de las concepciones y creencias sobre las matemáticas, su enseñanza y su aprendizaje.

\section{CAPITULO II}

\section{MARCO DE REFERENCIA CONCEPTUAL}

\subsection{Historias de vida}

En el marco de los procesos de consolidación epistemológica de los estudios fundamentados en la existencia humana, cuya utilización se ha afianzado en la investigación educativa de los últimos años, desde la revisión de sus supuestos, puede afirmarse que la perspectiva de las historias de vida tiene elementos comunes y complementarios que enriquecen el ejercicio investigativo centrado en los sujetos. La perspectiva de la historia de vida procura interpretar y comprender las diversas dimensiones de los escenarios en que se desarrollan los sujetos participantes, es decir, los marcos o tramas en que se ha desarrollado determinadas existencias.

Desde aquí, mencionamos algunos elementos que favorezcan una ubicación contextual de las historias de vida para entender mejor su presente revalorización en el ámbito de la investigación de ciencias sociales y humanas, y en particularmente en educación.

Las historias de vida incorporan de manera especial, los problemas enraizadas en la cotidaneidad y en la existencia humana destacando la perspectiva de los sujetos en el análisis de determinada situación del mundo social. Esta orientación ha hecho que desde sus orígenes los estudios biográficos (o historias de vida) se encuentren en el cruce de distintas 
disciplinas, en la intersección de múltiples conocimientos, tantos como han abordado el conocimiento de lo humano. Es decir, las historias de vida han contribuido al análisis de problemas socio-culturales, personales o históricos desde la dimensión personal de los actores así como la comprensión de formas constituidas del pensamiento.

Por lo mismo, no existe un modo único de realizar dentro de este método. Sus implicaciones se diversifican según las dimensiones humanas que quieren ser investigadas, las lineas de problematización, las rutas genealógicas de las preguntas sobre la subjetividad y en suma la orientación de los problemas que pretenden ser abordados.

Las investigaciones a través de historias de vida o como historias de vida no es algo nuevo ni circunscrito al ámbito de las ciencias de la educación (Albert, 2007; Moreno, 2006). Aunque hasta hace relativamente poco tiempo no había adquirido el significado y la importancia que actualmente tiene, constituyéndose como un material de primera magnitud en el campo de la investigación cualitativa. Por otro lado, en los últimos treinta años estamos viviendo transformaciones decisivas que están alterando radicalmente los diferentes sectores de la vida humana: la globalización, el avance de tecnologías de la información y de la comunicación, el aumento de las migraciones y el cambio climático, etc. En este marco sociocultural cambiante, las personas están llamadas a realizar un intenso trabajo de biografización, para dar sentido a sus vidas y trayectorias (González, 2008/2009).

Después de una revisión de algunos documentos relacionados con respecto las historias de vida, coincido ampliamente con el sociólogo francés Daniel Bertaux, que la investigación en el campo de las ciencias sociales el enfoque cualitativo viene tomando desde hace un tiempo un auge muy importante y la tendencia actual está en el pluralismo. El pluralismo teórico y metodológico (Bertaux, 1980).

Este auge puede dar la impresión de ser algo nuevo, especialmente a los investigadores noveles, de que el enfoque cualitativo es nuevo y constituye un logro y una conquista de las orientaciones más actuales de la ciencias que, para muchos viene a ser una verdadera revolución. En realidad, el énfasis en lo 
cualitativo precede históricamente al énfasis en lo cuantitativo en todos los campos de la ciencia, sobre todo, en las ciencias que se ocupan de conocer cuanto atañe específicamente al ser humano, a sus formas de vida y su conducta (Moreno, 2006).

Esto ha permitido el desarrollo las historias de vida dentro del enfoque cualitativo y despertado un interés creciente por las historias de vida en el campo de la educación a comienzos de los años noventa (Chapman, 2008; González, 2008/2009). Según Goodson (2003, p. 733), "Aunque durante el siglo pasado se ha podido rastrear muestras intermitentes de interés, los estudios sobre las historias de vida de profesores han sido hasta hace poco un género tristemente dejado en el abandono más completo. Claro ésta que siempre ha habido excepciones y, en algunas culturas, como es el caso de Japón, una larga tradición de biografías de docentes que ha proporcionado datos muy valiosos para los que están metidos con el trabajo de historias de vida". Si se abandonó, es porque había antes, no se puede abandonar una cosa que no existía. El estado de abandono en el que se encontraba el docente dentro los estudios de educación ha sido resumido de una forma muy clara sencilla y convincente por Lortie (1975), citado por Goodson (2003), "La enseñanza tiene mucho de prescripción y poco de descripción, porque son muchos los libros y los artículos en los que se dice a los docentes cómo deben comportarse; los estudios empíricos sobre el trabajo docente, así como sobre los puntos de vista de quienes hacen funcionar las escuelas siguen siendo excepcionales".

El termino historia de vida ha sido definido de muchas maneras en la literatura de la investigación y utilizadas de múltiples formas dependiendo de la perspectiva en el cual ha sido ideada. Como ya manifestaba Sarabia (1985), el término "historia de vida" ha sido tomado en un sentido amplio que ha englobado las autobiografías, biografías, relatos de toda una vida, narraciones parciales de ciertas etapas. El término se refiere no sólo al relato en sí, sino a toda la información acumulada sobre la vida objeto de estudio: informes procedentes de etapas escolares, de fuentes sanitarias, etc., y, obviamente, a la labor de análisis por el, o los investigadores" 
En base de los documentos tanto teóricos como empíricos disponibles a nuestro alcance sobre las historias de vida: Pujadas (2002), El método biográfico: El uso de las historias de vida en ciencias sociales; Pujadas (2000), "El método biografico y los géneros de la memoria"; Sarabia (1985), "La historia de vida", Bertaux (1980), "Método biográfico: su validez metodológica, sus potencialidades", Franco Ferrarotti (2007) "Historia de vida como método" Bolivar (2002), “¿De nobis ipsis silemus?”: Epistemología de la investigación biográfico-narrativa en educación; Bolívar, Domingo y Fernández (2001), Investigación biográfico-narrativa en educación; Goodson (2003), "Hacia un desarrollo de las historias personales y profesionales de los docentes"; Goodson (2004), Historias de vida del profesorado; Hornillo y Sarasola (2003), "El interés emergente por la narrativa como método en el ámbito socioeducativo. El caso historia de vida"; Mallimaci y Giménez (2006), "Historias de vida y método biográfico"; y Chapman (2008), "Narratives in mathematics teacher education", se ha podido constar que desde la perspectiva cualitativa ha sido usado como: técnicas de recogida y análisis de datos, métodos de investigación cualitativa (método biográfico) y enfoque de investigación cualitativa.

\subsection{Origen del término "historia de vida"}

En el campo científico de la sociología, existe unanimidad entre los investigadores, que el término historias de vida está en estrecha relación con la aparición del método biográfico. De acuerdo a Sarabia (1985) y Pujadas (2002) se empezó a usar el término Life history (historia de vida) en la obra pionera de William I. Thomas y Florian Znaniecki (1918-1920), The Polish Peasant in Europe and America (El campesino polaco en Europa y America).

Según Sarabia (1985) el primer volumen de Thomas y Znaniecki data de 1918. En el caso de la sociología, la historia de vida fue aplicada por primera vez por el Departamento de Sociología de la Universidad de Chicago que acabaría siendo el centro de la disciplina en los Estados Unidos durante muchos años y fundando una línea de pensamiento sociológico, denominado la Escuela de Chicago. Thomas y Znaniecki, miembros de este departamento de 
sociología, publicaron en 1918 la obra The Polish Peasant in Europe and America, un estudio macrosociológico, donde lo novedoso era la metodología empleada durante los ocho años que duró la investigación.

De acuerdo a Moreno (2006), dos fueron los temas principales que ocuparon las investigaciones de la Escuela de Chicago: la inmigración y la delincuencia, principalmente la juvenil. William I. Thomas trabaja, especialmente, en la migración y los problemas que presentan en la ciudad de Chicago de principios del siglo XX. A los estudiosos estadounidenses les resultaba incomprensible las conductas delictivas de muchos inmigrantes, pues ellas se salían del marco de los parámetros en que ese mismo tipo de comportamientos tenía sentido en la tradición delincuencial de sus propios connacionales.

Moreno (2006), señala que Thomas después de su doctorado viaja por varios países europeos de los que proviene buena parte de la inmigración, se pregunta si la explicación de lo que a él y a sus colegas les resulta difícil de entender no estará precisamente en las formas de las comunidades de origen de los mismos inmigrantes.

Thomas tiene en cuenta especialmente a los polacos, muy abundantes en la ciudad de Chicago de esa época, cuya conducta parece en extremo contradictoria: por un lado aceptan sumisamente la autoridad con un comportamiento que para él es típicamente campesino, pero, por el otro, parecen pensar que la libertad en su nuevo país es ilimitada y en consecuencia entran en graves y permanentes conflictos con la policía. Thomas emprende esta investigación en 1908, a la que le dedicará varios años. Se traslada a Polonia para recoger toda la documentación posible acerca del campesinado polaco. En Varsovia en 1913 se encuentra con Florián Znaniecki, quien por su cuenta venía ya estudiando la sociología de la inmigración. Juntos trabajan desde entonces en lo que será la obra de la Escuela de Chicago. La información se basó en materiales autobiográficos, correspondencia familiar, facturas, artículos de periódicos, archivos de tribunales, sermones de sacerdotes de las comunidades polacas tanto en Polonia como en Chicago y otros documentos personales, resaltándose la actitud y la definición de la 
situación por el actor, poniéndose de relieve el énfasis en los aspectos interpretativos.

Moreno (2006), escribe sobre la primera y segunda Escuela de Chicago. La primera Escuela de Chicago conocida como cualitativista hasta 1935 y la segunda escuela de Chicago netamente cuantitativista. No porque en ella haya que situar el origen o la invención de dichos métodos, enfoques y orientaciones, sino porque la Escuela de Chicago los desarrolló ampliamente cuando se iniciaba, en forma sistemática y modernamente científica, los estudios sociales.

Es importante conocer y reconocer que la historia de vida no tiene origen en la historia general, sino que surge dentro del enfoque cualitativo como una alternativa de investigación. Aunque las historias de vida fueron utilizados tanto por positivistas y humanistas. Las historias de vida, que principalmente habían sido consideradas parte del campo de interés y de los métodos de antropología, la sociología y la psicología, pero no de la historia. Fue sólo con la apertura y la reconsideración crítica formulada desde la "historia social" respecto de su campo disciplinario, que las historias de vida entraron a formar parte de los intereses metodológicos y productivos del campo historiográfico.

De acuerdo a Sarabia (1985, p. 165), "La utilización de las historias de vida como métodos de investigación e instrumentos de reflexión y análisis por parte de los historiadores, antropólogos, psicólogos sociales, sociólogos, entre otros, tiene una larga tradición". Las historias de vida fueron Ilevadas acabo entre las dos guerras por los sociólogos de Chicago. Sin embargo, después de la Segunda Guerra Mundial, esta forma de observación desapareció de la panoplia metodológica internacional (Bertaux, 1980). La Escuela de Chicago tuvo su gran apogeo en la década de los 20, después de los 35 considerada como la segunda escuela de Chicago estuvo caracterizada por su declive. Además después de la segunda Guerra Mundial vino el apogeo del método cuantitativo como señala Sarabia:

(...) tras la Segunda Guerra Mundial, la veloz expansión de métodos y técnicas de investigación de corte cualitativo, alejó la atención de los historiadores y científicos sociales de los documentos y testimonios de carácter oral o escrito 
que constituyen la base de datos a partir del cual se constituyen las historias de vidas. (1985, p. 165).

Según Bertaux (1980), desafortunadamente los sociólogos, obnubilados por una investigación con apariencia de cientificidad, se vuelven cada vez más hacia lo cuantitativo y menospreciando los relatos de vida. Aunque, no desapareció del todo el enfoque cualitativo y en particular las historias de vida, uno de los que continuó fue Oscar Lewis autor de Los hijos de Sánchez. Bertaux (1980), señala que Langness (1965) recolectó cuatrocientos ejemplares de historias de vida. Aunque para Sarabia (1985), "curiosamente las historias de vida en España e Hispanoamérica ha sido un género escasamente cultivada". Sin embargo la situación ha cambiado para Argentina (Mallimaci y Gimenez, 2006).

De acuerdo a Pujadas, la investigación biográfica desde la historia de vida ha seguido un esquema temporal de aparición a comienzos del siglo XX en la Escuela de Chicago y un posterior desuso en la década de los cuarenta y cincuenta por la hegemonía de la perspectiva positivista en las ciencias sociales durante un largo periodo, que va desde los años cuarenta a los años setenta (Pujadas, 2002). Para el autor es indudable que exista en las ciencias sociales una especie de la ley del péndulo, que se manifiesta en forma de escuelas y tendencias que, en diferentes momentos, suponen el predominio de sensibilidades y enfoques de carácter positivista o humanista. Para otros como Sarabia (1985), tras la Segunda Guerra Mundial asistimos ante la veloz expansión de los métodos y técnicas de investigación de corte cuantitativo que alejó la atención de historiadores y científicos sociales de los documentos y los testimonios de carácter oral y escrito, que constituyen la base de datos a partir de la cual se construyen las historias de vida. Mientras que para Morin (1980), citado por Bertaux (1980), "esta forma de investigación disminuyó en el curso de los años cincuenta y setenta". Aunque no existe la unanimidad en las fechas, pero todo están de acuerdo en su declive del enfoque y su desuso de las historias de vida. 


\subsection{Términos afines a la historia de vida}

A lo largo del tiempo los autores de diferentes disciplinas y escuelas que sustentan la historia de vida, han generado una multiplicad terminológica sin ofrecernos definiciones precisas. Por ello existe hoy en día toda una terminología redundante y a veces polisémicas que puede dificultar la comprensión de parte del lector de a qué nos estamos refiriendo en cada caso. Los términos más utilizados son biografía, autobiografía, historia personal, narración biográfica, relato de vida, fuente oral, documentos personales. (Pujadas, 2002; Sarabia, 1985; Mallimaci y Giménez, 2006 y Moreno, 2006).

\section{La biografía}

El origen del género biográfico encuentra registros en la historia antigua, siendo de larga tradición en la historia de la cultura, a pesar de que no se consideren parte de la terminología científica hasta los albores del siglo VII. En un estudio de Rojo (1997) se afirma que las primeras manifestaciones literarias de carácter biográfico, que se remontan a varios siglos antes de Cristo, recreaban la vida de determinados tipos humanos o de personajes insignes. Se podría considerar que se ajusta a lo que hoy denominamos biografías. El término biografía, es el relato de una persona, escrito en tercera persona y elaborada por una persona ajena al protagonista, ya sea sobre una base exclusivamente documental, o mediante una combinación de documentos, entrevistas al biografiado y a otras personas de su entorno (Pujadas, 2002).

Es muy importante la distinción dada por Pujadas entre "lo biográfico" de "las biografías". Para el autor: "lo biográfico" es el dominio general de cualquier trabajo humanístico o científico-social orientado al establecimiento de trayectorias personales, sea en base a fuentes orales o escritas. Sin embargo, "las biografías" constituyen un género histórico literario específico en el que un investigador "reconstruye" una trayectoria individual sobre la base de documentos perfectamente escrita y con el auxilio eventual de fuentes orales en el caso que se trate de la biografía de una persona contemporánea. Normalmente el género biográfico se orienta hacia personajes históricos 
relevantes y públicos por su aportación en los campos de la política, la ciencia, el arte, la educación, entre otros.

\section{La autobiografía}

La aparición de la autobiografía es más tardía y aparece como desarrollo final de una conciencia reflexiva, rasgo distintivo de la naturaleza humana (Sarabia, 1993). La autobiografía constituye la narración de la propia vida, contada por su propio protagonista. Para Mallimaci y Giménez (2006, p. 178) "Es la historia de vida de personas contadas por ellas mismas". La autobiografía es un relato en primera persona sobre una serie de experiencias. Se refiere a la narración de la propia vida explicada por su propio protagonista, produciéndose así una simbiosis entre narrador y protagonista. Es un documento personal donde el individuo plasma una narración retrospectiva sobre su experiencia, desarrollando secuencialmente los hechos de su vida más significativos. Según Pujadas (2000) autobiografía es el término favorito utilizado entre los antropólogos que han combinado la etnografía y la recopilación de las trayectorias profesionales.

El origen del término autobiografía sería indudablemente para marcar distancia al de biografía, en sentido que las fuentes escritas y la distancia del investigador respecto a su objeto de estudio biográfico son sustituidas aquí por la relación estrecha del investigador con un sujeto con quien éste adquiere un compromiso de respetar su oralidad y estilo. Según Tójar (2006), las autobiografías y los relatos de vida son un tipo particular de los documentos personales. Según Pujadas (2002), existe otra modalidad de autobiografía, usada más frecuentemente por los sociólogos:

Consiste en el encargo a un informante de la redacción de su historia de vida, a partir de unas instrucciones escuetas y claras y a cambio, normalmente, del pago en efectivo de una cierta cantidad de dinero. Tal fue el sistema utilizado por Thomas y Znaniecki (1958) para conseguir la autobiografía de Wladed, el campesino polaco residente en Chicago, que constituye el documento más valioso... (Pujadas, 2002, p.127). 


\section{El biograma}

Un biograma consiste en la elaboración de un mapa con la trayectoria profesional que reúne los acontecimientos mas destacados junto a la cronología correspondiente (Tójar, 2006, p. 262). Una forma inicial de análisis de una historia de vida es mediante la elaboración de un mapa de su trayectoria que conjuga los acontecimientos y la cronología. Según Bolívar et al (2001), "la confección de biogramas de la vida profesional permite representar las trayectorias individuales como encadenamiento cronológico de situaciones administrativas diversas, compromisos institucionales adquiridos, destinos ocupados, actividades formativas realizadas y discontinuidades experimentadas, así como otros acontecimientos de relevancia sufridos a lo largo de la vida y de la carrera".

\section{La historia oral}

La historia oral es el proceso de obtener y preservar los recuerdos de los cuales una persona puede hablar en relación a sus conocimientos de primera mano de ciertos eventos y experiencias. La historia oral nos provee una manera de capturar las historias y experiencias significativas de individuos, familias y comunidades que no están registrados en documentos escritos y que por esa razón pueden perderse. Las historias orales pueden aumentar los documentos escritos pasado al proveer voces a las silenciosas fotografías y aclarar el significado de documentos escritos. La historia oral es una herramienta importante para preservar el pasado, debido a que sólo una pequeña porción del pasado se documenta, y que una pequeña parte de lo que se recuerda se registra.

Una historia oral es una entrevista grabada de audio o video realizada en forma de preguntas y respuestas. Un proyecto de historia oral es una serie de entrevistas orales acerca de la historia que se concentra en documentar un tópico, tema, época, lugar, organización, evento o conjunto de personas. El hacer entrevistas para la historia oral es algo desafiante, demandante, interesante y extremadamente satisfactorio, tanto para los maestros, bibliotecarios o archivistas profesionales, como para cualquier persona que 
hace la entrevista y también para los que son entrevistados. La historia oral se trata de un tipo de investigación que se nutre de la reflexión individual sobre eventos específicos de la historia de una sociedad, analizando sus múltiples causas, consecuencias y efectos sobre la vida individual/familiar de los participantes y otros actores sociales. La historia oral como proceso descriptivo y narrativo es tan antigua como la historia misma, de modo que las sociedades antiguas la transmisión oral era la forma de perpetuar los acontecimientos, conocimientos y saberes. Uno de los trabajos que puede consultar en España es La historia oral: métodos y experiencias de Marinas y Santamarina (1993) ocupa un lugar de primera fila en la literatura metodológica española.

\section{Los documentos personales}

Para Pujadas (2002), con el término documentos personales se describe cualquier tipo de registro no motivado o incentivado por el investigador durante el desarrollo de su investigación y que posea, sobre todo, un valor afectivo o simbólico para el sujeto analizado, junto a la función de detonante del proceso de rememoración de los acontecimientos pasados. Una de las definiciones dada por Allport:

Entendemos por documento personal todo escrito o manifestación verbal del propio sujeto que nos proporciona, intencionadamente o no, información relativa a la estructura y dinámica de la vida del autor. Se incluyen con toda seguridad en este grupo: 1) las autobiografías generales o limitadas a un aspecto; 2) diarios personales y anotaciones diversas; 3) cartas; 4) cuestionarios libres (test no estandarizado); 5) manifestaciones verbales obtenidas en entrevistas, declaraciones espontáneas, narraciones; 6) ciertas composiciones literarias. Es importante observar que todos estos documentos proceden del propio sujeto; son documentos en primera persona. Existen, además, documentos en tercera persona, consistentes en manifestaciones de otros individuos sobre el sujeto: estudio de caso, historias de vida, biografías. (Allport, 1966, 472; citado por Rojo, 1997, p. 386).

Pujadas (2002) hace una distinción entre documentos personales $y$ registros biográficos obtenidos por encuesta al proporcionarnos una amplia clasificación de lo que considera el dominio del método biográfico. En los 
primeros incluye autobiografías, los diarios personales, la correspondencia, las fotografías, películas, videos o cualquier otro tipo de registro iconográfico y los objetos personales. En el segundo establece una división entre historias de vida, relatos de vida y biogramas (2002, p. 14).

En otro documento Pujadas citando al sociólogo británico Ken Plummer nos muestra que hay una gran multiplicidad de documentos personales:

El mundo está abarrotado de documentos personales. La gente lleva diarios, envía cartas, hace fotos, escribe informes, relata biografías, graba, pinta, publica sus memorias, escribe cartas a los periódicos, deja notas de suicidio, escribe frases en las tumbas, filma películas, dibuja cuadros, hace música e intenta consignar sus sueños personales. Todas estas expresiones de la vida personal son lanzadas al mundo a millones y pueden ser de interés para cualquiera que se preocupe de buscarlas (Plummer, 1989, p. 15)

\section{Los relatos de vida}

Los relatos de vida o relatos biográficos entendidos como registro literal de las sesiones de las entrevistas que el investigador ha realizado con el entrevistado. El término "relatos de vida" ha sido uno de los más afines a "historias de vida", especialmente en la primera etapa, aunque en la actualidad se encuentran trabajos de investigación que emplean el término de manera distinta.

De acuerdo a Bertaux (1980), se ha pasado un largo periodo de indecisión terminológica, hasta que propuso el sociólogo norteamericano Norman K. Denzin (1970) la distinción entre "life story" (relato de vida) y "life history" (historia de vida). La primera como la narración realizada por el protagonista, tal como lo cuenta quien lo ha vivido y la segunda como construcciones narradas de la vida de alguna persona realizada por los investigadores o biógrafos. Daniel Bertaux (1980) fue el que introdujo en francés como "recit de vie" y "history de vie" y en español fue planteado como "relatos de vida" e "historias de vida" respectivamente por Juan José Pujadas (2002).

Los relatos de vida según Denzin, son narraciones realizadas por el propio protagonista, tal como lo cuenta quien lo ha vivido. En la transcripción 
del material recogido se minimiza la intervención del investigador. Es muy cercano al testimonio utilizado por el periodismo.

Pujadas recoge la diferenciación propuesta por Norman Denzin entre historia de vida (life history) y relato de vida (life story), esta distinción luego fue respaldad por Daniel Bertaux y otros autores, en Francia y otros países. En España, por ejemplo antes que Pujadas (2002, pp. 13 -14), el sociólogo Lorenzo Chacón en 1989 ya había recogido dicha precisión terminológica:

En 1970 N. K. Denzin propone distinguir life story y life history. El primero designaría la historia de una vida tal como la cuenta la persona que la ha vivido. Denzin propone reservar el segundo, a los estudios de caso sobre una persona dada, que comprenden no sólo su propio relato, sino también todo tipo de documentos. La expresión propuesta por Bertaux (1980, p. 200) como equivalente a life story en francés sería récit de vie; en castellano el término equivalente puede ser relato de vida, reservando historia de vida para life history (Chacón, 1989, citado en Valles, 2000, p. 240).

Los relatos de vida constituyen una herramienta incomparable de acceso a lo vivido subjetivamente, y la riqueza de sus contenidos es una fuente de hipótesis inagotable (Bertaux, 1980).

\section{La historia de vida}

Según Pujadas (2002), desde el último volumen The Polish Peasant, de Thomas y Znaniecki, se enpezó a usar el término life history, tanto para describir la narrativa vital de una persona recogida por un investigador, como la versión fina elborada a partir de dicha narrativa, más el conjunto de registros documentales y entrevistas a personas del entorno social del sujeto biografiado que permiten completar y verificar el texto biográfico inicial.

La historia de vida se destaca por la interpretación de la vida del sujeto por parte del investigador. Además, según Pujadas (2002), N. Denzin propone reservar el término "historia de vida" para los estudios de caso sobre una persona determinada. Mientras que Ferrarotti (2007) da argumentos de fondo que legitiman a los métodos cualitativos como estrategias privilegiadas para el estudio de lo social, en particular las las historias de vida y uno de los 
argumentos centrales es que el hombre no es un dato sino un proceso, el cual actua en forma creativa en su mundo cotidiano.

Los dos términos: relatos de vida e historias de vida han sido utilizado muchas veces indistintamente. Al respecto Sarabia (1985) dejaba ya constancia escrita de la necesidad de clarificar el término. En un trabajo de una publicación pionera en la literatura en castellano, indicando que el término tiene una polisemia.

El término historias de vida ha sido tomado en un sentido amplio que ha englobado las autobiografías como vidas narradas por quienes las han vivido, o informes producidos por los sujetos sobre sus propias vidas, y las biografías, entendidas como narraciones en las que el sujeto de la narración no es el autor fina de la misma." (Sarabia, 1985, p. 171).

Aunque lo más cercano a las historias de vida han sido los relatos de vida. Pero es de interés de los investigadores precisar los términos entre ellos podemos señalar a Denzin, que en 1970 propone distinguir entre life story y life history. El primero designaría la historia de vida tal como lo cuenta la persona que la ha vivido y propone reservar el segundo a los estudios de caso sobre una persona que comprenden no su propio relato sino también todo tipo de documentos. Diez años después Bertaux (1980), propone que el equivalente a life story en francés sería récit de vie, mientras a life history sería histoire de vie y Pujadas (2002), sostiene que e castellano es relatos de vida para el primero y historias de vida para el segundo. Los relatos de vida son un tipo particular de documentos personales, mientras que las historias de vida son reconstrucciones narradas de la vida de alguna persona realizadas por un investigador. Runyan (1982), ha acuñado el término life course (curso de vida), para referirse a la trayectoria individual o grupal, "experiencias" y eventos desde el nacimiento hasta la muerte, y la cadena de estados personales y situaciones vividas, que han sido influenciada por esta secuencia de sucesos, reservando la el término historia de vida sólo para el caso individual.

Adopto la definición dada por Pujadas (2002):

(...) entendemos por historia de vida el relato autobiográfico, obtenido por el investigador mediante entrevistas sucesivas, en las que el objetivo es mostrar el testimonio subjetivo de una persona en la que se recogen tanto los 
acontecimientos como las valoraciones que dicha persona hace de su propia existencia. En la historia de vida el investigador es solamente el inductor de la narración, su transcriptor y tambien el encargado de "retocar" el texto, tanto para ordenar la información del relato obtenido en las diferentes sesiones de entrevistas, como el responsable de sugerir al informante la necesidad de cubrir los huecos informativos olvidados por el sujeto. (Pujadas, 2002, pp. 4748).

A continuación se presenta las diferentes tipologías, clasificaciones 0 funciones que se le atribuye a las historias de vida.

\subsection{Tipologías de historias de vidas}

Existen una única variedad de tipologías o clasificaciones de las historias de vida, de acuerdo los diferentes autores. En este apartado hemos registrado las clasificaciones de Ruíz Olabuénaga (1999), Mckernan (1999) y Pujadas (2002).

\section{Ruíz Olabuénaga (1999)}

Este autor expone tres tipos de historias de vida según el enfoque utilizado para construirla:

1. La reminiscencia. Cuando el interés es la reconstrucción de una época y se utiliza las experiencias de las personas que la han vivido.

2. El assesment. Cuando el interés reside en el diseño de las políticas sociales y asistenciales y para ello se basa en historias de personas que conforman personas con especiales dificultades.

3. La investigación teórica. Cuando está centrado en el estudio de los factores que conllevan a una trayectoria vital vinculada a situaciones marginales. 


\section{Mckernan (1999)}

Este autor también distingue tres modalidades de historias de vida:

1. Historias de vidas completas. Estas abarcan todo el curso de vida o carrera profesional del individuo.

2. Historias de vidas temáticas. Estas son similares a las completas pero ciñen la investigación a un tema, asunto o periodo particular de la vida de la persona en cuestión para indagar a fondo.

3. Historias de vidas editadas. Estas pueden ser completas 0 temáticas, su característica principal es que combina la narración de la historia junto a comentarios y explicaciones de alguna otra persona que no es el protagonista de la biografía.

\section{Pujadas (2002)}

El autor distingue tres tipos de historias de vida, en su libro "Método biográfico: El uso de las historias de vida en ciencias sociales.

1. De relato único. Hay que conseguir un sólo buen informante, que tenga una buena historia que contar. Se requiere, además, un relato que narrativamente sea interesante y que sea completo. El sujeto dede ser brillante, genuino, sincero, que explique con claridad e introduzca en su relato elementos significativos, que sea autocrítico y analice con cierta perspectiva su propia trayectoria vital y, sobre todo sea constante y esté dispuesto a llegar hasta el final. Sin estos requisitos es difícil que el investigador se decida a ensayar esta forma de documento científico, la historia de vida.

2. De relatos cruzados. Se trata de un "pequeño coro de voces familiares" que acompañan a la voz del solista que es el protagonista que relato su biografía.

3. De relatos paralelos. Es la recopilación de relatos biográficos sobre un mismo tema a diferentes personas, en base a una selección tipológica de la muestra, siguiendo un criterio de edad, estrato social, nivel educativo, etc. 
Juan José Pujadas es un autor español clásico, que es citado por los diferentes investigadores en campo de la sociología, particularmente en la historia de vida.

Por otro lado, José González (2008/2009), de la Universidd de Sevilla, presenta la historia de vida considerada en su triple función:

\section{González (2008/2009)}

1. Función investigadora, la dimensión investigadora de enfoque bigráfico-narrativo.

2. Función formativa, la dimensión formativa.

3. Función testimonial, contribye a la memoria histórica.

En base a las clasificaciones señaladas por Mckernan (1999) y Pujadas (2002), presentamos el siguiente cuadro:

\begin{tabular}{|c|c|c|c|c|}
\hline & \multicolumn{3}{|c|}{ HISTORIA DE MDA } \\
\hline & & Completa & Temática & Editada \\
\hline \multirow{3}{*}{ 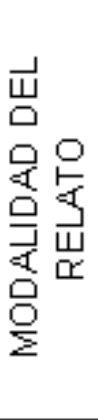 } & Único & $\begin{array}{l}\text { Historia de wida } \\
\text { completa de } \\
\text { relato único }\end{array}$ & $\begin{array}{l}\text { Historia de wida } \\
\text { temática de relato } \\
\text { único }\end{array}$ & $\begin{array}{l}\text { Historia de wida } \\
\text { editada de } \\
\text { relato único }\end{array}$ \\
\hline & Cruzado & $\begin{array}{l}\text { Historia de uida } \\
\text { completa de } \\
\text { relato cruzado }\end{array}$ & $\begin{array}{l}\text { Historia de wida } \\
\text { tematica de relato } \\
\text { cruzado }\end{array}$ & $\begin{array}{l}\text { Historia de uida } \\
\text { editada de } \\
\text { relato cruzado }\end{array}$ \\
\hline & Paralelo & $\begin{array}{l}\text { Historia de vida } \\
\text { completa de } \\
\text { relato paralelo }\end{array}$ & $\begin{array}{l}\text { Historia de wida } \\
\text { temática de relato } \\
\text { paralelo }\end{array}$ & $\begin{array}{l}\text { Historia de wida } \\
\text { editada de } \\
\text { relato paralelo }\end{array}$ \\
\hline
\end{tabular}

Nuestro estudio se enmarca dentro de la coordenada temático-única. Es decir, se trata de una historia de vida temática de relato único. La historia de vida puede ser vista, desde esta perspectiva, como una contribución esencial a la memoria histórica de la educación boliviana.

\subsection{Renacer de las historias de vida}

Existe un amplio consenso entre los científicos sociales que defienden el método biográfico (historias de vida) sobre la trascendencia y las implicaciones epistemológicas de su utilización. Bertaux (1980), advierte de que "no se trata tan solo de adoptar los relatos de vida como una nueva práctica empírica, que 
presupone una redefinición gradual de la aproximación global a la practica sociológica". Por otro lado la interrelación de las diferentes disciplinas a las investigaciones interdisciplinarias, sin dejar de lado las investigaciones especializadas. En la actualidad estamos frente a un pluralismo teórico y metodológico (Bertaux, 1980).

Por otro lado Bertaux (1980), Ferrarotti (1981), mostraron a los sociólogos el potencial actual de las historias de vida entre finales de los setenta y principios de los ochenta. Por ejemplo, Bertaux dice "las historias de vidas, redescubiertos al fin, son utilizadas de muchas maneras. Pero ya hacen que la investigación se centre en el punto de articulación de los seres humanos y podría ser que de la diversidad de sus utilizaciones emerja poco a poco un enfoque unificador que sobrepase las fronteras actuales de la sociología como tal" (Bertaux, 1980).

En torno a la utilización de las historias de vida ya sea como fuente o como método de investigación se ha creado un interés común interdisciplinario. Las historias de vida son entonces un recurso renovado y un método revalorado mediante el cual se han desarrollado enfoques cualitativos desde los años setenta. Para Pujadas (2002, p. 27), "La revitalización del enfoque humanista en las ciencias sociales a lo largo de las últimas tres décadas puede ser interpretado, como una reacción frente al papel hegemónico de las perspectivas positivistas durante un largo periodo que va desde los cuarenta a los setenta. Esta forma de investigación disminuyó en el curso de los años cincuenta y setenta. (Morin, 1980; citado por Bertaux, 1980).

Aunque no desapareció del todo porque encontramos un grupo limitado de investigadores que continuaron las obras pioneras, las de Thomas y Znaniecki (1918-1920) de la Escuela de Chicago, se señala a los que han seguido esta tradición estadounidense a Dollard (1935), que destaca la gran utilidad de esta técnica de análisis en los estudios de comunidad, para dar cuenta de las "fuerzas emocionales en la sociedad", esto es, para captar los aspectos subjetivos de la cultura y las motivaciones individuales y ocultas de los individuos en su participación en la vida social. Sin embargo, el trabajo pionero de Oscar Lewis, supuso la reaparición del interés hacia los enfoques 
biográficos, rechazando la metodología cuantitativa, Lewis optó por la observación participante y por las entrevistas en profundidad para recoger relatos de vidas de familias pobres rurales y urbanas de México y Puerto Rico. Se trata de relatos de vida cruzados y con una estructura polifónica, puesto que los diferentes miembros de la familia narran su vida en común situado en un contexto social y histórico. Los hijos de Sánchez el libro más popular de Lewis (1971), contribuyó a legitimar una manera de hacer antropología más integral (holística).

Según Sarabia (1985) y Bertaux (1980), Langness en 1965 en su obra: The Life History en Antropological Science, libro dividido en tres partes, la primera pasa revista a los trabajos realizados siguiendo esta técnica, tomando como punto de partida el trabajo Kluckhohn de 1942, hasta principios de los años sesenta; la segunda parte explora las tendencias y los temas de estudio que son más proclives al uso del método biográfico, mientras que la última parte es una presentación sucinta del uso de las técnicas biográficas en el trabajo de campo. Según Sarabia (1985), existe un trabajo de June Nash que data de 1974, artículo basado en la biografía familiar de Juan Rojas, minero del altiplano, Oruro, Bolivia. La biografía familiar de Juan Rojas representa el análisis de los reflejos y derivaciones de los movimientos sociales en Bolivia en la década de los años cincuenta y sesenta, constituyendo un microcosmos y una metáfora de estos. Según Pujadas (2002, p. 95), la obra central de una de las figuras más prestigiosas es el libro Storia e storie di vita del sociólogo italiano Franco Ferrarotti publicada en 1981. El libro sienta las bases epistemológicas y metodológicas del uso de historias de vida en la investigación social.

Daniel Bertaux de la escuela sociológica francesa y Franco Ferrarotti de la italiana proporcionan argumentos de fondo que legitiman a los métodos cualitativos como estrategias privilegiadas de para el estudio de lo social, en forma particular el caso de las historias de vida.

Documentos de autores españoles que hemos tenidos a nuestra disposición son de Bernabé Sarabia (1985), Historias de vida, este documento ha sido muy útil en esta investigación, porque ha sido el documento que nos 
introdujo en las historias de vida. Otro documento muy valioso es el libro de Juan José Pujadas (2002), El método biográfico: El uso de las historias de vida en ciencias sociales es un texto introductorio, teóricamente sólido y bien informado. Definitivamente crítico del positivismo, se inclina por una clara posición epistemológica, teórica y metodológica renovada y centrada en la revaloración de lo humano para la ciencia. Además, se encuentra la fundamentación filosófica y ética que sostiene el método. Un tercer libro es de Marinas y Santamarina (1993), La historia oral: Métodos y experiencia, es una obra excelente de recopilación de textos significativos de los principales autores a se han referido a la historia de vida: Bertaux, Ferrarotti, y otros que están bien representados.

No solamente se ha redescubierto la historia de vida o en su conjunto el genero biográfico, sino que en estas tres últimas décadas hemos asistido a una progresiva recuperación del método biográfico y ha da lugar a un resurgimiento de interés por las historias de vida desde los años setenta en la antropología, sociología, psicología social y la pedagogía. Los libros recientes de investigación educativa dedican algunos apartados a método biográfico o historias de vida, por ejemplo, Bisquerra (1989), no contiene un apartado sobre historias de vida, pero en Bisquerra (2004), si, se proporciona un capítulo sobre el método biográfico o historias de vida. En la misma línea Sandín (2003) dice: "en las últimas décadas estamos asistiendo a un renovado interés para la investigación narrativo-biográfica".

\subsection{Las Historias de vida en ciencias sociales y humanas}

En los últimos treinta años estamos viviendo transformaciones decisivas que están alterando radicalmente los diferentes sectores de la vida humana. Por ejemplo, la globalización, los avances de la tecnología de la información y la comunicación, el flujo migratorio y el cambio climático. También se dio una "ruptura epistemológica" que dio un giro hermenéutico en las ciencias sociales, de la perspectiva positivista a la perspectiva interpretativa.

La recuperación y auge del método biográfico (historias de vida) en estos últimos treinta años forma parte de la revaloración del actor social 
(individual y colectivo), no reducible a la condición de dato o variable, sino caracterizado de configuración compleja y que lleva aparejada de profundizar en lo que las personas y grupos hacen, piensan y dicen como finalidad de ensayar interpretaciones de la realidad a partir de la subjetividad individual o grupal, más que a través de sofisticadas y deshumanizadoras reglas metodológicas que a menudo, instrumentalizan la realidad social para dar salida a una realidad autoconstruida y cientifista (Pujadas, 2002, p .127).

Los estudios a partir de las historia de vida sea como instrumento o técnica (Sarabía, 1985, Hornillo y Sarasola, 2003), como método (Bertaux, 1980, Ferrarotti, 1981, 2005, 2007), sea como enfoque (Ferrarotti, 1988, Bolivar, 2002) de investigación, sea como estudio de caso que verifica tal o cual teoría interpretativa han revalorizado esta tradición desde diferentes perspectivas y orientaciones (Mallimaci y Giménez, 2006). Por parte de los historiares, antropólogos, psicólogos sociales, sociólogos, escritores y otros. Por ejemplo según Sarabia (1985):

(...) En el área de la psicología social se ha empleado las biografías como historia clínicas en las que se perfila el entorno social de cada individuo analizado. La psicología de la personalidad, desarrolló lo que H.Murray Kluckhohn denominaron desde los años treinta "el estudio de vidas". Estas historias de vida se indagaban a través de entrevistas, test o cuestionario y años más tarde sería analizada en la obra de Gordon Allport (1942), The Use of Personal Documents in Psychological Science.

En Medicina existe una larga tradición de recogida de información carácter biográfico con fines terapéuticos. El estudio de caso ha sido un método compartido con la psiquiatría y la psicología clínica. A mediados de la década de los 80, áreas con la enfermedad mental se han visto iluminados por estudios de carácter biográfico, tal es el caso de las obras como la de Peter Wilson (1975), Oscar: An Inquiry Into the Nature of Sanity.

En antropología, las historias de vida conforman, sobre todo inicialmente, un intento de comprender la vida de los pueblos primitivos. En este sentido, los libros de los primeros antropólogos, como fue señalado por Marsal (1975), no diferian en exceso en cuanto a sus garantías de fiabilidad y validez los relatos de los misioneros, exploradores y viajeros en general, muchos de los cuales 
ofrecen una minuciosidad, exactitud y veracidad, equiparables a los relatos de los primeros antropólogos profesionales (Sarabia, 1985, pp. 167-168).

El interés por las historias de vidas no es reciente, como ya se ha dicho, el despegue de la metodología de los relatos de vida coincide con el apogeo de la Escuela de Chicago en los años veinte del siglo pasado. La sociología, como se ha visto en esta investigación ha sido precursora e innovadora en esta temática. Por ejemplo, Mallimaci y Giménez (2006), señalan los trabajos de Thomas y Znaniecki (1918-1920), The Polish Peasant in Europe and America. El trabajo de Thrasher (1928), investigación sobre las pandillas en Chicago a partir de entrevistas e historias de vidas. De Shaw (1930), estudio sobre la delincuencia a partir de una historia de vida. El autor busca verificar su teoría a partir de una biografía que considera representativa. En todo esto podemos constar que existe una interesante tradición metodológica sobre el uso de las historias de vida, aunque ensombrecida por el pretendido "mito de la cientificidad sociológica" que redujo el protagonismo de la metodología cualitativa entre los años cuarenta y setenta del siglo pasado.

En los años setenta se detecta un interés nuevo y renovado por los investigadores por el uso de las historias de vida como instrumentos heurístico. Será en los años ochenta cuando se concreta diversas formas de revalorización del método, pues según Sarabia (1985), en el IX Congreso Mundial de Sociología celebrado en 1978 en Uppsala, Suecia, "marcó el arranque de la veloz expansión actual del uso de las historias de vida como instrumento de reflexión teórica y práctica metodológica"

Se han dado argumentos profundos que legitiman a los métodos cualitativos como estrategias privilegiadas para el estudio de lo social, en forma particular, el caso de las historias de vida; uno de los argumentos es que el hombre no es un dato sino un proceso. Tanto Daniel Bertaux y Franco Ferrarotti, ambos con una amplia trayectoria en la aplicación de historias de vida en sus investigaciones, defienden revindicar lo biográfico como enfoque teórico-metodológico y no simplemente como una herramienta o técnica. El primero insiste en historias de familias y en sumar otras fuentes, el segundo 
sólo se interesa en el relato de una persona pues ella sintetiza lo social, lo estructural, las múltiples mediaciones. (Mallimaci y Geménez, 2006).

Según Mallimaci y Giménez (2006), la perspectiva del sociólogo italiano Franco Ferrarotti (1988), complementa y se diferencia del resto de los autores. Para este autor la historia de vida no es un método o una técnica más, sino una perspectiva de análisis única.

La historia de vida para Ferrarotti significa profundizar en el mundo de los valores, de las representaciones y subjetividades que escapa a la atención de las ciencias sociales en nombre de datos y variables. Para este autor, las experiencias y los valores compartidos constituyen el hilo conductor y el objeto privilegiado de las ciencias sociales. Las historias de vida tienen la capacidad de expresar y formular lo cotidiano de las estructuras sociales.

En 1985 Sarabia escribe: "que el uso científico de las historias de vida, se está replanteando desde las perspectivas ontológicas y metodológicas de gran interés" y Pujadas (2002), señala que "la historia de vida había experimentado una progresiva recuperación no exenta de contradicciones" y el mismo autor en 2002 nos decía, que hay una recuperación y gran auge de las historias de vida en las dos últimas décadas. Esto puede dar la impresión de que las historias de vida se han expandido en gran manera en las ciencias sociales, pero en la misma línea Franco Ferrarotti (2005) al responder en una entrevista realizada por Iniesta y Feixa, dice:

Bien, en primer lugar os diré que estoy de acuerdo que hay interés por las historias de vida, por la aproximación autobiográfica, pero desgraciadamente no creo que, hoy por hoy, este interés sea mayoritario. La mayoría de las investigaciones realizadas en Italia en este momento en el campo de las ciencias humanas (psicología social, antropología, sociología,....) todavía se basan en métodos y técnicas cuantitativas, sobre todo el sondeo centrado en una muestra más o menos representativa. Se trata de investigaciones financiadas por entes públicos y privados - empresas, ayuntamientos, sindicatos, etc.-, que obtienen de este modo datos más fácilmente presentables como seguros. A los administradores de las grandes empresas les gusta sobre todos los resultados que se pueden presentar en tablas, el apartado estadístico, los porcentajes, las correlaciones, la medición de los fenómenos. 
Dicho esto, estoy de acuerdo en que no se puede negar que hay en Italia una conciencia creciente del carácter ilusorio de estas mediciones, del carácter ilusorio de la seguridad que dan las investigaciones cuantitativas, que miden fenómenos con gran minuciosidad estadístico-matemática, pero que son limitadas desde el punto de vista de la interpretación.

Por eso no ha de extrañarnos que, sobre todo para algunos problemas, el interés por la aproximación autobiográfica esté aumentando. $\mathrm{Y}$ ello por dos razones. La primera es que a menudo los problemas sociales más graves de una sociedad son problemas clandestinos que no se pueden cuantificar. La segunda, porque ciertos colectivos sociales importantes, como por ejemplo los toxicómanos, no son representativos desde un punto de vista estadístico. Y sólo se pueden estudiar como hemos hecho nosotros, intentando de establecer una relación de confianza, lo que no ofrecen las investigaciones tradicionales, que no consideran esta relación necesaria (...).

Esta es una breve apreciación de la historia de vida en las ciencias sociales, en forma particular en el campo de la sociología. Pero, no sólo es necesario estudiar a los delincuentes o toxicómanos, etc., sino también es necesario estudiar desde esta perspectiva en el campo de la educación y en forma particular en la educación matemática.

\subsection{Historias de vida en investigación educativa}

La historia de vida en educación se asienta, pues, dentro del "giro hermenéutico" producido en los años setenta en las ciencias sociales (Bolívar, 2002). Parafraseando a Pujadas (2002), señalamos que hubo un amplio consenso entre los científicos sociales que defienden las historias de vida sobre la trascendencia y las implicaciones epistemológicas de su utilización.

El periodo de la hegemonía del positivismo según Pujadas (2002), Sarabia (1985) y otros fue de los cuarenta a los setenta del siglo pasado. Después vino un giro hermenéutico de la perspectiva positivista a la interpretativa.

La actitud teórica del positivismo es considerada como dogmática, por cuanto tiende a construir un fetiche de sus normas técnicas y a abandonar la perspectiva de su objeto de investigación original: el ser humano y sus relaciones sociales (Pujadas, 2002, p. 9). 
Para fines de este estudio coincido ampliamente con Smith (2001), en que "la historia de vida es una aproximación para entender la experiencia del profesor". Además las historias individuales de los profesores ayudan a ilustrar la complejidad de la enseñanza. Porque estás revelan que "ser profesor involucra más que un dominio de un conjunto de habilidades" (Muchmore, 2002). Según Chapman (2008), algunos de los autores que impulsaron esta tendencia son Clandinin y Connelly (2000), Elbaz (1990), Carter (1993) y Schön (1983). Aunque el énfasis está más en el relato de vida que en la historia de vida.

La investigación educativa como historias de vida está adquiriendo cada día mayor relevancia y altera los modos habituales de lo que se entiende por conocimiento pero también de lo que importa conocer. El incremento y la popularidad alcanzada por las investigaciones narrativas sobre las historias de vida, se ve reflejado tanto en lo cuantitativo y lo cualitativo de las publicaciones sobre el tema. (Bolívar et al, 2001).

Las historias de vida han visto luz como herramientas de investigación, pero puede ser utilizada también como herramientas pedagógicas (Chapman, 2008), aunque, Bolívar et al (2001), ya señalaban que dentro de la multifuncionalidad de la narración en educación, ellos se dedicaban a los usos de investigación narrativa que al empleo pedagógico habitual que la narración ha tenido y tiene en la educación.

La investigación biográfico-narrativa, más allá de una mera metodología de recogida/análisis de datos, se ha constituido hoy en día en una perspectiva propia, como forma legítima de construir conocimiento en la investigación educativa. Como tal, defendemos que constituye un enfoque propio ( $y$ no otra metodología "cualitativa" más), que altera algunos supuestos de la investigación sobre el profesorado y la enseñanza, así como el propio lenguaje de investigación (Bolívar et al, 2001, p. 10).

La base de esta sección son los documentos de Bolívar (2002), “¿De nobis ipsis silemus?: Epistemología de la investigación biográfico-narrativa en educación"; Bolívar et al (2001), La investigación biográfico-narrativa en educación: Enfoque y metodología; Smith (2001), "Life History as Key Factor in Understanging Teacher Collaboration and Classroom Practice"; Goodson 
(2003), "Hacia un desarrollo de las historias personales y profesionales de los docentes; Goodson (2004), Historia del profesorado y González (2008/2009), "La historia de vida y teorías de la educación: Tendiendo puentes".

En base a estos documentos y otros se constata que existe un creciente interés por las historias de vida de los profesores, por ejemplo, Muchmore (2002), dice: "durante la década pasada ha habido un creciente interés por el uso de las historias de vidas y una aproximación narrativa en el estudio del pensamiento y desarrollo del profesor"; otro grupo de investigadores en el campo de la educación conformado por Sancho, Hernández, Duran, Martínez, Hermosilla, Giambelluca y Creus (2005) también apoyan esa apreciación. Hernández en el prólogo al libro Historia de vida del profesorado de Goodson (2004), muestra que en los últimos años hay un creciente interés sobre las historias de vida. Este crecimiento con respecto a los trabajos publicados no es sólo cuantitativo sino también cualitativo y diversificado.

El incremento y la popularidad alcanzada por la investigación narrativa sobre las historias de vida y biografías de los actores educativos, lleva aparejada la voluntad de profundizar en lo que los profesores hacen, piensan y dicen con la finalidad de ensayar interpretaciones de la realidad a partir de la subjetividad del individual o grupal del docente.

Las historias de vida y las biografías parecen tener en este momento, una importancia nueva. Precisamente porque hay una revisión en profundidad de nuestros saberes sociales - no sólo sociológicos - ante el conjunto de fenómenos de ruptura de códigos culturales e ideológicos, de los sistemas de referencia convencionales (...) hay interés en los procesos de memoria individual y colectiva, en un momento en que precisamente la sociedad de los medios de masificación, pretende homogenizar todas las formas de saber y comunicación social” (Sandín, 2003, p. 147).

En el ámbito de la investigación educativa, consta la reivindicación del sujeto personal (profesor) que está adquiriendo una mayor relevancia. Esto induce a que, las historias de vida sean ampliamente utilizadas en los estudios sobre experiencias educativas.

La razón principal para el uso de la narrativa (historia de vida) en la investigación educativa es que los seres humanos somos organismos 
contadores de historias, organismos que, individual o socialmente, vivimos vidas relatadas. El estudio de la narrativa, por lo tanto, es el estudio de la forma en que los seres humanos experimentan el mundo (...) la educación es la construcción y reconstrucción de historias personales y sociales; tanto los profesores como alumnos son contadores de historias y también personajes en las historias de las demás y con las suyas propias" (Connelly y Clandinin, 1995; citado por Sandin, 2003, p. 147).

Las historias de vida guardan una relación íntima con las narraciones biográficas o investigación biográfica. Aunque, no son necesariamente idénticas. Para Bolívar (2002) la investigación narrativo-biográfica (historia de vida) es más que una metodología cualitativa, se ha constituido actualmente en una perspectiva o enfoque específico de investigación educativa. En la misma línea Tójar (2006), señala que las técnicas narrativas tienen en su conjunto una identidad suficiente para ser contempladas como método o enfoque de investigación, porque van mucho más allá de la obtención y análisis de información. Además, poseen una larga y relevante historia y tradición en numerosas disciplinas.

En la actualidad estamos asistiendo a un renovado interés por las historias de vida entre los científicos de las ciencias sociales y particularmente entre los investigadores del ámbito de la educación. Además las historias de vida del profesor constituyen una importante línea de investigación como señala Colas (1997) citado por Sandin (2003):

A través de las historias de vida se puede llegar a averiguar que conocen los profesores de la enseñanza, como están organizados sus conocimientos y cómo cambia su conocimiento a través de la experiencia. La historia de vida pude reflejar el discurso dominante de los profesores (...) La historia de los profesores constituye una importante línea de investigación sobre la formación del profesorado. Su aplicación también resulta oportuna para el estudio de las "voces" en el aula" (Colas, 1997c, p. 282-283; citado por Sandín, 2003, p. 148).

Según Smith (2001) muchos investigadores han desarrollado investigaciones orientadas en las vidas individuales de los profesores, sobre profesores de escuela elemental, de nivel secundario y nivel superior, pero no 
existen trabajos con profesores jubilados que continuaban comprometidos con la educación. Ese es el caso de nuestro estudio.

La presentación de la posición de González (2008/2009) respecto de la historia de vida en educación es más amplia, porque considera en su triple función: investigadora, formativa y testimonial. En su función investigadora, el enfoque de la historias de vida aparece como metodología de investigación cualitativa y una alternativa al positivismo y a la investigación social basada en el experimento y en encuestas estadísticas. Como técnica de investigación social, la historia de vida aparece a inicios del siglo $\mathrm{XX}$ como ya señalamos, con la sociología de la Escuela de Chicago. El autor señala que en la Escuela de Chicago tres focos de interés: la explicación histórica y evolución de la vida de las personas, grupos o unidades sociales; el desarrollo de la teoría; y los problemas metodológicos.

Las historias de vida como instrumentos de formación, Según González tiene cinco secciones: educadores, educación de adultos, memoria histórica y testimonios, genealogía y familia, y formación mediante autobiografías educativas. En la sección del profesor es donde esta situado la presente investigación.

\subsection{Historias de vida en educación matemática}

Los documentos relacionados sobre el uso de las historia de vida en educación matemática es muy limitado a diferencia de la educación en general. La base de esta sección son dos documentos: el artículo de Chapman (2008), "Narratives in Mathematics Teacher Education"; el documento señala que las historias de vida pueden ser vista como herramientas de investigación en educación matemática y herramientas pedagógicas en la educación del profesor de matemáticas. Aunque, llega a la conclusión de que las historias de vida parecen haber recibido mas atención en estudios relacionados para la formación del profesor de matemáticas que las herramientas pedagógicas. Su foco central está la narración como instrumento pedagógico de prospectiva en la educación del profesor de matemáticas. 
La incorporación de las historias de vida en educación matemática, permitirá comprender la complejidad de la enseñanza de las matemáticas y acercarnos a las experiencias de docentes expertos, como un eco del pasado y la ventana del futuro que permite comprender el presente. Como escribe, Fernando Hernández, en el prólogo de Goodson (2004): "la historia de vida es una estrategia de visualización y generación del saber pedagógico”.

\section{9 Concepciones y creencias de profesores de matemáticas}

En esta investigación no nos preocupa sólo la historia de vida de Jaime Escalante, sino también me pareció interesante tratar de indagar las crencias y concepciones que guian su acción instructiva.

Las creencias, concepciones y sistemas de creencias han sido el centro de atención de una gran parte de la investigación educativa durante los últimos años (Pajares, 1992). La investigación en Educación Matemática también ha puesto de relieve este interés (Thompson, 1992). Sin embargo, a pesar de las numerosas investigaciones realizadas no existe consenso en la definición ni en la relación entre concepciones y creencias. Las creencias no pueden ser directamente observadas o medidas y se deben inferir de lo que las personas dicen, pretenden y hacen (Llinares, 1996).

Investigar a los buenos profesores es complejo porque se corre el riesgo de generalizar trivializando sus características, por lo mismo, es fundamental no caer en la tentación de pensar que son ideales, puesto que son seres humanos que viven su existencia al igual que cada uno de nosotros, sólo que con compromiso y amor por lo que hacen. Las historias de vida nos permiten entender y comprender el proceso de la profesionalización docente, desvelar sus concepciones y creencias (Smith, 2001). La elabración de una historia de vida nos aporta luces para entender y explicar qué es lo que hace a un profesor. Esto es, la valoración del sentido común, la improvisación, la conciencia del cambio, la reflexión y la acción pedagógica. Sus características pueden ser intencionalmente promovidas en las distintas etapas de formación profesional porque tienen la cualidad de generar entusiasmo, contagio con un compromiso pedagógico, social y político, y por el trabajo bien hecho. 
Martínez (2003), citando a Contreras señala que la actividad que los profesores desarrollan en sus aulas parece estar orientada en sus concepciones. Estos son como un filtro que regula el estilo personal de enseñar y las decisiones que se toman durante la instrucción. Las concepciones de los profesores influyen directamente en la visión que los alumnos adquieren en relación a la naturaleza de las matemáticas, y su sentido de aprendizaje y los valores inherentes a ella.

La visión que los alumnos tienen de la matemática como disciplina, su finalidad en la enseñanza, la toma de conciencia de sus capacidades para aprenderla, los valores socioculturales que pueden llegar a atribuirle....dependen en gran medida de los mensajes que reciben del profesor, mensajes que son elaborados desde sus concepciones. (Contreras, 1999; citado por Martínez, 2003, p. 42).

Algunos autores también atribuyen al conocimiento y las creencias del profesor que afectan el proceso de enseñanza. Lo que ocurre en el aula no sólo esta relacionado con lo que el profesor cree sobre las matemáticas, su enseñanza y aprendizaje, sino también con lo que el profesor conoce sobre el tema. En esta orientación citamos a Carrillo:

Lo que un profesor cree sobre la enseñanza y el aprendizaje de las matemáticas y lo que un profesor conoce del contenido, métodos y materiales disponibles para enseñar matemáticas influyen en las decisiones del profesor relativas a la instrucción. (Carrillo, 1998; citado por Martínez, 2003, p. 43).

Otro de los autores que apunta en el mismo sentido es Ernest (1989), que entre muchos factores que influyen en la práctica de la enseñanza de las matemáticas, destacó tres:

1. Los contenidos o esquemas mentales de los profesores particularmente el sistema de creencias, concernientes a la matemática, su enseñanza y aprendizaje.

2. El contexto social de la situación de enseñanza, particularmente las limitaciones y oportunidades que provee.

3. El nivel de reflexión y los procesos de pensamiento de los profesores. 
De acuerdo con Thompson (1992), tanto en el ámbito de las investigaciones realizadas en este campo, como diseños de investigaciones realizados, han cambiado a lo largo del tiempo.

(...) Los estudios de las creencias y concepciones de los profesores de matemáticas se han centrado en las creencias sobre las matemáticas, creencias sobre la enseñanza y aprendizaje de las matemáticas o ambos. Algunos estudios han examinado la relación entre creencias de profesores y su práctica instruccional.

(...) Los diseños de investigación también han variado considerablemente, dependiendo de las características del estudio, desde la etnografía del estudio de casos de uno o dos profesores, a la estandarización de un inventario de creencias. (Thompson, 1992, p.131).

Muchos han sido los estudios que se han realizado desde los comienzos del siglo pasado tratando de investigar el papel que juega el profesor en la enseñanza en general y en la enseñanza de las matemáticas en particular.

Según Thompson (1992, p. 129), en el primer cuarto del siglo pasado, hubo un considerable interés entre los psicólogos sociales en el estudio de las naturaleza de las creencias y su influencia en las acciones de la gente. En las décadas que siguieron, el interés se disipa y casi desaparece como un tema en la literatura psicológica, debido en parte a la dificultad en acceder a estas creencias para estudiarlas y, en parte, a la emergencia en los años 1930 del asociacionismo y el conductismo. En los años 1960, el interés en los estudios sobre las creencias fue renovado, pero variado entre los psicólogos. El surgimiento de la ciencia cognitiva en los años 1970 creó un lugar para el estudio de los sistemas de creencias en relación a otros aspectos de la cognición humana y los afectos humanos. Los años 1980 fueron testimonio del resurgimiento del interés en las creencias y los sistemas de creencias entre los escolares desde disciplinas tan diversas como la psicología, la ciencia política, la antropología y la educación. El interés en el estudio de las concepciones y creencias de los profesores estuvo alimentado por un cambio en los paradigmas de investigación sobre la enseñanza. Promovida, en parte por la información procedente de la teoría y otros aspectos desarrollados en la ciencia cognitiva, las investigaciones sobre la enseñanza comienzan a cambiar en los 
años 1970 desde un paradigma proceso-producto, en el cual el objeto de estudio eran las conductas de los profesores, a uno centrado en el pensamiento del profesor, en los procesos de toma de decisiones.

El cambio de foco en la cognición del profesor, condujo a un creciente interés en identificar y entender la composición y la estructura de "sistemas de creencias y concepciones", "esquemas mentales de acción", subrayando el pensamiento y decisiones de los profesores.

Thompson (1992, p. 129), citando a Nespor, señala que bajo la influencia de la herencia del conductivismo, en la década de los sesenta y setenta, los estudios se orientaron principalmente a la investigación de actitudes, directa o indirectamente orientadas a las creencias y concepciones de los profesores.

Sin embargo, muy pocos estudios estuvieron relacionados específicamente a la educación matemática. Desde los años 1980, muchos estudios en educación matemática se han orientado en las creencias sobre las matemáticas, su enseñanza y aprendizaje. Estas investigaciones han trabajado desde la premisa que para entender la enseñanza desde la perspectiva de los maestros, tenemos que entender las creencias con las cuales ellos definen su trabajo.

De acuerdo con Ponte y Chapman (2006, pp. 462-463), el desarrollo se divide en tres periodos: 1977 - 1985, 1986 - 1994 y 1995 - 2005; como una base para considerar las posibles tendencias en términos cuantitativos (número de artículos en cada periodo) y términos cualitativos (objetos de estudio, énfasis teórico, aproximaciones metodológicas y otros problemas). En el primer periodo hay muy pocos artículos, en el segundo periodo aparecen y en el tercer periodo hay un crecimiento cuantitativo y cualitativo.

Para Ponte y Chapman (2006, p. 472), las creencias y las concepciones han jugado un rol importante como una base del estudio del profesor y su enseñanza. Además, los investigadores señalan que "detrás de cualquier modelo de enseñanza de las matemáticas hay una filosofía de la matemática" (Thompson, 1992; Ponte, 1999). Esto es innegable, porque cualquier práctica en un campo profesional necesariamente se realiza desde alguna perspectiva 
en relación con los objetos centrales en ese campo. Dado el importante papel del maestro en el proceso educativo, parece bastante natural estudiar con detenimiento su o sus filosofías personales sobre matemática (Ponte, 1999).

\subsection{Caracterización de concepciones y creencias}

En mayor parte de la literatura revisada sobre el tema, los términos concepciones, creencias, incluso conocimientos son utilizados de manera ambigua. Mientras que algunos autores manejan los términos concepciones y creencias como sinónimos, otros indican que son diferentes tipos o niveles de conocimiento, y por lo tanto, forman parte de un conocimiento profesional del profesor. Por ello, en un intento de precisar los términos que utilizaremos en nuestra investigación, realizaremos una búsqueda del significado atribuido a estos términos en algunas de las investigaciones realizadas sobre el tema.

El Diccionario de la Real Academia (Real Academia Española, 1984) los define:

Creencia: firme asentimiento y conformidad con alguna cosa. Completo crédito que se presta a un hecho o noticia como seguros o ciertos. (p. 394)

Concepción: Acción y efecto de concebir

Concebir: formar idea, hacer concepto de una cosa, comprenderla (p. 351).

Thompson (1992, p. 131), considera que no se ha descrito con precisión en la literatura de investigación, el concepto de creencia y su relación con el conocimiento, pese a la difusión que esta línea de investigación haya alcanzado recientemente. Para muchos estudios, el significado de creencias parece inadvertido o no lo consideran un problema. En general, tales términos como: creencias, concepciones, vistas, perspectivas, percepciones, constructos personales, sistemas de creencia e imágenes son usados sinónimamente o intercambiablemente.

\section{Creencias}

En relación al uso del término creencias, Flores (1998), recorre sistemáticamente el sentido que se le atribuye al término creencias. Considera las creencias como un hecho humano, la primera distinción que se establece 
tiene un alcance popular y consiste el conociendo por sus fuentes: fuentes propias al sujeto y fuentes externas.

Las primeras son la propia experiencia de la vida y también la capacidad intelectual de cada uno; por las que llegamos a obtener determinados conocimientos: esto es lo que propiamente sabemos. A esto se añade lo que conocemos por medio del testimonio o de la información procedente de otras personas; pero que nosotros no hemos podido comprobar o de hecho no hemos comprobado: esto es lo que propiamente hablando, creemos. (Vicente, 1995, p. 13, citado en Flores, p. 28).

El uso lingüístico del término creencias se puede reducir a tres significados principales cada uno de ellos precisa más el campo de uso.

1. Está en primer lugar el uso en sentido amplio, impreciso, que incluye a cualquier tipo de conocimiento o noticias. En lugar de "yo pienso" decimos frecuentemente "yo creo".

2. Luego vendría un sentido un poco más preciso. Se trataría de un conocimiento del que no tenemos plena evidencia ni certeza; pero que es compatible con un saber probable, basada en algunos indicios o pruebas razonables. En este caso, "creer" equivale a "tener opinión" sobre algo; es decir, poseer un conocimiento basado en algunas pruebas, datos 0 comprobaciones, (..) Aquí se distingue mejor entre "saber" y "creer", conocimiento cierto y conocimiento solamente probable.

3. Finalmente, cabría un significado de "creer" todavía más estricto, como confiar en alguien; presentar nuestro crédito a otras personas "a las que creemos". En este sentido "creer" significa asentir, aceptar como verdadero aquello que se nos comunica, (...) De esta forma el "creer" se diferencia netamente del "saber", si por eso entendemos el conocimiento de algo bajo una verificación y comprobación personal. (Vicente, 1995, p. 37-38; citado por Flores, 1998, p. 28-29).

Esta caracterización gradual según Flores (1998), lleva a delimitar el sentido de "creencia" al asentimiento o aceptación de una comunicación de otras personas. En este sentido las creencias son:

De hecho en la mayoría de los casos se trata de creencias en el sentido estricto. Son, en efecto, ideas u opiniones que la gente tiene en la cabeza, pero sin haber comprobado ni haberse detenido a examinar si se trata de algo fundado o sin fundamento; simplemente se limita "creerlo" por haberlo recibido 
de los mayores, del ambiente cultural o social, porque "siempre se ha entendido así" o "todo el mundo lo dice". Como decía Ortega, no son propiamente ideas, sino "algo en lo que se está" y de lo que ni siquiera nos permitimos dudar. (Vicente, 1995, p. 39; citado por Flores, 1998, p. 29).

Ponte (1994), toma las creencias en el sentido de proposiciones no demostradas. Distingue tres tipos de conocimiento: científica, actividad profesional y conocimiento vulgar, y establece las repercusiones que tiene cada uno sobre las creencias, aunque hace la diferenciación entre creencias y conocimiento:

(...) Podemos ver las creencias como una parte del conocimiento relativamente "poco elaborado" en vez de verlos (conocimiento y creencias) como dos dominios distintos. En las creencias predominaría la elaboración, más o menos fantástica, y no confronta con la realidad empírica. En el conocimiento más elaborado de naturaleza práctica, predominarían los aspectos experienciales. En el conocimiento de naturaleza teórica predominaría la argumentación racional. (Ponte, 1994, p. 125).

Para Ponte, el sistema de creencias no requiere un consenso sociall relativo a su validez o adecuación.

Recientemente Ponte y Chapman (2006, p. 472), señalan que: "Las creencias son verdades personales incontrovertibles sostenidos por cada uno, derivados desde la experiencia o desde la fantasía teniendo un fuerte componente evaluativo y afectivo..."

Thompson (1992), en el campo concreto de la investigación en educación matemática, caracteriza de alguna forma las creencias cuando las diferencia del conocimiento:

- Pueden ser sostenidas con varios grados de convicción. El creyente puede estar pasionalmente entregado a su punto de vista o en el otro extremo podría considerar una afirmación de un asunto como más probable o no.

- No están consensuadas.

- Están caracterizadas por una falta de acuerdo sobre como son evaluadas o juzgadas.

- Se justifican con razones, pero no por criterios preestablecidos distingue tres dimensiones en el sistema de creencias: 
- Tienen estructura cuasi-lógica con creencias primarias y creencias derivadas

- Tienen una dimensión espacial según el grado de convicción: creencia central y creencia periférica.

- Están agrupados en compartimentos más o menos aislados (clusters) caracterizados por la forma de relación entre agrupaciones.

(Thompson, 1992, p. 129-130)

Por otra parte, Pajares (1992), destaca tres componentes de la creencia: un componente cognitivo, que representa conocimiento, un componente afectivo, capaz de provocar emoción; y conductual, activado cuando lo requiere la acción.

En base a la revisión de la literatura relacionada con respecto a las creencias y nuestra reflexión, para los propósitos de este trabajo de investigación se considera las creencias de la siguiente manera: las creencias son verdades personales indiscutibles sostenidas por cada uno, derivadas desde la experiencia, la interacción o desde la visión (concepción) que tiene un fuerte componente evaluativo y afectivo, y las creencias se manifiestan a través de declaraciones verbales (lo que dice) o acciones (lo que hace). La coherencia entre lo que dice y hace es lo que piensa, el profesor no es lo que siempre dice ni lo que siempre hace, pero sí es lo que él piensa.

\section{Concepciones}

Las concepciones aparecen como otra estructura importante para describir pensamiento humano, y el término fue usado por Piaget en el título de algunos de sus influyentes estudios psicológicos (Ponte, 1999).

Por su parte, Ruiz (1994), establece dos dimensiones para asentar las concepciones. Por una parte se diferencian las concepciones subjetivas o cognitivas de las epistemológicas; y por otra parte las concepciones locales de las globales. Las concepciones subjetivas se refieren al conocimiento y creencia de los sujetos. Las concepciones epistemológicas se refieren a tipologías de conocimiento existente en un cierto periodo histórico, circunscritos a los textos o programas de cierto nivel de enseñanza. 
Al respecto coincidimos con Flores (1998), en que las concepciones subjetivas son mantenidas por cada sujeto, de manera individual. En nuestra investigación estas concepciones serán las que mantenga el profesor Jaime Escalante. Específicamente las concepciones sobre la matemática, su enseñanza y aprendizaje. Las concepciones epistemológicas se sostienen por la comunidad matemática a lo largo de la historia, y se refiere a los problemas que plantea la propia comunidad dentro del ámbito de la disciplina (concepciones sobre la matemática), a la forma en que se accede a este conocimiento (concepciones gnoseológicas sobre el conocimiento matemático) o a problemas de otras disciplinas que son susceptibles de resolución mediante los conocimientos matemáticos (concepciones sobre la utilidad de las matemáticas).

Las concepciones globales describen integralmente las concepciones ligadas a un concepto $\mathrm{u}$ otro objeto, mientras que las concepciones locales tienen en cuenta aspectos parciales de los sistemas anteriores.

La caracterización de concepción según Ruiz (1994):

- Los invariantes que el sujeto reconoce como notas esenciales que determinan el objeto

- El conjunto de representaciones simbólicas que le asocia y utiliza para resolver las situaciones y problemas ligados al concepto

- El conjunto de situaciones, problemas, etc. Que el sujeto asocia al objeto, es decir, para las cuales encuentra apropiado su uso como herramienta.

(Ruiz, 1994, pp. 71-72).

Martínez (2003), instituye una diferencia entre concepciones y creencias señalando que las concepciones son organizadores implícitos de conceptos, de naturaleza esencialmente cognitiva y que incluye creencias, significados, conceptos, proposiciones, reglas, imágenes mentales, preferencias, etc.; que influyen en lo que se percibe y en los procesos de razonamiento que se efectúan. El carácter subjetivo es menor en cuanto se apoya sobre un fundamento filosófico que describe la naturaleza de los objetos matemáticos. Las creencias son de carácter no racional, constituyen una base en que se apoya el conocimiento. Por el contrario, las concepciones son organizadores de 
nuestro conocimiento forman un "sustrato" conceptual anterior a los conceptos. Funcionan como filtros, es decir, son simultáneamente condición y límite de nuestro conocimiento de la realidad. Pero además permiten interpretar esta realidad a la vez que son elementos bloqueadores de esta interpretación, luego distorsionan lo que se nos presenta.

Ponte (1994) presenta una caracterización de concepción :

(...) Las concepciones pueden ser vistas en este contexto como el plano de fondo organizador de conceptos. Ellas se constituyen como "miniteorías", o sea cuadros conceptuales que desempeñan un papel semejante a los presupuestos teóricos de los científicos. Las concepciones condicionan las formas de abordar las tareas,... Estrechamente ligadas a las concepciones están las actitudes, las expectativas y el entendimiento que cada uno tiene de lo que constituye su papel en la situación. (Ponte, 1994, pp. 195-196).

Thompson (1992), diferencia en principio explícitamente las concepciones compuestas de creencias y otras representaciones:

Además de la noción de sistemas de creencias, este capítulo se referirá a las "concepciones" de profesores, vistas como una estructura más general, incluyendo creencias, significados, conceptos, proposiciones, reglas, imágenes mentales, preferencias y similares. Aunque puede que la distinción no tenga una gran importancia, en ocasiones será más natural referirse a las concepciones de los profesores sobre las matemáticas como disciplina, que hablar simplemente de las creencias de los profesores sobre las matemáticas. (p. 130).

Sin embargo, al tratar las investigaciones Thompson (1992) emplea indistintamente el término creencias (beliefs) y el término concepciones (conceptions). Aunque aparece con más frecuencia la palabra creencias que la palabra concepciones (Flores, 1998).

Por su parte Ponte y Chapman (2006), señalan que "las concepciones son marcos organizadores de conceptos, poseen una naturaleza esencialmente cognitiva. Ambos son parte del conocimiento". 


\subsection{Concepciones sobre las matemáticas}

Con el objetivo de poder situar las concepciones y creencias del profesor Jaime Escalante sobre la matemática, su enseñanza y aprendizaje, vamos a presentar en esta sección un panorama general sobre cuestiones más importantes que se plantea la epistemología de las matemáticas, así como las posturas más significativas en la enseñanza y aprendizaje de las matemáticas. Nos apoyamos en dos documentos Thompson (1992) y Ernest (1989).

Según Thompson (1992):

Una concepción del profesor sobre la naturaleza de las matemáticas puede ser vista como creencia, conscientes o inconscientes de los profesores, conceptos, significado, regla, imágenes mentales y preferencias, concernientes a la disciplina de las matemáticas. Estas creencias, conceptos, puntos de vista y preferencias, constituyen los rudimentos de una filosofía de las matemáticas, aunque para algunos profesores ellas pueden no estar desarrolladas y articuladas dentro de una filosofía coherente (Ernest, 1988; Jones, Henderson, y Cooney, 1986). La importancia para la enseñaza de las concepciones de los profesores del tema del contenido de la materia ha sido ampliamente reconocido, tanto a través de un recorrido de las áreas del curriculum (Clarck y Petrson, 1986; Feinman-Nemser y Floden, 1986; Grossman, Wilson, y Shulman 1989) y como se ha señalado antes en matemáticas (e. g.; Ernest, 1985; Hersh, 1986; Lerman, 1983; Tom, 1973: Thompson, 1982, 1984). (Thompson, 1992, p. 132).

El otro trabajo muy importante para esta investigación, es el artículo de Ernest (1989) "El impacto de las creencias sobre la enseñanza de las matemáticas". Thompson (1992), hace mención a Ernest (1988), que es un artículo preparado para ICME VI, en Budapest, Hungría en julio de 1988. Nosotros hemos accedido a la página Web de Ernest y aparece con 1989.

Para Ernest (1989), la concepción del maestro sobre naturaleza de matemática, es el conjunto o su sistema de creencia acerca de la naturaleza de la matemática. Esta visión forma la base de la filosofía de matemática, aunque la visión de algún maestro no se puede haber elaborado en las filosofías totalmente articuladas.

Ernest (1989), distingue tres concepciones de las matemáticas: 
- La concepción instrumentista de las matemáticas

- La concepción platónica de las matemáticas

- La concepción dinámica o vista de las matemáticas como resolución de problemas.

La primera concepción de la matemática, denominada visión instrumentalista (Ernest, 1989), ve la matemática como una bolsa de herramientas, que están formadas de una acumulación de hechos, reglas y habilidades para ser usadas hábilmente por expertos en la adquisición de algún fin externo. Así, las matemáticas (Thompson, 1992) son un juego de efectivas y útiles reglas y hechos. La segunda concepción de la matemática, denominado visión Platónica (Ernest, 1989), ve la matemática como un cuerpo estático pero unificado de conocimiento, una esfera cristalina de interconexiones de estructuras y verdades, rodeadas por filamentos de lógica y significado. Así las matemáticas son monolíticas, un producto inmutable. Las matemáticas son descubiertas y no creadas. La tercera concepción de la matemática denominada, visión dinámica (Ernest, 1989), basada en la resolución de problemas; punto de vista de las matemáticas como un campo en continua expansión de la creación e invención humana.... Las matemáticas no son un producto acabado, y sus resultados permanecen abiertos para revisión.

De estas tres concepciones o filosofías de las matemáticas Ernest (1989) conjetura como sistemas psicológicos de creencias formando tres niveles:

- La visión Instrumentista de la matemática está en el nivel más bajo, mientras involucrando conocimiento de hechos matemáticos, reglas y métodos como las entidades separadas.

- En el próximo nivel está la visión Platónica de matemática, involucrando una comprensión global de matemática como un consecuente, conectado y la estructura objetiva.

- El nivel más alto, la visión Dinámica de resolución de problemas que ve la matemática como una estructura dinámicamente organizada, localizada en un contexto social y cultural. 
Ernest (1996) escribe sobre la relación entre las concepciones sobre la matemática y su enseñanza. La pregunta que guía su investigación es: ¿Cuál es la relación entre las concepciones de la naturaleza de la matemática y la enseñanza? El autor sugiere que existe una relación fuerte entre las filosofias personales de matemática del maestro y la experiencia matemática de sus alumnos en el aula.

Ernest (1996) presenta algunas perspectivas filosóficas de la matemática:

1. Absolutismo: se concibe la matemática como conocimiento objetivo, un cuerpo absoluto, un conjunto de conocimiento cierto e incorregible que descansa en los fundamentos firmes de la lógica deductiva. Es una de las perspectivas del siglo XX en la filosofía de la matemática.

2. Platonismo: se considera la matemática como un sistema riguroso para garantizar el conocimiento matemático absolutamente. Asi, según el absolutismo el conocimiento matemático es eterno, aunque nosotros padamos descubrir nuevas teorías y verdades para agregar, es sobrehumano y ahistórico, es conocimiento puro y aislado que pasa a ser útil debido a su validez universal; es libre del valor y la cultura. El resultado es por consiguiente una imagen filosófica de la matemática como rígida, fija, lógica, absoluta, inhumana, fría, objetiva, pura, abastracta, remota, extremadamente racional.

3. Falibilismo: Una de las posiciones más recientes en la filosofía de la matemática es el falibilismo que acentua la práctica y el lado humano de la matemática. El falibilismo ve la matemática como resultado de procesos sociales. El conocimiento matemático es falible y enteramente abierto a la revisión, ambos por lo que se refiere a sus pruebas y conceptos. Esta concepción abraza como precupaciones filosóficas legítimas las prácticas de matemáticos, su historia, aplicaciones, el lugar de la matemática en la cultura humana, incluso los problemas de valores y educación. Admite la cara humana de la matemática. 
Es probable y concebible, que las concepciones individuales de las matemáticas de los profesores incluyan aspectos de más de uno de los señalados, aunque aparentemente conflictivos.

Como escribe Martínez (2006) al referirse a dos grandes hombres de la historia de las ciencias y las matemáticas: tanto Descartes como Newton dan origen a un modelo científico que trasciende hacia las ciencias humanas. Ambos aceptaban y distinguían el mundo natural y el sobre natural, al cual pertenecía el hombre. Para ambos el concepto de Dios era un elemento esencial de su filosofía y de su visión del hombre y del mundo. Ambos estaban muy lejos de usar el método mecanicista, a que dan origen para estudiar y comprender al hombre. Descartes distingue muy claramente la res cogitans (relacionada con el espíritu humano) de la res extënsa (puramente material). Y Newton tiene profundos y complejos escritos acerca de religión y teología que llamaron la atención de los teólogos de su tiempo. Así, pues, habría que concluir que ni Newton era tan newtoniano, ni descartes era tan cartesiano, como lo han sido muchos de sus epígonos y seguidores en la aplicación del método científico. (Martínez, 2006, p. 29; el énfasis es mio).

\subsection{Concepciones sobre la enseñanza y aprendizaje de las matemáticas}

Las concepciones de los profesores sobre la enseñanza están configuradas por aspectos muy diversos como los señala Thompson (1992, p. 135): "lo que considera un profesor como objetivos deseables del programa de matemáticas, su propio rol en la enseñanza, el rol de los estudiantes, las actividades apropiadas del salón de clases, la aproximación a la práctica instruccional deseable, la legitimación de los procedimientos matemáticos y los resultados aceptables de la instrucción todos son parte de las concepciones de la enseñanza de las matemáticas. Diferencias en las concepciones sobre las matemáticas parecen estar relacionadas a diferencias en sus puntos de vista sobre la enseñanza de las matemáticas"

Diversos estudios tanto teóricos como empíricos (Ernest, 1996), han encontrado que las diferencias en las concepciones de los profesores sobre las 
matemáticas estaban relacionadas con las diferencias en sus opiniones sobre lo que constituyen evidencias de la comprensión de las matemáticas de sus estudiantes y las diferencias en sus percepciones del propósito de la planificación de las lecciones.

Al respecto Thomson (1992), apoyándose en los resultados de diversas investigaciones señala que:

(...) Las concepciones sobre la enseñanza de las matemáticas, son también probablemente reflejo de los puntos de vista, aunque tácitos, del conocimiento matemático de los estudiantes, de cómo ellos aprenden matemáticas, y los roles y objetivos de la escuela en general. Una fuerte relación ha sido observada entre las concepciones de los maestros sobre la enseñanza y sus concepciones sobre el conocimiento matemático de los estudiantes. (Thompson, 1992, p. 135).

Es completamente difícil concebir los modelos de enseñanza, sin subrayar alguna teoría de cómo los estudiantes aprenden matemáticas; incluso si la teoría es incompleta e implícita. Las concepciones sobre el aprendizaje y la enseñanza tienden a estar eclécticamente agrupadas en creencias y opiniones que parecen ser más el resultado de sus años de experiencia en el salón de clase que algún tipo de estudio formal o informal (Martínez, 2003).

Thompson (1992), presenta cuatro modelos de enseñanza de las matemáticas identificados por Kuhs y Ball (1986):

1. Centrado en el aprendiz, la enseñanza de la matemática que se centra en la construcción personal del conocimiento matemático por el aprendiz.

2. Centrado en el contenido con énfasis en la comprensión conceptual: la enseñanza de las matemáticas que se conduce por el contenido en si, pero enfatizando la comprensión conceptual.

3. Centrado en el contenido con énfasis en el desempeño: la enseñanza de las matemáticas que enfatiza el desempeño de los estudiantes y el dominio de las reglas y procedimientos matemáticos; y

4. Centrado en el aula: la enseñanza de las matemáticas basada en el conocimiento en el aula efectiva. 
De acuerdo Kush y Ball citado Thompsón (1992: 135), un punto de vista constructivista de la enseñanza de las matemáticas subraya una enseñanza centrada en el aprendiz.

Desde una perspectiva de la enseñanza centrada en el aprendiz, el profesor es visto como un facilitador del aprendizaje del estudiante y estimulador del aprendizaje del estudiante, planteando interesantes preguntas y situaciones de investigación, desafiando al estudiante a pensar y ayudándole a descubrir inadecuaciones en sus propios pensamientos.

El segundo punto de vista discutido por Kush y Ball (1986), el centrado en el contenido con énfasis en la comprensión, es el punto de vista de la enseñanza derivado directamente desde la concepción de la naturaleza de las matematicas que Ernest (1989, 1996), llamó platónica.

Kush y Ball (1986) caraterizaron este punto de vista con aquel en el cual la instrucción hace del cotenido matemático el centro de la actividad en el aula, mientras se enfatiza en el entendimiento de las ideas y procesos de los estudiantes.

El tercer punto de vista, centrado en el contenido con énfasis en la actuación, también hace del contenido matemático su punto central. Este modelo está estrechamente relacionado con el punto de concepción instrumentalista de la naturaleza de las matemáticas.

El cuarto punto de vista cómo las matemáticas deberían ser enseñadas identificadas por Kush y Ball (1986), es el punto de vista de la enseñanza centrada en el aula. Lo fundamental de este punto de vista es la noción de que la actividad deberia estar bien estructurada y eficientemente organizada de acuerdo a conductas efectivas del profesor identificadas en los estudios proceso-producto.

En el modelo de enseñanza centrado en el aula, el profesor está mirando cómo jugar un activo rol dirigiendo todas las actividades del aula, presentando claramente el material de la lección a toda la clase o a pequeños grupos, y proporcionando oportunidades a los estudiantes de prácticas individualmente. Desde esta perspectiva, los profesores efectivos son aquellos quienes diestros en la explicación, asignan tareas, y monitorean a los estudiantes, proporcionan retroalimentación a los estudiantes y controlan el medioambiente del aula, 
previniendo, disrupciones que pueden interferir en el curso de la actividad planificada.

Por consiguiente, el rol de los estudiantes es escuchar atentamente al profesor y cooperar siguiendo las direcciones, contestando preguntas y completando tareas asignadas por el profesor. (Kush y Ball, 1986, p. 26 citados por Thompson, 1992, p. 137).

Desde la psicología del aprendizaje, tenemos también las siguientes teorías resumidos por Schuman (1996):

Conductismo: se basa en los cambios observables en la conducta del sujeto. Se enfoca hacia la repetición de patrones de conducta hasta que estos se realizan de manera automática.

Cognoscitivismo: se basa en los procesos que tienen lugar detrás de los cambios de conducta. Estos cambios son observados para usarse como indicadores para entender lo que esta pasando en la mente del que aprende.

Constructivismo: se sustenta en la premisa de que cada persona construye su propia perspectiva del mundo que le rodea a través de sus propias experiencias y esquemas mentales desarrollados. El constructivismo se enfoca en la preparación del que aprende para resolver problemas en condiciones ambiguas.

Apoyándome en los documentos analizados respecto al tema de las crencias y concepciones, me sitúo en la postura de que existe una estrecha relación entre las concepciones y creencias sobre la matemática, su enseñanza y su aprendizaje.

Comparto la definición de Gil y Rico (2003) de los siguientes significados:

Creencias: son "verdades personales indiscutibles sustentadas por cada uno, derivadas de la experiencia o de la fantasía, tiene un fuerte componenete evaluativo y afectivo (Pajares, 1992). Las creencias se manifiestan a través de declaraciones verbales 0 acciones (justificándolas)". 
Concepciones: son "los marcos organizadores implícitos de conceptos, con naturaleza esencialmente cognitiva y que condicionan la forma en que afrontamos las tareas (Ponte, 1994)."

Después de haber estudiado los diferentes documentos sobre las concepciones y las creencias de los profesores sobre la matemática, su enseñanza y aprendizaje, se ha tomado base a los documentos de Ernest (1989, 1991 y 1996) y he elaborado el siguiente cuadro que relaciona el impacto de las creencias y concepciones sobre las matemáticas, su enseñanza y aprendizaje de los profesores en su práctica.

En este cuadro la base es Ernest (1989):

\begin{tabular}{|c|c|c|c|c|}
\hline Filosofía & $\begin{array}{l}\text { Concepción de } \\
\text { la matemática }\end{array}$ & $\begin{array}{l}\text { Concepción } \\
\text { de la } \\
\text { enseñanza }\end{array}$ & $\begin{array}{l}\text { Concepción } \\
\text { del } \\
\text { aprendizaje }\end{array}$ & Uso de textos \\
\hline Absolutista & $\begin{array}{l}\text { Instrumental: } \\
\text { Conjunto de } \\
\text { verdades y } \\
\text { reglas, cuerpo } \\
\text { incuestionables } \\
\text { de } \\
\text { conocimiento }\end{array}$ & $\begin{array}{l}\text { Instructor: } \\
\text { dominio de } \\
\text { habilidades } \\
\text { con la } \\
\text { actuación } \\
\text { correcta. }\end{array}$ & $\begin{array}{l}\text { Recepción } \\
\text { pasiva del } \\
\text { conocimiento. } \\
\text { Conducta } \\
\text { sumisa y } \\
\text { dócil y } \\
\text { dominio de } \\
\text { habilidades. }\end{array}$ & $\begin{array}{l}\text { Siguen el } \\
\text { esquema del } \\
\text { texto }\end{array}$ \\
\hline Absolutista & $\begin{array}{l}\text { Platónica: } \\
\text { comprensión } \\
\text { global de la } \\
\text { matemática } \\
\text { como una } \\
\text { consecuencia } \\
\text { conectada y } \\
\text { objetiva. }\end{array}$ & $\begin{array}{l}\text { Explicador: } \\
\text { comprensión } \\
\text { conceptual } \\
\text { con el } \\
\text { conocimiento } \\
\text { unificado. }\end{array}$ & $\begin{array}{l}\text { Recepción } \\
\text { de modelo de } \\
\text { conocimiento, } \\
\text { comprensión } \\
\text { de estructuras } \\
\text { y aplicación }\end{array}$ & $\begin{array}{l}\text { Modifican el } \\
\text { acercamiento } \\
\text { del libro de } \\
\text { texto, } \\
\text { enriqueciendo } \\
\text { con } \\
\text { problemas y } \\
\text { actividades } \\
\text { adicionales. }\end{array}$ \\
\hline Falibilista & $\begin{array}{l}\text { Dinámica: ve } \\
\text { la matemática } \\
\text { como una } \\
\text { resolución de } \\
\text { problemas, una } \\
\text { estructura } \\
\text { dinámica } \\
\text { organizada y } \\
\text { localizada en } \\
\text { un contexto } \\
\text { social y } \\
\text { cultural. }\end{array}$ & $\begin{array}{l}\text { Facilitador: } \\
\text { proponiendo } \\
\text { y resolviendo } \\
\text { problemas de } \\
\text { la vida } \\
\text { cotidiana. }\end{array}$ & $\begin{array}{l}\text { Construcción } \\
\text { activa del } \\
\text { conocimiento, } \\
\text { la exploración } \\
\text { y la } \\
\text { persecución } \\
\text { autónoma del } \\
\text { propio modelo } \\
\text { de interés. }\end{array}$ & $\begin{array}{l}\text { El maestro } \\
\text { construye el } \\
\text { plan de } \\
\text { estudios de } \\
\text { matemática } \\
\text { de la escuela. }\end{array}$ \\
\hline
\end{tabular}


Este capítulo presenta el enfoque metodológico, el sujeto de investigación, el método biográfico que se apoya en tres técnicas de investigación: dos interactivas, que son la de narración y la de observación, y una no interactiva, que es la de documentación. Los instrumentos de recogida de información y la estrategia de análisis utlizado ha permitido la elaboración de una historia de vida del profesor Jaime Escalante e indagar sus concepciones y creencias sobre la matematica, su enseñanza y aprendizaje.

\section{CAPÍTULO III}

\section{MARCO METODOLÓGICO}

\subsection{Fundamentación metodológica}

No es posible relizar un trabajo científico y riguroso, si el investigador no se integra, totalmente, en la filosofía del método que va utilizar. En lugar de que el investigador adopte un método, más bien, el investigador parece ser adoptado por un método. Su ubicación teórico-metodológica le permite estructurarse en torno al método, visualizando el problema con más lucidez, analizando con mayor profundidad, interpretando con menos posibilidades de error y comprendiendo en toda su amplitud y dimensión, para después exponer con convicción y seguridad los resultados alcanzados o las conclusiones formuladas sobre el problema objeto de estudio.

De esta manera, se torna evidente que la búsqueda de alternativas metodológicas en la educación matemática supone, en primer lugar, una postura epistemológica que identifique el polo investigador como sujeto de la investigación.

En ocasiones, desde el diseño del proyecto hay una identificación con un enfoque de investigación y, en consecuencia, los demás enfoques parecen insuficientes o limitados para abordar el problema que interesa estudiar. En mi 
caso, ha sido en la medida que se ha ido afinando el problema, preguntas, objetivos de investigación, he analizado varias corrientes metodológicas de investigación, especificamente, la cualitativa.

\section{Enfoque metodológico}

Este estudio se enmarca dentro un enfoque de "investigación cualitativa”. La definición aportada por Denzin y Lincoln (1994), de que la investigación cualitativa, implica un análisis interpretativo, naturalista hacia el objeto de estudio. Es decir, las investigaciones cualitativas estudian la realidad en su contexto natural e interpretan los fenómenos de acuerdo con los significados que tienen para las personas implicadas.

Aunque el enfoque cualitativo posee una definición amplia que engloba bajo el término diferentes orientaciones. Sin embargo en el campo de la educación estoy de acuerdo con Sandín (2003, p. 123), "la investigación cualitativa es una actividad sistemática orientada a la comprensión en profundidad de los fenómenos educativos y sociales, a la transformación de prácticas y escenarios socioeducativos, a la toma de decisiones y también hacia el descubrimiento y desarrollo de un cuerpo organizado de conocimientos hacia el descubrimiento y desarrollo de un cuerpo organizado de conocimientos.

Según Cook y Reichardt (1986), en la perspectiva cualitativa la primacía de su interés radica en la descripción de los hechos observados para interpretarlos y comprenderlos en el contexto en el que se producen con el fin de explicar los fenómenos.

Mientras que Sandín (2003), señala que una variedad de perspectivas teóricas y tradiciones que se engloban bajo el término "investigación cualitativa" dificultan el establecimiento de características generales, aunque presenta en un cuadro el resumen de las características de la investigación cualitativa. (Sandín 2003, p. 125). 
Una de las perspectivas de la investigación cualitativa es la historia de vida como plantean Franco Ferrarotti (1981), Bolívar (2002), y Mallimaci y Giménez (2006). En consecuencia este estudio se inscribe en el enfoque de la "historia de vida" (o enfoque biográfico) es una rama de investigación interpretativa (o ideográfica) y comparte algunos principios metodológicos generales de la investigación cualitativa, especialmente la perspectiva hermenéutica (Bolívar et al, 2001).

Por otro lado Mcmillan y Schumacher (2005), presentan dos enfoques de investigación educativa: cuantitativo y cualitativo.

Los términos "cuantitativo" y "cualitativo" se utilizan frecuentemente para identificar diferentes modalidades de estudio o aproximaciones a la investigación. Cuando se emplea estos términos, se hace en dos niveles de discurso. En un primer nivel, cuantitativo y cualitativo se refiere a la distinción sobre la naturaleza del conocimiento: cómo entiende el investigador el mundo y el objeto último de la investigación. En otro nivel, los términos se refieren a los métodos de investigación (cómo se recogen y analizan los datos) y al tipo de generalizaciones y representaciones que se derivan de ellos. (Mcmillan y Schumacher, 2005, pp. 17-18).

Para los autores, la aproximación de la investigación en el campo de la educación se puede utilizar ambos enfoques: el cuantitativo y el cualitativo. Además, proponen que una manera de distinguir el enfoque de la investigación, es por la forma en que se presentan los datos:

La forma más evidente para el lector pueda distinguir entre una investigación cuantitativa y cualitativa es la forma de presentación de datos. La investigación cuantitativa presenta resultados estadísticos en forma de números, mientras que la investigación cualitativa presenta los datos como una narración. Sin embargo estas diferencias van más allá de la forma en que se presentan los datos (Denzin y Lincoln, 1994). Los puristas sugieren que los métodos de investigación cuantitativa y cualitativa se basan en diferentes concepciones del mundo, en el objeto de la investigación, en los métodos de investigación... papel del investigador y la importancia del contexto en el estudio. (Mcmillan y Schumacher, 2005, p.18).

Como señala LeCompte (1995), los términos utilizados para conceptualizar cada uno de estos enfoques denotan la importancia de los 
constructos participantes o los significados que los sujetos de la investigación asignan a sus acciones, el contexto del estudio, la relación entre el investigador y los que están siendo estudiados, los procedimientos y las técnicas para la recogida de datos, los tipos de evidencias aducidas en apoyo a las afirmaciones realizadas, así como los métodos y la importancia del análisis utilizado.

Sandín (2003), señala ocho principales tradiciones en la investigación cualitativa: narrativo-biográfico, estudios fenomenológicos, la teoría fundamentada, etnográfica, investigación-acción, estudio de casos, investigación evaluativa y en otros ubica la fenomenografía y la etnometodología.

A partir de estos documentos se encamina el estudio, por el enfoque cualitativo, o investigación cualitativa. Entendiendo que el enfoque cualitativo va más allá de la forma de presentación de datos. Es decir, depende de las diferentes concepciones del mundo.

Aunque no existe un único relato sobre el origen y desarrollo histórico del método cualitativo como señala Valles (2000, p. 21):

Debe insistirse en que no hay un único relato histórico que documente de manera comprehensiva e indiscutible, la génesis y desarrollo de la perspectiva metodológica cualitativa en las ciencias sociales (ni en todas en conjunto, ni en ninguna de ellas por separado). No obstante, las reflexiones de tipo histórico proporcionadas desde diversos ángulos se consideran muy necesarias, tanto en la formación del sociólogo o politólogo como en el entendimiento de la investigación cualitativa por parte de estos y otros profesionales de lo social.

De acuerdo con Kirk y Miller (1986, p. 10), "la investigación cualitativa es un fenómeno empírico, localizado socialmente, definido por su propia historia, no simplemente una bolsa residual conteniendo todas las cosas que son no cuantitativas".

Además, la pertinencia de la contextualización histórica, como umbral de paso obligado en el tratamiento de lo epistemológico y metodológico fue recomendada también por autores que resaltan el aspecto filosófico de las ciencias sociales: 
(... ) Debemos seguir el consejo de Toulmin y abstenernos de considerar la epistemología como disciplina autónoma sin raíces en el pensamiento de un período histórico determinado (...). Por ejemplo... Descartes y Locke, dos de las principales figuras filosóficas, pese a su genio fueron hombres de su tiempo y examinaron los principios del conocimiento humano a la luz de las ideas que entonces prevalecían sobre el orden de la naturaleza y el sitio que ocupaba el hombre dentro de éste. Según Toulmin, dieron por supuesto tres lugares comunes: que la naturaleza era fija, inmutable y podía conocerse con ayuda de principios racionales igualmente fijos, inmutables y universales; que existía un dualismo entre la mente y la materia (...); y, finalmente, que el criterio del conocimiento, de certeza inobjetable, lo suministra la geometría, criterio conforme al cual debía juzgarse toda otra forma de conocimiento (...) esta concepción ofrecía tanto una descripción ontológica básica del mundo como prescripciones epistemológicas sobre el modo en que ese mundo debía investigarse. Dirigía la atención de los científicos y filósofos y, con el tiempo, se estableció como versión autorizada del mundo (...). (Hughes, 1980/1987:24-25; citado por Valles, 2000, p. 22).

En Valles (2000), se puede revisar la exposición de las diferentes perspectivas históricas, por ejemplo: la perspectiva histórica de Hamilton (1994), sobre la génesis de la investigación cualitativa en las ideas kantianas y el desarrollo de tradiciones, preferencias y posturas. La perspectiva histórica de Conde (1994), génesis de lo cualitativo (frente a lo cuantitativo) en la filosofía griega de Platón y Aristóteles. El recorrido histórico de Vidich y Lyman (1994), analiza la historia de la investigación cualitativa, desde la antropología y la sociología, considera las siguientes etapas en su evolución: la etnografía primitiva, en la que tiene lugar el descubrimiento del otro; la etnografía colonial, donde se destaca la labor de los exploradores de los siglos XVII, XVIII y XIX; la etnografía del indio americano, llevada acabo por la antropología a finales del siglo XIX y comienzos del XX; la etnografía de los otros ciudadanos, de comunidades y las etnografías sobre inmigrantes americanos (desde comienzos del siglo XX hasta los años setenta); estudios sobre la etnicidad y la asimilación (desde mediados del siglo XX hasta la década de los ochenta) y el momento actual caracterizado por el cambio postmoderno. 
La cronología de Denzin y Lincoln (1994), centrándose en lo que va del siglo pasado, se establecen cinco periodos de investigación cualitativa: tradicional (1900 - 1950), el modernista o edad de oro (1950 - 1970), géneros impreciso $(1970$ - 1986), la crisis de representación (1986 - 1990) y la era postmoderna (1990 - en adelante).

CUADRO 1.2. Temporalización histórica de la investigación cualitativa en el siglo XX.

\begin{tabular}{|c|l|l|}
\hline $\begin{array}{c}\text { Paréntesis } \\
\text { cronológico }\end{array}$ & \multicolumn{1}{|c|}{$\begin{array}{c}\text { Denominación } \\
\text { del periodo histórico }\end{array}$} & \multicolumn{1}{c|}{ Caracterización } \\
\hline $\begin{array}{c}(1900-1950) \\
(1959-1970)\end{array}$ & $\begin{array}{l}\text { Tradicional } \\
\text { Modernista o "edad dorada" }\end{array}$ & $\begin{array}{l}\text { Positivismo. Época del etnógrafo solitario } \\
\text { Postpositivismo. Análisis cualitativo rigu- } \\
\text { roso: Boys in White (Becker } \text { et al., 1961), } \\
\text { The Discovery of Grounded Theory (Gla- } \\
\text { ser \& Strauss, 1967). } \\
\text { Interpretativismo. Geertz (1973; 1983) }\end{array}$ \\
$(1970-1986)$ & $\begin{array}{l}\text { Géneros desdibujados } \\
\text { Blurred genres) } \\
(1986-1990)\end{array}$ & $\begin{array}{l}\text { Crisis de representación } \\
\text { Reflexividad, (auto)crítica. Marcus y Fis- } \\
\text { cher (1986)..., Clifford (1988) } \\
\text { Descubrimiento y redescubrimiento de } \\
\text { modos de investigar cualitativos }\end{array}$ \\
\hline
\end{tabular}

Fuente: Basado en Denzin y Lincoln (1994a: 1-2, 6-11).

Bogdan y Biklen (1982) establecen cuatro fases fundamentales en el desarrollo de la investigación cualitativa en educación. Un primer periodo que va desde finales del siglo XIX hasta la década de los treinta, donde se presentan los primeros trabajos cualitativos y adquieren madurez diversas técnicas cualitativas como la observación participante, la entrevista en profundidad o los documentos personales, impone su sello la Escuela de Chicago y tiene lugar el nacimiento de la sociología de la educación. Un segundo periodo que comprende desde la década de los treinta a los cincuenta, en lo que se produce un declive en el interés por el enfoque cualitativo. Un tercer momento se produce en torno a la década de los sesenta, época marcada por el cambio social y el resurgimiento por los métodos cualitativos. Y el cuarto periodo, iniciado en la década de los setenta comienza a realizarse investigación cualitativa por los investigadores educativos y no por antropólogos y sociólogos como había sido la norma hasta ese momento.

Martínez (2003, p. 210), señala tres aspectos fundamentales que diferencian la investigación con orientación cuantitativa y cualitativa: 
1. La distinción entre explicación y comprensión como objeto de investigación.

2. La distinción entre una función personal y una función impersonal del investigador.

3. Una distinción entre conocimiento descubierto y conocimiento constructivo.

Según Mcmillan y Schumacher (2006), la investigación cualitativa está centrada en la comprensión de una situación educativa desde la perspectiva de los participantes, no en establecer relaciones entre variables, o en establecer relaciones de causa efecto, sino en comprender la particularidad del caso, se interpretan los acontecimientos, la investigación cualitativa pone énfasis en la interpretación.

\section{La perspectiva de la historia de vida}

Cuando el interés de la investigación se centra en una sola persona, la historia de vida ya no es sólo una técnica o método, se convierte en una perspectiva de investigación cualitativa (Ferrarotti, 1981, 1988; Bolívar, 2002; Mallimaci y Giménez, 2006 y González, 2008/2009), cuando la historia de vida se convierte en el qué de la investigación.

Desde la sociología plantea Franco Ferrarotti (1988) que la historia de vida no es un método o una técnica más, sino una perspectiva de análisis única (Mallimaci y Giménez, 2006). En la misma línea, pero desde el campo investigación educativa Bolívar también plantea que la historia de vida se ha constituido actualmente en una perspectiva o enfoque específico de la investigación educativa y no sólo una metodología cualitativa más para añadir a las existentes.

Como nuestro estudio se orienta hacia una sola persona la inscribimos dentro de la perspectiva de la historia de vida, ya que la historia de vida es el qué de la investigación.

\section{Sujeto de estudio}

El criterio que se ha tomado para decidir sobre el sujeto de investigación es en base a la caracterización de Pujadas (2002, p. 47): 
(...), la meta más deseada y difícil de alcanzar es conseguir hallar las circunstancias que permitan una buena historia de vida. Esto no es nada fácil, pues hay que conseguir no sólo un informante, que esté inmerso en el tema que estamos estudiando, y que tenga además una buena historia que contar. Se requiere, además, un relato que sea narrativamente interesante y sea completo, de lo que depende enteramente las características del sujeto elegido: que sea brillante, genuino, sincero, que explique con claridad e introduzca en su relato elementos amenos, que sea autocrítico y analice con una cierta perspectiva su propia trayectoria vital. Sin todos estos requisitos es difícil que el investigador se decida a ensayar esta forma de documentos científicos, la historia de vida.

Considerando las características descritas por Pujadas, Jaime Escalante tenía una experiencia personal que contar y narrativamente era interesante y completo, además estaba dispuesto a contar aunque no tenía mucho tiempo, a causa de sus múltiples compromisos. Hemos conseguido ganarnos su confianza que es un elemento muy importante en la elaboración de la historia de vida, este elemento puede ser ignorado por los investigadores cuantitativos.

El sujeto de investigación para este estudio es el profesor Jaime Alfonso Escalante Gutiérrez.

\subsection{El método biográfico}

En este estudio, entendemos por método biográfico, como la utilización sistemática de documentos que reflejan la vida de una persona, momentos especiales de ella o aspectos que se pretenden destacar. Las experiencias personales suelen reflejar tanto la vida, como el contexto histórico social en el que la obra de esa persona cobra sentido. El método biográfico incluye diferentes modos de obtener y analizar relatos referidos a cualquier testimonio. También ha recibido diferentes denominaciones: método humanístico (Plummer, 1989), el método biográfico o historia de vida (Valles, 2000), o investigación narrativo-biográfica (Bolivar, 2002). Rastreando a través de la bibliografía existente y disponible a mi alcance, se ha constatado que hay un resurgimiento de interés por los investigadores del campo de las ciencias sociales y particularmente en el educación. (Ferrarotti, 1981; Berteaux, 1980; 
Pujadas, 2002; Bolivar, 2002; Goodson, 2003; Martinez, 2006; Moreno, 2006; Mallimaci y Giménez, 2006; González, 2008/2009).

Según los autores que el método biográfico, por lo general se usa desde el enfoque cualitativo. La reconstrucción biográfica nace esencialmente de una persona y de su testimonio, ya sea oral o escrito, y de su interacción con el que lo retoma, interpreta o rehace (aún cuando este sea el mismo protagonista de los hechos que asume el rol de escritor como el caso de las autobiografías), de modo que el juego de intersubjetividades va a ser una dinámica inherente y permanentemente presente. Igualmente emerge un mecanismo enmarañado, complejo, dinámico, selectivo y efectivo, cual es la memoria (Sanz, 2005).

Por la importación de los métodos cualitativos en el campo de la investigación educativa, existe una pluralidad terminológica y varias clasificaciones de los mismos según criterios distintos. Sabariego et al (2004) exponen los principales métodos orientados a la comprensión que se vienen utilizando en investigación cualitativa según la clasificación de Rodríguez, Gil y García (1996:41):

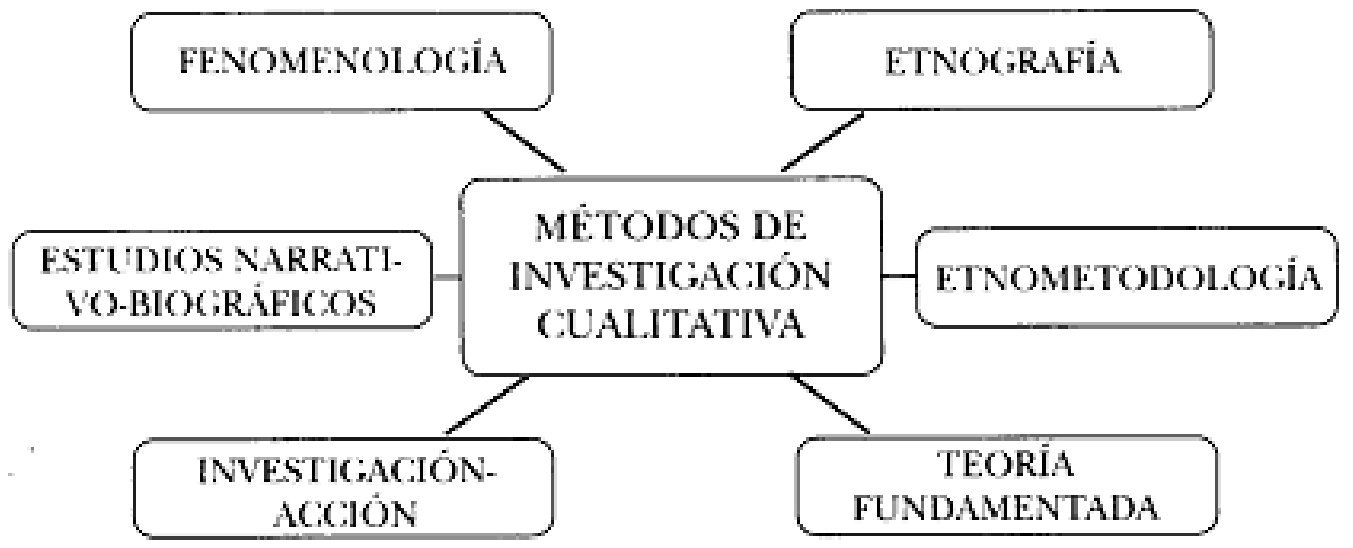

Cuadro tomado de Bisquerra 2004 p. 294.

De todos ellos, la teoría fundamentada se distingue del enfoque meramente comprensivo e interpretativo, y adquiere unas características peculiares en tanto en cuanto su principal finalidad es construir teoría para explicar la realidad sobre la base de la recogida y análisis sistemático de los datos. Por su parte, la investigación-acción pretende llegar al cambio, a la transformación de la realidad, más allá de la mera comprensión de los fenómenos educativos. Siguiendo con la perspectiva orientada a la 
comprensión, en las páginas siguientes se exponen algunos de los métodos cualitativos más relevantes en el ámbito educativo.

La investigación etnográfica o la etnografía es quizá el método más conocido y utilizado en el campo educativo para analizar la práctica docente, describirla "desde el punto de vista de las personas que en ella participan" y enfatizar las cuestiones descriptivas e interpretativas.

La teoría fundamentada es un método de investigación de naturaleza exploratoria cuyo propósito es descubrir teorías, conceptos, hipótesis y proposiciones partiendo directamente de los datos. Se denomina teoría porque su objetivo es recoger y analizar los datos resultantes de la investigación a fin de generar una teoría, y fundamentada porque la teoría se genera y fundamenta sobre la base de datos. La idea esencial de la teoría fundamentada es que la teoría se desarrollará inductivamente a partir de los datos. Este enfoque resulta adecuado en áreas de investigación sustancialmente nuevas, donde hacen falta conceptos fundamentados para describir y explicar lo que sucede.

La elección del método biográfico favorece los enfoques interdisciplinarios y niega el ideal positivista de establecer una distancia entre investigador y objeto investigado y sitúa a los informantes como protagonistas principales y sujetos de la investigación. El interés se centra en cuestiones subjetivas y asuntos vitales, obtenidos a través del relato que, como modo de conocimiento, permite captar la riqueza y detalles de experiencias vividas de una persona y sus sentimientos, pero fundamentalmente, la elección de sus recuerdos, las maneras de interpretarlos sus creencias y sus valores, que no pueden ser expresados en definiciones, enunciados factuales o proposiciones abstractas, como hace el razonamiento lógico-formal. (Sabariego et al., 2004). En las historias de vida encontramos puntos de inflexión o hitos que permiten entender con mayor profundidad los contextos en que se inscriben esa vida.

En el ámbito educativo el método biográfico (historia de vida) aporta un nuevo enfoque y nuevas posibilidades para su estudio:

Nuevas maneras de entender cómo se describe el comportamiento de los demás, nuevas vías para evaluar el impacto de los procesos educativos en el 
alumnado y el profesor y nuevos procedimientos para explicar la incidencia de las políticas educativas en las personas". (Kridel, 1998; citado por Sabariego, et. al., 2004, p. 327).

Por su parte Sandín (2003) efectúa una interesante recopilación de los usos del método biográfico en el ámbito de la investigación educativa; entre otras obras, destacan los trabajos sobre el pensamiento del profesorado, interesados en conocer cuales son los procesos de razonamiento que ocurre en la mente del docente durante su actividad profesional para aportar conocimientos útiles desde el punto de vista de la formación y desarrollo profesional del docente.

El tema medular del método biográfico es el estudio de las experiencias vitales de las personas y el significado que adquiere para ellas.

Para Sabariego et al. (2004), "con este propósito se utilizan distintas técnicas de investigación cualitativa como la observación, la entrevista, y el análisis de los documentos, personales y oficiales (...) orientados a profundizar en el sentido de las situaciones y el significado que las personas les atribuyen".

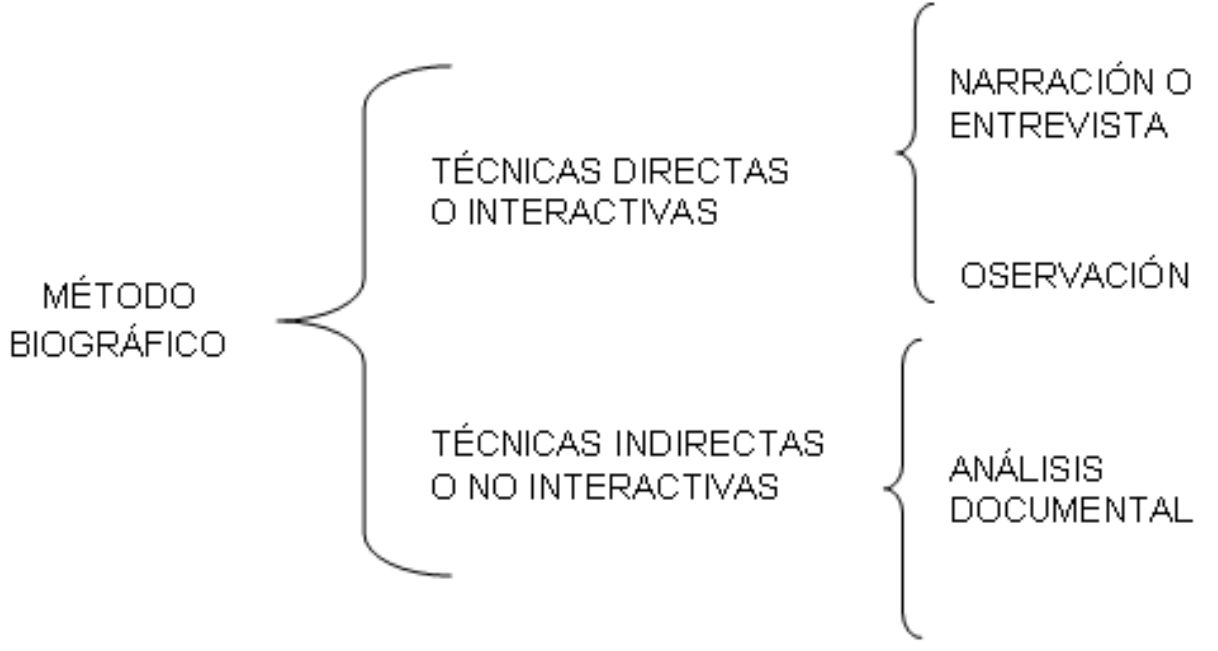




\subsection{Técnicas de investigación}

\section{Técnicas directas o interactivas}

Las técnicas directas 0 interactivas que se utilizadas en esta investigación son: la técnica de las entrevistas y la técnica de la observación.

\section{Técnicas de entrevistas}

La técnica de entrevista engloba una serie de expresiones 0 acuñaciones usadas para referirse a modos de entrevistar, más o menos próximos al polo de la conversación ordinaria (Valles, 2000, p. 177).

El autor presenta tres acercamientos al término de entrevista: la conversación en la vida cotidiana como referente de la entrevista, de los tipos de entrevistas profesionales a la entrevista de investigación social y sus variedades, y los modelos teóricos de comunicación e interacción social en la definición de entrevista.

En cuanto a la conversación en la vida cotidiana como referente de la entrevista, para este acercamiento, el arte de conversación, aprendido de modo natural en el curso de la socialización, constituye la mejor base para el aprendizaje de las técnicas de cualquier forma de entrevista profesional. Valles (2000) extrae citas de trabajos: uno en el campo de la salud Schatzman \& Strauss (1973), Field research. Strategies for a natural sociology y otro en el campo de la educación Erlandson, Harris, Skipper, Allen (1993), Doing naturalistic inquiry.

Del primer trabajo se extrae la siguiente cita:

En el campo, el investigador considera toda conversación entre él y otros como formas de entrevista... El investigador encuentra innumerables ocasionesdentro y fuera de escena, en ascensores y pasillos comedores e incluso en las calles- para hacer preguntas sobre cosas vistas y oídas... Las conversaciones pueden durar sólo unos pocos segundos o minutos, pero pueden conducir a oportunidades de sesiones más extensas. (Schatzma y Strauss, 1973; citado en Valles, 2000, p. 178).

En la cita se transmiten dos ideas: la primera, que su variedad abarca modalidades equiparables a las conversaciones informales y casuales; la 
segunda, que uno de sus rasgos distintivos tiene que ver con la duración del encuentro conversacional.

Los otros autores desde su experiencia educativa trazan un esbozo de entrevistas:

(...) en la investigación naturalista, las entrevistas adoptan más la forma de diálogo o una interacción (...). Permite al investigador y al entrevistado hacia atrás y hacia delante en el tiempo (...). Las entrevistas pueden adoptar una variedad de formas, incluyendo una gama desde que son muy enfocadas 0 predeterminadas a las que son muy abiertas (...). La más común, sin embargo, es la entrevista semiestructurada que es guiada por un conjunto de preguntas y cuestiones básicas a explorar, pero ni la redacción exacta y el orden de las preguntas están predeterminados. (...). (Erlandson et al, 1993; citado en Valles, 2000, pp. 178-179).

Algunas pistas de por qué la entrevista es similar y sin embargo diferente de la conversación, es captado por Valles (2000). Por un lado, en beneficio del funcionamiento de la entrevista, "el entrevistado debe percibirla como una conversación, sin que se de cuenta de la estructura de la interrogación y el orden de las preguntas o los objetivos del entrevistador (Caplow, 1956; citado en Valles, p. 179). Por otro lado, afirma que la "entrevista formal" se diferencia de la conversación de la vida cotidiana (sobre todas las mantenidas entre extraños o entre partes con intereses contrapuestos), respecto a las que resulta más gratificante y presenta las siguientes razones:

a En la entrevista, la participación del entrevistado y del entrevistador cuenta con "expectativas explícitas"; "el uno de hablar y el otro de escuchar".

b El entrevistador anima constantemente al entrevistado a hablar, sin contradecirle ("las resistencias encontradas corrientemente en la conversación espontánea se suprimen")

C A los ojos del entrevistado, el encargado de organizar y mantener la conversación es el entrevistador ("esto crea a menudo una ilusión de fácil comunicación que hace parecer breves las sesiones prolongadas") 
También es presentada la tipología de las entrevistas según Patton (1990) en Valles (2000, p. 180):

a La entrevista conversación informal, caracterizada por el surgimiento y realización de las preguntas en el contexto y en el curso natural de la interacción (sin que haya una previa selección de temas, ni una redacción previa de preguntas).

b La entrevista basada en un guión, caracterizada por la preparación de un guión de temas a tratar (y por tener libertad el entrevistador para ordenar y formular las preguntas, a lo largo del encuentro de la entrevista).

c La entrevista estandarizada abierta, caracterizada por el empleo de un listado de preguntas ordenadas y redactadas por igual para todos los entrevistados, pero de respuesta libre o abierta.

d La entrevista estandarizada cerrada, caracterizada por el empleo de un listado de preguntas ordenadas y redactadas por igual para todos los entrevistados, pero de respuesta cerrada.

De estos cuatro tipos de entrevistas, sólo los tres primeros cabe considerarlos, propiamente, dentro de las entrevistas cualitativas. El tercer tipo puede estar entre la cualitativa y la cuantitativa. Pero el último tipo corresponde claramente al tipo de entrevista encuesta.

Este acercamiento que presenta Valles (2000) en base a la entrevista profesional (Professional interviewing) de Millar, Crute y Hargie (1992) engloba bajo una misma denominación que da título a su obra Professional interviewing.

Dentro de esta supracategoría, los autores distinguen cinco categorías menores:

1. La entrevista de asesoramiento (counselling interview). Esta categoría es la más genérica e indefinida de las cinco, pues abarca una gama de profesionales y clientes muy variada. El asesoramiento puede ser jurídico, financiero, laboral, psiquiátrico, médico, de imagen, etc.

2. La entrevista de selección, utilizada ampliamente para evaluar los candidatos para un empleo. 
3. La entrevista de investigación (research interview), entendida como técnicas de obtención de información relevante para los objetivos de un estudio. Su campo de utilización se encuentra en las ciencias sociales.

4. La entrevista médica (medical interview), o "profesionales de la salud". Hoy se habla de la medicina comunitaria, porque el cuidado de la salud ya no se restringe al acto médico. (Trabajadores sociales, psicólogos, etc.)

5. La entrevista de evaluación o promoción laboral (appraisal interview). Como su nombre indica, se trata de una modalidad de entrevista caracterizada por su aplicación, formación y gestión de recursos humanos.

Esta clasificación de entrevistas profesionales permite enmarcar la entrevista de investigación social. Dentro de la entrevista de investigación social y la entrevista en profundidad acuñada por Raymund L. Gorden en1954, parece tener precedentes en las confesiones de Santo Tomas de Aquino.

La expresión entrevista en profundidad se ubica en el conjunto de la entrevista de investigación. Para Valles (2000), la entrevista en profundidad parece haber ganado la batalla del uso entre una serie de términos afines con desigual solera en la literatura y señala como un glosario mínimo de obligada referencia:

1. Entrevista focalizada (focused interview), acuñada por Robert $\mathrm{K}$. Merton (1946).

2. Entrevista estandarizada no programada, entrevista no estandarizada.

a. Entrevista estandarizada programada

b. Entrevista estandarizada no programada

c. Entrevista no estandarizada

3. Entrevista especializada y a elites.

4. Entrevista biográfica; intensiva; individual abierta semidirectiva; larga, etc. 
La categoría de entrevista en profundidad podría extenderse, abarcando al menos expresiones:

1. Entrevista biográfica

2. Entrevista intensiva

3. Entrevista individual abierta semidireccionada

4. Entrevista larga

Según Valles (2000, p. 191). El modelo teórico de comunicación e interacción social en la definición de la entrevista, pretende mostrar algunas reflexiones más a fondo sobre la entrevista, llegando a trazar modelos teóricos (con sus correspondientes implicaciones metodológicas). El autor, el "modelo contextual" de comunicación de Gorden (1975). Según este modelo, el proceso comunicativo de obtención de información mediante entrevista depende de:

a) La combinación de tres elementos internos a la situación de entrevistas (entrevistador, entrevistado y tema en cuestión).

b) Los elementos externos ("factores extra-situacionales que relacionan la entrevista con la sociedad, la comunidad o la cultura").

\section{Entrevista biográfica}

La entrevista biográfica, se puede llamar también entrevista narrativa 0 relato de vida consiste en reflexionar y rememorar episodios de la vida, donde la persona cuenta a propósito de su biografía (vida profesional, familiar, afectiva, etc.), en el marco de intercambio abierto (introspección y diálogo), que permite profundizar en su vida por las preguntas y la escucha activa del entrevistador, dando resultado como una "coproducción". Los sujetos son inducidos a reconstruir su historia de vida, mediante un conjunto de cuestiones temáticas que van estimulando que el entrevistado recuente su vida. La conversación se transforma en un instrumento de investigación (Bolívar, et al 2001, p. 159).

El entrevistado o narrador, inducido o guiado, cuenta lo que ha sido su vida como una totalidad en sus dimensiones más relevantes, o bien se cifra en algunos momentos o temáticas específicas, de modo que tenga un cierto orden 
coherente. Dicha reconstrucción no debe quedar en una suma de datos o hechos sueltos, es una oportunidad para dar sentido a su vida y producir una identidad. Esto supone dar coherencia a los episodios biográficos, en un argumento con un sentido dado a la trayectoria. Normalmente combina el enunciado de "hechos" (acontecimientos, contextos, acciones, etc.) externos al locutor, con tomas de posiciones internas acerca de esos hechos. La entrevista biográfica ha sido empleado por otros investigadores.

\section{Técnicas de Observación}

Se entiende por técnicas de observación, los procedimientos en los que el investigador presencia el fenómeno que estudia. Según Valles (2000) se presentan tres ejes de distinción de la observación científica y la observación común suele ser uno de los ejes en torno a los que gira la reflexión de algunos metodólogos (Valles, 2000)

La observación es una de las actividades de la vida diaria...Esta observación común y generalizada puede transformarse en una poderosa herramienta de investigación social y en técnicas científicas de recogida de información si se efectúa:

- Orientándola y enfocándola a un objetivo concreto de investigación, formulado de antemano.

- Planificándola sistemáticamente en fases, aspectos, lugares y personas.

- Controlándola y relacionándola con proposiciones y teorías sociales...

- Sometiéndola a controles de veracidad, objetividad, de fiabilidad y de precisión

(Ruíz Olabuenaga y Izpesua, 1989; citados en Valles, 2000, pp. 143).

Segunda distinción: otra distinción frecuente que se plantea al referirse, por un lado, a la observación científica en tanto método de conocimiento presente en cualquier forma de investigación y por otro lado las técnicas concretas de observación directa. Esta vía de reflexión metodológica lleva la diferencia entre la "observación" en sentido restringido, y la experimentación, la encuesta o la documentación. La diferencia entre el experimentador y el observador es que el observador no manipula el contexto natural donde tiene 
lugar la acción que se investiga, y la diferencia del encuestador o del documentalista, el observador no puede contentarse sólo con la información indirecta de los entrevistados o de los documentos (Valles, 2000, p. 144).

Esta caracterización de la distintiva de la observación se fundamenta:

a) La búsqueda del realismo (frente al control logrado en el experimento o en la encuesta, pero a través del artificio contextual).

b) La reconstrucción del significado, contando con el punto de vista de los sujetos estudiados.

La observación permite al investigador contar con su versión, además de las versiones de otras personas (protagonistas informantes...) y contenidas en los documentos.

Tercera distinción: se trata respecto a las técnicas de observación: la observación participante como la modalidad de observación exógena propia de los sistemas observados y la autoobservación, considerada una de las modalidades posibles de observación endógena.

\section{Técnicas indirectas o no interactivas}

En cuanto a las técnicas indirectas o no interactivas, sólo se ha tomado una técnica que es la de análisis documental. El análisis documental puede ayudar a complementar y validar la información obtenida con la entrevista o la observación. "El análisis documentos es una fuente de gran utilidad para obtener información retrospectiva y referencial sobre una situación, un fenómeno o un programa concreto" (Sabariego, et al, 2004, p. 349).

Se diferencia de las técnicas de entrevista y la observación, donde el investigador se convierte en el instrumento principal de obtención y registro de datos, porque el análisis documental es una activada sistemática y planificada que consiste en examinar documentos ya escritos que abarcan una amplia gama de modalidades. Por medio de ellos es posible captar información valiosa. Los documentos son una fuente bastante fidedigna y práctica para revelar los intereses y las perspectivas de quienes lo han escrito. Además, los documentos pueden ofrecer información acerca de los acontecimientos que no 
pudieron observarse antes comenzar el estudio o fueron parte de intercambios privados en los que no participó el investigador.

\section{Documentos oficiales}

Tomamos la clasificación de Del Rincón (1997), quienes agrupan los documentos escritos dos tipos: los documentos oficiales y los documentos personales.

Se entiende por documentos oficiales toda clase de documentos, registros y materiales oficiales y públicos disponibles como fuente de información: artículos de periódicos, registros de organismos, documentos de organizaciones, informes gubernamentales, transcripciones judiciales, horarios, actas de reuniones, programas planificaciones y notas de lecciones, registros de alumnos, manuales escolares, fichas de trabajos, murales y fotografías, películas y diplomas. Estos materiales pueden se internos 0 externos.

Los documentos oficiales tienen un status especial porque son registros públicos y suelen reflejar la perspectiva oficial o institucional. El contexto narrativo en los cuales estos documentos se han escrito y se utilizan es crucial para su interpretación posterior.

Los documentos personales se refieren a cualquier tipo de registros no motivados o incentivados por el investigador durante el desarrollo de su trabajo, que posea un valor afectivo y/o simbólico, es decir relatos en primera persona producido por un individuo que describe sus propias experiencias y creencias.

En mi caso he tomado la clasificación presentada en Pujadas (2002, p. 14):

1.1. Autobiografías.

1.2. Diarios personales.

1.3. Correspondencia.

1.4. Fotografías, películas, videos o cualquier otro tipo de registro iconográfico.

1.5. Objetos personales. 


\subsection{Recogida de información: Instrumentos}

La recolección de información procede de tres técnicas y en tres etapas esquematizada en el siguiente cuadro:

\begin{tabular}{|l|l|l|l|}
\hline & $\begin{array}{l}\text { Antes de la } \\
\text { entrevista }\end{array}$ & $\begin{array}{l}\text { Durante la } \\
\text { Entrevista }\end{array}$ & $\begin{array}{l}\text { Después de la } \\
\text { entrevista }\end{array}$ \\
\hline $\begin{array}{l}\text { Entrevista } \\
\text { narrativa }\end{array}$ & $\begin{array}{l}\text { Conversaciones } \\
\text { generales }\end{array}$ & $\begin{array}{l}\text { Entrevista } \\
\text { grabada } \\
\text { relacionada con } \\
\text { la investigación }\end{array}$ & $\begin{array}{l}\text { Transcripción de } \\
\text { la entrevista y } \\
\text { conversaciones } \\
\text { complementarias }\end{array}$ \\
\hline Observaciones & $\begin{array}{l}\text { Clases, } \\
\text { seminarios, } \\
\text { talleres para } \\
\text { profesores y } \\
\text { estudiantes }\end{array}$ & $\begin{array}{l}\text { Uso de materiales } \\
\text { y recursos } \\
\text { didácticos }\end{array}$ & $\begin{array}{l}\text { Videos y } \\
\text { Películas }\end{array}$ \\
\hline Documentos & $\begin{array}{l}\text { Libros, película, } \\
\text { bocetos } \\
\text { biográficos en la } \\
\text { Internet, artículos } \\
\text { de periódicos }\end{array}$ & $\begin{array}{l}\text { Fotografías, } \\
\text { Diplomas y } \\
\text { certificados, } \\
\text { leccionarios y } \\
\text { manuscritos }\end{array}$ & $\begin{array}{l}\text { Análisis de los } \\
\text { documentos } \\
\text { públicos y } \\
\text { personales }\end{array}$ \\
\hline
\end{tabular}

Como se indica en la sección de los antecedentes de esta investigación, la recogida de los documentos y la observación de diferentes clases, seminarios y talleres para profesor y estudiantes se realizaban con anterioridad a la definición del problema de investigación. En la etapa inicial de la investigación, se elaboró un planteamiento teórico del problema y la determinación del estado de cuestión. En esta etapa se hizo las consultas de disponibilidad y viabilidad de la investigación a través de la comunicación telefónica con el profesor Jaime Escalante.

En la fase de la encuesta, el aspecto más trascendente es la selección de un buen informante. Se trata de una relación cara a cara entre el sujeto y el investigador, en la que lo principal es que exista una buena armonía y entendimiento ente ambos. Jaime Escalante aunque radicaba en Cochabamba, Bolivia, viajaba con frecuencia a los Estados Unidos donde están sus hijos. Por otro lado yo estaba en España por motivos de estudio. Finalmente, pudimos hacer coincider nuestras agendas.

Pues vamos a considerar las tres técnicas, en esta investigación 
La entrevista biográfica o relato biográfico se realizó en su domicilio en la ciudad de Cochabamba; a pesar de su predisposición para la entrevista no disponía de mucho tiempo para la entrevista y nos vimos obligados a realizarle por las noches, aunque este hecho favoreció la entrevista al encontrar un lugar tranquilo en su casa. Me explicó con bastante claridad, sus motivaciones, sus frustraciones y también sus logros. A pesar de eso no fue fácil el trabajo de transcripción.

En la fase del registro y transcripción de la entrevista grabada se ha dispuesto de tres registros de la entrevista:

1. Una primera copia o registro original con la transcripción de toda la entrevista.

2. Una segunda copia es el registro cronológico, en el que vamos ordenando toda la información de acuerdo con las etapas sucesivas de la vida del profesor Jaime Escalante desde su infancia hasta el momento, sólo que el profesor falleció a consecuencia de un cáncer antes de que se termine el trabajo.

3. Una tercera copia es el registro temático, en esta investigación estaba orientada hacia las concepciones y creencias sobre la matemática, su enseñanza y aprendizaje.

Toda entrevista tiene diferentes fases como señala Atkinson: las fases de una entrevista son: la planificación, realización de la entrevista y la transcripción y la interpretación (Atkinson, 1998; citado por Valles, 2000).

Para esto se ha utilizado los diferentes instrumentos como:

- La guía de entrevista (que sirvió como guía de la entrevista en las diferentes sesiones).

- $\quad$ MP3 (se utilizó un MP3 para grabar el audio de la entrevista y yo lo llevaba prendida en el cuello para no perder ninguno detalle de la conversación.)

- Video grabadora (para captar las imágenes del entrevistado, especialmente cuando explica el uso de los materiales didácticos). 
La observación es una de las actividades comunes de la vida diaria, sin embargo, esta observación común y generalizada puede transformarse en una poderosa técnica de investigación. Además, la observación es considerada por varios investigadores como un método de investigación, especialmente en los estudios de caso.

Según Bisquerra (1989), la observación puede tener distintos sentidos fundamentales:

- como técnica de recogida de datos dentro del proceso de investigación;

- como método de investigación.

En esta investigación, la observación se considera una técnica de investigación. Según Tójar (2006), la observación es inseparable de otros instrumentos como la entrevista en profundidad, realizada a informantes seleccionados, junto con lo que consigue recabar los denominados datos primarios del trabajo de campo. Dichos datos primarios han de ser complementados con otros datos secundarios, obtenidos a partir del análisis de la tradición oral, la consulta de documentos de diversos tipos de archivos y otros estudios.

Una recomendación que se debe tener en cuenta es que el observador ha de tener la capacidad de dejar a un lado sus propias ideas previas, su cultura, sus valores, y aceptar e integrar la escala de valores de la persona biografiada. Porque lo que es válido para este tipo de observación no consiste en lo que el investigador consigue descubrir o interpretar. La versión válida es la que tiene al propio protagonista. Lo que interesa es como él interpreta sus propias acciones.

En este estudio utilizamos la observación como una técnica complementaria a las otras dos técnicas de entrevista narrativa y documentación. La observación se refiere en las clases con alumnos del Instituto Normal Superior Adventista y seminarios y talleres para profesores en La Paz, Oruro, Tarija y Santa Cruz. La observación nos permitirá el análisis y la descripción de los recursos didácticos implementados por Jaime Escalante en la enseñanza de la matemática para el nivel secundario. 
Por otro lado nos permitirá verificar las categorías de las creencias y concepciones sobre las matemáticas, su enseñanza y aprendizaje y la implementación de los recursos didácticos.

Entre las técnicas no interactivas hemos empleado la técnica de documentación tanto los documentos públicos como y personales.

Antes de abordar los pormenores de cómo definir y clasificar los documentos susceptibles de construir la materia prima (principal o complementario) de posibles investigaciones conviene tomar nota de esta estrategia metodológica denominada documentación (y no observación o narración) en el oficio del investigador de la perspectiva de la historia de vida (Valles, 2000).

Las técnicas de documentación son reunidas, a veces, bajo la denominación genérica de análisis documental (Tójar, 2006). La revisión de la literatura (que supone estar al día de lo publicado sobre el tema que se pretende investigar) son tareas siempre presentes en estudios cuantitativos y cualitativos (Valles, 2000). Sin embargo, no se agota ahí la investigación documental.

El tema clave del método biográfico es el estudio de las experiencias vitales de las personas y el significado que adquieren para ellas. Por lo tanto, su punto de partida son las distintas expresiones de significados aportados por los participantes del estudio que pueden estudiarse, construirse, reconstruirse y escribirse en documentos personales (Bisquerra, 2004). Denominamos documentos personales a las que orientan a escribir la propia vida 0 experiencias vitales de las personas.

Algunos de los documentos personales más representativos y utilizados en la investigación socioeducativa, según Bisquerra (2004) son: las autobiografías, las biografías, los relatos de vida, los diarios, las cartas personales y las historias de vida. Mientras que para Pujadas (2002) la clasificación se presenta de la siguiente manera:

1. Documentos personales

1.1. Autobiografías

1.2. Diarios Personales 


\subsection{Correspondencia}

1.4. Fotografías, películas, videos o cualquier otro tipo de registro iconográfico.

1.5. Objetos personales

2. Registros biográficos obtenidos por encuestas

2.1. Historia de vida, que pueden ser:
A. De relato único
B. De relatos cruzados
C. De relatos paralelos

2.2. Relatos de vida, que son sometidos a tratamientos analíticos (cualitativos o cuantitativos) distintos a la historia de vida.

\subsection{Biogramas.}

Siguiendo al autor, se ha utilizado en este estudio para definir el problema de investigación propiamente dicha. Es decir, se trata del primer acercamiento a problema de investigación y la determinación del enfoque metodológico.

La técnica de documentación utilizada en este estudio, se caracteriza por el uso de trabajos basados en documentos recopilados de archivos que pueden ser oficiales o privados. Es importante para conocer los nombres, los papeles, los cargos de las personas a quienes se le va pedir la colaboración, los que pueden ser importantes. Según Tójar (2006) todas estas informaciones preliminares han de ser tomadas con las necesarias reservas, contrastadas y revisadas a medida que se realiza el trabajo (con entrevistas y observaciones), o con la incorporación de nuevos documentos.

Los documentos son muy importantes para una investigación histórica, especialmente para una historiografía tradicional que solo se basa en documentos existentes. Al respecto Ruiz (1976), señala que se ha repetido mucho la frase de Seignobos "sin documentos no hay historia" y para el autor todos los historiadores están de acuerdo con esta constatación.

Una de las definiciones relacionadas con los documentos escritos de acuerdo al diccionario de uso del español, Moliner (1984, p. 1030) distingue tres aspectos al definir el Término documento: 
1. Testimonio escrito de épocas pasadas que sirven para reconstruir su historia.

2. Escrito que sirve para justificar o acreditar algo; tal como un título profesional, una escritura notarial, un oficio o un contrato.

3. Instrucción o enseñanza de una materia.

La primera acepción (Valles, 2000) establece una equivalencia que responde a un uso cultural, ligado a una época determinada (siglo XIX y primera mitad del $\mathrm{XX}$ ), De hecho hoy en día esta acepción es discutible, ya que excluye todo tipo de documento que no sea papel (historia oral, documentos sonoros, visuales, audiovisuales, etc.).

Uno de los autores que nos ha ayudado en aclaración del método biográfico es Valles (2000). Quién sostiene de que el método biográfico no solamente está enraizado en las técnicas de conversación, sino también en la documentación y la observación. Además, señala a Paul Thompson como uno de los defensores y máximo exponente de la historia oral, ya que Thompson afirma que el futuro de la historia ya "no estará atado a la significación cultural del documento papel." Las razones que acentúa este autor se encuentra en el cambio de la función social del propio documento:

Hemos llegado... a la era del teléfono y la grabadora: un cambio en los métodos de comunicación que con el tiempo traerá alteraciones tan importantes en el carácter de la historia como hicieron en el pasado el manuscrito, la prensa impresa, y el archivo. (Thompson, 1988, p. 55).

La segunda acepción del término documento (según el diccionario consultado) recalca la equiparación con el material escrito, y más concretamente con los documentos de carácter legal. Sin lugar a dudas estos sirven para dar crédito, pero de acuerdo a Valles (2000) pueden resultar ser falsos. Por lo que debe analizarse au autenticidad y la originalidad.

Finalmente, la tercera acepción aparecida en el diccionario citado (Valles, 2000, p. 119) recoge el uso más ligado a la raíz etimológica del vocablo documento (del verbo latino dosere: enseñar instruir). Precisamente el verbo documentarse se define así: "instruirse convenientemente sobre algo antes de tratarlo o escribir sobre ello" (Moliner, 1984, 1030). 
Para Ruíz Olabuenaga y Ispizua, citado en Valles (2000, p. 120), "A la observación y la entrevista podemos añadir una tercera técnica de recogida de datos, la lectura de textos, entendiendo por tales, todos los documentos que contienen significados."

Según Valles (2000), las técnicas cualitativas de investigación social son: documentación, la observación y la narración (conversión). En otra parte, el mismo Valles (2000) cita a Erlandson y otros (1993) al definir el término documento:

El término documento se refiere a la amplia gama de registros escritos y simbólicos, así como cualquier material y datos disponibles. Los documentos incluyen prácticamente cualquier cosa existente previa y durante la investigación, incluyendo relatos históricos o periodísticos, obra de arte, fotografías, memorando, registro de acreditación, transmisiones de televisión, periódicos, folletos, agendas y notas de reuniones, audio o videocinta, extractos presupuestarios o estados de cuenta, apuntes de estudiantes o profesores, discursos...

Los datos obtenidos de los documentos pueden usarse de la misma manera que los derivados de la entrevista o las observaciones. (Erlandson et al., 1993, p. 99; citado en Valles, 2000, p. 120).

La clasificación de los documentos hemos tomado la definición de MacDonald y Tipton (1993), en Valles (2000, p. 120), aunque, esta definición pertenece a la sociología, pero la investigación educativa pertenece a las ciencias de la educación que también es una ciencia social.

Los documentos son cosas que podemos leer y que se refieren a algún aspecto del mundo social. Claramente esto incluye aquellas cosas hechas con la intención de registrar el mundo social-los informes oficiales, por ejemplo-pero también los registros privados y personales como cartas, diarios y fotografías, los cuales puede que no se haya hecho para sacarlos a la luz pública. No obstante, además del registro intencionado, puede haber cosas abiertamente traten de provocar diversión, admiración, orgullo o goce estético-canciones, edificios, estatuas, novelas-y que, sin embargo, nos dicen algo sobre los valores, intereses y propósitos de aquellos que las encargaron o produjeron. Tales creaciones pueden ser consideradas "documentos" de una sociedad o 
grupo, que puede ser leído, si bien en un sentido metafórico." (Macdonald y Tipton, 1993, p. 188; citado en Valles, 2000, p. 120).

El uso de los materiales documentales posee las dos caras: ventajas e inconvenientes. Como registra Valles (2000), que detrás del uso de los documentos algunos autores han visto las siguientes ventajas generales (Webb y otros, 1966; Hodder, 1994, citados en Valles, 2000, p. 129):

a. Bajo coste de una gran cantidad de material informativo, que en algunos casos tiene un carácter periódico (los medios de comunicación por ejemplo, o el Diario de las Secciones de la Corte).

b. No reactividad. A diferencia de la información obtenida directamente por el investigador, mediante técnicas de observación o conversación (cuestionarios y entrevistas), el material documental suele producirse en contextos naturales de interacción social. Esto significa que, debido a la ausencia del investigador, no habrá que preocuparse por las reacciones que este puede provocar en las personas cuando se saben investigadas. Claro que otras fuentes de reactividad (o de otro tipo) si pueden haber contaminado ya la información contenida en los documentos. Pero estos son problemas que se detectan y resuelven en la evaluación e interpretación de la documentación.

c. Exclusividad. El contenido informativo que proporcionan algunos materiales documentales y tienen cierto carácter único, pues defiere del que puede obtenerse mediante las técnicas directas de observación o conversación

d. Historicidad. Los escritos, las imágenes y las voces grabadas permanecen en el tiempo, si alguien las conserva o las archiva.

En cuanto a las desventajas o inconvenientes de los materiales documentales, también señalados por Valles (2000) son las siguientes:

a Selectividad en la producción, o registro, y en la conservación, o archivo, del material documental. Se trata de un "riesgo que siempre esta presente" (que denominan "depósito o supervivencia del material"), ocacionado por "elementos reactivos u otros en el proceso de producción de datos" (...).

b La propia naturaleza secundaria del material documental (numérico escrito y visual) plantea, en opinión de algunos autores (Almarcha y otros, 1969, 164), el "gran inconveniente...en gran medida insuperable y por 
eso se aconseja que los datos secundarios sirvan de un hábil complemento a los datos primarios y no constituyan la única referencia documental de las monografías...a menos que estas sean muy epecializadas o excluyan por la temática de los datos primarios”. El carácter secundario significa que se trata de una información producida, generalmente con propósitos diferentes a los del investigador social. Por tanto, presenta rigideces y limitaciones de partida que dificultan su uso.

La interpretatibilidad múltiple y cambiante del material documental, dependiendo del contexto y a lo largo del tiempo. Para Hodder (1994), una vez producido los textos escritos o los artefactos dentro de una cultura, la distancia que separa del autor al lector se agranda y aumenta la posibilidad de múltiples interpretaciones. El material documental puede ser manipulado y alterado diciendo y haciendo cosas diferentes en contextos nuevos a lo largo del tiempo. (...).

d La denominada crítica etnometodológica a la utilización de las fuentes documentales oficiales: estadísticas e informes públicos. Para Hammersly y Atkinson (1994:152-155) "el gran valor de la crítica metodológica" es que plantea la necesidad de tratar, la información procedente de fuentes oficiales, como socialmente producida. Sin embargo, estos autores advierten que, por otro lado, "la crítica etnometodológica incurre en aseveraciones engañosas" o salteamientos radicales. (...).

La evaluación de los materiales documentales denominados también por algunos autores como la crítica interna y externa (Ruiz, 1976; Cohen y Manión 2002), están referidos a la veracidad y la autenticidad de los materiales documentales.

La crítica externa relacionada con la autenticidad y la legitimidad de los datos. Para Cohen y Manion (2002) está dirigida al documento mismo (u otra fuente) en lugar de las declaraciones que contenga. Por lo tanto está dirigida a descubrir fraudes, falsificaciones, engaños, invenciones o distorsiones. La autenticidad según Valles (2000), determina la autoría, reproducción o edición original, fecha.

La crítica interna. Una vez establecida la autenticidad del documento, la tarea inmediata del investigador es evaluar la precisión, la veracidad y el valor de los datos contenidos en él. Para Ruiz (1976) es "la interpretación del 
contenido de los datos" mientras que para Cohen y Manion (2002), "Aunque puedan ser legítimos, no necesariamente tienen que descubrir el retrato más fiel. En su preocupación por establecer el significado y la fiabilidad de estos datos, el investigador se enfrenta con un problema más difícil que la crítica externa, ya que ha de establecer la credibilidad del autor del documento".

Para el desarrollo del análisis documental se ha seguido las recomendaciones de Sandoval (1996) citado diez años después por Tójar (2006) quien establece cinco etapas:

1. Rastreo de documentos existentes y disponibles.

2. Clasificación de documentos obtenidos.

3. Selección de documentos pertinentes

4. Lectura profunda del contenido y realización de notas marginales (memos), buscando tendencias, similaridades, contradicciones, patrones, $\ldots$

5. Lectura cruzada y comparativa de documentos, con intención de ir construyendo una síntesis comprensiva global.

Para esta investigación de "Historia de vida y metodología de enseñanza de la matemática de Jaime A. Escalante Gutiérrez" se han utilizado los siguientes documentos:

1. Libro: Escalante: The best teacher in America de Jay Mathews, (1988).

2. Película: Stand and Deliver (Con ganas de triunfar) (1988), Duración 105 minutos, Estado Unidos. Drama, Protagonizada por Edward James Olmos, Estelle Harris, Virginia Paris, Andy García. Nominada al Oscar por mejor actor 1988. Distribuída por Blockbuster México.

3. Currículum Vitae 2006.

4. Periódicos de Bolivia y Estados Unidos.

5. Fotografías.

6. Apuntes de clases.

7. Presentaciones de conferencias.

8. Grabaciones de seminarios para profesores de matemáticas.

9. Recursos y materiales didácticos. 
10. Reconocimientos honoríficos.

11. Escrito de opiniones.

12. Biografías o semblanzas en Internet.

\subsection{Estrategias de análisis de información}

Toda la información obtenida y registrada a través de las diferentes técnicas empleadas para la presente investigación, la conversación, la documentación y la observación se transcribió para su posterior análisis.

El análisis de información constituye una etapa clave en el proceso de investigación cualitativa que aparece indisolublemente unido a la recogida de la información (Gil, 1994; Gotees y Lecomte, 1988) citado por Bisquerra (2004).

Ciertamente, en la misma recopilación de información ya existe un grado de análisis de información, en el sentido que señala Bisquerra (2004) sobre la observación. De hecho, cuando registramos y describimos lo que observamos a través de las notas de campo, de alguna manera ya estamos efectuando un análisis de información, pues inevitablemente interpretamos la realidad y la categorizamos aunque sea implícitamente en el uso del lenguaje”.

Como dice Bisquerra, si tenemos en cuenta el énfasis de la metodología cualitativa en la captación de significados y la definición de la situación, el análisis se ve obligado a someter el texto a múltiples manipulaciones a través de un proceso cíclico de selección, categorización, comparación de la realidad registrada en todas las fases de la investigación, con la finalidad de encontrar un sentido a la información.

Para Ruiz Olabuénaga (1999) cuando habla del "método cualitativo de análisis de contenido" para referirse al proceso de datos cualitativos. Lo define como "una metodología que utiliza varios procedimientos para efectuar inferencias válidas de un texto que debe entenderse y tratarse como un escenario de observación, o como el interlocutor de una entrevista, del cual se extrae información para someterla a un análisis e interpretarla posteriormente.

Bisquerra (2004) nos dice que se han planteado varios modelos para sistematizar la actividad analítica. Citando a (Tesch, 1990; Goetz y Lecompte, 1988; Miles y Huberman, 1984) dice, que el proceso de análisis puede 
entenderse como el flujo y conexión interactiva de tres tipos de operaciones básicas: 1. la reducción de la información, 2 . la exposición de los datos y 3 . la extracción o verificación de conclusiones, y se ilustra en el siguiente figura.

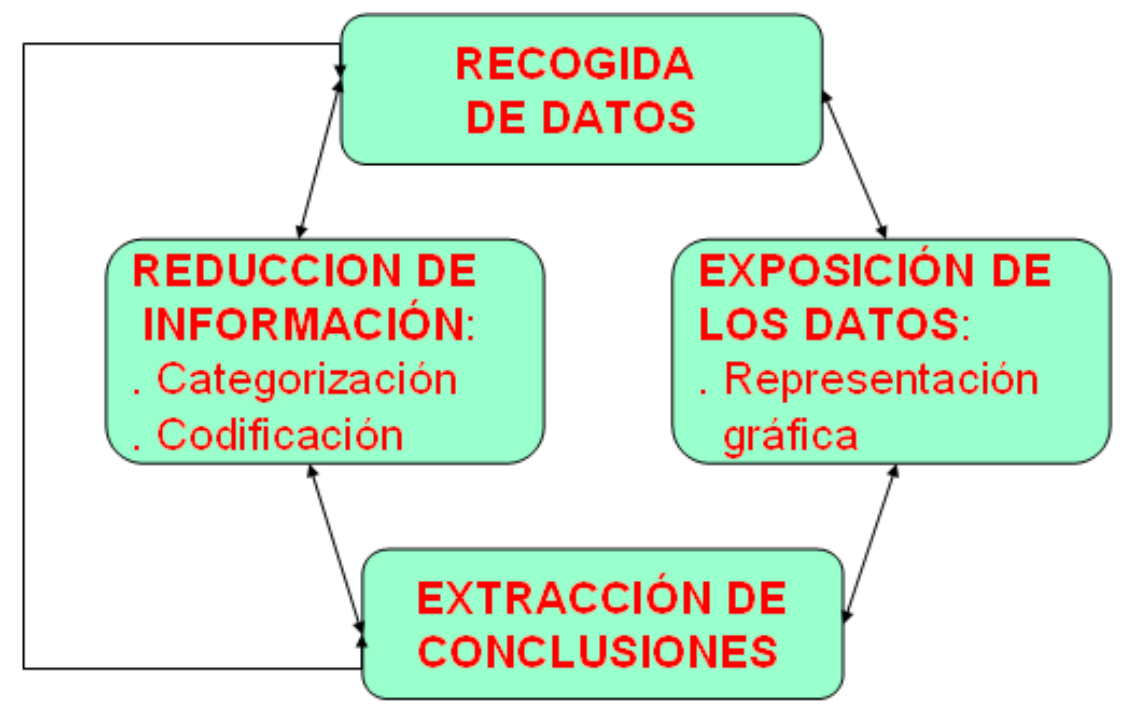

Proceso de análisis de datos (Miles y Huberman, 1984)

En base al cuadro propuesto por Miles y Huberman, observamos que previamente la ordenación sistemática y la manipulación de los datos es importante revisar la calidad de la información obtenida, para facilitar las otras operaciones del trabajo de investigación.

La reducción de la información significa seleccionar, focalizar y abstraer los datos brutos en unidades de significados que se denominan categorías de contenido, de acuerdo con unos criterios temáticos determinados. Esta idea resume el procedimiento fundamental de análisis de datos cualitativos que consiste en buscar temas comunes o agrupaciones conceptuales en un conjunto de narraciones recogidas como datos de base o de campo.

Posteriormente, toda información se organiza y se sistematiza en gráficas o matrices que permiten obtener una perspectiva global de los datos estudiados y elaborar las conclusiones finales. A este propósito se dirige la siguiente fase en el proceso de análisis cualitativo, la exposición organizada de los datos en procedimientos gráficos y matrices descriptiva y explicativa. 
Finalmente, la extracción de conclusiones responde a una actividad que se inicia en la recogida de datos, ya que la actividad del investigador no se limita, únicamente, a registrar la información sino que comporta una reflexión permanente sobre el proceso y el contenido de los datos o información. Inicialmente, estas conclusiones son abiertas y vagas. A lo largo del proceso de reducción y exposición de estos datos estas conclusiones se van desarrollando hasta que permiten identificar regularidades, patrones, explicaciones, así como la elaboración de determinadas generalizaciones, tipologías y modelos.

Para el análisis de la información en esta investigación he utilizado el esquema del árbol de Massot (2001) tomado de Bisquerra (2004). La Historia de Vida y la Metodología de la Enseñanza de la Matemática del profesor Jaime Alfonso Escalante Gutiérrez. En base al esquema se realizó el análisis de la información obtenida por las técnicas de interactivas y no interactivas: narración, observación documentación.

Se utilizó el siguiente esquema del árbol.

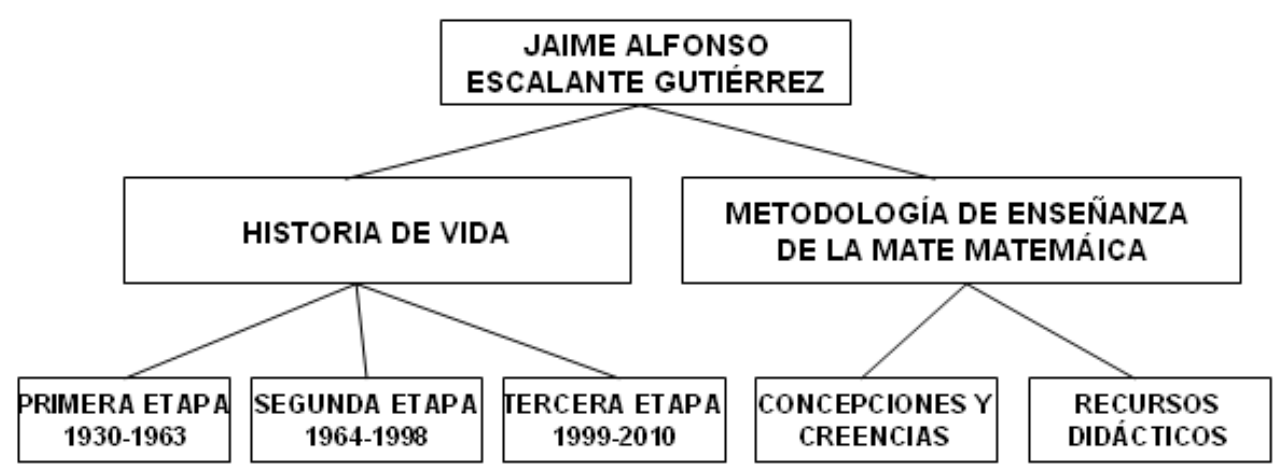


Este capítulo presenta una historia de vida un profesor de matemáticas de origen boliviano que concitó la atención nacional en Estados Unidos en la década de los ochenta. El estudio está dividido en tres etapas: su vida en Bolivia, en Estados Unidos y a Nivel Internacional, como también sus obras y reconocimientos más relevantes.

\section{CAPITULO IV}

\section{HISTORIA DE VIDA DE JAIME ESCALANTE}

\subsection{Introducción}

Esta investigación es una historia de vida y no la historia de vida, para no pecar de pretencioso. Como ya señalamos en la justificación de esta investigación, el propósito fundamental es facilitar el acceso a la vida y obra del profesor de matemáticas Jaime Alfonso Escalante Gutiérrez a profesores y estudiantes, investigadores en educación, administradores y responsables de políticas educativas, específicamente en lo que respecta a la enseñanza de la matemática.

Jaime Alfonso Escalante Gutiérrez nació en La Paz, Bolivia. Después de enseñar Física y Matemática durante 12 años en su país, emigró a los Estados Unidos y trabajó como un chico de recados (busboy), cocinero y técnico en electrónica, mientras conseguía el grado de matemática y la credencial de enseñanza (Bay, 1999).

En 1974, Escalante se incorporó como profesor de matemáticas en Garfield High School, una escuela en el interior del Este de Los Angeles (California). Su éxito fue inmediato y espectacular ya que consiguió crear e implementar su Programa de Matemáticas Avanzadas. Organizó a un grupo de estudiantes que habían sido etiquetados con epítetos poco laudatorios por la sociedad, y transformó la imagen de la institución que estaba a punto de perder 
la acreditación en 1975, ubicándola en el cuarto lugar del ranking nacional en 1987 (Novak, 1993).

Esta escuela, estaba localizada en un barrio conflictivo, donde las drogas, pandillas y la violencia eran sucesos de la vida diaria. A pesar de estos obstáculos, Escalante pudo motivar a un grupo pequeño de estudiantes para tomar y aprobar el examen de Advanced Placement (AP) de cálculo en 1982. Los miembros del Servicio de Evaluación Educativa (Educational Testing Service), invalidaron las puntuaciones, creyendo que los estudiantes habían hecho una trampa. La mayoría de los alumnos volvieron a realizar el examen, y esta vez pasaron el $100 \%$ de los alumnos con mejores resultados, haciendo de Escalante un héroe educativo de Estados Unidos de la noche a la mañana.

Esta experiencia fue motivo de inspiración de un libro: "Escalante: The Best Teacher in America" (Mathews, 1988), y una película "Stand and Deliver" (Menéndez y Musca, 1988). A mi entender, estos documentos no reflejan toda la experiencia del profesor Jaime Escalante, a pesar de que ya es un gran esfuerzo para hacer conocer su vida y obra.

El profesor Jaime Escalante recibió muchos reconocimientos. Los detalles se presentan en los apartados siguientes, pero en Bolivia, su país natal, no recibió ningún reconocimiento de parte de las autoridades nacionales ni de las instituciones educativas. En Jaime Escalante se cumplió la frase acuñada por Jesucristo: "nadie es profeta en su propia tierra".

\subsection{Datos biográficos}

1930 Jaime Alfonso Escalante Gutiérrez nace en La-Paz, Bolivia, el 31 de diciembre.

1941 Empieza a estudiar en la escuela "México" La-Paz, Bolivia.

1944 Se incorpora al colegio Jesuita "San Calixto" de La-Paz, Bolivia.

1951 Empieza la carrera de magisterio para ser profesor de Matemática y Física en la Normal Superior "Simón Bolívar" de La-Paz, Bolivia.

1952 Empieza a trabajar como profesor de Física en el Instituto Americano. 
1954 Se gradúa como profesor de Matemáticas y Física de la Normal Superior "Simón Bolívar". Comienza a trabajar como profesor de matemáticas en el colegio "San Calixto". Se casa con Fabiola Tapia Valle, el 25 de noviembre.

1955 Nace Jaime Jr. (Jaimito), el 27 de septiembre.

1962 Estudia Matemáticas y Ciencia en la Universidad de Puerto Rico.

1963 Emigra a los Estados Unidos, llegando a California en la víspera de Navidad.

1964 Comienza a trabajar en el Restaurante Van de Kamp. Empieza a estudiar en la Pasadena City College (Universidad de la Ciudad de Pasadena).

1967 Comienza a trabajar en electrónica en Burroughs Corporation.

1969 Nace su segundo hijo Fernando el 14 de julio. Se gradúa en el Pasadena City College en Electrónica.

1972 Trabaja en Guadalajara, México, como Administrador de Burroughs Corporation.

1973 Recibe su grado de Matemáticas de la California State University, Los Ángeles.

1974 Alcanza a conseguir la Credencial de Enseñanza para California. Comienza a enseñar matemáticas en Garfield High School en el Este de Los Ángeles.

1978 Empieza a enseñar cálculo para Advanced Placement (AP).

1979 De los cinco alumnos que preparó, dos aprobaron el examen de AP.

1980 La clase creció a nueve alumnos, y siete aprobaron el examen de AP.

1981 La clase había crecido a quince estudiantes, de los cuales catorce consiguieron aprobar el AP.

1982 Captó la atención nacional cuando los 18 estudiantes preparados por Escalante, aprobaron, 14 fueron acusados de fraude y 12 repitieron el examen aprobando con mejores calificaciones que en 
el primero, haciendo famoso a Escalante de la noche a la mañana.

Empieza a trabajar en la East Los Angeles College (ELAC).

1988 La historia de Escalante y sus estudiantes inspiró un número de libros que se han escrito acerca de su vida: Escalante: "The Best Teacher in America", y la película "Stand and Deliver". Posteriomente, se escribieron los libros sobre Jaime Escalante: Inspirational Educator (1998), Jaime Escalante: Sensational Teacher (1996), y Jaime Escalante: Inspirational Math Teacher (2009).

1988 Medalla Presidencial a la Excelencia en Educación, otorgada por el presidente Ronald Reagan.

Premio a la Herencia Hispánica.

1989 Doctor Honoris Causa en Ciencias otorgado por la Universidad Massachusetts Boston.

1990 Doctor Honoris Causa en Humanidades, Universidad Estatal de California, Los Angeles.

Doctor Honoris Causa en Educación, Concordia University, Montreal.

Doctor Honoris Causa en Leyes, Universidad del Norte de Colorado.

Doctor Honoris Causa en Letras Humanas, Wittenberg.

1998 Premio Espíritu Libre, del Foro de la Libertad.

Premio Andrés Bello, de la Organización de los Estados Americanos (OEA).

1999 Introducción al "The National Teachers Hall of Fame".

2005 Premio al Alto Servicio del Center for Youth Citizenship.

2008 Honrado por la Legislatura de California con el premio al Espíritu Latino.

2010 Jaime Escalante falleció el 30 de marzo en California, Estados Unidos. 


\subsection{Primera etapa: Jaime Escalante en Bolivia (1930 a 1963)}

\section{Orígenes familiares}

El protagonista de esta historia de vida, Jaime Alfonso Escalante Gutiérrez $^{1}$, nació el 31 de diciembre de 1930 en La Paz, una ciudad situada a 3.649 metros sobre el nivel del mar, que tiene la forma de un cañón al pie del nevado de Illimani, denominado el protector de nuestra señora de La Paz (Mesa et al. 2003). Esta ciudad está asentada sobre las riveras del río Choqueyapu, que cruza de oeste a este y pequeños ríos que nacen en las laderas altas y depositan sus aguas a lo largo del trayecto de este río. Esta ciudad fue fundada en 1548 por Alonzo de Mendoza en Laja, como punto de descanso entre el tránsito Potosí (Bolivia) y Cuzco (Perú). Posteriormente, se trasladó al borde del altiplano donde se inicia la quebrada, un lugar más cálido, llamado Chuquiago, que viene de Choqueyapu (en aymara Chuquiyapu "chacra de papas" (patatas) o de oro). Debido al clima benigno de este valle, las cosechas de patatas y otros cereales eran magnánimas y, por otro lado, el río de las laderas altas arrastraba el oro. El nombre completo designado por los conquistadores españoles fue Nuestra Señora de La Paz, constituyéndose en la tercera ciudad, después de Sucre (1538) y Potosí (1543). Su nombre conmemora la restauración de la paz después de la guerra civil que siguió a la insurrección de Gonzalo Pizarro contra Blasco Núñez Vela, primer virrey de Perú. (Mesa et al, 2003).

En 2001, La Paz tenía 2.350.466 habitantes y era la primera ciudad en importancia demográfica y la sede del gobierno nacional de Bolivia.

Jaime era hijo de una pareja de maestros de educación primaria: Sara Gutiérrez Valle y Zenobio Escalante Rodríguez. La familia tuvo cinco hijos: Olimpia, Jaime, Bertha, José y Raúl (Escalante, 2007; Mathews, 1988). Sus padres fueron destinados a trabajar en Achacachi, provincia de Umasuyos, Departamento de La Paz.

\footnotetext{
${ }^{1}$ Nombre real
} 


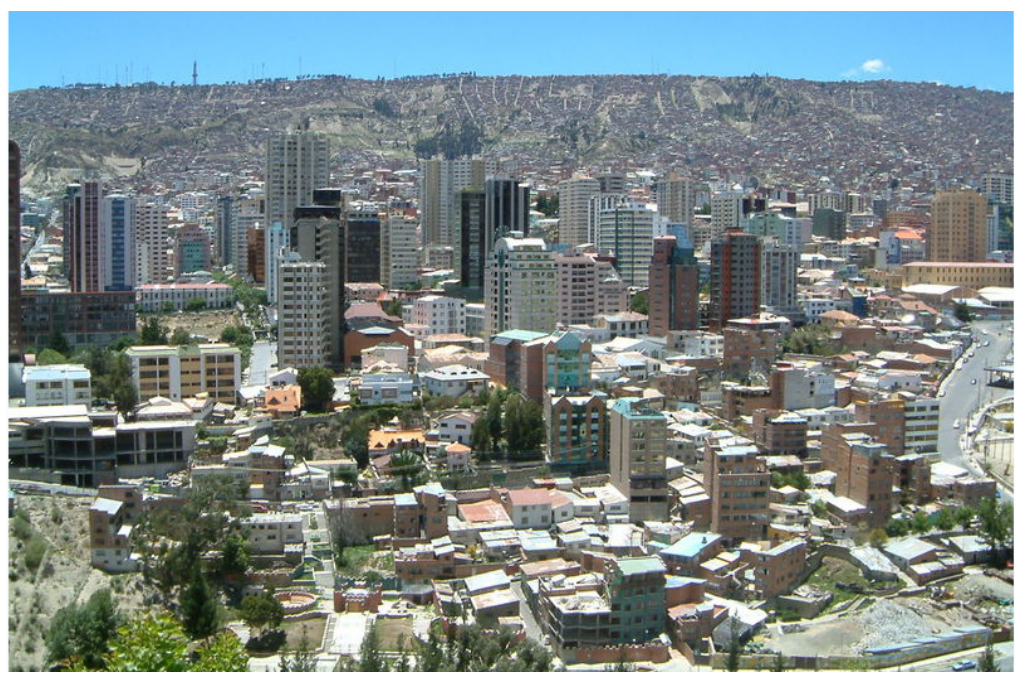

Una vista del centro de la ciudad de La Paz

Achacachi es un pueblo ubicado en la meseta del altiplano boliviano, entre las cordilleras del este y del oeste de Los Andes. Además, se encuentra cerca del Lago Titicaca, que comparten Perú y Bolivia.

El Lago Titicaca, conocido como el "Lago sagrado de los Incas", está ubicado a 3.800 metros sobre el nivel del mar y es el segundo lago más grande de Sudamérica. Es el lago navegable más alto del mundo. Su profundidad máxima se estima que supera los 360 metros. Estas medidas aumentan en la época de lluvias. El Lago Titicaca mide 204 km. de largo por 65 km. de ancho,

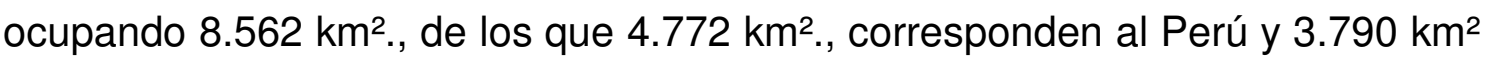
a Bolivia, como se observa en el cuadro de la siguiente página.

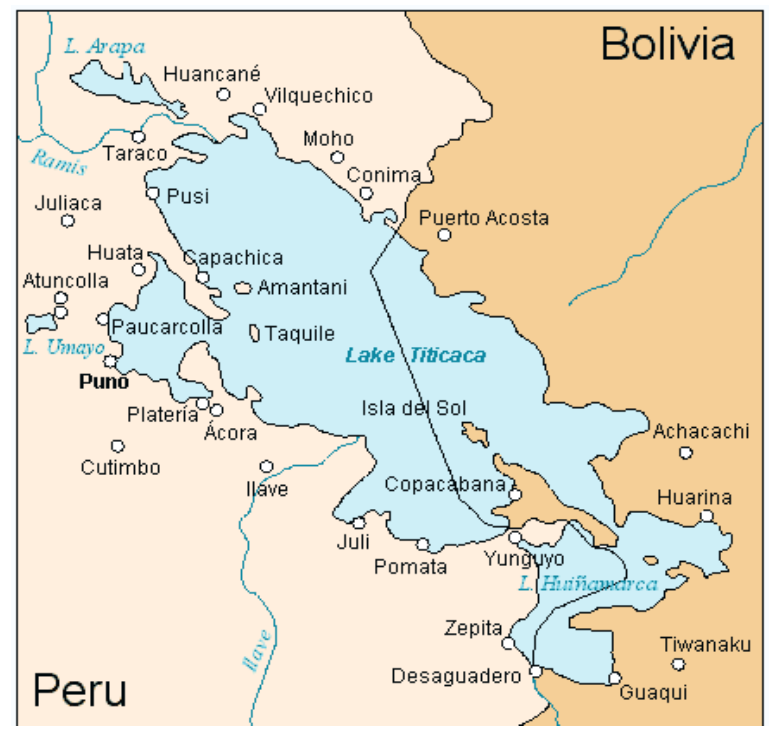

Los límites entre Perú y Bolivia que comparten el Lago Titicaca 
El 13 de agosto de 2007, el lago Titicaca fue inscrito, de forma oficial, en la competición virtual de la Fundación New Seven Wonders que busca elegir a las siete maravillas naturales del mundo ${ }^{2}$.

El idioma oficial de la zona es el Aymara, que se habla hasta el día de hoy, seguido por el quechua, el lenguaje del Imperio Incaico.

En la entrevista a Jaime Escalante conseguimos la siguiente narración:

Yo originalmente soy de La Paz. Mis padres eran profesores y ellos fueron destinados a la provincia Umasuyos cuya primera capital es Achacachi. Yo pasé mi infancia en Achacachi. Me crié prácticamente con los indios. Estuve más con los Aymaras, porque mi tía tenía sus fincas y yo estaba más con ellos en las fincas. Yo no hablaba el castellano, no sabía el castellano, porque mi idioma original en cierto modo era el aymara. (Escalante, 2007, párrafo 1).

Según el periodista de Washington Post, y autor del libro Escalante Best Teacher in América, Mathews (1988), en Achacachi los servicios médicos eran inadecuados en aquel tiempo, aunque las cosas no han cambiado en la actualidad a pesar de algunas mejoras. Por ese motivo Sara tuvo que dejar el pueblo de Achacachi por algunas semanas antes que naciera Jaime. Ella se quedó con sus familiares en la zona de Sopocachi (La Paz).

A pesar de haber nacido en la ciudad de La Paz, por motivos de trabajo de los padres, Jaime pasó la mayor parte de su infancia en el pueblo de Achacachi, en medio de la cultura Aymara. Por eso, prácticamente se crió con los indios, y estuvo con los Aymaras a causa de las fincas de su tía. Esta situación determinó que Jaime Escalante aprendiera como su primera lengua, el Aymara.

La cultura Aymara muestra un desarrollo de la matemática bastante avanzado para su época, lo cual se refleja en el parque Arqueológico de Tiwanacu. El científico boliviano Iván Guzmán de Rojas, es investigador en el campo de la lógica matemática y autor del Aymara Siwi Trivalente. Fue pionero en la investigación y desarrollo de sistemas en el campo de la ingeniería del lenguaje, creador de los sistemas de software ATAMITI (Sistema de traducción computarizado multilingüe) y YATIRI (Manejador inteligente de una base de

\footnotetext{
${ }^{2}$ http://www.la-razon.com/versiones/20090403 006686/nota 244 789331.htm
} 
datos), (Extraído del currículum de Iván Guzman de Rojas). En Internet encontramos "Científico boliviano desarrolla traductor multilingüe automático."3

Achacachi fue capital del señorío aymara "Umasuyus", que estaba ubicada en el lado este del lago Titicaca, en el altiplano Boliviano. Al ser invadidos por el Imperio Inca, los Umasuyus resistieron el embate. Es por eso que aún hablan su propio idioma: el aymara (Jaya mar aru = lengua antigua). No hablan el quechua como lo hacen los pueblos conquistados por los Incas. Achacachi fue fundada (como capital administrativa), el 24 de enero de 1826, casi un año después de la independencia de Bolivia (6 de agosto de 1825). Como la ciudad ya existía, el Decreto de la fecha es sólo un reconocimiento a esa existencia.

Jaime Escalante, al echar raíces indígenas entre los aymaras y adquirir como su lengua materna el Aymara, no sabía hablar el castellano, como él mismo dice: "Yo no hablaba el castellano, no sabía el castellano, porque mi idioma original en cierto modo era el aymara". De adulto Escalante decía: "los aymaras conocían matemáticas antes que lo griegos y lo romanos", es la traducción de "The Aymara knew math before the Greeks and the Egytians"4, citado por Schraff (2009, p.12).

La familia de Jaime Escalante en Achacachi, vivía en una casa con tres habitaciones alquiladas que distaba unos $100 \mathrm{~m}$. de la plaza, donde estaban las tiendas, la iglesia y la oficina de la alcaldía, en medio tenía unos asientos y algunos viejos cipreses (Mathews, 1988). En Achacachi, la mayoría de las casas se encontraban dentro de un patio y estaban construidas de adobe y azulejos (Mathews, 1988, p. 9).

Jaime Escalante, en su infancia, pasó mucho tiempo inventando sus propios juegos en el patio de su casa y jugando al futbol con su amigo Armando, que vivía en la misma calle, frente a la casa de los Escalante. Otras veces, Jaime acostumbraba salir a pasear con su abuelo, un profesor de filosofía jubilado (Mathews, 1988). El señor mayor delgado y alto como su hija, sacaba al nieto a pasear a la plaza después de la siesta y le distraía con juegos de palabras y de cuentas matemáticas. Jaime Escalante aprendió a leer

\footnotetext{
${ }^{3} \mathrm{http}: / /$ www.noticiasdot.com/publicaciones2002/0502/2305/noticias2305/noticias2305...

4 http://www.netaonline.org/ERFUTUREI.html
} 
y escribir como también la aritmética con su abuelo José Gutiérrez, como dice: "mi abuelo de parte de mi madre es el que me enseñó a leer las primeras letras, yo me acuerdo bien, cuando tenía cinco o seis años" (Escalante, 2007, párrafo 2). El abuelo le enseñaba todas las mañanas con una pajita y un libro que se llamaba "paso a paso". En el futuro, esta frase fue parte de su metodología de la enseñanza de las matemáticas con sus estudiantes de Garfield High School.

Jaime Escalante no fue a la escuela porque la tasa de escolaridad en Bolivia para ese tiempo era 1 de cada 12 niños en la zona urbana y 1 de cada 400 niños en la zona rural (Mesa et al, 2003). Jaime Escalante también pasó mucho tiempo en las fincas de su tía, él iba de una finca a otra y le gustaba pasear por las playas del Lago Titicaca (Escalante, 2007).

Cuando Jaime tenía nueve años de edad, su padre no regresó a casa una noche. Sara no sabía si estaba borracho o con otra mujer, pero realmente el problema no le importaba. Mathews (1988), registra algunos detalles del incidente. Cuando Jaime se levantó encontró a su madre ya preparada para el viaje, y le dijo: "estoy llevando a Olimpia, Bertha y José a La Paz". El muchacho confundido, vio el camión amarillo cubierto con una carpa, esperando a los pasajeros cerca de la plaza. Sus hermanas y el hermano pequeño ya estaban caminando hacia el camión. Su madre le dejó con un pedazo de pan y una advertencia de que debía quedarse y estar con su padre. Su madre y sus hermanos se trasladaron de Achacachi a La-Paz en ese camión, el medio de transporte más usual del pueblo a la ciudad. En la actualidad, son los pequeños autobuses llamados "Trufis".

Zenobio apareció en casa, padre e hijo se saludaron, cada uno parecía confundido por la situación. Luego, el padre discutió la situación con otros familiares. Después de un poco de vacilación, le dio a Jaime el ticket del autobús para La Paz y una indicación con la dirección de algunos familiares de su madre (Mathews, 1988).

Jaime Escalante se montó en el autobús y miro fijamente el altiplano a través del polvo espeso producido por las ruedas traseras del autobús, estiró la mirada en las diferentes direcciones, vio las montañas a la distancia y las 
ovejas y las vacas que comían pastos en los pantanos del Lago Titicaca. Así partió con destino a la ciudad de La Paz. En su mente había sentimientos encontrados, tristeza porque dejaba a sus amigos, especialmente a Armando, y por otro lado, en la ciudad encontraría a su madre y a sus hermanos.

El viaje de Jaime Escalante desde Achacachi hasta la ciudad de La Paz duró aproximadamente seis horas. Cuando el autobús estaba bajando por las colinas que rodean La Paz, pudo contemplar todo el panorama de la ciudad de aquel entonces, que es una de las características de ese descenso hasta el día de hoy. Finalmente paró el autobús, y Jaime descendió de un salto con su equipaje sobre la espalda, que era la poca ropa que llevaba atada en una manta (mantel). Caminó siguiendo las indicaciones de su padre, cuando llegó a la puerta, su madre estaba allí. Ella tomó a Jaime en sus brazos y lo abrazó.

Jaime Escalante era un niño obediente hacia sus padres, muy trabajador y educado con el rigor de la época. Siempre habló de usted a su padre, de tú a su madre, pero era un muchacho muy listo.

Al sur de Achacachi está el Parque Arqueológico Tiwanacu, una cultura andina preincaica. Por consecuente, es una cultura precolombina. Pero Escalante no llega a conocerla hasta que se encuentra en la Escuela Normal, estudiando para ser profesor de Matemática y Física. Sin embargo, Escalante menciona muchas veces la importancia de esta cultura en su metodología de la enseñanza de la matemática.

\section{Expectativas familiares}

Su madre era una mujer muy trabajadora y luchadora, de altos estándares, con gran visión y deseos de progreso para sus hijos. A pesar de que ganaba poco dinero como maestra de educación elemental, su corazón de madre siempre deseaba lo mejor para ellos. Ella, buscando la superación de su familia, llevó a sus hijos a la ciudad de La Paz en la primera oportunidad que tuvo de trasladarse, enviándolos con esfuerzo a estudiar. Jaime Escalante al respecto, dice:

Mi madre, por alguna razón, se trasladó de Achacachi a La Paz, para trabajar como profesora. En ese tiempo, yo tenía más o menos la edad de diez años. 
Al llegar a la ciudad de La Paz, empecé ir a la escuela elemental. Mi madre me matriculó en la "Escuela República de México" más conocido como la escuela "México" (Escalante, 2007, párrafo 3).

Esa mujer comprometida con la educación de sus hijos, consiguió que todos sean profesionales: Olimpia y Bertha son profesoras de Química y Filosofía respectivamente, José es administrador universitario, Raúl es banquero y Félix es consultor financiero (Mathews, 1988, p. 232). Félix, es un sobrino que formó parte de la familia.

Por otro lado, su padre (Mathews, 1988), era otra historia. El hombre había caído en el problema del alcoholismo que destruyó sus expectativas y capacidades de su potencial. Zenobio era un hombre fuerte y exigente con la familia, sin embargo no era fuerte con el alcoholismo. Jaime vio más de una vez, que Zenobio golpeaba a Sara y la ira del padre también cayó ocasionalmente sobre el pequeño niño. Jaime heredó la energía y algunos humores negros de su padre. Según Escalante (2007), en su padre sólo estaba el rigor y un trato violento y nada más. Él pensaba que su hijo sería un sastre o un zapatero, pero no pensaba que podría llegar ser un gran maestro.

La situación de la familia de Jaime Escalante parece coincidir con el Informe de Inclusión Social en España 2009 de la Obra Social Caixa Catalunya: "El nivel educativo de los padres es la principal clave de los logros escolares que cosechan sus hijos. $Y$ el perfil de los estudios de los progenitores, y sobre todo el de las madres, es el factor más determinante para el éxito escolar de sus vástagos" (Mari-Klose, 2009, p. 48).

\section{Sus primeros estudios}

Jaime Escalante reconoce que la primera escuela que uno tiene, es el hogar. En este sentido, su madre fue quién le motivó y le educó juntamente con su abuelo José Gutiérrez (Escalante, 2007; Mathews, 1988), porque no fue a la escuela hasta los diez años. Sus estudios formales empezaron en la escuela pública "Escuela México"; después pasó a estudiar en los colegios privados "La Salle" y "San Calixto", y terminó la educación secundaria en San Calixto. Posteriormente llegó estudiar para profesor de Física y Matemáticas en la 
Escuela Normal de La Paz. Siendo ya profesor de Física y Matemáticas obtuvo una beca de cooperación para Bolivia del gobierno de Estados Unidos para estudiar en la Universidad de Puerto Rico, donde estudió las asignaturas de ciencias y matemática.

\section{El nivel primario}

Cuando su madre tuvo la oportunidad de cambiar de trabajo de la zona rural a la zona urbana. Jaime llegó a la ciudad de La Paz a finales de su primera década. Fue matriculado por su madre en la "Escuela México" que está ubicada en la calle Graneros. Cuando Jaime se incorporó a la escuela por primera vez, los otros muchachos lo miraron fijamente y se rieron de él, porque llevaba la vestimenta del niño aymara que consistía en un pantalón y una chaqueta (cazadora) de bayeta (material elaborado por los mismos campesinos de la lana de la oveja y tejidos en un telar) y las abarcas (hechas de gomas de camiones) en lugar de zapatos. Como nos narra Escalante:

En la escuela estaba acomplejado. Primero por la vestimenta que llevaba, ya que estaba acostumbrado a la chaqueta y al pantalón de bayeta como lleva el indio de la tierra. Para mi era normal porque yo no había conocido otra cosa. Siempre calzaba abarcas del indio y no usaba zapatos. Segundo, porque los muchachos me miraban y se reían, diciendo: "éste es un indio, no sabe leer, no sabe escribir, no sabe nada". Y tengo que admitir que tenían razón. No cursé los tres primeros grados de educación elemental y pasé directamente al cuarto año con la consiguiente dificultad de entender lo que el profesor decía (Escalante, 2007, párrafo 5).

Al ser matriculado directamente al cuarto año de educación primaria por la edad que tenía, sólo contaba con lo que había aprendido en su hogar, lo que había aprendido con su abuelo José Gutiérrez y su madre en el pueblo de Achacachi.

Por otro lado, parece tener relación con el trabajo de Marta Samatán, abogada, profesora universitaria y escritora nacida en Santa Fe, Argentina. Samatán (1965), desarrolló la vida de cinco figuras clave del mundo de la educación, la ciencia y la literatura que tenían algo en común: habían aprendido sin maestro. La selección de autores recayó en Domingo Faustino 
Sarmiento, Benjamin Franklin, Juana Paula Manso, Florentino Ameghino y Gabriela Mistral. Las biografías de estas personas muestran cómo la tenacidad y la inteligencia de quienes, a pesar de las situaciones más adversas, lograron construir páginas imborrables en la historia de la humanidad. Otro trabajo es de Fernando Corbalán al escribir Galois Revolución y Matemática, que señala:

En sus primeros años Évariste y sus hermanas fueron educados personalmente por su madre, sin ir a ningún centro de enseñanza. Y esa sería la única educación de la hija, cuyo porvenir no contemplaba otra posibilidad fuera del matrimonio. Pero para los hijos habría que buscar otras salidas. En 1823, con doce años, Galois comenzó sus estudios fuera de la casa y dio inició así a una etapa importante de su vida, aunque bastante dura, porque las condiciones de los centros de la época no eran, en absoluto envidiables (Corbalán, 2000, p. 34).

Aunque no es exactamente igual, tiene algunas similitudes con la vida de Jaime Escalante. La diferencia es que Escalante adquiere raíces indígenas. La inmensa mayoría de los indios bolivianos, que eran los quechuas conocidos antes como los Incas, y los Aymaras sus adversarios asentados en colinas del altiplano entre las cordilleras de Los Andes y los Guaraníes en los llanos del oriente boliviano, tenían muy poca escolarización. Cualquier gobierno de turno era de los pocos descendientes de los españoles (Mesa et al, 2003). Bolivia era dos países distintos hasta el día de hoy, con la diferencia de que ahora el gobierno de turno es parte de los indígenas. Pero para Jaime Escalante, esta mezcla de culturas favoreció su visión de la vida, su espíritu de lucha y constancia, y le ayudó a alcanzar logros como profesor de matemáticas en los Estados Unidos.

Él indica que, cuando estaba en la escuela, tenía dificultad en entender lo que el profesor hablaba, pero esta experiencia de estudiante de escuela fue uno de los componentes que le ayudó para plantear su metodología de enseñanza de la matemática en el futuro.

Cuando su profesor usó la palabra carátula, le impresionó mucho y se animó a preguntarle el significado de la palabra. Al respecto narra de la manera siguiente: 
Una cosa que me impresionó mucho fue cuando el profesor nos mandó hacer una carátula. No le entendí y le pregunté: “¿Qué significa la palabra carátula?” Entonces él me explicó y me dijo: "es lo primero que ves cuando abres una carpeta para saber de qué es y a quién pertenece. Puso en la pizarra unos dibujos con motivos Tiwanacotas del altiplano y le pedí que me dejara copiarlo. Me ofreció algunos modelos, de los cuales copié tres o cuatro y los adorné con colores. Al fijarme en el trabajo y los materiales de mi compañero de a lado, me dí cuenta de que yo no lo podía hacer mejor y no presenté ninguno. Mi intensión era hacerlo mejor, creando mi propio estilo con algunos arreglos y presenté mi trabajo. El profesor me dijo: "está muy bien, sigue adelante" (Escalante, 2007, párrafo 6)

Una característica muy importante de Jaime Escalante, es que, en la escuela primaria adquiere la habilidad de hacer las cosas a su propio estilo. A pesar de que los recreos para él eran un sacrificio, muchas veces se quedaba en el aula, porque sus compañeros se reían y se burlaban de él. Hasta que un día Jaime fue a la casa y dijo a su madre "no quiero volver a la escuela, no quiero saber nada de la escuela". Su madre se esforzó en animarle y le preguntó, ¿quién se burla de ti?, pero Jaime estaba decidido a dejar la escuela. Él recuerda de la siguiente manera:

El recreo era un sacrificio para mí, porque mis compañeros se burlaban. Un día, al llegar a casa le dije a mi madre: "no quiero volver al colegio", y ella dijo: “¿alguien se burla de ti?", yo le dije: "no, y no quiero saber nada del colegio". La prima de mi madre le dijo: "cámbiale la ropa para que vaya como sus compañeros". Yo no sé que sacrificios hizo mi madre, me puso unos zapatos que no podía caminar, un pantalón de tela y una chamarra (cazadora) que le regaló la directora de su colegio. Con eso ya me identificaba con mis compañeros. Poco a poco, con el paso del tiempo, pasé al quinto grado de educación elemental y tuve un profesor muy bueno y aprendí el idioma, lo que me dio cierta confianza. (Escalante, 2007, párrafo 7).

Luego, ya se identificó con ellos y no tardó en impresionar a todos con su habilidad para la aritmética, así como el futbol, el baloncesto y particularmente en la pelota de mano, y con el transcurso del tiempo, se fue adaptando poco a poco y consiguió pasar a quinto, en ese curso tuvo un profesor muy bueno, además aprendió el idioma y tenía más confianza 
(Escalante, 2007). Además, La Paz, era un jardín de encanto después de la simplicidad de Achacachi con su única plaza (Mathews, 1988).

Sin embargo, ya de adulto decía: "The day someone quits school he is condemning himself to future of poverty", su traducción sería: "El día que alguien abandona la escuela se está condenando a si mismo a un futuro de pobreza." En la escuela, Jaime había adquirido la reputación como genio y peleador de la calle, se resistió a la dura labor académica, salvo a las Matemáticas, la Física y las Ciencias, donde encontró nuevos problemas difíciles de resistir como a las salteñas (empanadas) calientes. Cuando Jaime estaba en el último grado de la educación primaria, es decir, en el sexto grado, su profesor de curso Humberto Bilbao, conocido como Bilbao la vieja, al ver que Jaime terminaba junto con él todo lo que explicaba, le asignó una tarea extra en relación a sus compañeros. Escalante narra este episodio de la manera siguiente:

Cuando el profesor explicaba algo, yo terminaba junto con él. Un día me llamó y me dijo: "Aquí tienes una cartulina, corta dos de este tipo y tendrás un rectángulo, la recta que une, no me dijo vértice, este punto con este punto se llama diagonal; corta y traza las diagonales y cuando termines me avisas. Yo corté y acabé pronto, y le dije: "ya esta listo" y él me dijo: "te dije que cortaras y trazaras las diagonales, ¿has hecho eso?", "Si, he hecho eso". No miró ni el papel ni nada, y me dijo: ¿cuántas diagonales has trazado? Le dije "ocho”. Él me dijo: “¿ocho?, cómo vas a sacar ocho, no sabes lo que dices. Haber, muéstrame, trae las cartulinas". Saqué las cartulinas y le dije: "aquí tienes dos y al otro lado dos, son cuatro por cartulina, entonces cuatro y cuatro son ocho", él quedó sorprendido con esta respuesta. (Escalante, 2007, párrafo 9).

Este mismo profesor se preocupaba por sus alumnos más allá de las aulas, se interesaba en el futuro de sus estudiantes y tenía altas expectativas sobre Jaime Escalante, y en alguna medida fue el que orientó su formación, dando algunas sugerencias a su madre:

Cuando estaba en último curso de la escuela elemental me identificó el profesor, Humberto Bilbao (conocido como Bilbao la Vieja), y me dijo: 
"tienes habilidades y hay que explotarlas, pero tienes un problema, en primer lugar el castellano no lo hablas bien, pero eso se puede solucionar, con lectura y con otras cosas. La otra cuestión es un poco más peligrosa, y es que eres muy inquieto. No estas en un solo lugar, estas moviéndote y haciendo cosas y eso tienes que corregirlo. Primero, es parte de la disciplina. Segundo, no está de acuerdo con lo que se pide aquí. Quiero hablar con tu madre". Entonces lleve a mi madre y le aconsejó que me educara para no ser tan salvaje". Mi madre me llamo la atención. (Escalante, 2007, párrafo 8).

Jaime Escalante reconoce que fue travieso, y dice: "yo entiendo a los muchachos, ya que fui expulsado más de cinco veces de la escuela" (Escalante, 2007, Hanson, 2003).

Este maestro le dijo: "quiero hablar con tu madre". Entonces Jaime llevó a su madre donde el profesor Bilbao. Éste le pidió a su madre "que le instruyera en casa para que no sea tan salvaje". Le contó el incidente arriba mencionado y le sugirió que lo llevara a un colegio donde puedan ayudarle a explotar sus potenciales.

\section{Nivel Secundario}

Su madre, haciendo un gran esfuerzo lo matriculó en el Colegio "La Salle". Sin embargo Jaime fue echado del colegio, porque tuvo un inconveniente con el profesor de matemáticas, que era un cura. Escalante (2007), nos narra:

La educación primaria la hice únicamente en la Escuela "México", de la calle Graneros. El nivel secundario lo cursé en el Colegio "La Salle", pero allí tuve inconvenientes, pues tuve una mala experiencia con el profesor de matemáticas por su vocabulario agresivo, al parecer, motivado por una mueca mía. Con el borrador que tenía en su mano, me lo lanzó a la cara, diciendo: "no te rías de mi". Me indigné, pues no creía haber hecho algo reprobable. Mi rebeldía hizo que agarrara el tintero y se lo lanzara al cura. Me echaron del colegio porque dijeron que era un insolente irrespetuoso y otros adjetivos. $A$ raíz de esto, mi madre hizo un enorme esfuerzo para enviarme a estudiar con los jesuitas en el Colegio "San Calixto". (Escalante, 2007, párrafo 4). 
Posteriormente su madre, haciendo un gran esfuerzo, logró enviarle al Colegio San Calixto. Un colegio dirigido por los Jesuitas. Éste era uno de los Centros Educativos con prestigio en el nivel secundario en La Paz. El edificio del colegio está ubicado cerca del palacio del presidente de Bolivia, conocido como el Palacio Quemado.

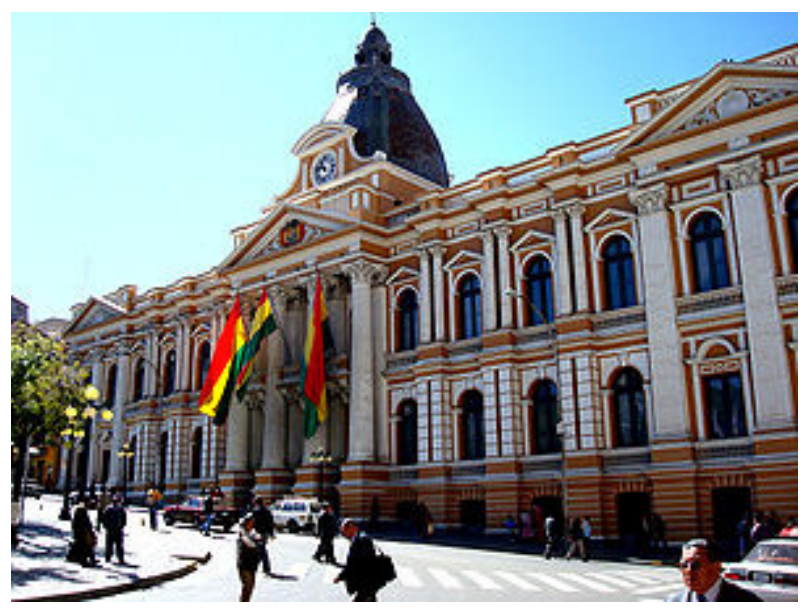

El palacio quemado de La Paz

El palacio de gobierno recibe este nombre desde que fue incendiado el 20 de marzo de 1875 por los partidarios de Corral, en contra del presidente Tomás Frías. Al respecto, Mesa et al. (2003) señalan:

Mientras sucedía esto, en La Paz se fraguaba un complot que estalló el 20 de marzo de 1875 dirigido por partidarios del presidente Corral. 133 hombres leales a la presidencia de Frías se parapetaron en el palacio de gobierno comandados por Mariano Baptista. Entre los defensores hubo pronto bajas importantes, como el coronel Joaquín Peña y el coronel Jofré. El jefe de la insurrección Resini decidió terminar pronto el ataque y desde los muros en construcción de la catedral, sus hombres lanzaron antorchas y trapos encendidos que lograron quemar parte de la cubierta, especialmente la madera que sostenía la teja. Los defensores tuvieron que abandonar paulatinamente el edificio. Mientras tanto bajó a la ciudad la fuerza del coronel Granier que trajo auxilio desde Viacha. Ambas fuerzas del orden la de los Colorados y la recién llegada, triunfaron sobre los sitiadores del palacio y hubieron muchos muertos que al día siguiente exhibieron en la plaza en número de 130. El palacio había quedado completamente destruido en su interior, salvándose tan solo las cuatro fachadas laterales y las columnas del patio principal. Desde entonces se lo ha llamado el "Palacio Quemado". (p. 439). 
Desde el exterior, el edificio del colegio presentaba paredes llanas de adobe enyesado, lanzando sombras en las calles estrechas. Mientras que cualquiera que entra, descubre un mundo de jardines escondido del sol, las fuentes efusivas, las placas conmemorativas y estratégicamente situadas y las canastas de baloncesto (Mathews, 1988).

Jaime estaba muy encantado en su nuevo colegio. San Calixto era para él, el cielo, un lugar donde sus habilidades y su pasión por el conocimiento humano podrían encantar a los sacerdotes y permitir perdonar muchas de sus transgresiones. El colegio tenía aproximadamente 750 alumnos (Mathews, 1988).

Escalante era muy bueno en la aritmética y en los deportes. Era el líder de sus compañeros de clases, pues era muy inteligente. La pelota de mano seguía siendo el primer amor de Jaime. Una pared de 12 metros de altura estaba en el extremo norte del patio del colegio. Durante el recreo (descanso pedagógico) jugaba muy bien a la pelota de mano en el frontón. Un día colocó una ramita en el timbre del colegio para bloquear el sonido, y de esta manera evitar que sonara el timbre, y así poder prologar el tiempo del descanso.

En San Calixto, su reputación de buen jugador y peleador había inspirado varias peleas organizadas. Un día, su amigo Roberto Cordero, un flaco pensativo y ayudante de campo, le dijo:

- ¡Eh, Jaime, ese llocalla de afuera, dice que te puede pegar! - dijo Roberto.

- ¡Oh!, me gusta eso. Eso es muy bueno. ¿El tiene ganas, no?

La palabra "ganas" significa "impulso" o "deseo". Fue la favorita de Jaime Escalante años más tarde, y el centro de su visión como maestro. Esto es lo que debe tener un maestro para animar a sus estudiantes.

Jaime Escalante participó en los concurso de matemáticas y física representando a San Calixto, consiguiendo las primeras posiciones.

Cuando vino los concursos de Matemáticas y Física, sobre todo los de Física, yo ocupaba el primer lugar. Yo no necesitaba prepararme, porque trabajaba con el padre Descottes, que era el encargado del sismógrafo San Calisto, existente hasta el día de hoy. Yo iba investigando por mi cuenta. Y vi que 
realmente era importante investigar y prepararme para la vida de manera autodidacta. (Escalante, 2007, parráfo 12).

Por sus habilidades académicas y deportivas, se convirtió en un líder de un grupo de estudiantes. Como líder tenía un grupo de compañeros que compartían hasta la comida. Ellos se organizaban para hacer las tareas del colegio en el fin de semana, especialmente los sábados que comenzaban a las 9:00 de la mañana hasta las 7:00 de la noche, entre Jaime y otros especialistas que disertaban el tema (Mathews, 1988). Así aprendió a trabajar en grupo.

Su madre se había acostumbrado al comportamiento errático de su hijo. Ella pensó que era inteligente, pero demasiado imaginativo. La imaginación es la habilidad de formar imágenes mentales. Además, se debe favorecer el desarrollo de la imaginación en los alumnos. Claxton presenta el siguiente principio:

Cuando la imaginación se vuelve más disciplinada, más se convierte en una fuente valiosa de intuiciones e hipótesis que pueden ser, al mismo tiempo, más seguras y más osadas que las del puro ensayo y error. (Claxton, 1994, citado en Alsina, 2007, p. 10).

La imaginación juega un rol muy importante en la ciencia. Einstein lo expresó explícitamente:

La imaginación es más importante que el conocimiento. Mientras que el conocimiento se limita a todo lo que ahora conocemos y entendemos, la imaginación abarca el mundo entero, todo lo que en el futuro se conocerá y entenderá (Citado, por Alsina, 2007, p.11)

Cuando llegaba el período de entrega del boletín de notas, Jaime las barajaba de un lado a otro, indicando: "Aquí está el de Bertha mamá, aquí está el de Olimpia y aquí está el mío". Sus manos rápidas, afiladas en el frontón, podían cambiar las tarjetas ante una pequeña distracción sin que sospechara Sara. Ella, al encontrar las calificaciones reales de Jaime, dio su propio discurso: "Yo sé que tú piensas que eres un cómico. Yo conozco cómo son tus chistes. Yo sé eso. Pero ellos no van a entenderlo. Mira esto". Mirando las calificaciones y las observaciones en la libreta, Jaime leyó las observaciones a su madre: "Jaime habla demasiado. A Jaime le gustan sus chistes." Continuó el discurso de su madre: "Esta es una recomendación mala. Las personas no van 
a decir que usted hace esto porque tiene un buen sentido del humor. Ellos van a decir que este tipo no es educado. O lo peor, van a culparme (Mathews, 1988). Según Escalante (2007), ella hizo una pausa, un truco para que Jaime no se olvidara: "esta es la última vez que voy a firmar esto. La próxima vez que pase, voy a enviarte a la escuela con el tío Arturo".

Jaime Escalante era muy inquieto y para él era muy difícil estar sentado y escuchar al profesor. Años mas tarde, recuerda su periodo estudiantil, y dice: "yo era muy activo, no podía estar sentado por más de dos minutos. Era hiperactivo" (Escalante, 2007).

De acuerdo a Mathews (1988), Sara Escalante se trasladó con su familia a una casa a la Calle Graneros. Era una calle muy empinada, que proporcionaba una diversión interminable para Jaime. Él estaba fascinado con los experimentos y se estaba haciendo un joven científico. Aunque Jaime confiaba sus sueños a su hermana mayor, Olimpia, su hermana menor, Bertha, era su compañera de muchos experimentos. Jaime Escalante, estaba muy interesado en descubrir como funcionan las cosas. Construyó un carro para bajar la calle Graneros. Bertha era su copiloto. También realizaba experimentos con la electricidad. De niño y de adolescente, era muy creativo y travieso.

A los 15 años Escalante descubrió su amor por la física. Un nuevo profesor entró en la vida del muchacho y congeniaron rápidamente. El Padre Descottes de Francia tenía un sentido del humor seco y una manera mágica de enseñar que le encantó a Jaime.

El profesor utilizó motores eléctricos para explicar el péndulo de una manera viva a la clase. No dijo exactamente cómo la ciencia trabaja, solo se lo mostró. Jaime se interesó en las cosas que su maestro hacía. El padre Descottes había traído buenos libros antiguos de matemática y ciencias para enseñar más allá del nivel del curso de Jaime. El muchacho se ofreció para guardar y limpiar el laboratorio y conseguir así que el profesor le prestara los libros. Tan pronto como tuvo los libros, Jaime leyó el material que le facilitó su profesor (Escalante, 2007). 
Su padre falleció cuando Jaime tenía 18 años, estaba terminando su educación secundaria, o el bachillerato.

\section{Nivel Superior}

Jaime Escalante tenía el sueño de ir a la Facultad de Ingeniería, pero la situación financiera no era favorable. Además, ya fallecido su padre, la única que tenía un sueldo era su madre. Consiguió algunos trabajos mientras pensaba qué sería de su vida. De pronto decidió estudiar en la Escuela Normal de La Paz. Lo siguiente es la descripción que otros han hecho de Jaime Escalante: hace casi sesenta años atrás, Jaime Escalante fue un brillante estudiante prometedor de la Escuela Normal Superior de La Paz, Bolivia, la escuela que prepara a los jóvenes bolivianos para la profesión noble de enseñar. Él fue a esta institución educativa para su formación de maestro de Física y Matemáticas.

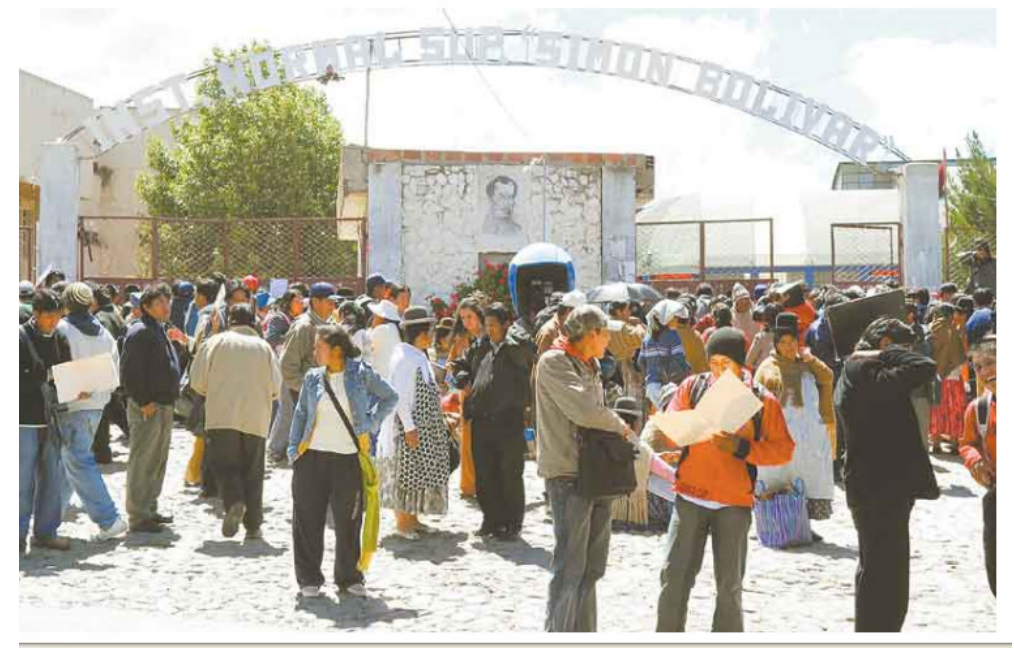

Foto: Periódico de La Razón. La Paz, Bolivia. 27-09-10

Mathews (1988), señala que el edificio contaba con varias aulas, pero había problemas incesantes con el agua y la electricidad. Varios meses después de que llegara Jaime Escalante, el portero se quejó a un grupo de estudiantes que él no podía conseguir la luz para trabajar apropiadamente. Escalante se ofreció a levantar el tejado y verificar las conexiones. Él corrió por las hojas empinadas de estaño (calaminas), como una pequeña tormenta del altiplano, rasgando fuera los alambres, tirando los cables, cortando y empalmando. Colgaba del borde. Sus pies daban tirones en el aire en busca de 
una posición estable, y después retrocedió para obtener seguridad. Muchos estaban observando lo que hicía Escalante, y el Decano dijo: "Usted se parece a un gato allí, Jaime" (Mathews, 1988).

Escalante, al llegar a Escuela Normal, se encontró con una forma de enseñanza teórica, y no estaba de acuerdo con esa forma de enseñanza. Además, vió que los alumnos tampoco respondían, entonces lo relacionó con su experiencia en la primaria.

Cuando fui a la Escuela Normal, no estaba de acuerdo con la forma en la que los profesores daban las clases. La manera teórica de impartirlas me hizo pensar que no tendría utilidad en el terreno práctico. Así, pasaba de curso llevando mis equipos y materiales para mostrar de forma práctica lo que enseñaba. Pensaba que a mis compañeros les pasaba lo mismo que a mí en primaria. Si el alumno viene sin ninguna base de lenguaje ni preparación, no va responder, porque el alumno tiene que entender para responder. Pero los alumnos de este curso, no respondían, bien por no tener la preparación adecuada, o no tiene voluntad de hacerlo. (Escalante, 2007, párrafo 19)

Jaime Escalante, vuelve a encontrar a su profesor de escuela primaria, Humberto Bilbao. Ahora Bilbao ya era el catedrático del Instituto Normal Simón Bolívar. Había ascendido a la educación superior y reconoció y recordó con afecto al muchacho pequeño con imaginación ardiente y el talento por la travesura creativa (Mathews, 1988).

El profesor de matemática, específicamente el de didáctica de la matemática me llamó y me dijo que quería hacer una instalación para demostrar la fotosíntesis y no sé que otras cosas más, me pidieron que le ayudara, entonces yo le ayudé, además me encantaba a mí. (Escalante, 2007, párrafo 20).

Mientras Jaime Escalante cursaba el segundo año de formación profesional para ser maestro de Física y Matemáticas, no había tenido todavía ninguna asignatura de técnicas de enseñanza. El profesor de matemáticas, que ya era autoridad en el Ministerio de Educación, le mandó para enseñar Física en el Instituto Americano, pues había una plaza vacante a causa de la muerte del profesor de Física (Mathews, 1988). El año siguiente hubo muchos levantamientos y la revolución, a causa de esta situación en 1952 tuvo más motivos para faltar, porque el profesor Bilbao le consiguió trabajo como 
profesor de matemáticas del Colegio Nacional Bolívar y fue enviado a fundar el colegio Gualberto Villarroel. Escalante tenía la carga completa en el colegio Villarroel y las horas extras en el colegio Bolívar (Escalante, 2007).

\section{Postgrado: Universidad de Puerto Rico}

Una vez concluida su formación de profesor de matemáticas y física, trabajando en diferentes establecimientos. Jaime Escalante organizó el Primer Encuentro de Profesores de Física en Bolivia. Esto y otras cosas, le permitió obtener una beca para estudiar un postgrado en la Universidad de Puerto Rico. Allí estudió Ciencias y Matemáticas. Al concluir los estudios retornó a Bolivia.

Al final del curso visitaron la Casa Blanca los becarios del proyecto de cooperación del gobierno de los Estados Unidos para Latinoamérica. Este curso fue exactamente un año antes de que Escalante partiera a los Estados Unidos.

\section{Origen de su decisión}

Escalante no pensaba en ser maestro, quería ser ingeniero. Después de la muerte de su padre, y por la insuficiencia financiera de su madre para pagar sus estudios, apartó la idea de asistir a la Facultad de Ingeniería. Encontró algunos pequeños trabajos que sabía hacer, mientras pensaba en su futuro.

En mayo de 1949, Jaime Escalante, a sus 18 años, fue reclutado para el servicio militar a causa de las huelgas y levantamientos de la izquierda en Sucre, Potosí, y otros pueblos del valle del sur de Bolivia, que obligó al presidente interino Mamerto Urriolagoitia a tomar un control militar (Mathews, 1988). A él y a sus amigos les gustó la idea de la aventura. El reclutador les dijo: "aquí estan sus uniformes y tienen una hora para cambiarse". Jaime Escalante no avisó a su madre ni dejó una nota.

Él lo cuenta de la siguiente manera: "Después de terminar la secundaria en San Calixto, fui al servicio militar obligatorio, y al salir fui a estudiar para ser maestro de Física y Matemáticas en la Escuela Normal de La Paz" (Escalante, 2007). 
Según Mathews (1988), encontramos algunos detalles más al respecto. Después de salir del servicio militar obligatorio, Jaime Escalante se encontró con su amigo y compañero de San Calixto, Roberto Cordero en la cafetería favorita del Prado. Compró cuatro salteñas y una cerveza, pero no estaba feliz, mientras que su amigo intentaba hacerle cambiar de humor, diciéndole: "Jaime, a ti que te gusta siempre trabajar con la Física, Matemáticas y Química. ¿Por qué no te inscribes en la Normal Superior, para ser maestro?" - Dijo Jaime "Ahhh, no. Yo no quiero eso".

Cordero insistió diciendo: "Mira, es una oportunidad. Algo para intentar. Puedes cambiar de idea si no te gusta. Yo voy a hacer la prueba porque quiero ser maestro de Química. Vamos los dos".

Jaime Escalante suspiró. Y dijo: "De acuerdo".

Según Mathews, Jaime raramente estaba en desacuerdo con Roberto. Su amigo era inteligente. Así, ambos muchachos de San Calixto fueron al examen de selectividad para la Normal Superior. La prueba fue fácil para ambos. Después de algunos días, llegó la carta de aceptación y empezaron a asistir a la Normal Superior en la Calle Campero. (Escalante, 2007).

\section{Influencia familiar en su vocación}

Los antecedentes profesionales educativos de Jaime Escalante se encuentran en la línea de la familia materna. Como ya señalamos, su madre era profesora, su abuelo materno José Gutiérrez fue profesor de filosofía; su tío Elizardo Pérez Gutiérrez, fundador de la primera Escuela Normal Rural de Warisata (Mesa et al, 2003; Jara y Sargárnaga, 2008; Escalante, 2007) y su tía Candelaria Pérez Gutiérrez, quien inició el programa de desayuno escolar (Escalante, 2007; Jara y Sagárnaga, 2008, Julio 6). Al recordar su infancia, Escalante cuenta un incidente de la manera siguiente:

Mi madre era profesora y aprendí mucho de ella. Cuando era niño mi pidió que la ayudara a llevar una cesta de naranjas a la escuela. No me gustaba la idea, porque yo quería jugar. Pero ella, cogía una naranja y hacía referencia a la esfera. Después cortaba alrededor y decía: "este es el circulo", cortaba por la mitad y hablaba de la simetría. Vengo además de una familia de educadores. 
Soy sobrino de Elizardo Pérez Gutiérrez, el fundador de la primera Normal Rural de Warisata, quien trabajó junto a su hermano Raúl. Ellos enseñaron allá a los campesinos aymaras que no conocían el idioma. Yo veía que tenían que enseñarles sonidos y buscar maneras de hacerse entender. Comprendí la paciencia que hay que tener. Y mi tía Candelaria hermana de Elizardo, inició los programas de desayuno escolar en Bolivia. (Escalante, 2007, párrafo 14).

En las conferencias que ofrecía en diferentes lugares o en entrevistas, le preguntaban sobre las influencias o motivaciones en concebir su estilo de enseñanza, y siempre señala a su madre como la persona que le inculcó la responsabilidad. Por ejemplo, en una entrevista Hanson (2003), hace la pregunta: ¿Hay alguien que influenció su vida cuando era niño, alguien que cambió su vida? La respuesta de Jaime es: "mi mamá."

Por otro lado, reconoce que proviene de una familia de educadores, señala a Elizardo, Raúl y Candelaria. De acuerdo a Mesa y colaboradores (2003), Elizardo Pérez Gutiérrez es considerado como el gran pedagogo, maestro y verdadero apóstol de la educación:

(...) surgió así una de las iniciativas más importantes para la educación. La tradicional visión prescindente o cuando menos discriminatoria con la educación indígena, tomó un rumbo nuevo con la obra del gran pedagogo Elizardo Pérez, maestro y verdadero apóstol de la educación. Pérez cambió radicalmente las ideas sobre la educación indígena. Dijo que ésta debía nacer de la realidad del campo y de lo que más importa de la cultura aymara y quechua. Para aplicar sus ideas creó la escuela de Warisata en el pueblo de ese nombre (cerca de Achacachi en el departamento de La Paz) el 2 de agosto de 1931. Fue una experiencia de educación a educadores, que llevó a la práctica por primera vez la idea de que el indio era sujeto y no un objeto educativo, que había que tomar los elementos del pasado prehispánico y hacer de la escuela un núcleo productivo. Warisata cambió la mentalidad general en relación al tema tan crucial y a pesar de su destrucción en 1941, sobrevivió en la medida de la reforma educativa de 1955" (Mesa, et al, 2003, p. 570).

Su abuelo José Gutiérrez, jugó un rol importante en la vida del niño. Escalante gustaba pasar tiempo junto a su abuelo. Además, el abuelo le enseñó las primeras letras y los números a Jaime con una paja y un libro que 
se llamaba "paso a paso," y algunas veces a través de juegos y preguntas de ingenio, mientras paseaban por la plaza del pueblo, después de la siesta.

Además, coincide su nacimiento con el año en que se hizo efectiva la reforma educativa gestionada por Daniel Sánchez Bustamante ${ }^{5}$, en el gobierno de Carlos Blanco Galindo (1930 - 1931), registrados por Mesa et al (2003).

En esta reforma educativa se insertó el concepto de que la educación es la más alta responsabilidad del estado y se puso el énfasis en la educación indígena. La educación indígena tomó un rumbo nuevo con la obra del gran pedagogo Elizardo Pérez Gutiérrez ${ }^{6}$, maestro y verdadero apóstol de la educación.

\section{Maestros que influyeron en su vocación}

Jaime Escalante, que transformó muchas vidas de sus estudiantes, también recibió el impacto y la influencia de sus profesores. Al respecto, indica que fue alumno de más de doscientos profesores, con quienes ha pasado clases en Bolivia, Estados Unidos y otros países. Recuerda perfectamente a cada uno de ellos con nombres y apellidos. Pero de otros se ha olvidado. De aquellos que no han hecho ningún impacto. Escalante señala que no todos los profesores tienen el mismo impacto. Uno de los profesores que tuvo muy de cerca, es su profesor de primaria, Humberto Bilbao. Le impactó con su palabra "carátula," y dibujos con motivos Tiwnacotas, una cultura preincaica que fue señalada en apartados anteriores. Este profesor le dijo que le enseñaría algo que recordaría toda su vida: las fracciones; aunque Jaime ya tenía una representación clara de las fracciones como resultado de las explicaciones de su madre con naranjas.

Jaime Escalante suele decir: "el mejor maestro que uno tiene es la experiencia," pero dice que uno recuerda a los profesores por dos motivos: a unos por las cosas positivas, y a otros por las cosas negativas, pero de otros no se acuerda nada, porque no dejaron huella en su vida (Escalante, 2007),

\footnotetext{
${ }^{5}$ Daniel Sánchez Bustamante (1987 - 1933). Abogado, escritor y periodista, pero por sobre todo de se ocupó de temas referidos a la educación.

${ }^{6}$ La actual Ley de Reforma Educativa es denominada, Ley de Reforma Educativa Avelino Siñani y Elizardo Pérez .
} 
aunque no existe consenso universal en qué consite una buema enseñanza (Wilson, Cooney y Stinson, 2005).

A parte de su madre, indica a familiares y profesores. Entre sus familiares, Escalante señala a sus tíos Elizardo y Candelaria Pérez. Entre algunos de sus profesores, a Humberto Bilbao, su profesor de primaria y mentor en la Escuela Normal, al padre Descottes, su profesor de San Calixto, que le encaminó en su pasión por la física y también fue alumno del destacado profesor matemático norteamericano Louis Leithol.

Si, mi profesor de primaria, Humberto Bilbao. En el último curso de primaria, repitió la palabra carátula con motivos Tiwanacota, y me dijo que había hecho una bonito carátula y que íbamos a hacer un viaje imaginario a Tiwanacu. Le pregunté qué quería decir con imaginario. Él me dijo, piensa que vamos a salir de aquí y llegar a Tiwanacu. Nos llevó a un monumento que estaba en Miraflores, (ahora ha vuelto a Tiahuanacu), en la zona del estadio de fútbol Hernando Siles, que es el monolito de Vennet (en honor a su descubridor). Miré que tenía aproximadamente siete metros, y me dijo: "esto han hecho los Tiawanacotas, ¿crees que esta pieza tan grande lo han puesto ahí?, no, es una sola pieza. Si te fijas en los ojos, parece haber llorado. Yo le dije: "¿con que tipo de cincel hacían esto?, me dijo: "nadie puede decir, porque no había ningún instrumento". Te fijas en la proporción y la potencia. Yo quedé asombrado con lo que él me explicaba y me dijo, que realmente eran matemáticos y tenían el concepto de cero, pero yo no le daba importancia. Nada tenía para enseñar. Esto me impresionó y él me dijo: ¿qué forma geométrica tiene esto? Yo le dije: "prisma", ¿de qué base vas a decir? Yo le dije: "cuadrada" y el me dijo: "más o menos por ahí". ¿La mano también es prisma? Yo dije: "si éste es de una sola pieza, entonces tiene que ser prisma". (Escalante, 2007, párrafo 16).

\section{Experiencias iniciales como maestro}

Cuando Jaime Escalante estaba cursando el segundo año de la carrera del Magisterio en la Escuela Normal, Humberto Bilbao, su maestro de primaria y posteriormente profesor en la Normal, trabajaba en el Ministerio de Educación y se encargaba de reclutar maestros. Cuando murió un profesor de Física del 
Instituto Americano, Bilbao fue a la Normal en busca de un reemplazo e invitó a Jaime (Escalante, 2007; Mathews, 1988).

Los graduados de la Escuela Normal en Física eran muy pocos. En la clase del último año había dos mujeres, y tenían bastantes problemas en completar sus requisitos de graduación. De los cursos inferiores, había dos muchachos que estaban dispuestos a ayudar, y le hicieron pensar en Escalante, ya conocido como Einstein.

Cuando Bilbao lo llamó, Escalante tenía 21 años. Él nunca había tenido un curso de técnica de instrucción porque recien había empezado su segundo año de la Escuela Normal, mientras cursaba las asignaturas de ciencias y matemáticas (Escalante, 2007; Mathews, 1988).

Bilbao le pregunto: “¿Usted puede enseñar?” Según Mathews (1988), Escalante olió los pesos. Escalante dijo: "si usted quiere, yo puedo enseñar. Ningún problema". Bilbao le dijo: "Vamos a ver al Director". Así comenzó a trabajar antes de terminar su formación de maestro en el Instituto Americano.

El Instituto Americano, establecido en 1907 por el misionero metodista americano Francis M. Harrington, estaba en la calle Landaeta, en la cuesta noroeste de la ciudad. Escalante no tenía ninguna idea dónde se había quedado el maestro anterior, inaccesible en su tumba. Tendría que enfrentar una clase de muchachos y muchachas, una innovación de los administradores de la educación americana, al cual él no estaba acostumbrado. Jaime Escalante, sin ninguna clase de técnicas de instrucción (Mathews, 1988), estaba fuera de lugar. Acababa de empezar el segundo año de Normal y los cursos de técnicas de instrucción no empezarían hasta el año siguiente (Escalante, 2007; Mathews, 1988).

El director Sr. Yoder, parecía apenado por esta noticia. Dijo el director a Escalante: "Usted sabe que debe prepararse aquí. Conocer la materia y los estudiantes, aún cuando ésta es una asignación temporal". Escalante dijo: "Oh, si. Yo se todo eso, señor," dijo, mientras miraba el suelo. El Director había desafiado el canon de Escalante, su confianza en sus propias habilidades. Él dio una mirada determinada al hombre, y le dijo: “¿puedo pedir un favor, señor?" por supuesto, dijo el Director. 
Jaime dijo: "la próxima semana voy a invitarle a ir a mi clase. Pero no esta semana, déme una semana".

Jaime Escalante tenía 21 años de edad y parecía uno de los alumnos mayores del colegio. No tenía ningún libro de texto y sus estudiantes tampoco. Tendrían que estudiar las notas que tomaran de la conferencia del profesor. Él reunió su propio surtido de libros y las notas personales que él había guardado de las clases de San Calixto (Mathews, 1988), y comenzó a enseñar como le habían enseñado.

Su primera clase en el Instituto Americano pareció ser realmente un desastre porque siguió el estilo que le habían enseñado en la secundaria (Escalante, 2007). Jaime Escalante cogió un pedazo de tiza y empezó a escribir en una pizarra grande. Las palabras, los diagramas, los resultados experimentales. Después de años se preguntaría, por qué ellos pudieron prestar algo de atención. El mayor tiempo de la clase estaba de espaldas a los alumnos, sólo dos o tres veces les daría la cara para ver si estaban atendiendo. Miraba a menudo el reloj, para ver cuando llegaba al final de la clase. Escribió algunos problemas para la revisión, y dijo: "hasta mañana," y salió.

Aprendería en el futuro que una simple muestra de competencia le bastaría normalmente al principio de la clase. Años después, cuando se encontró con un sistema americano rico en libros de texto, se alegró porque había aprendido el valor de enseñar de sus propias notas. En Bolivia, nunca tuvo la oportunidad de cambiar de una editorial a otra, cuando las escuelas americanas lo hacen menudo.

Según Mathews (1988), su técnica de clase mejoró. El primer día de clases llevó unas notas. El segundo día, en acto típico de arrogancia, sólo llevo una hoja con veintiocho nombres. Memorizó la lección y la practicó de camino a la escuela. Cada fin de semana dedicaba horas ideando sus explicaciones y ejercicios. Aunque su presentación estaba tiesa y sin humor, sus estudiantes escuchaban.

A inicios de los años 50, el último examen de la escuela secundaria, aunque corto y limitado, se daba casi siempre con otro instructor, normalmente de otra escuela. (Mesa et al, 2003). Este examen estaba acercándose. No 
podía controlar que preguntas le harían, y encontró un incentivo poderoso para la enseñanza cuidadosa. (Mathews, 1998).

Cuatro semanas antes de que el supervisor llegara, Escalante hizo una prueba de práctica. Más de diez de sus veintiochos estudiantes, fallaron. Estaba frustrado y aplastado. Había entregado su alma al curso, había faltado a clases de la normal, se había privado de sus tardes y fines de semana de juegos de pelota de mano, había llenado tanta información en cada minuto de la clase, había llevado a sus estudiantes más allá de lo que el supervisor exigía, pero les había dejado débiles en los elementos esenciales. Pensaba que si esto llegaba a oídos a los profesores de la Normal, todo se estropearía. Llamó a sus alumnos y se dirigió a la clase: "Miren, muchos de ustedes están fallando. Nosotros tenemos que hacer algo. Yo quiero que todos regresen todos los martes y jueves a las cuatro. Conseguiremos ponernos en forma”. Los alumnos fueron para las clases y cuando vino el supervisor para la evaluación, las respuestas saltaron de sus bocas.

La Revolución que vivió Bolivia en 1952 es un hecho fundamental en la historia contemporánea, pues cambió el país, al punto que es imposible comprender la Bolivia de hoy sin entender el significado de la Revolución.

Mesa et al. (2003), hacen las siguientes consideraciones:

Bolivia había llegado en 1952 a un punto de no retorno. Las ideas liberales acuñadas a fines del siglo pasado habían dado de sí todo lo que podían dar. El país había experimentado un modelo con sus virtudes y defectos. La receta estaba agotada.

El diagnóstico de lo que representó el llamado viejo orden lo daba en algún sentido el censo que hizo el gobierno de Urriolagoitia en 1950. el país casi había duplicado en cincuenta años. De 1,8 millones pasó a 3.019.031 habitantes. La población urbana creció, pero Bolivia seguía siendo un país eminentemente rural. Si en 1900 vivían en el campo casi el 90\% de los bolivianos, en 1950 el porcentaje de la población rural era el 66\% contra el 33\% de población urbana. Sin duda el fenómeno mas importante lo vivió La-Paz que pasó de 60.000 habitantes en 1900 a 321.073 en 1950; un aumento de casi seis veces, el mayor que haya tenido la sede de gobierno en toda su historia. En cambio, las otras ciudades importantes crecieron en una proporción menor (...). (Mesa et al, 2003, p. 649) 
Jaime Escalante sufrió escasez temporal de alimento. A pesar de que Bolivia era un país agrícola, no se abastecía, como sostienen Mesa et al. (2003):

A pesar del despertar de los indios en el altiplano y valles, a partir de la creación de sindicatos y de las movilizaciones de 1945, la agricultura (con menos del $2 \%$ cultivado del total del país) estaba en mano de los grandes propietarios (terratenientes) que, especialmente en el altiplano y el valle, controlaban la producción. Desde el punto de vista social el indio dependía totalmente del hacendado, cultivaba una pequeña parcela cambio del salario y su condición general era realmente lamentable. Hasta 1945 se mantuvo el pongueaje (el Gobierno de Gualberto Villarroel lo abolió), un eufemismo de un sistema de semiesclavitud que obligaba a trabajos no renumerados del colono, generalmente en la ciudad a favor del propietario de la hacienda. (pp. 649-650).

En un contexto de graves contradicciones económicas, sociales y políticas, la Revolución de 1952 marcó la culminación de un proceso que se había desencadenado en la guerra del Chaco (1932 - 1935), cuando todo el país tuvo que enfrentarse a su fracaso y, sobre todo, pudo reconocerse en el propio campo de batalla en su realidad social y en sus limitaciones estructurales.

Para Mesa et al. (2003), muchas veces se ha usado la palabra Revolución desde un motín cuartelero, hasta un golpe de estado, pasando por un levantamiento masivo violento. Pero los autores precisan con claridad que el único momento en que la palabra Revolución cuadra realmente, es en la de 1952.

Este proceso representó un desplazamiento de clases a nivel de decisión en el seno del gobierno y en el conjunto de la sociedad. La minúscula clase dominante que dirigía el país fue sustituida por una "clase media" (difícilmente definible sociológicamente) que además afectó severamente los intereses de la elite al expropiar las grandes minas y los latifundios. (Mesa et al., 2003, p. 651) Víctor Paz Estenssoro asume la presidencia de Bolivia el 15 abril de 1952, quizás una de las figuras más relevantes del siglo XX en Bolivia (Mesa y colaboradores, 2003). Las principales medidas de gobierno de Paz Estenssoro 
fueron la nacionalización de las minas, la reforma agraria, el voto universal y la reforma educacional.

De acuerdo a Mesa et al. (2003):

Estos cambios trajeron consigo una serie de problemas que afectaron en plazo inmediato al consumidor. Así, se produjo un nivel de inflación elevado como consecuencia de una devaluación permanente del signo monetario. Se produjo también ocultamiento y especulación de productos de primera necesidad, cuyo control pasó a manos del MNR, que aprovecharon para sí la situación de crisis al controlar los "cupos" de alimentos, artefactos domésticos, divisas y contrabando. (p. 655).

Como consecuencia de esto, Escalante sufrió escasez temporal de alimento y tenía que hacer filas grandes para adquirirlas. Según Mathews (1988), Jaime Escalante no dio importancia a estas revoluciones porque el tenia su propia pequeña revolución. Su jefe Bilbao había encontrado otro trabajo para maestro de Física en el Colegio Nacional Bolívar, una buena escuela cerca del Instituto Americano. Jaime Escalante había levantado una objeción: "yo no tenía ninguna credencial. Yo no tengo ninguna licencia para enseñar." Bilbao dijo: "usted se olvida del título. Yo soy el que ejecuto la revisión aquí. Yo voy a darle el trabajo."

Luego fue a presentarse al Director del Colegio Nacional Bolívar, Sr. Pavón. Según Mathews (1988), se puso una mano sobre su cabeza de apariencia de hombre duro, sabiendo que no tenía ninguna credencial. "Nosotros hemos estado mirando" dijo él: "usted tiene un sistema bueno, usted habla fuerte y claramente, pero usted no sabe usar una pizarra."

Escalante se quedó callado y atento extraordinariamente. El Sr. Pavón dijo: "Me parece que usted se prepara muy bien. Usted estudia. Usted prepara el plan de la lección. Pero usted no pone bastante énfasis en la tarea".

El señor Pavón le recomendó: "allí esta su tarjeta de entrada. Cuando vaya a la clase debe llegar temprano. Usted debe esperar a sus estudiantes, no hacer que le esperen a usted. Usted tiene que estar listo".

Jaime Escalante estaba comenzando el tercer año de la normal (Mathews, 1988). El Director del Colegio Nacional Bolívar le recomendó que 
observara al Sr. Gómez, indicando: "el maestro de Física del curso superior tiene estas cosas."

Jaime Escalante observó al profesor, pero no se impresionó. Escalante lo describe de la siguiente manera: "el hombre trabajó sus problemas metódicamente en la pizarra. Él no hizo ningún experimento" (Escalante, 2007; Mathews, 1988).

Como el Sr. Gómez no le causó ninguna impresión, buscó otra recomendación. Esta vez, el Sr. Pavón le recomendó observar a otro profesor de ciencias: Tito Melean.

Después de mirar unos minutos al pequeño hombre robusto con el pelo gris, Escalante quedó impactado. Melean había adquirido de sus estudiantes un apodo de Mariscal Tito. "...the Erstern European he most resembled was Count Vlad the Impaler" (Mathews, 1988, pp. 41-42). Mientras él disertaba, sacó un hueso largo que parecía de la pierna de algún mamífero grande, los estudiantes creyeron que era de un ser humano.

Le dio un consejo a Escalante: "un maestro debe tener varios trucos; es la única manera de conseguir buenos resultados. Algo que usted produce, algunos trabajos que usted tenga, analícelo. Si funciona, úselo, guárdelo, estúdielo y analícelo.

\section{Ejercicio pleno de la docencia}

En la entrevista con Jara y Sagárnaga (2008, julio 6), Jaime Escalante señala que en los años 50, en ciudad de La Paz, él fue profesor de los colegios: San Calixto, Bolívar, Gualberto Villarroel y Militar. Además, fue uno de los fundadores del Colegio Gualberto Villarroel. Trabajar con alumnos de diferentes culturas y diferentes niveles académicos favoreció su experiencia como dice: "Por lo tanto, estuve expuesto a diferentes culturas y clases de alumnos". Uno de los colegios que le ayudó a crear su metodología de la enseñanza de la matemática fue San Calixto. "Los jesuitas tenían la idea de mantener al alumno el mayor tiempo posible en el colegio. Esto apliqué en Estados Unidos. Así los jóvenes se alejaban de senderos equivocados como las pandillas, porque no tenían ningún control en casa”. 


\section{La decisión de emigrar a los Estados Unidos}

Al respecto de los años de trabajo de Jaime Escalante en Bolivia no existe uniformidad. Unos dicen nueve, algunos doce, y otros 14 años. Por ejemplo, para Bay (1999), son 9 años, y Wapedia registra 12 años. Posiblemente para algunos esta variación de años de servicio no tiene importancia, pero se debe precisar la información.

Esta variación se debe a que cada uno mira desde diferentes perspectivas y Jaime Escalante inició a trabajar en un colegio sustituyendo a un profesor que falleció, ese año no cuenta para algunos. Y otro año que estuvo becado en la universidad de Puerto Rico. Entonces trabajó en Bolivia, 12 años. (Escalante, 2006b).

Jaime Escalante, a insistencias de su esposa había decidido ir a los Estados Unidos en busca de mejores condiciones de vida para ellos y para sus hijos. Después de más de cuatro décadas, Jaime Escalante dice: "Estados Unidos me ha ayudado mucho, me ha dado muchas oportunidades y yo no he dejado escapar ninguna" (Escalante, 2007). Jaime Escalante, sabía que tenía que empezar desde abajo el eslabón de una escalera muy alta.

Entre las razones que suscitaron en Jaime Escalante a tomar la decisión de emigrar a los Estados Unidos, hay muchas. Sin embargo el profesor nos ha manifestado algunas: la situación deprimente del país, la demanda de su esposa y la relación con la administración de San Calixto, el colegio donde tenía el mayor número de horas. La primera razón atribuida, es la situación deprimente del país y cuando estuvo de presidente el Dr. Víctor Paz Estenssoro. (Escalante, 2007). Según Mesa et al. (2003, p. 674) hubo un grave error político, porque el problema de la sucesión presidencial acabó por desmoronar toda la estructura del partido de gobierno. Víctor Paz Estenssoro decidió ir a la reelección, un grave error político. Inmediatamente los varios sectores del Movimiento Nacional Revolucionario (MNR) declararon su oposición. Al respecto Escalante narra de la siguiente manera:

La situación en Bolivia era muy deprimente. El presidente era el señor Víctor Paz Estensoro. Para comprar, uno tenía que anotarse en listas y hacer largas filas, porque no se conseguía nada. Me acuerdo bien, que había una tienda de 
zapatos cuyo dueño era argentino y había una fila enorme. Yo ya era profesor. Un día, haciendo fila para comprarme un par de zapatos. Cuando llegó mi turno, solo conseguí lo que se llama la chula, es decir, un solo zapato. Yo le dije al dueño: “¿qué hago yo con un solo zapato?”, y me dijo: "busque al que tiene el otro par”, entonces busqué y encontré, y le dije: “¿usted quiere este zapato?, yo soy profesor y tengo que estar bien presentable”. Me dijo: “¿por qué no me das tanto por el otro par?", yo le dije: "encantado"; le pagué y se lo compré. A ese extremo estaba la situación. (Escalante, 2007, párrafo 29).

La segunda razón, aparece en varios documentos y Escalante vuelve a mencionarla en la entrevista que efectuamos en su domicilio. Es que a instancia de su esposa decidió ir a los Estados Unidos. En la vida de Jaime Escalante se cumple esa frase popular que "detrás de un gran hombre hay una gran mujer" porque Escalante reconoce que viajó a instancia de su esposa:

Mi señora tenía familiares en los Estados Unidos. Ella me dijo: "has estado en Puerto Rico, fuiste becado por el gobierno de los Estados Unidos que buscó a los mejores profesores de Física" y así fue. Me dijo: "aquí no tienes futuro, tu eres gran profesor y todos te conocen. Las cosas que haces aquí son papel mojado. Tienes que irte al norte". Yo le dije: "no". Yo no quería (Escalante, 2007, párrafo 32)

Una tercera razón, es señalada por Mathews (1988), Jaime Escalante estaba vacilando en dejar Bolivia. Sus estudiantes del último curso del Colegio San Calixto hicieron un viaje de fin de grado a Copacabana, los muchachos dinámicos y animosos cometieron un error que era motivo de expulsión de los estudiantes del San Calixto. Escalante se desilusionó y se enojó con ellos, pero luchó para que estos muchachos no fueran expulsados del Colegio. Porque según Escalante estos muchos no merecían que sus futuros fueran frustrados. Este incidente es ampliamente descrito por Mathews (1988, p. 910).

En pocos meses, su mujer había conseguido los papeles necesarios para que Jaime pudiera viajar a los Estados Unidos. Hizo los arreglos con su hermano menor que ya vivía en California, para que fuera el patrocinador oficial. Porque los recién llegados a Estados Unidos necesitaban de un 
patrocinador que se comprometiera a sostener incluso económicamente si fuera necesario, y no sea una carga para el país.

Jaime Escalante y su esposa planificaron, que primero viajaría él solo, hasta poder encontrar un trabajo y un lugar donde vivir, luego llevaría a su familia. Mientras, Fabiola y su hijo podrían vivir en Cochabamba con su familia. Vendieron todo lo que tenían incluyendo los mobiliarios, hasta el terreno donde pensaban construir su vivienda. Ellos no volverían para atrás.

Un día Jaime Escalante, se reunió con sus hermanos, Félix y Raúl en una cena. Tras balancear la decisión, anunció a su familia: "Yo tengo que dejar este país", con lágrimas en los ojos dijo: "yo no puedo progresar aquí. Fabiola tiene razón. Mis amigos siempre me llaman, me tienen fuera para una bebida. Yo estoy bebiendo demasiado...me iré a Estados Unidos y triunfaré, aunque tenga que empezar de cero" (Mathews, 1988, p. 51).

El último día que pasó Jaime Escalante en La-Paz, fue muy duro. Su hermana mayor Olimpia planchó la camisa para que Jaime Escalante pueda verse muy guapo cuando llegue a los Estados Unidos. No podía ir a despedirse personalmente de su madre, pero dejó una nota en medio folio de papel escrita con tinta verde. Sara la guardó bajo su almohada el resto de su vida:

Querida viejita: Yo no quiero darte ningún mal momento, pero no puedo partir sin escribirte estas palabras... Dios permita que yo regrese algún día a casa. Esto es mi destino elevar el nombre de mi familia y yo estoy animado a tener éxito. Querida Sarita no te preocupes sobre tu hijo Jaime, quien siempre te tiene en sus pensamientos. Las lecciones del ayer serán bueno para mañana...adios a todos. (Mathews, 1988, p. 52)

Si a sus 10 años pasaba de la zona rural del altiplano a la ciudad de La Paz cargado en sus hombros un poco de ropa en una manta, ahora a la edad de 33 de años pasaría de La Paz a Los Angeles, California cargado una alforja de sueños donde llevaba tres cosas: fe, voluntad y talento. Escalante lo resume en "ganas". 


\subsection{Segunda etapa: Jaime Escalante en los Estados Unidos (1964-1998)}

A finales del mes de diciembre de 1963, Escalante partió desde la ciudad de El Alto, e hizo un largo viaje por Latinoamérica, haciendo un recorrido por Lima (Perú), Quito (Ecuador), Tegucigalpa (Honduras), México D. F. (México), y finalmente llegó al Aeropuerto Internacional de Los Angeles en vísperas de la Navidad. Allí lo esperaba su hermano político Samuel Tapia Valle, hermano menor de Fabiola. Jaime Escalante estaba muy cansado y atípicamente callado. Samuel le acompañó respetuosamente a recoger su equipaje y lo llevó a su casa (Escalante, 2007; Mathews, 1988).

Según los datos registrados por Mathews (1988), Jaime Escalante era uno de los 728 últimos bolivianos en entrar legalmente a los Estados Unidos en 1963. Según la opinión del autor, un país como Bolivia con 3 millones de habitantes (Mesa et al, 2003), nunca podría proporcionar más de un goteo de inmigrantes a los Estados Unidos. La inmigración legal de Sudamérica en 1963 fue de 22.919 frente a 55.253 de México. (Mathew, 1988, p. 53).

Samuel Tapia había elegido vivir en Pasadena, en el suburbio del noreste de Los Angeles porque las rentas eran baratas (Mathews, 1988). Pasadena tenía una cosa muy útil para los nuevos inmigrantes: la Pasadena City College, que se inició en 1924 con menos de quinientos estudiantes y menos de una centena de docentes. Pero creció rápidamente en la década de los cicuenta del siglo pasado y la Universidad de Pasadena era la institución que tenía un mayor crecimiento. Muchos recién llegados del extranjero, como el hermano de Fabiola, habían aprendido inglés en esta universidad.

Ahora necesitaba un trabajo porque tenía que sostener a su familia, compuesta por su esposa y su hijo Jaimito. Escalante casi no hablaba inglés, aunque había memorizado algunas palabras para poder preguntar por algún trabajo.

En Bolivia, Jaime Escalante había sido profesor de matemáticas y física por más de doce años. Era un dinámico y brillante profesor. Su pasión por la enseñanza de la matemática y su sentido del humor había hecho amar a sus estudiantes. Además, era tutor de estudiantes particulares y no tenía suficiente 
tiempo para atender a todos los que querían estudiar con él. Incluso varios colegios en Bolivia habían rivalizado por sus servicios. Ahora, Jaime Escalante era otro inmigrante más, que buscaba empleo.

Jaime Escalante había llegado con 3000 dólares americanos. Dando así el primer paso importante para incorporarse al estilo de la vida americana, compró un Volkswagen verde claro del año 1964, cuyo coste fue de 2400 dólares americanos. Esta suma era parte del dinero que él había llevado desde Bolivia. Estaba muy contento con su coche propio, ya que había deseado tener un coche por mucho tiempo (Mathew, 1988, p. 54).

Jaime Escalante, no sabía qué hacer con el resto del dinero. Aunque Fabiola le había sugerido que se incorporara a la Universidad de Samuel, la Pasadena City College (PCC), para seguir la carrera de Ingeniería Electrónica que siempre había soñado.

En Mayo de 1964, Fabiola y Jaimito, de ocho años, llegaron a Los Angeles, después de una serie de vuelos complicados y una tormenta eléctrica espantosa sobre la ciudad de México. Escalante no pudo ir a recibirlos al aeropuerto, porque estaba trabajando en ese horario (Mathews, 1988).

\section{Los primeros trabajos de Jaime Escalante}

Jaime Escalante estaba solo en los Estados Unidos, no conocía a nadie excepto los familiares de su esposa. Pasó varios días frente al televisor en la casa de Samuel Tapia. Tuvo la oportunidad para inspeccionar las entrañas de todos estos aparatos y aprender a arreglarlos. Cuando Samuel podía acompañarle, salían ambos a buscar un trabajo para Jaime, pero cuando Samuel no estaba en casa, Jaime salía a pasear alrededor del barrio. Un día particular, paseaba por una calle en Pasadena y paró junto al Pasadena City College, viendo al frente un restaurante grande de color azul: el restaurante de Van de Kamp. (Mathews, 1988). Escalante cruzó la calle, entró al restaurante y preguntó por un trabajo, utilizando las palabras que había memorizado en inglés. El administrador del restaurante, Karl Polsky, vio a un hombre ya mayor, a diferencia de los otros empleados. Pero necesitaba a alguien para fregar el suelo. Polsky entregó a Escalante una fregona. 
Se produjo un cambio total en la vida de Escalante. El profesor de matemáticas que había sido admirado por sus alumnos en Bolivia, ahora tenía que demostrar que podía fregar el suelo. Escalante, primero barrió y luego fregó el suelo hasta sacar el brillo. Al terminar el día, a las 7:00 p. m., apiló todas las sillas sobre las mesas y dio una dura fregada. "Hasta mañana" dijo Poslky, contento por el progreso de su pupilo. (Mathews, 1988).

Cuando llegué a los Estados Unidos, mi primer trabajo era lavar los platos, que para mi no era nada raro, ya que lo había hecho en mi casa. Cuando empezaron a mostrar los diferentes menús en la cocina, para mi no era nada difícil, pues yo veía el menú y podía prepararlos todos, por lo que acabé siendo el jefe de cocina. Así, el administrador me dijo aquel era mi puesto. Eso era lo que había aprendido cuando era niño. (Escalante, 2007, párrafo 31).

Tapia no podía entender cómo semejante hombre educado podía rebajarse tanto. Escalante era uno de los maestros bolivianos más prominentes de su generación.

Tapia se ofreció a llevarlo a la Pasadena City College, para que realizara la inscripción para estudiar. Este incidente es presentado con mayor detalle en la parte de estudios.

Antes de que llegase Fabiola a los Estados Unidos, es decir, antes de los cinco meses de trabajo, Jaime ya había sido promovido para cocinero del restaurante de Van de Kamp. Había reorganizado el menú y el horario de trabajo. Polsky estaba decidido a convertirlo en el administrador del restaurante, por este motivo, Jaime Escalante no pudo ir a recoger a Fabiola y Jaimito al aeropuerto. (Mathews, 1988).

A Fabiola no le gustó el trabajo de Jaime. No le gustó tampoco Pasadena, porque su ambiente contaminado ahogaba sus pulmones, y la gente era fría y hostil. Pero había sido idea suya. No había ninguna manera fácil para regresar a Bolivia después de que habían vendido todo lo que poseían. Además, su marido estaba muy ocupado y tenía muy pocos amigos para pasar el tiempo bebiendo como en Bolivia.

En cambio, a Jaimito le encantó California. Además, volvía a estar junto a su padre. Había mucho por conocer y nuevas aventuras por vivir; como dar instrucciones desde el asiento de atrás del Volkswagen cuando su madre 
estaba aprendiendo a conducir. Pero también estaba la parte nostálgica y pasaba todos los días un tiempo escuchando la música boliviana en los equipos de música de su tío. Los Escalante vivieron en el piso que había alquilado Samuel Tapia, no era lo suficientemente amplio, el dormitorio era muy pequeño, así como el baño y la sala de estar. Jaimito no sabía inglés y vivía en una casa donde no hablaban ese idioma. Además, Jaimito utilizaba para hacer sus deberes escolares de cuarto grado la mesa de la cocina de Tapia. Consultaba sus libros de inglés, mientras su madre se sentaba a su lado, esforzándose para ayudarle.

Jaime Escalante tenía su propia rutina: de día en el trabajo y de noche en la universidad PCC. Además, ignoró las quejas de Fabiola sobre el trabajo. El sueldo no era lo que le molestaba tanto a Fabiola, porque ganaba más que en Bolivia. Ella estaba en desacuerdo que un hombre con grado y reputación profesional tuviera que trabajar como aquellos limpiabotas que están fuera del Palacio Quemado.

Fabiola dijo: "Jaime, usted puede conseguir un buen trabajo, si busca," mientras que Jaime Escalante pensaba que todo aquello era temporal. Lo hacía porque tenía que aprender inglés. Esperaba que después de algunos cursos en PCC, pudiera escribir una carta al Estado para enviar su credencial y reconocimientos, e informarles que había estado en la Casa Blanca. Quizá entonces, tuvieran trabajo de maestro para él (Escalante, 2007; Mathews, 1988).

Jaime Escalante quería retornar a la enseñanza porque ése era el trabajo que amaba. Envió una carta con su historial académico y su experiencia en la enseñanza en Bolivia al Departamento de Educación de California. En agosto de 1964, Escalante recibió una carta de respuesta a su solicitud del Departamento de Educación de California. Parecía ser una carta formal, correcta y corta. Su educación y su credencial boliviana no eran aceptables en California. La sección lo sentía, pero necesita una prueba de dominio del plan de estudios de la universidad americana antes de ser considerado.

Jaime Escalante difícilmente se descorazonaba, pero esta vez estaba muy afectado. Si deseaba enseñar en América, tendría que repetir el curso 
completo. Los cuatro años de estudio de educación universitaria, más otro año para obtener la credencial de instrucción. Se preguntaba, ¿cuánto tiempo le llevaría esto simplemente estudiando por las noches? No podría apoyar a su familia si pudiera llevar la carga académica completa. Podría llevarle una década, a la edad en la que otros maestros habían hecho su mejor trabajo. Sin embargo, estaba seguro que podría ofrecer algo a su nuevo país.

Con más fuerza, Fabiola dijo: "Jaime, esto significa que usted no necesita volver a enseñar," sugiriéndole que se dedicara a la electrónica, porque siempre había estado interesado en eso. “¿No vinimos a América para eso? Usted podría hacer algo diferente, tal vez trabajar en la NASA. (Mathews, 1988).

En 1967, Jaime Escalante consigue un trabajo en Burroughs Corporation. Por la expansión de la industria, la compañía necesitaba muchos técnicos. Burroughs era uno de los más grandes ensambladores de ordenadores del mundo. (Burroughs, se llama en la actualidad Unisys Corporation). En la opinión de Fabiola, Jaime hablaba mejor el inglés en comparación a muchos otros trabajadores de la corporación. Su inglés había progresado grandemente desde que asistió al Pasadena City College. Pero su sueño era retornar a la enseñaza, aunque parecía muy distante. Escalante fue contratado en el Departamento de almacén. Era el responsable de controlar los componentes de ordenadores. Estaba ganando menos que en el restaurante Van de Kamp. El primer día encontró el trabajo desordenado y aburrido. Pero no tardó en encontrar la manera de hacerlo interesante. Reorganizó el sistema del almacén con códigos de colores. Cuando alguien necesitaba alguna cosa, podían ubicarla rápidamente. Uno de los problemas en Burroughs, era que estaba fallando el disco duro donde tenían almacenados todos los datos. Había un técnico que atendía estos fallos, pero a menudo estaba ausente. Escalante se encargó de ese trabajo. Necesitaba algún tiempo para aprender todo los detalles, y después lo hizo funcionar eficientemente. Este incidente ayudó a que Escalante fuera promovido tan pronto a inspector de equipos. Ayudó a resolver varios problemas de la corporación y sugirió hacer algunos procedimientos más dinámicos y reducir los costes. Además, 
siempre se estaba moviendo de arriba para abajo en su trabajo con su mandil blanco. En cada cosa que hacía, siempre estaba buscando cómo mejorarla. Buscaba la excelencia en todo tiempo. El mensaje en sus conferencias era: "Nunca pares de probar tus talentos, no tengas miedo de probar tus límites. El éxito de una persona va más allá de sus límites."

En 1969, Escalante se graduó como Ingeniero en Electrónica de Pasadena City College. La Burroughs, en 1972, le ofreció el trabajo de supervisor en una nueva planta en Guadalajara, México. Viajó para valorar, pero regresó inmediatamente, porque no quería que nada interfiriera la educación americana de sus hijos. Además, estaba muy cerca de conseguir el grado (Licenciatura) de matemáticas en la California State University.

Escalante había disfrutado del trabajo en la Burooughs Coorporations. Gustaba hacer cambios en las cosas que hacía. Pero después de varios años, el trabajo se tornó aburrido para él, porque no le gustaba estar en la oficina con los equipos y los papeles. Anhelaba estar trabajando con personas, con estudiantes a quienes pudiera animar a realizar grandes cosas.

En 1973, se graduó en la California State University, en matemáticas, y ganó una beca de National Science Foundation para conseguir su credencial para la enseñanza. Después de una década de estancia en Estados Unidos, en 1974 comienza el trabajo en el Garfield High School. Esto se detalla más adelante.

\section{Estudia otra vez en los Estados Unidos}

Jaime Escalante, tenía una formación de profesor de matemáticas y física en Bolivia y un Posgrado en Puerto Rico. Además, contaba con una experiencia de doce años en la educación secundaria entre los colegios: San Calixto, Nacional Bolívar y Gualberto Villarroel, y en educación superior: El Colegio Militar. A pesar de su formación y su experiencia, tuvo que empezar de cero y realizar su educación completa en Estados Unidos.

Una de las razones que impedía que Escalante consiguiera otro trabajo, era que no sabía hablar inglés. Samuel Tapia le ayudó a incorporarse a la universidad. Al llegar al PCC, preguntaron por el examen de matemáticas. El 
instructor responsable de admisión de nuevos estudiantes del horario nocturno, le explicó que debía realizar un examen de dos horas. El instructor le dijo a Tapia, aclara a tu cuñado que no puede hacer ninguna pregunta antes de terminar el examen. "Dígale a su cuñado que se siente ahí y haga el examen, mientras yo estoy en mi despacho," dijo el instructor. Escalante sonrió un poco y se sentó. Abrió el folleto y comenzó a trabajar. Los problemas para él eran fáciles. Necesitó sólo un octavo de tiempo asignado para este examen. Es decir, después de 25 minutos de haber iniciado el examen, se levantó y empezó a caminar despacio hacia la puerta del despacho del instructor. Hizo señas a Tapia y tocó la puerta del despacho.

El instructor dijo: "Esto nunca falla. Ya le dije a usted que no podía hacer ninguna pregunta antes de terminar el examen. El examen es de dos horas. Dígale a su hermano que vaya a sudar solo."

Escalante, con la ayuda de Tapia, pudo explicar que ya había terminado. El instructor sacó el folio con las respuestas, e inmediatamente confrontó los resultados. Todo estaba perfecto. El instructor quedo sorprendido por el examen de Escalante, y le dijo: "usted hizo todo perfecto" (Escalante, 2007; Santana, 2003, Mathews, 1988).

De esta manera, Jaime Escalante se incorporó a la Pasadena City College, y en un principio tomó 12 asignaturas, incluyendo inglés, matemáticas y electrónica (Escalante, 2007; Schraff, 2009).Él recuerda que ésta fue otra prueba, porque era "uno de los semestres más difíciles." Escalante, después del trabajo, estaba en clases o en la biblioteca hasta que el hombre de seguridad le decía que tenía que irse. Era el único tiempo que disponía para hacer sus deberes.

En 1969, se graduó de Ingeniero en Electrónica en Pasadena City College, y en 1973, en matemáticas en la California State University. Parecía estar cerca su sueño de volver a la enseñanza, pero todavía faltaba.

Uno de los profesores de California State University, le dijo que tenía los talentos para ir tan lejos como él quisiera en el campo de la electrónica. Y le preguntó qué iba a hacer con la matemática. La respuesta de Escalante fue: "voy a enseñar matemáticas". Su profesor, al oír la respuesta llena de 
convicción, le indicó que era una excelente oportunidad para solicitar una postulación a The National Sciencie Foundation. La beca que se ofrece a las personas dotadas que buscaban enseñar. La Fundación Nacional de Ciencias (NSF) es descrita por Schraff (2009).

The National Science Foundation (NSF) was created by Congress in 1950 as an independent federal agency. The goals were "to promote the progress of science; to advance the national health, prosperity, and welfare; to secure the national defense". In many areas like mathematics, computer science, and the social science, NSF is the primary source of federal backing. The SNF had the task of keeping the United States on the leading edge of discovery in everything from astronomy to zoology. (Schraff ,2009, p. 62).

Jaime Escalante ganó esta beca. Pero tuvo que realizar un examen en tres áreas: el primero fue un examen escrito en el área de matemáticas y física. No tuvo ningún problema en esta parte, que dominaba ampliamente. El segundo era oral y Escalante tenía que explicar su filosofía de la educación, y tampoco tuvo problema porque tenía una filosofía fuerte y creía en ella. "Un profesor debe ser capaz de amar los desafíos. Los estudiantes ven mi pasión por el asunto. Mi pasión es la enseñanza."

Hay que cumplir muchos requisitos para ser profesor en los Estados Unidos. Es un poco difícil conseguirlo, sobre todo porque tienes que vencer el handicap del idioma, segundo porque tienes que tener un certificado o un documento de una de las universidades que está acreditada en el estado de California, que diga que uno ha terminado sus estudios en matemáticas y puede empezar en la escuela de educación. Entonces se empieza el curso de formación pedagógica que dura un año, y tenía que llevar pedagogía, didáctica, psicología, aunque para mi no tenía mucho valor. Pero tenía que hacerlo, aunque yo tenía mi propia pedagogía, mi propia psicología y más que nada toda mi experiencia de haber enseñado, no sólo, en Guadalajara, sino también en Puerto Rico y en Bolivia. No tenía temor a ese curso, así que cumplimos y pasamos todos los requisitos del examen de selección: examen de ingles, examen de la especialidad y examen de pedagogía; todo lo que se pedía en aquella época. (Escalante, 2007, párrafo 36)

La tercera parte de este examen era el más desafiante. Consistía en la demostración de las habilidades de enseñanza por la observación del comité 
de becas. A esta fase sólo habían llegado cinco finalistas Escalante y otros cuatro. Escalante (2007) dice: "yo era el único latino".

Los finalistas tenían que presentar una clase de 30 minutos a un grupo de 15 estudiantes adolescentes que había sido escogido entre los más indisciplinados. Cuando Escalante entró al salón de clases, los estudiantes se mofaron y dos de ellos peleaban en una esquina. Se acercó a los estudiantes para saludarles con los brazos abiertos como para abrazarlos. No les gruñó nada. “¿Ustedes señores, quieren luchar? ¡Yo pienso que eso es maravilloso! Eso es un buen ejercicio. Yo voy a pelear con cada uno de ustedes después de la clase. Yo era un buen luchador en mi país, ustedes verán" Esto no era la respuesta que esperaban. Los estudiantes volvieron a sus lugares para sentarse.

Escalante se presentó a sí mismo. En ese tiempo, ya había mejorado su inglés con un acento pesado. Los miembros del tribunal de becas estaban observando atentos cómo comenzaba su lección. Escalante lanzó la discusión de trucos para que los estudiantes no tuvieran la necesidad de memorizar la tabla de la multiplicación.

"Tome cualquier número de cinco dígitos, reste la suma de los dígitos, tache un dígito del nuevo número y me dice la suma de los dígitos restantes"

"Doce," dijo un muchacho. "Eso significa que usted tachó el seis", dijo Escalante. El muchacho parecía ligeramente asombrado. "Si" dijo, mientras estudiaba su papel. "Eso es correcto" (Mathews, 1988).

Los estudiantes quedaron atrapados con estos trucos y todos estaban atentos. Su tono de voz vivo y su mirada traviesa parecían cautivar a cada estudiante. Concluyó la clase con una discusión de sustracción. Los estudiantes estaban preguntando, ¿cómo saca usted esto?

Jaime Escalante obtuvo el primer lugar y ganó la beca. De esta manera, se dedicó al estudio por el periodo de un año. Finalmente, en 1974, tenia en sus manos el documento de la credencial de enseñanza del Estado de California. Conseguir este documento le llevó diez años. Escalante, a la edad de cuarenta y tres años, regresó a la carrera que él amaba. 
Comprendió desde el principio de la entrevista de trabajo con el encargado de la Unidad del Distrito Escolar de Los Angeles, que el proceso era diferente a la forma como ocurría en Bolivia. El hombre sacó un mapa, puso sobre su escritorio y lo desplegó delante de Escalante, para enseñar las comunidades asentadas por diferentes grupos étnicos. Estaba la comunidad negra, la comunidad anglo y la comunidad chicana. Escalante estaba interesado en enseñar en una escuela Latina. Escogió la comunidad chicana porque conocía el idioma. Además, este barrio era el más cercano a Monrovia, donde él vivía (Mathews, 1988). Escalante tenía tres instituciones para escoger: la escuela Belvedere y dos colegios secundarios, Roosevelt y Garfield en el Este de Los Angeles, abrumadoramente poblado por hispanos. En mayo de 1974, Jaime Escalante (Mathews, 1988), visitó Garfield por primera vez. Quedó impresionado por los árboles de jacarandá que dejaban caer sus flores y por el trato que le dispensó el Director de Garfield: Alex Avilez. Éste, al observar los folios del curriculum de Escalante, se percató que el profesor tenía amplio conocimiento en ordenadores y era perfecto para su proyecto de implementar estos cursos. Cuando Avilez le dijo a Escalante que sería un maestro de computadoras de un nuevo programa que tendremos aquí, y Escalante dijo: "Maravilloso. ¡Oh!, gracias señor. Eso es exactamente lo que quería". (Mathews, 1988). Escalante decidió quedarse en Garfield High School. Fue contratado como profesor de computadoras. Estaba fascinado con este cargo porque era lo que él quería. Llamó inmediatamente a Fabiola para que cancelara la entrevista con las otras escuelas.

\section{Garfield High School}

Garfield High School fue construido en 1925 en el Este de Los Angeles (Mathews, 1988, p. 2). En ese tiempo, la zona era bastante rural (Schraff, 2009, p. 68). Su nombre completo es A. James Garfield High School. Es el nombre del vigésimo presidente de Estados Unidos.

El entorno a Garfield High School era como un pequeño bloque sobre el Boulevar Atlantic con cabinas de teléfonos, muchos automóviles usados, tiendas de modas, bancos, bares, puestos de hamburguesas-burrito, iglesias y 
estaciones de servicio. El resto era área residencial. Hay algunos apartamentos ruidosos que no son de buena calidad y la mayoría de las personas viven en casas pequeñas y muy apiñadas. Por otro lado, es necesario considerar los datos señalados por Mathews (1988), alrededor de los años 1950, el 59\% de los inmigrantes eran de origen europeo, el $22 \%$ hispanos y el $6 \%$ asiáticos. Sin embargo, en los 1970 habían cambiado estas proporciones, ya que el $18 \%$ eran europeos, $41 \%$ hispanos y el treinta y $6 \%$ asiáticos. En 1973, los latinos se habían vuelto el grupo minoritario más grande de las escuelas públicas de Los Angeles, pasando a los negros (Mathews, 1988, p. 77).

Varios documentos (Menéndez y Musca, 1988; Mathews, 1988; Schraff, 2009), indican que la colectividad de estudiantes de Garfield estaba conformada por familias latinas con poco dinero y educación formal. Muchos eran padres inmigrantes mexicanos recién llegados que hablaban muy poco de inglés, si alguno hablaba.

En la descripción de Mathews (1988), por lo menos el $80 \%$ de los estudiantes de Garfield calificaban para el programa de almuerzo gratis o precio reducido, lo cual significa que sus ingresos anuales estaban por debajo de 15.000 dólares por familia de cuatro personas. Muchos padres ganan un salario inferior a éste. El $25 \%$ de los estudiantes proviene de familias que reciben ayuda con niños dependientes, y este cuadro podría ser más grande según el autor porque muchos extranjeros ilegales temían buscar ayuda gubernamental.

Según Schraff (2009), en la década de los setenta, la Garfield High School de Los Angeles, Califonia, era terrible. Era uno de los peores institutos públicos de enseñanza secundaria. Las bandas (pandillas), habían dividido la escuela en zonas donde ellos gobernaban. Las drogas y la violencia eran cosas de la vida cotidiana. Se planeaba llevar a cabo ataques dentro de la escuela. Muchos estudiantes estaban abandonándola antes de graduarse. Escalante señala: "Yo elegí la escuela de Garfield, pero no sabia que estaba tan mal, porque vivía en otra ciudad" (Escalante, 2007).

Sin embargo, en septiembre de 1974, Escalante se incorpora al centro educativo y recibe su horario de clases, y se lleva la primera sorpresa. En su 
horario no aparecían sus clases de computación, sino sólo de matemática elemental. Inmediatamente presentó su reclamo indicando que él fue contratado cómo profesor de computación y no como profesor de matemática elemental. El decano le explicó indicando que lo sentía mucho, que no habían encontrado financiamiento para el proyecto. Además, tendría que enseñar matemática elemental porque todos los profesores nuevos comenzaban enseñando matemáticas elementales (Mathews, 1988; Escalante, 2007).

Escalante fue enviado a la sala de reuniones y allí se encontró con sus colegas de matemáticas que estaban discutiendo nuevos métodos de enseñanza de las matemáticas. Escuchó la discusión, pero no estaba de acuerdo. Los profesores estaban diciendo que se debía pedir a los alumnos que corten los cuadros de objetos conocidos en la casa, y luego los armaran como puzzles. Escalante observó, que los otros profesores estaban muy ocupados en armar los puzzles. Mientras él pensaba que esto era muy sencillo, porque esto se hace en la educación primaria o elemental en Bolivia. El jefe del departamento le dijo: “Usted tiene que aprender estas cosas, porque usted es nuevo, mientras que nosotros llevamos ventaja porque ya lo hemos utilizado" (Mathews, 1988).

Al llegar a las aulas, Escalante sufrió otra desilusión porque sus alumnos usaban los dedos para sumar. El nos lo relata de esta manera:

Yo elegí la escuela de Garfield, pero no sabía que estaba tan mal, porque vivía en otra ciudad. Cuando llegué a Garfield, al terminar la clase el primer día, llamé a mi compañía y le dije: "me he equivocado. Quiero volver a trabajar donde trabajaba antes, me retiro, porque estos analfabetos no están en condiciones de aprender, no saben que la educación es boleto al éxito. Yo me voy". Cuando me fui en mi coche Volkswagen, dije: "me voy, pero antes les voy a enseñar el respeto, respeto a las personas, respeto a la materia que es la matemática. También les voy a enseñar quien soy yo". (Escalante, 2007, párrafo 38).

Algunos estudiantes conversaban ruidosamente e ignoraban totalmente al profesor que entraba a la clase. Otros estaban peleando y utilizaban palabras soeces. Los estudiantes se comportaban como si eso fuera una parte 
normal de la rutina escolar. Escalante miró alrededor del salón de clases y la encontró desordenada y lleno de grafitis (Schraff, 2009).

Jaime Escalante se puso un desafío de transformar a estos muchachos.

Llegué por la mañana, como la película refleja, y pregunté a los alumnos: “¿ha estado usted en la playa?, ¿ha jugado con arena?". "Si", responde el alumno. El hoyo que queda es negativo y la arena que sale es positiva. Por tanto, hay que completar, y le dijo a uno de ellos: “¿menos uno más uno?” Me miró sin responder, como quien dice qué me estas preguntando. Yo le dije: "yo sé que tu puedes. No eres tan bruto como se imagina la gente. “Menos uno más uno?" Él me seguía mirando sin responder. Yo le dije: "yo sé que tu puedes, piensa. Debes uno y pagas uno, ¿cuánto te queda?” Con rabia me respondió: "icero!" "Ya ves que sabes, le respondí. Tú puedes tapar cualquier agujero". Se quedaron callados, y empecé a decirles que les iba a enseñar matemáticas. Mientras explicaba, me fijé en una alumna que copiaba con lápices de colores lo que yo escribía en la pizarra.

Me acerqué y le pregunté: “¿te gusta las matemáticas? ¿Quieres algún sistema de matemáticas? Me respondió que sí, y hablé con el director para enseñar álgebra en vez de aritmética elemental. El director se rió y me dijo: "estos vienen únicamente a perder el tiempo porque viven del sueldo que les da el gobierno y nada más. Usted está perdiendo el tiempo. Hable con el jefe del departamento de matemáticas". Cuando fui a hablar con él le dije que quería impartir álgebra en los cinco periodos que tenía de aritmética. "No te hagas muchas ilusiones!, no vas a poder porque estos son unos vagos, unos mal entretenidos que solamente se agarran a cadenas y a balas”. Le dije: “¿no me das una oportunidad?" Me respondió que no había libros, y entonces le dije: "no te preocupes de los libros. Yo conozco la materia y puedo enseñar". El me contestó que lo hiciera sin molestar a nadie, y yo estuve de acuerdo. (Escalante, 2007, párrafo 39).

En la opinión del Director y los profesores, los alumnos eran ineducables. La razón era que los mismos profesores no tenían expectativas sobre sus pupilos. Sin embargo, Jaime Escalante tenía una opinión completamente diferente. Jaime Escalante, tenía altas expectativas sobres sus alumnos y sabía, que si al estudiante se le motiva a dar lo mejor de sí, podía desarrollar sus potenciales. 
Escalante comenzaba siempre por los objetos que sus alumnos conocían, y enfocaba los conceptos matemáticos desde las metáforas deportivas. Hablaba del equipo de Basketball: los Lakers de Los Angeles, y sugería a sus estudiantes que deberían colocar los pósters de sus estrellas. Muchos de ellos eran hinchas de este equipo y les gustaba hablar de los Lakers. Al encontrar los intereses comunes con sus estudiantes, Escalante mostró la necesidad de limpiar y pintar el salón antes de traer y colocar los pósters de sus estrellas. El ambiente de aprendizaje fue cambiando, pero esto era solo el comienzo (Escalante y Dirmann, 1990).

En Jara y Sagárnaga (2008, Julio 6), Escalante señala que con el trabajo de varios años en Bolivia y alguna experiencia en Puerto Rico, vio que era necesario desarrollar la habilidad personal de los alumnos, interpretarles y aprovechar todo lo posible lo que ellos puedía dar. "No creo en los dotados, creo en los jóvenes que ponen un poco de ganas y pueden responder."

Ahí comencé la primera clase que tenía once alumnos, como vi que aprendían, decidí quedarme. En los siguientes años el número aumentó, y pasamos de Algebra I a Algebra II. Pasaron dos años y el profesor de biología me dijo: "hay unos concurso de matemática avanzada. Puedes participar con tus estudiantes, aunque dudo que ganen". Le dije: "vamos a conseguir, porque tengo la experiencia de San Calixto". Cuando llevé a mis alumnos al concurso, sacaron primeros puestos dos mafiosos pandilleros. El periodista me dijo: "¿por qué usted no se viste como ellos para una foto?. La foto apareció en le periódico de la ciudad, diciendo que unos pandilleros habían ocupado los primeros puestos y explicaba una pequeña historia. Esto llamó la atención, haciendo que la gente se interesara. Ahí empecé a usar mi sistema que no es nada difícil, pues todo es fácil cuando uno pone ganas. (Escalante, 2007, párrafo 40).

Los métodos tradicionales no llegarían a estos estudiantes, como lo refleja Stand and Deliver. Jaime Escalante no era un profesor tradicional y su clase siempre tenía sorpresas. Entró con su traje de Chef y un cuchillo grande y partió las manzanas para enseñar las fracciones desde los porcentajes.

No fue fácil hacer frente a un programa deficiente del Distrito Escolar de Los Angeles. Busque ayuda del East Los Angeles College (ELAC). El presidente de ELAC, señor Ávila, administradores George Madrid y Paul Powers, y el señor 
Villavicencio, maestro de la escuela Griffith Junior High School, fueron mis fieles colaboradores. Con respecto a la motivación, en mi concepto "Latino", no podía aceptar que Garfield High School ofrezca un programa insuficiente con requisitos mínimos en la preparación para nuestra gente. Ejemplos: Solo 10 unidades en matemáticas (aritmética elemental equivalente a un tercero o cuarto grado de instrucción primaria), artes plásticas, imprenta, cerámicas, hojalatería, y carpintería. Con este tipo de instrucción secundaria engañamos y no preparamos a nuestros alumnos para un mejor futuro. (Escalante, 2007, párrafo 41).

He peleado con muchos directores, con muchos consejos y con la mayor parte de los administradores porque me decían que estaba haciendo cosas que no tenían ninguna importancia en el campo de la matemática, debía dedicarme únicamente a enseñar lo que dice el programa y se acabó. Yo les dije: "el programa que tienen no sirve porque es teórico y ellos nunca van a leer. En primer lugar ese libro que usted tiene está bien para un barrio que tienen dinero, como Beverly Hill donde están los chicos de padres ricos, pero para estos que son de la escuela minoritaria donde todos hablan mitad ingles $y$ mitad castellano, este libro no funciona, solo el hecho de ver los signos les lleva a poner a un lado. Tiene que ser un libro donde el alumno pueda entender lo que esta haciendo. Tenemos que escribir los planes de lección. (Escalante, 2007, párrafo 42).

\section{El examen de Advanced Placement}

Desde su inicio modesto en 1955, el Advanced Placemente Program (Programa de Colocación Avanzada), ${ }^{7}$ fue creciendo en Estados Unidos, promoviendo la excelencia académica en la escuela secundaria. La raíz del programa puede hallarse en la idea que emerge a inicios de los años 50 s del siglo pasado de mejorar la educación americana. La idea era permitir en las escuelas de nivel secundario impartir las clases de nivel universitario.

Jessness (2002), y Mathews (1988), indican que Escalante había estado en Garfield más de un año antes de conocer de la existencia del examen de Advanced Placemenet. Jaimito no había participado en Pasadena High

\footnotetext{
${ }^{7}$ http://apcentral.colegeboard.com/apc/programan/history/8019.html
} 
School, porque no era un examen común para los estudiantes de todos los colegios, sino era casi exclusivo de los colegios privilegiados de barrios con altos recursos económicos.

Según Mathews (1988, p. 109), pocos estudiantes pasaban el examen AP de cálculo. En Garfield había habido algún esfuerzo desganado sobre el examen AP de cálculo, pero los estudiantes abandonaban antes de terminar. Y por eso, los profesores no creían que los estudiantes podieran conseguirlo. Escalante estaba un poco desanimado por estas historias, por lo que declinó la invitación inicial a llevar la clase AP. Sin embargo, tenía la experiencia en Bolivia, en el colegio San Calixto y contaba con el conocimiento de matemáticas, y tenía altas expectativas sobre sus estudiantes, pero también conocía que sus alumnos no estaban recibiendo la matemática para este nivel de exigencia. Escalante siempre estaba buscando cómo motivar a sus estudiantes y que los alumnos tuvieran metas que alcanzar.

A Jaime Escalante le gustó la idea, y finalmente se decidió a llevarle a cabo. En su opinión, el examen sería muy bueno, porque esto revela lo que el profesor está haciendo. El dijo: "yo puedo decirte que soy un buen profesor porque mis alumnos consiguen las calificaciones más altas, pero el examen es importante para comprobar si yo lo estoy haciendo."

Escalante comenzó a preparar las clases AP, pero antes de comenzar, tuvo que vencer muchas dificultades. Él necesitaba buenos libros para sus estudiantes, el libro que usaba titulado "Consumer Math", era un libro agradable y ayudaba a introducir los conceptos básicos para sus estudiantes,, pero no era suficiente para prepararlos para el examen AP de cálculo. Esta situación le obligó a buscar ayuda en algunas personas e instituciones.

En junio de 1978, comenzó a considerar los programas de verano y empezó a reclutar estudiantes para su primera clase de AP. Estaba entusiasmado al convencer a su clase entera de matemáticas. Consiguió catorce estudiantes. Después dirá que la clave fue tener a los alumnos por tres años y tres veranos con el mismo profesor o con el mismo equipo (Escalante, 2007). Además, no quería que sus estudiantes pensaran que el cálculo era difícil, y trataba de ablandar la imagen del cálculo. Sus principales dispositivos, 
según Mathews (1988), eran el humor, la indiferencia y apelar al espíritu de equipo. Por otra parte, puso en el aula en un lugar muy visible un lema, que decía: "No hay necesidad de facilitar el cálculo porque ya es fácil."

En 1979, se presentaron al examen de AP de cálculo 5 alumnos, de los cuales dos pasaron la prueba. En 1980, el número había crecido a 9, de los cuales la pasaron 7. En 1981, la clase se había incrementado a un número de 15 estudiantes, de los cuales 14 consiguieron aprobar. En 1982, captó la atención nacional cuando el número de alumnos aprobados fue del $100 \%$ de los 18 estudiantes. En el siguiente año, 33 alumnos, de los cuales 30 aprobaron. En 1987, el programa escaló al punto máximo, cuando 73 estudiantes aprobaron el examen. Esto fue el pico del programa y Garfield se ubicó en el cuarto lugar del ranking nacional por el número de alumnos que realizaban el examen de AP de cálculo.

En 1982, ocurrió su mayor triunfo, cuando 18 alumnos de Garfield, preparados por Jaime Escalante, realizaron el examen avanzado de cálculo. Las calificaciones de catorce estudiantes fueron puestas en duda, alegando que habían copiado, porque los administradores del examen no podían creer que los estudiantes chicanos del Este de Los Angeles fueran así de inteligentes. Los estudiantes fueron obligados a volver a realizar el examen. Doce de los catorce que hicieron el examen volvieron a salir aprobados, muchos con notas más altas que la primera vez.

Se organizó un equipo de trabajo y necesitaba dinero para los que iban a dirigir el equipo. Pedí a la administración que colaborara para que se reconozca lo que yo estaba haciendo. Conseguí una ayuda financiera de Richfield Atlántica, de una empresa que se dedicaba al negocio del petróleo. Ésta me dio dos mil dólares, después 20 mil y posteriormente 40 mil. Cuando tuve el éxito completo en Estados Unidos, el presidente Ronald Reagan reconoció mi labor, entregándome la medalla presidencial a la excelencia. Dio una ayuda económica de medio millón de dólares para que siga mi programa con estos muchachos. Con eso, ya estaba bien situado y pensé que no sólo necesito libros, sino que estos niños necesitaban estar en sitios diferentes, porque yo recordaba mi infancia. Me dije que deberíamos llevar a comer a estos niños a un restaurante cercano y el siguiente año a otro de mayor jerarquía. Y Así 
sucesivamente hasta el último año, que les llevaré a donde comen los artistas, y el menú cuesta 50 dólares. Voy a vestirles bien y prepararles para desenvolverse adecuadamente. Voy a demostrarles que la gente que acude a esos sitios tiene jerarquía. Pero ellos no son nada. Ustedes llegarán a ser mejores que esos. Me podía permitir esto por las aportaciones que había recibido. Quería mostrarles a los diferentes grupos étnicos de California, que ellos podían cambiar su posición social. (Escalante, 2007, párrafo 46).

\section{Visita de Bush a la clase de Escalante}

Jaime Escalante recibió la visita de muchas personas celebres como por ejemplo, la visita del presidente de Estados Unidos George Bush. Al respecto Jaime Escalante declara:



El presidente Bush en la clase de Escalante

(...) Nunca pensé que un presidente de un país tan poderoso llegaría a visitarme a mi clase. Ese día me sentí muy seguro porque estaba el FBI. Me preguntó que tenía que hacer para aprender matemáticas que todos temen. Le dije que debía asistir a clases, hacer sus tareas y confiar en el entrenador para dominar la cancha. Fue una sola broma. (Escalante, 2007, párrafo 53).

Según Perkins (2003), Escalante había cultivado su pequeña clase como un jardín de preciosas flores. Hizo popular el cálculo en Garfield. En 1991, el número de estudiantes de Garfield que se presentaban al examen de AP en matemáticas y otras materias llegó a 570. Como Escalante había concitado la atención a nivel nacional, su aula se había convertido en un escaparate de Garfield y recibía la vista de muchos reporteros y personalidades importantes del país, como la vista del presidente George Herbert Walker Bush 
y el actor Arnold Schwarzenegger, que posteriormente fue gobernador de California.

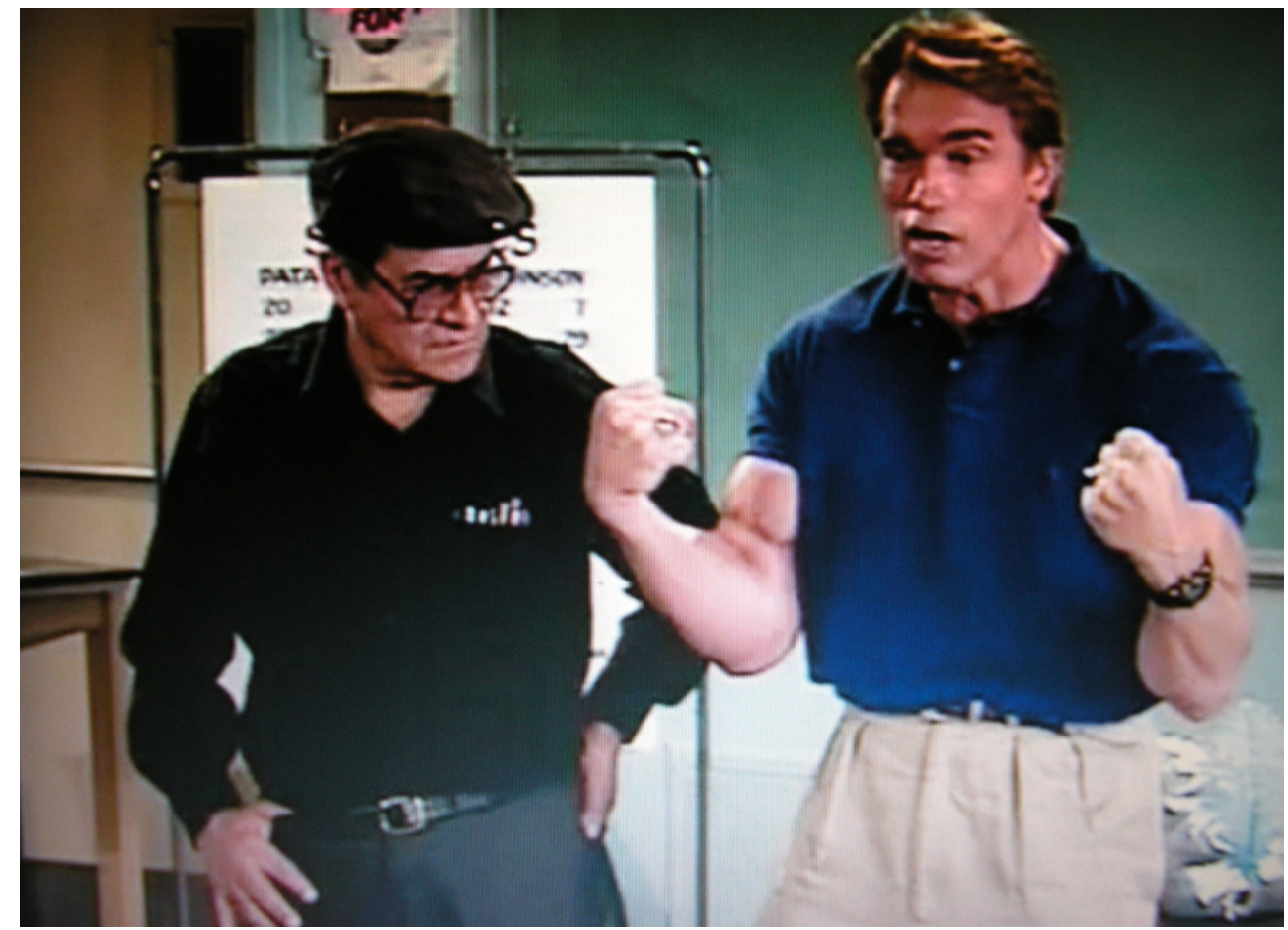

Escalante explicó la función cuadrática apartir de los músculos de Arnold Schwarsenegger

Todo esto despertó celos entre sus colegas, y Escalante recibió amenazas por carta. Ese mismo año, por motivos políticos y personales, abandonó Garfield. El docente Angelo Villavicencio tomó el programa en sus manos y enseño a 107 alumnos divididos en dos clases, y aprobaron 47 alumnos.

El programa aplicado en Garfield declinó rápidamente, al parecer debido a la salida de Escalante y otros maestros asociados a su implementación y desarrollo. En el lapso de algunos años, Garfield experimento la caída en el número de alumnos que aprobaban la prueba de AP de cálculo.

\subsection{Tercera etapa: Escalante a nivel internacional (1999 - 2010)}

Jaime Escalante, un maestro comprometido con la educación y la juventud, trabajó hasta final en la Hiram W. Johnson High School del Distrito Escolar de Sacramento, aunque allí no consiguió el mismo éxito como en Garfield High School. En su opinión estuvo poco tiempo y tenía diferentes 
grupos étnicos. Escalante era un profesor muy imaginativo y reflexivo en elsentido de Schön (1992).

Escalante formó parte de la eliminación de la educación bilingüe en 1998 en el Estado de California.

Al principio yo creía mucho en el sistema bilingüe porque creía que había que enseñarle al alumno en el idioma que él entendía, pero en el campo de la ciencias son idiomas especiales los que se deben aprender, entonces vi que al alumno había que enseñarle en el idioma que iba tener éxitos.

Yo he sido parte de la eliminación de la educación bilingüe, porque he visto que el idioma en que el alumno iba tener éxito es el inglés. Desgraciadamente todo, ya sea solicitudes de trabajo o entrevistas, venían en una sola lengua. El alumno tenía que tener el dominio de esa lengua.

Las pruebas para entrar a la universidad (S.A.T) eran solamente en inglés, al igual que todos los textos que se usaban, incluso las escuelas bilingües. Entonces cuando teníamos exámenes que pedía el distrito, nosotros ocupábamos siempre los últimos lugares porque ese examen venía en inglés y el alumno tenía que ser fluido para poder tener éxito. (Escalante, en BBC MUNDO, 2003, Junio 03).

Por haber apoyado la eliminación de la educación bilingüe se ganó algunos enemigos de la asociación de profesores. Por esos motivos y otros decidió retirarse del sistema de la educación americana. En 1998, se jubiló a la edad de sesenta y siete años. Sin embargo, continuó comprometido con sus estudiantes. Tras su jubilación Escalante regresó al Este de Los Angeles, California, para hablar con los estudiantes que se acercaba alrededor de él. Según Schraff (2009, p. 108) un observador notó, cómo los alumnos se agrupaban cerca de él y poniendo sus brazos alrededor de él, gritaban por su antiguo sobrenombre, Kimo.

Escalante estaba profundamente emocionado y comentó: "el regresar a aquí con estos niños, recordar la buena vida del pasado, es la mejor recompensa".

En 1999, Escalante fue introducido en la National Teachers Hall of Fame. Fue honrado por sus 24 años de trabajo en Estados Unidos y 12 en Bolivia, haciendo un total de 36 años, al servicio de la educación. (Bay, 1999). 
A pesar de la fama conseguida, Escalante nunca cambio su humildad y espíritu de servicio.

En agosto de 2003, Jaime Escalante dio una charla en el Hotel los Tajibos de la ciudad de Santa Cruz, al concluir un acto de distinción denominado "Hijos Triunfadores", organizado por la universidad empresarial Mateo Kuljis (Unikuljis), y dijo: "Para triunfar en necesario tener ganas."

El maestro señaló tres puntos que ponen en riesgo la educación de niños y jóvenes: alcohol, drogas y sexo. En contrapartida destacó los valores que deben ser cultivados: la experiencia, responsabilidad y actitud. "De los tres destaco la última porque cuanto más tiempo pasa, más me doy cuenta que una persona deja un impacto en sus quehaceres cotidianos", expresó el profesor. No dudó en decir que la actitud es un factor más importante que el dinero, la disertación testimonial, manifestó que "tenemos que jugar a la vida con talento, inteligencia y responder a las circunstancias con buenos modales."8

En 2002, fue nombrado Miembro Asesor del Presidente de la Comisión de Excelencia Educacional para Hispanos Americanos. En 2003, fue invitado para asesorar en la estrategia educacional en la campaña del candidato a gobernador de California, Arnold Schwarzenegger. En 2005, recibió el reconocimiento de Mejor Docente en América del Norte- Foro de la libertad.

Después de estar casi cuatro décadas lejos de su familia y sus amigos. Jaime Escalante, su esposa y sus hijos con sus familias, regresaron a Bolivia, y se establecieron en la ciudad de Cochabamba., aunque sus hijos volvieron a los Estados Unidos.

Escalante volvió a Bolivia con la esperanza de contribuir con la enseñanza en el país, al respecto declara Escalante (comunicación personal, 20 abril de 2008): "No tenía ningún motivo para venirme a Bolivia, pero lo hice, porque quería ayudar a mi país, quería decirles a mis colegas que ya no tienen que seguir enseñando de la manera que aprendimos".

Pero sufrió una decepción al no encontrar el apoyo de las autoridades educativas ni políticas. En una entrevista de Dica Rodríguez, publicada en el periódico El Deber de Santa Cruz el 5 de septiembre de 2004. Al responder a la

\footnotetext{
${ }^{8}$ http://www.eldeber.com.bo/anteriores/20030829/santacruz 4.html
} 
pregunta ¿Se queda definitivamente en Bolivia? Jaime Escalante dice: "Por la situación política del país no sabemos. Mis hijos se volvieron a Estados Unidos, allá esta su vida". Además, "lo que más me amarga es la injusticia y la corrupción en el país. Quiero tranquilidad no amenazas de bloqueos y falta de respeto a las autoridades".

En Cochabamba trabajó en varias Universidades: Universidad del Valle, Universidad Franz Tamayo y Universidad Mayor San Simón y ofreció varios seminario y talleres para estudiantes y profesores en la Universidad Adventista de Bolivia.

Continuamente era invitado por universidades y autoridades educativas nacionales e internacionales para dar seminarios-talleres, conferencias y charlas motivacionales. Ha participado en Chile, Uruguay, Argentina y a veces regresaba a Estados Unidos para visitar a sus hijos y dar discurso motivacionales. Por ejemplo, la conferencia que dio el 21 de septiembre de 2006 en la Universidad de Lyon, donde lo llamaron el genio de la profesión de la enseñanza 9 .

En 2005, recibió el Premio al Alto Servicio del Center for Youth Citizenship. Enseñó en la Universidad del Valle, Cochabamba (Bolivia), hasta 2008. En mayo de 2009 los médicos diagnosticaron un cáncer de vejiga.

Su último viaje a Estados Unidos, fue para recibir un tratamiento contr el cancer en un hospital de Reno que le había dejado postrado en una silla de ruedas y casi sin capacidad de habla.

El actor Edward James Olmos, pasó gran parte del año antes de empezar la película y también estuvo junto a Escalante en su última etapa y dijo: "Tres presidentes - Ronald Reagan, George H. W. Bush, William Clinton han invitado al notable profesor a la Casa Blanca en el pasado. Ahora que Escalante no puede viajar, le pido a Dios que el presidente Obama vea la forma de ver a Jaime Escalante y agradecerle por todo lo que ha hecho por nuestra nación". (Rocha, 2010).

Jaime Escalante falleció a sus 79 años, el 30 de marzo de 2010 tras una larga enfermedad que le había tenido internado en un centro médico de Reno,

\footnotetext{
${ }^{9}$ http://www.lyon.edu/webdata/groups/greensheet06-09-18
} 
en Nevada. Edward James Olmos, el día anterior condujo al profesor de matemáticas hasta su domicilio en Roseville, California, donde pasó sus últimas horas. El dijo: "Escalante murió rodeados de sus hijos y nietos".

El sábado 17 de abril de 2010, los restos mortales de fue motivo de tributo, con asistencia del gobernador de California, Arnold Schwarzenegger, congresistas, senadores y otras autoridades de ese país, y estudiantes que la llamaron su héroe, su maestro o su inspiración rindieron homenaje al educador. Al evento también asistieron su media docena de nietos, sus hijos Jaime y Fernando y vuida Fabiola, así como sus tres hermanos provenientes de La Paz: Olimpia, Bertha y Raúl.

El féretro estuvo durante un día en el salón donde cientos de estudiantes aprendieron ecuaciones, álgebra y cálculo impartidos por el profesor Escalante. "Una de las últimas cosas que me pidió, fue regresarlo al salón de clases donde, con tanto gusto, enseñó, matemáticas. Y así lo hice”, expresó el actor con voz entrecortada. El salón de clases de secundaria de Garfield fue cuidadosamente arreglado para que estuviera lo más parecido posible al que utilizó el maestro Jaime Escalante durante 17 años. Los mensajes positivos, la palabra "ganas", un pizarrón lleno de fórmulas matemáticas. "el Cálculo no necesita hacerse fácil, ya es fácil" decía un letrero.

El cortejo fúnebre partió de Garfield High School encabezado por Edward James Olmos, así como también los hijos, familiares, exalumnos, amigos y personas que, aunque no compartieron con él, conocían su trayectoria, cientos de personas caminaron hasta el estadio del East Los Angeles College (ELAC), a poco más de 2 kilómetros de ese colegio.

La ceremonia fue precedido por Edward James Olmos, el actor que lo personificó a Jaime Escalante en la película de Stand and Deliver en 1988 y que le permitió al actor recibir una nominación al Oscar como el mejor actor. Durante ese tiempo se recordó las anécdotas más destacadas del profesor Jaime Escalante.

Elsa Bolado ex alumna de Escalante y ahora profesora de desarrollo en el aprendizaje de inglés fue una de las alumnas de aquel grupo de estudiantes, en su mayoría latinos que dieron por segunda vez el examen de matemáticas, 
sorprendiendo a las autoridades educativas. Bolado expresó: "siempre le recordaré, porque me dejó muy grandes enseñanzas". El mandatario de California manifestó: "Escalante hizo que cada estudiante progresara.

Los restos de Escalante fueron sepultados en el cementerio Rose Hills Memorial Park en la ciudad de Whittier, al sur del Estado de California.

\subsection{Obras de Jaime Escalante}

El profesor Jaime Escalante trabajó en Bolivia y Estados Unidos. Como ya se ha dicho fue en una escuela secundaria del este de Los Ángeles, la Garfield High School, donde concitó la atención internacional. Sus estudiantes, la mayoría de familias de bajos recursos y de barrios de habla hispana, pasaron las pruebas de cálculo con puntajes muy altos. Al inicio se sospecha de fraude, pero luego descubrieron en Escalante a un excelente maestro. (Hanson, 2003). Este profesor ha dejado un legado muy importante en el campo de la educación matemática, como señala Perkin (2003), no sólo aportó conocimiento, sino también un arsenal de estrategias.

\section{El Programa de Matemática Jaime Escalante en Garfield}

El programa de matemática Jaime Escalante que se diseñó y se implementó en la Garfield High School se basa en la idea emergente al principio de su carrera docente en la década de los cincuenta: comprendió que los niños aprendían más rápido, cuando el aprendizaje era divertido, se trata de un juego o un reto (Escalante y Dirmann, 1990; Escalante, 2006, 2007).

En los años ochenta y noventa en el barrio de Los Ángeles le dio un enfoque de equipo, el profesor como técnico, los alumnos en el papel de equipo y el examen AP como el rival. El objetivo era ganar el partido, pero para esto introdujo a los alumnos en la disciplina y una dinámica trabajo duro. (Escalante y Dirmann, 1990; Escalante, 2007). 


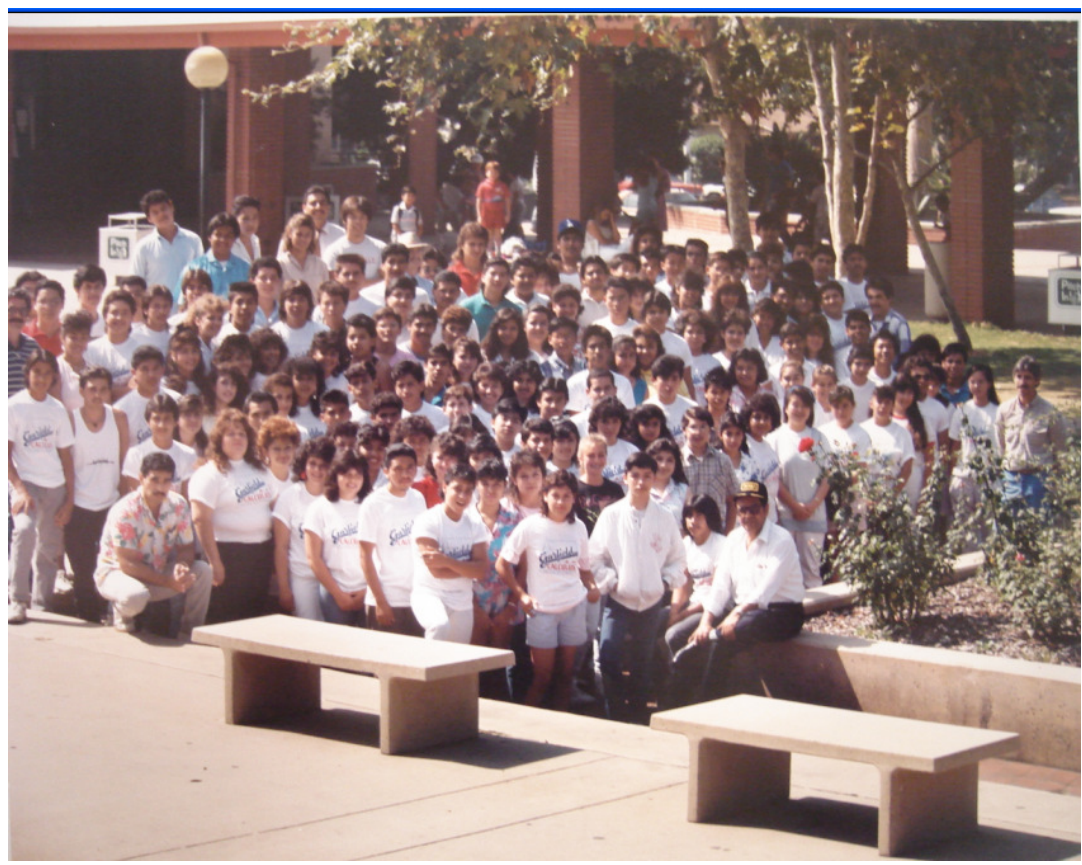

Estudiantes del Programa de Matemáticas de Escalante

El examen Advanced Placemend (AP), era la prueba más difícil de todos los exámenes administrados a nivel nacional para estudiantes de nivel secundaria y se pone cada año más duro. Menos del $2 \%$ de los alumnos de la escuela secundaria se presentaban al examen. En los años 1990 de todos los hispanos que asistían al examen, el veinticinco o treinta por ciento eran del Programa de Matemáticas de Jaime Escalante. Los que aprobaban tenían la posibilidad de ganar los créditos en la universidad en los cursos de matemáticas. (Escalante, y Dirmann, 1990).

La Garfield, estaba a punto de perder la acreditación en década de los 70 por ser uno de los peores colegios de enseñanza secundaria y los resultados de la educación eran paupérrimos ${ }^{10}$. Sin embargo, en 1987 el colegio fue ubicado en el cuarto lugar en el ranking nacional por el número de alumnos que aplicaban al examen de cálculo AP (Novak, 1993).

Posteriormente el Programa pasó a formar parte del Programa de verano del East Los Angeles College, que estaba diseñado para los cuatro últimos años de secundaria.

El criterio de selectividad para este programa, era, si el alumno quería formar parte del mismo y sinceramente quería aprender matemáticas. No era

\footnotetext{
${ }^{10}$ http://www.lanacion.comar/nota.asp?nota-id=574003
} 
una clase de dotados, la única cosa que se exigía era que tuvieran ganas (Escalante y Dirmann, 1990).

Escalante (2007), narra cómo empezó el Programa de matemáticas que él implementó en Garfield High School y cuál fue su motivación.

No fue fácil hacer frente a un programa deficiente del Distrito Escolar de Los Ángeles. Busqué ayuda del East Los Angeles College (ELAC). El presidente de ELAC, señor Ávila, administradores George Madrid y Paul Powers, y el señor Villavicencio, maestro de la escuela Griffith Junior High School, fueron mis fieles colaboradores. Con respecto a la motivación, en mi concepto "Latino", no podía aceptar que Garfield High School ofrezca un programa insuficiente con requisitos mínimos en la preparación para nuestra gente. Ejemplos: Solo 10 unidades en matemáticas (aritmética elemental equivalente a un tercero 0 cuarto grado de instrucción primaria), artes plásticas, imprenta, cerámicas, hojalatería, y carpintería. Con este tipo de instrucción secundaria engañamos y no preparamos a nuestros alumnos para un mejor futuro. (Escalante, 2007, párrafo 41).

Un periodista preguntó a Jaime Escalante: ¿si en algún momento sintió ganas de retirarse o no le salieron las cosas como esperaba?

Él respondió de la siguiente manera:

Uff, yo estuve en la lona más de 10 veces. He estado K.O. muchas veces, tuve que pasar muchas dificultades, no sólo económicas si no de otra índole, como el Handicap del idioma y la arrogancia del gringo que si te ve en el suelo te pisa y no te levanta. Pero no se cuenta las veces que uno esta en la 'lona'. Lo que se cuenta son las veces que uno se levanta. Para esto, aplique mi formula que dice: determinacion + disciplina + trabajo fuerte = camino al éxito. (Escalante, 2007, párrafo 35).

Escalante nunca imaginó que el éxito lagrado por sus alumnos que le llevaría a un reconocimiento internacional

Nunca paso por mi mente llegar a ser consejero de tres presidentes de este gran país. Llegué a formar muchos profesionales y mandar muchos estudiantes a las mejores universidades del país. Nunca pensé ser reconocido por colegios y universidades en tantos estados de la unión y en otros países como Canadá, México y Chile. (Escalante, en Pérez, 2009). 
El curriculum del Programa de Matemática de Jaime Escalante, estaba organizado de la siguiente manera:

Un estudiante debía cursar y aprobar las siguientes asignaturas para presentarse al examen AP: Algebra I, Geometría, Algebra II, Trigonometría, Análisis Matemático, Cálculo AB (de primer año de universidad) y Cálculo BC (de segundo de universidad). Esto era un programa de seis años pero debían completar en tres, por eso se implementó los cursos de verano. (Escalante y Dirmann, 1990).

Normalmente, Álgebra se tomaba durante el primer año, en verano después del décimo grado debían dominar la Geometría en un intensivo de ocho semanas. Algebra II en el undécimo grado, el Análisis Matemático y trigonometría era conseguido durante el verano entre el undécimo y duodécimo y en su último año los estudiantes tomaban el curso de Cálculo $A B$ que corresponde al primer año de universidad.

\section{Programa de Matemáticas de Escalante en el East Los Angeles College (ELAC)}

El éxito personal de Jaime Esclante y sus 18 estudiantes de Garfield en 1982, concitó la atención nacional e internacinal. Este incidente permitió a Jaime Escalante trabajar y llevar a acabo su programa de matemáticas en la ELAC, y en 1983 recibió el apoyo financiero de la fundación $A R C O$, que fue muy importante para el programa de verano en la ELAC. Al año siguiente la National Science Foundation (NSF) se unió al ARCO por tres años. (Escalante y Driman, 1990). Con la subvención de NSF, Escalante contrató cuatro profesores de secundaria y cuatro profesores de primaria para el programa de verano. Estos profesores se sumaron a Escalante y él les enseñó cómo motivar a los alumnos de noveno grado a estudiar matemáticas.

Escalante, se hizo conocido a través de la película Stand and Deliver (1988), y fue inundado por la visita de muchas personalidades. Esto desperto el celo profesional entre sus colegas. 


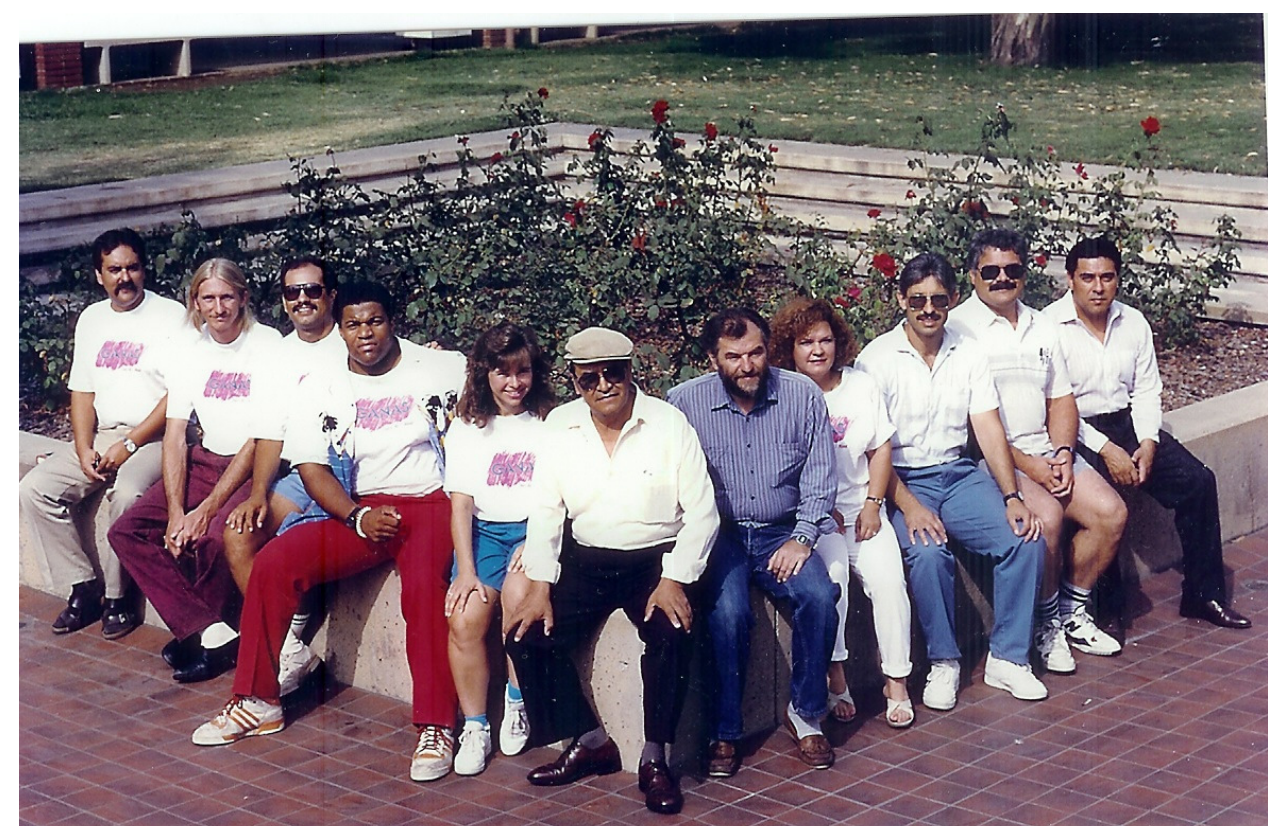

El equipo de profesores del Programa de Matemáticas de Jaime Escalante En los últimos años he sido inundado con preguntas de los docentes interesados, los líderes de la comunidad, y los padres acerca de mi éxito en la enseñanza de la matemática a los niños de las minorías pobres. Yo no soy un teórico, mi experiencia es en el salón de clases y mi primer compromiso es con mis alumnos.

Sin embargo estoy dispuesto a compartir mis opiniones sobre este tema en la esperanza de que podría ser útil para otros profesionales en el campo de la educación. Tengo la esperanza, que este artículo proporcionará algunas repuestas. (Escalante y Dirmann, 1990)

\section{Influencia en el cambio del Currículo Nacional de Estados Unidos}

Jaime Escalante influyó en el cambio del Currículo Nacional y su método fue adoptado por los colegios en todos los Estados Unidos (Durán, 2010). En la misma línea el periodista Jay Mathews, que escribió el libro Escalante The Best Teacher in America, volvió a escribir sobre Jaime Escalante en Washington Post diciendo que "Jaime Escalante cambió por completo la educación secundaria", ademas, manifestó que "gracias a Escalante se decidió a escribir sobre educación"; fue reproducido en el periódico El Deber de Santa Cruz, Bolivia por Souza (2010, Abril 4). Además, el periodista boliviano señala que ahora Mathews, es una eminencia y elabora el ranking nacional (Challenge 
index), y que evalúa las escuelas públicas más prestigiosas de los Estados Unidos.

Escalante con la sencillez y la humildad que lo caracteriza comenta de la manera siguiente:

Lo primero que hice en Estados Unidos fue infundir confianza en la materia que todos tenían como imagen negativa. Luego procuré atraer a los padres de familia porque la escuela sóla no puede educar. También vi la necesidad de apoyo económico, entonces pedí a una compañía petrolera que me colaboró. Con estos tres aspectos consolidados busqué a algunos profesores que me siguieran en la metodología basada en el criterio "aprender haciendo." (Escalante, en Jara y Sagárnaga, 2008, julio 6).

Según Perkins (2003), "Escalante y su colega Benjamín Jiménez expandieron el programa de enseñanza del cálculo", pero de acuerdo Mathews (1988), Jiménez era un profesor joven que estaba a punto de dejar la docencia por no poder controlar la disciplina en el aula, sin embargo, al trabajar con Escalante, llegó a ser un profesor galardonado. (Escalante y Dirmann, 1990).

Escalante (2007, párrafo 34), reconoce que Estados Unidos le ayudó mucho. Le dio las oportunidades y él no dejó pasar ninguna; desde lavador de platos, administrador de la empresa donde trabajó y en la enseñanza de las matemáticas, pero reconoce que él también ha ayudado en el cambio del currículun de la enseñanza de las matemáticas en Estados Unidos:

Desde luego he cambiado el sistema de educación en los Estados Unidos. Hice una innovación completa donde los niños podían aprender algebra al cuarto o quinto año de primaria. Hacer el álgebra con los cuadraditos que me has visto. (Entrevista, 2007, párrafo 61)

Su contribución al sistema educativo de Estados Unidos no sólo fue desde Garfield high School, sino también desde FUTURES con Jaime Escalante. Sus recursos didácticos o materiales educativos en un principio eran elaborados por el mismo. En la siguiente página se muestran algunos de los recursos que ha utilizado el profesor Jaime Escalante en los seminarios para estudiantes y profesores en la Universidad Adventista de Bolivia. 




Escalante, fue invitado a la Casa Blanca por tres presidentes de Estados Unidos: Ronald Reagan, George H. W. Bush y William Clinton.

El éxito personal del profesor Jaime Escalante en el Garfield High School y su programa encendió el aprecio por las matemáticas y las ciencias entre millares de estudiantes de las escuelas secundarias del Este de los Angeles y de las escuelas secundarias menores. El programa ahora se reconoce a nivel nacional para sus realizaciones en producir estudiantes excepcionales y acertados.

Jaime Escalante influyó en el sistema de educación en los Estados Unidos. Creía en la capacidad intelectual de los estudiantes y generando un cambio.

\section{FUTURES with Jaime Escalante}

En los años noventa el profesor Jaime Escalante participó en un programa televisivo sobre educación, en la que defundió su singular forma de impartir la enseñanza de las matemáticas a través del humor y el estímulo a la confianza y autoestima. Fue la serie televisiva de Public Broadcasting Service (PBS), denominado "FUTURES with Jaime Escalante", donde fue conductor de Futures 1 y Futures 2. La serie era uno de los programas educativos más populares de la historia de PBS y fue visto por miles de espectadores. 


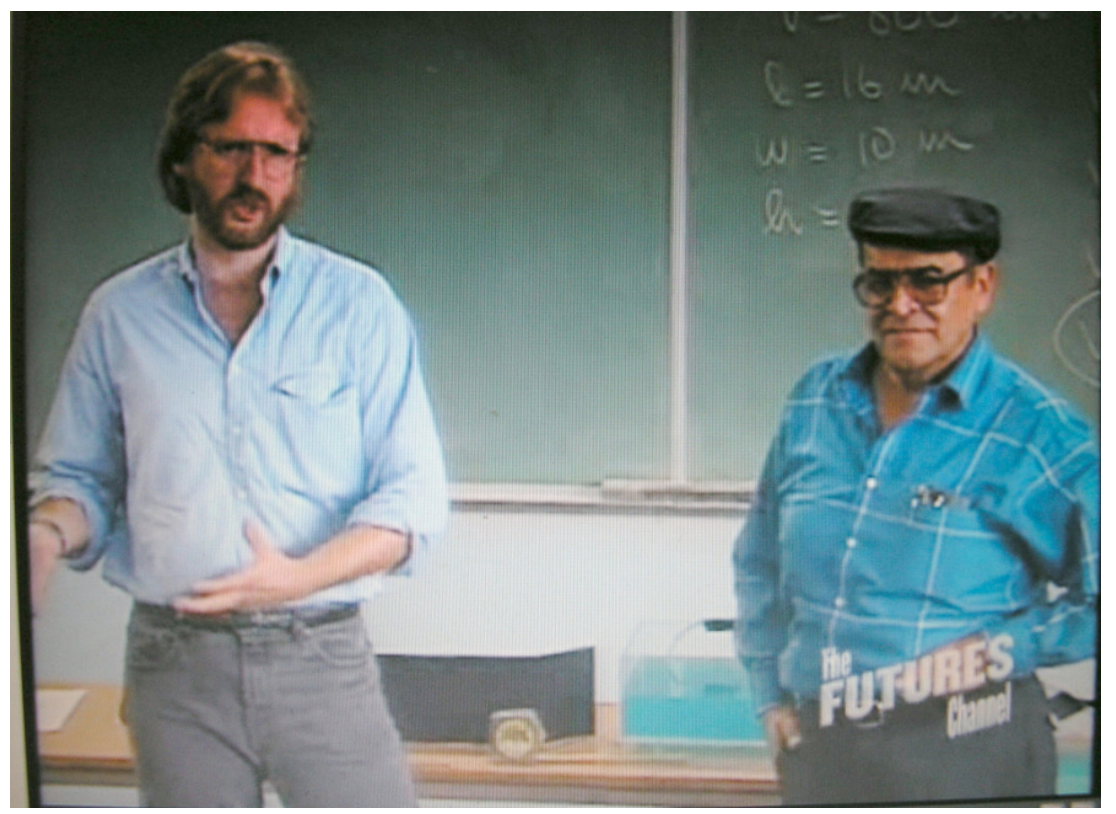

Jaime Escalante con James Camerun

Científicos, astronautas, ingenieros y famosos visitaron el aula televisiva donde dictaba clases y hablaron con los estudiantes de cómo las matemáticas pueden ser utilizadas en cualquier labor del quehacer humano.

El profesor boliviano logró establecer técnicas para que los estudiantes capten la importancia y servicio de carreras donde se aprende matemáticas y física. Esto puede ser utilizado con estudiantes de nivel secundario y universidad. El programa demuestra las aplicaciones matemáticas en diversas profesiones como la agricultura, moda, la ingeniería y los deportes. Ha sido honrado con más de cincuenta premios de organizaciones educativas y profesionales, incluyendo el honor más alto del campo que difunde, la concesión Foster de George Peabody (Bay, 1999).

\subsection{Premios y Reconocimientos}

El profesor Jaime Escalante, uno de los máximos representes de la intelectualidad boliviana en el extranjero, fue motivo y merecedor de varios premios y reconocimientos en Estados Unidos y fuera de ese país:

- La Medalla Presidencial a la Excelencia Académica

- El Premio internacional de Educación "Andrés Bello"

- Grados de Doctor Horis Causa (8 Universidades).

- Introducción al The National Hall Fame in Education. 


\section{La Medalla Presidencial a la Excelencia Académica}

En 1988, el presidente Ronald Reagan, le otorgó: The Presidential Medal for Excelence in Education (La Medalla Presidencial a la Excelencia en Educación), en reconocimiento a sus logros increíbles con sus estudiantes del Garfield High School en el Este de Los Angeles, California, particularmente en el año 1982. ( Mathews ,1988, p. 185).

\section{El Premio internacional de Educación "Andrés Bello"}

En 1992, el Consejo Interamericano para la Educación, la Ciencia y la Cultura de la Organización de los Estados Americanos (OEA) otorgó a Jaime el Premio Internacional de Educación "Andrés Bello". Una fotocopia de este documento adjunta en la sección de anexos de este trabajo y dice:

Mención Honorífica correspondiente al año mil novecientos noventa y uno como reconocimiento a la eficacia del método por él creado para la enseñanza de la matemática en el nivel de educación secundaria y firman el Secretario General y el Secretario del Consejo. Washington, D. C., 13 de enero de 1992.

\section{Grados de Doctor Horis Causa}

Entre las universidades que le confirieron el Grado de Doctor Honoris Causa, tenemos identificados las siguientes:

1. La University of South Carolina, le otorgó el grado de Doctor en Ciencias (1989).

2. El GMI Engineering \& Management Institute, le dio el grado de Doctor en Humanidades (1989)

3. La ST. John Fisher College, le confirió el grado de Doctor en Humanidades y Letras (1990).

4. La California State University, le dio el grado Doctor en Humanidades y Letras (1990).

5. La Concordia University. Le reconoció con el grado Doctor en Leyes (1990).

6. La University of Northern Colorado. Le otorgó el grado de Doctor en Leyes (1990) 
7. La Wittenberg University, le confirió el grado de Doctor en Humanidas y Letras (1998).

8. La Susquehanna University, le dio el grado de Doctor en Educación (2006).

\section{Otros reconocimientos}

Es imposible registrar todos sus reconocimientos que ha recibido, como él mismo dice: "ya no tengo espacio para colocar las plaquetas". Las paredes tanto de su biblioteca personal y la de su laboratorio de su casa en Cochabamba estan llenas de plaquetas. Pero, no estan todas.

En Estados Unidos se ha levantado un enorme mural junto a Edward James Olmos, quién lo personificó en la película Stand and Deliver, en la intersección del Boulevard Wilshire y la Calle Alvarado, en el Distrito Westlake justo al noroeste del centro de Los Ángeles. Su experiencia inspiró la edición de varios libros y artículos relacionados con la educación y la película más popular en educación Stand and Deliver.

\subsection{Escalante en la opinión de otros}

En este apartado hemos visto conveniente, registrar las opiniones de algunas otras personas:

David Perkins autor del best-seller The Mind's Best Work, codirector del Harvard Proyect Zero (centro de investigación para el desarrollo cognitivo) e investigador superior asociado en Harvard Graduate School of Education, vive en Estados Unidos, en Cambridge, Massachussets, dice: "Escalante no sólo aportó conocimiento sino un arsenal de ingeniosas estrategias para motivar a sus alumnos". El mismo autor señala que "el estilo de enseñanza de Jaime Escalante es un verdadero paradigma de la Teoría Uno, con explicaciones claras y gráficas, prácticas y realmente abundantes y motivación en gran escala".

La Teoría Uno afirma:

La gente aprende más cuando tiene una oportunidad razonable y una motivación para hacerlo. (Perkins, 2003, p. 53). 
Para el senador Harry Reid Jaime Escalante no puso un granito de arena, sino una montaña de arena para mejorar la educación de Estados Unidos e hizo la siguiente declaración registrada y publicada por diferentes medios de comunicación:

Nuestro país sufrió ayer la pérdida de un gran hijo, quien puso no un grano de arena, sino una montaña de arena para mejorar nuestra sociedad. Como maestro, Jaime Escalante sacó a decenas de estudiantes adelante, labrando exitosos profesionales de adolescentes cuyo futuro fuese dudoso antes conocerle. (Duran, 2010).

Vanesa Márquez ahora profesora de Garfield, quien fué como alumna en 1988, "Yo no tuve buenos profesores, pero con el profesor Escalante yo entendía todo mejor y mas fácil”"11.

La Hispanic Heritage Foundation (La fundación de herencia hispana), reconoce con Honor en Educación a Jaime Escalante en 1988 al considerar un visionario y héroe ${ }^{12}$. Desde que ganó el reconocimiento nacional por sus logros en la enseñanza de la matemática avanzada con los estudiantes catalogados como inenseñables, él ha sido muy venerado por los educadores, administradores profesionales y líderes políticos. La controversia del 1982 hizo de Jaime Escalante un héroe nacional resaltando su aproximación innovadora de los estudiantes a través de las ganas.

Como ha dicho Jay Mathews periodista de Washington Time, escribió un libro titulado "Escalante: The Best Teacher in America" y dice que le pone ese adjetivo porque no conoce otro profesor que haya conseguido un resultado tan extraordinario (Mathews, 1988).

El actor Edward James Olmos, nominado al Oscar por su actuación como Escalante, pasó gran parte de un año con Escalante antes de comenzar la película, dice: "pude hacer amistad con una de las mejores personas del planeta"13 proclamanado que Escalante tenía la mayor profundidad de carácter de cualquier personaje que él hubiera representado.

\footnotetext{
${ }_{11}^{11}$ http://www.laprensa.com.bo/noticias/04 03 10/noticiasphp?nota=04 03 10segu3.php.

${ }_{12}$ http://www.hispanicheritage.org/hispanic det.php?id=21

${ }^{13}$ http://www.diario.com.mx.php?notaid=c6d10c7e8blbbbe59cb56af799b7c2b6b
} 
El famoso boliviano, Jaime Escalante, profesor de matemáticas y símbolo de la comunidad latina en los Estados Unidos...Escalante conocido por sus alumnos como "Kimo". El actor norteamericano Edward James Olmos destaca como colaboró con los estudiantes californianos con una convicción reconocida por la educación norteamericana. Recordaba por reflejar la emotividad que imprimía el profesor boliviano a la hora de enseñar matemáticas. "Now, Kimo needs your help"14 (Ahora Kimo Necesita tu ayuda).

Lo que es la vocación... y también la fama. No es para menos cuando se tiene todo el curriculum conquistado en Estados Unidos, una película sobre su experiencia e incluso un colegio que en Cochabamba lleva su nombre. (Revista suplementaria ASI de Opinión.)

\footnotetext{
${ }^{14}$ http://www.eldeber.com.bo/2010/2010-03-05/vernotaahora.php?id
} 

Este capítulo ofrece las creencias y concepciones del profesor Jaime Escalante sobre las matemáticas, su enseñanza y su aprendizaje, que subyacen en su metodología y algunos recursos didácticos implementados para la enseñanza de las matemáticas en el nivel secundario.

\section{CAPITULO V}

\section{METODOLOGÍA DE LA ENSEÑANZA DE LA MATEMÁTICA}

\subsection{Introducción}

El binomio enseñanza-aprendizaje es, sin duda, el corazón de la educación en general, que busca provocar en el ser humano su crecimiento intelectual y el desarrollo de competencias técnicas propias a la intencionalidad curricular del proceso de enseñanza y aprendizaje. Este proceso, ampliamente estudiado por educadores profesionales (Sillero y Balmori, 2008), ha creado una variedad de métodos o modelos, cada uno con el propósito de imprimirle efectividad a la finalidad del acto educativo.

Los métodos en general, se diferencian por la intensidad de interacción concedida entre el profesor y el alumno; algunos métodos asignan la responsabilidad total al profesor, dejando poco o nada la iniciativa de participación del alumno; contrariamente, otros centran una participación extensa al alumno y muy poca al profesor; otros mantienen un equilibrio compartido entre ambos.

En sus enfoques más tradicionales, la Educación Matemática ha dado especial atención a la transmisión de conocimientos. Pero en enfoques más innovadores, aparecen objetivos más ambiciosos como es el desarrollo de la creatividad matemática de los estudiantes (Alsina, 2007). Esta es una de las clasificaciones más aceptadas entre los educadores matemáticos: la metodología pasiva y la metodología activa. Aunque el concepto de la buena 
enseñanza de la matemática es un concepto huidizo, no obstante ha permeado las publicaciones de las últimas décadas (Wilson, Cooney y Stinson, 2005).

Muchos investigadores educativos creen que la nueva visión de aprendizaje que ha aparecido en las últimas décadas debe tratar con un importante cambio en la enseñanza (Lunenberg, Korthagen y Swennen, 2007).

Muchas personas entre investigadores, profesores y estudiantes, señalan que Jaime Escalante fue conocido por su forma singular de enseñar matemáticas. Los documentos Stand and Deliver (Menéndez y Musca, 1988), Escalante: The Best Teacher in America (Mathews, 1988), y Jaime Escalante: Inspirational Math Teacher (Schraff, 2009), resaltan éste fenómeno desde diversas perspectivas.

En base a las entrevistas a Jaime Escalante, las observaciones de sus seminarios y talleres para profesores, y los documentos existentes que han estado a mi alcance, he hecho una aproximación a la metodología de enseñanza de matemáticas, centrada en las concepciones y creencias sobre la matemática, su enseñanza y aprendizaje.

\subsection{Enriquecimiento Matemático - Método Escalante}

El método de enseñanza de Jaime Escalante parte de una premisa: los alumnos tienen una idea flaca o imagen negativa de las matemáticas. Su metodología está basada en el principio de "aprender haciendo" (Escalante, en Jara y Sagárnaga, 2008, Julio 6).

En 1952, por la invitación del profesor Humberto Bilbao, comenzó a enseñar matemática y física en el Instituto Americano, aún siendo estudiante de segundo año de Magisterio, después en el Colegio Bolívar y finalmente en el San Calixto (Escalante, 2007). Al principio de su carrera encontró que los niños aprendían más rápido cuando el aprendizaje era divertido, cuando se trata de un juego o reto (Escalante y Dirmann, 1990).

La acción crea las condiciones para el aprendizaje, y lo hace más efectivo y más gratificante. Escalante lo primero que hace es infundir confianza 
en la matemática que la mayoría tiene imagen negativa, pero dice: "que no ha patentado el método, aunque tiene su propia dinámica"

No he patentado el método, pero tiene su propia dinámica. Muchos profesores lo han adoptado, sobre todo en Texas y en California. Ellos vieron primero la parte humana, la parte pedagógica de este maestro, y ellos adoptaron y pusieron en marcha estos mismos principios: Primero, si vas a suspender a un alumno que tiene condiciones, tienes que contar 10 antes de colocar la calificación mala. Para que veas que está suspendido, tienes que averiguar por qué no puede. Tal vez son factores económicos. Segundo, tal vez son factores sociales o de familia: la madre y el padre están peleados, no colabora el padre, es decir, no hay colaboración en el hogar. Tercero, a lo mejor tiene un complejo el alumno, o una idea flaca de las matemáticas, es decir, odia la matemática y por consiguiente te odia a ti también. Entonces tienes que acercarte, es como cuando uno va al médico y le dice que está enfermo. Lo primero que el médico pregunta ¿de qué adolece? De acuerdo a eso le da prescripción, el mismo principio vamos a seguir. Es eso, lo que yo hacía del Yocalla, (muchacho), que no puede, hay que saber si está metido en pandillas. Saber qué es lo que hace, entonces lo primero que yo hacía al entrar a las clases, era preguntarle si fumaba. "Ah, eso mata a las hormonas, no vas a pasar de curso, es temprano, muy temprano para empezar. Usted chupa, le tira al trago, eso es peor, porque el alcohol va directamente al cerebro, no pasa por la digestión, te embrutece, te quita toda la posibilidad de tener la memoria retentiva que necesitas, porque cuando yo ponga algo en la pizarra tienes que sacar una fotografía y eso llama memoria visual". Segundo, respeto al estudio y aprovecha todas las oportunidades que te ofrece este país. Pocos ofrecen eso. (Escalante, 2007, párrafo 59).

Jay Mathews, actual columnista del Washington Post y autor del Escalante The Best Teacher in America, cree que Escalante es el mejor profesor de Estados Unidos porque "ningún profesor ha hecho tanto como él, cambiar aquella creencia de que los chicos de hogares pobres no pueden aprender mucho. Nadie como él ha hecho tanto para convencer a otros profesores que lo que esos estudiantes necesitan es más tiempo y también los motiven para aprender"15. Esta fue una de las razones para el título del libro.

\footnotetext{
${ }^{15}$ http://www.eldeber.com.bo/2010-03-12/vernotaahora.php?id=100312142749
} 
Un investigador de Harvard, David Perkins (2003), en su libro Smart Schools. From Training memories to educating minds (la escuela inteligente: del adestramiento de la memoria a la educación de la mente), pone como un ejemplo la experiencia de Jaime Escalante al analizar los "Jardines de victoria para revitalizar la educación".

Otros documentos de columnistas, los testimonios de sus estudiantes y sus amigos, destacan su forma singular de enseñanza de las matemáticas, indicando que Jaime Escalante trasformó el programa de estudios de matemática de la escuela secundaria de Garfield del Este de Los Ángeles e impulsó a sus estudiantes a dar lo mejor de sí hasta que Garfield llegó en 1978 al cuarto lugar en el ranking nacional, por el número de alumnos que realizaban el examen AP de cálculo (Novak, 1993).

Algunos investigadores de educación han intentado capturar los principios pedagógicos y otros se han quedado con la parte humana, su espíritu de superación, etc. Por ejemplo, Perkins describe de la manera siguiente:

Cuando Jaime Escalante llego a Garfield y dio los primeros pasos que luego lo llevaría al reconocimiento de toda la nación, el lugar no era lo que se dice favorable. El 95\% de los alumnos eran latinos y provenían de familias de pocos recursos económicos y escasa educación. La tasa de deserción era muy alta. Los logros académicos raros. Es difícil imaginar un sitio menos propicio para aplicar un programa de esas características. Sin embargo, muchos alumnos de Escalante aprobaron exámenes de cálculo de nivel superior, como los de la famosa Bronx High School of Science (Escuela secundaria de ciencias del Bronx).

¿Qué recursos mágicos empleaba? Ante todo, cabe decir que nada que exija tanta dedicación tiene que ver con la magia. Para Jaime Escalante, la enseñanza de la matemática se convirtió en una obsesión que le demandaba, prácticamente, las veinticuatro horas del día. Se encontraba con los alumnos antes y después del horario de clases. En las primeras horas de la noche, solía visitar a los padres que obligaban a sus hijos a mantener empleos incompatibles con los estudios. Pero Escalante era una persona comprometida y con una voluntad de hierro. Discutía, halagaba y amenazaba a los padres, 
directores y alumnos sin otro propósito que inculcar el espíritu de la matemática y desarrollar la comprensión y la destreza en la materia. (Perkins, 2003, p. 198).

Como ya fue expuesto en el marco teórico, que "detrás de cada modelo pedagógico existe una filosofía de la matemática," pero la filosofía personal del profesor está configurada por un sistema de creencias (Thompson, 1992), y la existencia de una fuerte relación del impacto de las creencias sobre la práctica (Ernest, 1989). Esto nos induce a mirar las concepciones y creencias que subyacen esta metodología del profesor Jaime Escalante.

Sierra (2004), apoyado en Steiner, sostiene que las concepciones acerca de las enseñanzas de las matemáticas están determinadas de modo más o menos explícitas por nuestras concepciones sobre las matemáticas como disciplina científica.

Los maestros poseen creencias particulares de grados variantes de convicción que desarrollan las perspectivas personales de la asignatura. El sistema de la creencia es organizado por la concepción de la matemática con componentes que consisten en creencias, conceptos, significado, reglas, imágenes mentales y preferencias conscientes o subconscientes acerca de la disciplina de matemática (Thompson, 1992).

Ernest (1989), cree que la concepción del maestro reside en su sistema de creencias, indicando que la clave de los componentes de la creencia del maestro de matemática es la concepción del maestro sobre la naturaleza de la matemática y su sistema de la creencia acerca de la naturaleza de la matemática en conjunto.

Las concepciones y creencias no pueden ser observadas ni medidas, pero pueden ser inferidas en base a lo que hacen, dicen y piensan. Estas han sido extraidos de la entrevista grabada, los documentos públicos y personales, las observaciones de los videos y los seminarios y talleres para profesores y estudiantes del magisterio tanto en la Universidad Adventista de Bolivia (Cochabamba) y otros departamentos del país, como: Tarija, Santa Cruz, La Paz y Oruro. 


\subsection{Concepciones y creencias sobre la matemática}

En este estudio se trata de indagar las concepciones y creencias sobre la matemática como disciplina científica de Jaime Escalante. No es muy fácil hacer la distinción entre las concepciones y creencias, e incluso carece de importancia para algunos investigadores, como Thompson (1992).

Jaime Escalante sostiene las siguientes concepciones o creencias:

- La matemática se descubre y se inventa por la necesidad de resolver problemas.

- La matemática es una actividad antigua y polivalente.

- La matemática está en todas las ciencias.

- La matemática es la ciencia del pensamiento.

- La matemática no necesita ser hecha fácil, ya es fácil.

- La matemática se define en cuatro palabras: concepto, lenguaje, procedimiento y aplicación.

\section{La matemática se descubre y se inventa}

Este problema ha preocupado a muchos educadores matemáticos, como hemos señalado a Ernest (1989), que distingue tres concepciones sobre la matemática. En la visión platónica las matemáticas son descubiertas y no creadas. Jaime Escalante tiene la concepción de que la matemática se descubre, por ejemplo, dice: "yo he descubierto este método de integración."

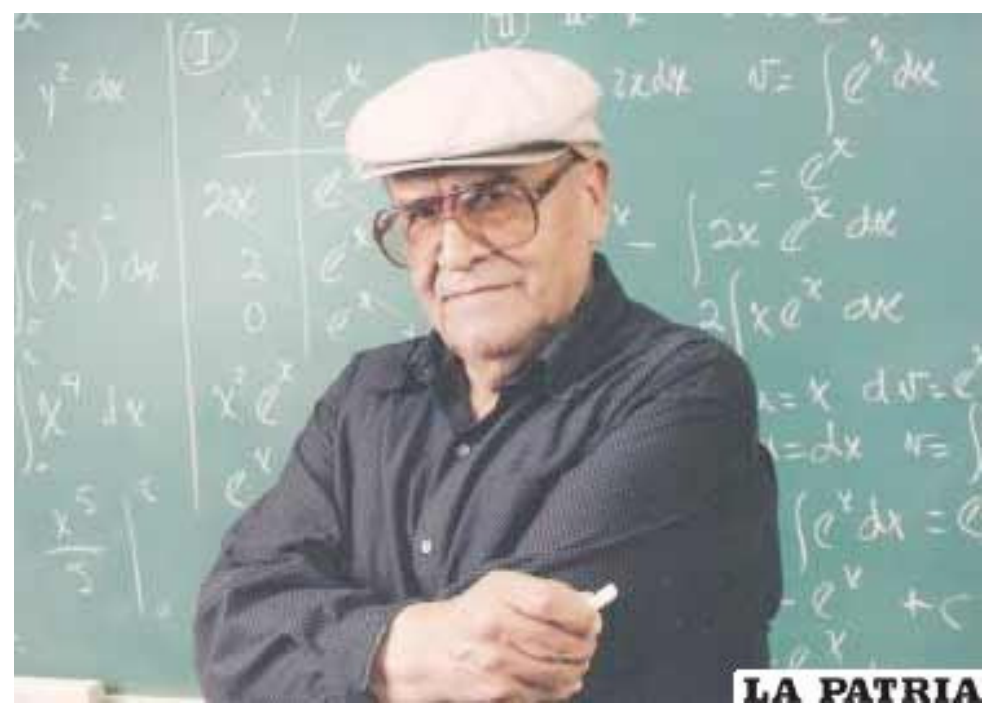


En la entrevista le pregunté: “¿cómo se aplicaba su método para la integral de logaritmo natural de x?", "Eso me gusta, lo vamos a mirar cuando tengamos un poco de tiempo", dijo Escalante. Pero, ya no hubo tiempo para seguir discutiendo a causa de su enfermedad. El solía decir: "constantemente estoy buscando el clic, algunas veces me he demorado uno o dos años, pero al final uno encuentra."

Creía que los signos matemáticos nos permiten ir más allá de lo que la mente puede cuantificar y sin exagerar decimos que los símbolos matemáticos están en segundo lugar después del alfabeto y son instrumentos del progreso humano. (Escalante, 2008)

Por otro lado, sostenía que los objetos matemáticos eran dependientes del ser humano y la matemática existe desde que existe el hombre. Esto explica la analogía utilizada para explicar el desarrollo de la matemática con el desarrollo de la comunicación y parte desde el Chasqui (Indio que llevaba las cartas corriendo de pueblo en pueblo), hasta la era digital en que vivimos (Escalante, 2007, párrafo 65). Además, señala que Newton y Leibniz disputaban la paternidad de la invención del Cálculo. Escribe lo siguiente:

Euclides se enfrentaba a su rey Ptolomeo por negarle atajos para la mejor comprensión del cálculo matemático. Newton y Leibniz disputaban la paternidad de la invención del cálculo diferencial que ayudaban al progreso de la ciencia del pensamiento lógico. ¿Por qué prestar atención a remotos intentos que hoy día han quedado ampliamente sepultados por el sistema binario y la conquista del espacio?

Simple, lo que es valioso en la matemática antigua ya fue incorporado en la matemática actual, entonces por qué no olvidarlo. No, no se puede, debemos recordar a los descubridores de esta ciencia, la influencia de los hindúes creadores o descubridores del CERO le pusieron la música y la letra a la NUMERACIÓN DECIMAL y los italianos pusieron en práctica en la Física, Química, Biología. Recordemos que somos herederos de culturas: Griega, Romana y Árabe para ellos posiblemente la matemática como ciencia no era esencial para nosotros es imposible hablar de ciencia sin mencionar a genios como Arquímedes, Fermat, Descartes, Al.kuwarizmi. Hoy la ciencia de los números nos permite vivir la ERA DIGITAL. (Escalante, 2008, p. 2) 
También se inscribe en la concepción o visión dinámica de Ernest (1989), que considera que las matemáticas como un cuerpo en continuo expansión como creación o invención humana. En las narraciones de la página anterior existen atisbos de que la matemática es una invención humana. En 1993, en la entrevista por Novak (1993), señala que: "por 10 semanas no usa libros, sólo hace experimentos en la clase para mostrar las aplicaciones y luego sacar los conceptos" también decía: "Yo he inventado la multiplicación con los dedos"

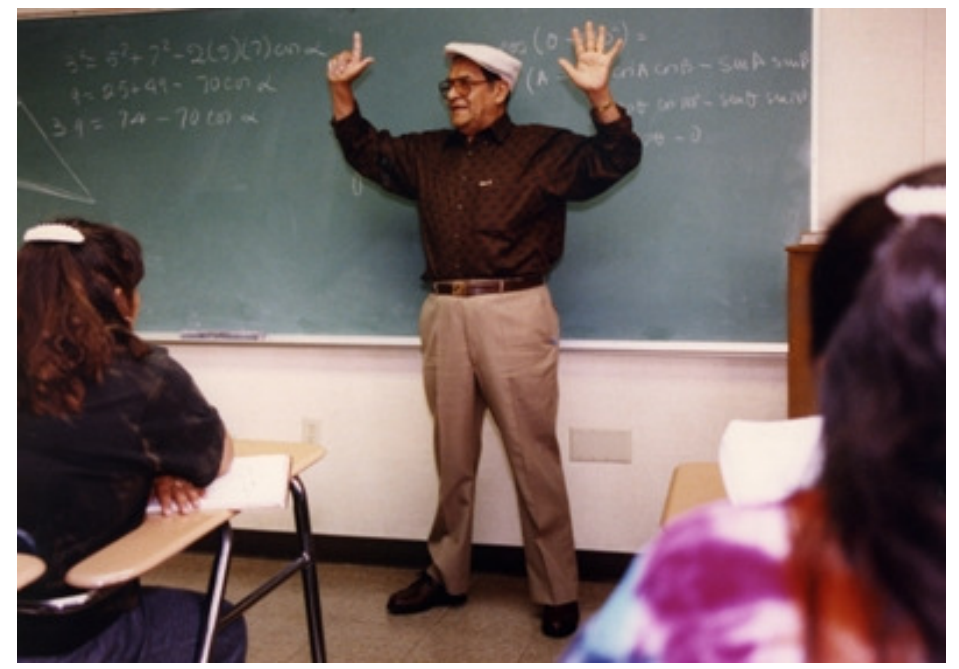

Jaime Escalante, tenía la concepción platonista y dinámica. Parece dar razón a Martínez (2006), quien al hablar de los métodos científicos concluye que: "ni Newton era tan newtoniano, ni Descartes era tan cartesiano". Pero Escalante, adoptó estas concepciones de manera conciente y voluntario.

Podríamos ubicar en la línea de Popper, las matemáticas a veces son construidas y descubiertas o, lo que es lo mismo, los objetos matemáticos son de invención o creación nuestra pero también existen independientes de nosotros los cuales deben ser descubiertas.

\section{La matemática es una actividad antigua y polivalente}

Para Jaime Escalante la matemática es una actividad antigua. Ella existe desde que existe el ser humano. Prácticamente todo ser humano es un matemático en algún sentido y dice: "El hombre primitivo no sabía leer no tenía un alfabeto pero si usaba matemáticas cuando con los dedos de la mano indicaba cantidades sin tener un sistema de numeración”. (Escalante, 2008, p. 
1). Y es polivalente porque ha tenido diferentes fines u objetivos. Además, sostiene que las diferentes civilizaciones tenían nociones de matemáticas:

Los PIELES ROJAS para contar usaban dedos de una mano y cuando llegaban a 5 usaban los dedos de la obra mano, y cuando llegaban a 10 usaban los dedos de los pies; cuando se les terminaba decían INDIO COMPLETO.

En la civilización AYMARA el pastorcito llevaba una bolsita (chuspa) en la cintura y en ella estaban el número de piedrecitas igual al número de ovejas del rebaño. Al final de la jornada sacaba de la chuspita una piedrita cada vez que entraba una oveja al corral, [1-1] (correspondencia de uno a uno) tal que entrando la última oveja él estaba sacando la última piedrita, lo contrario significaba que la ecuación no verificaba, había que buscar la oveja perdida.

Estas referencias son testimonio de los inicios de la matemática como ciencia. En este tipo de análisis es fácil ver en la cultura TIHUANACOTA la puerta del sol presenta la geometría plana de Euclides, se observa el concepto de simetría, el círculo, la circunferencia, el cubo, el cuadrado, las rectas paralelas, perpendiculares, los ángulos, etc. esto muestra que esta civilización conocía esta ciencia no se sabe si la puesta del sol y los palacios decorados con monolitos tallados a mano son contemporáneos con las pirámides de Egipto pero si muestran la evolución de la ciencia del pensamiento.

Los INCAS seguían las posiciones del satélite Luna para sembrar mientras que Pitágoras contribuidor de esta ciencia en su secta vegetariana sacrificaba bueyes a los dioses para acelerar el descubrimiento de su teorema. (Escalante, 2008, p. 1).

En 2005, en su disertación en XI Congreso de la Sociedad Boliviana de Matemáticas celebrado en Cochabamba, dijo: "Los Aymaras conocían la matemática antes que los Griegos y Egipcios" y a sus alumnos de Garfield donde la mayoría eran hijos de familias mexicanos, Escalante les decía: "Ustedes burros, llevan la matemática en la sangre, sus antepasados los Mayas, conocían el cero antes que los Griegos y los Romanos" (Mathews, 1988).

\section{La matemática está en todas las ciencias}

Para Jaime Escalante, cree que "la matemática está presente en todas las ciencias" en una conferencia para profesores de matemáticas dijo: "la 
matemática está presente en las más insospechosas expresiones de la vida cotidiana" por eso decidió mejorar la alicaída imagen que tiene esta ciencia entre los alumnos y por eso siempre estaba buscando una forma de enseñar y aprender Matemáticas de una manera divertida y efectiva. Parece coincidir con National Council Teacher of Mathematics (NCTM, 1991), que registra, la matemática está en el corazón de muchas carreras y vidas exitosas.

Vivimos en la ERA DIGITAL, esto significa que no debes levantar las mano, no te rindas, aprovecha esta oportunidad, ten confianza, elige una carrera que va de acuerdo al avance de la tecnología con una mejor remuneración económica. LAS MATEMÁTICAS están en todas las otras ciencias. Recuerda que tu obligación y responsabilidad es beneficiarte con el aprendizaje de esta ciencia. (Escalante, 2008, 1).

A sus estudiantes de Garfield les decía: "mis dos puertas están abiertas a lo largo del día. Recuerden que estamos en Garfield. Nosotros preparamos a los estudiantes para la universidad. Si usted ve la química, física, biología, electrónica el lenguaje es matemática” (Escalante, 2007; Mathews, 1988, pp. 249-250; Schraff, 2009, p. 70)

\section{La matemática es la ciencia del pensamiento}

Según Jaime Escalante la matemática es la ciencia del pesamiento y los signos matemáticos permiten ir más allá de lo que la mente puede cuantificar

La matemática, como objeto de enseñanza es quitar el velo y gozar de sus encantos, su escritura, (símbolos) conceptos (lenguaje) preguntas y porque no decir su evolución, su historia, todo esto revela la belleza de esta ciencia del pensamiento. Les digo a mis alumnos - Muchas de las cosas que nos rodean pueden ser descritas matemáticamente -, aun conceptos matemáticos son inherentes en la estructura de células vivientes. (Escalante, 2008, p. 3)

\section{Jaime Escalante define la matemática en cuatro palabras}

La matemática según Jaime Escalante se define en cuatro palabras: concepto, lenguaje, procedimiento y aplicación. Esta definición fue dada en el cierre del II Congreso Nacional De Ingeniería Civil, celebrada en Oruro, Bolivia entre los días 16 al 20 de octubre de 2006. 
(...) El profesor boliviano define las matemáticas en cuatro palabras: Concepto, lenguaje, procedimiento y aplicación, pilares fundamentales para practicar la materia. (Congreso Nacional de Ingeniería Civil, 2006)

\section{$\underline{\text { Concepto }}$}

El concepto es tener una representación clara de las cosas. El concepto debe sacarse de las cosas que el alumno más conoce o sabe. Si hay algo que el alumno conoce, entonces se enciende el foquito verde y comprende (Escalante, 2007). Enfocaba los conceptos matemáticos de una manera vivaz, utilizando las metáforas extraídas del deporte a fin de que los estudiantes recordasen y captasen las ideas (Perkins, 2003). En Garfield High School uno de los deportes que utilizó, fue el basketball y relacionó los conceptos con la pasión de muchos alumnos (Escalante, 2007; Escalante y Dirmann, 1990). Escalante recuerda las enseñanzas de su madre de la siguiente manera:

Mi madre era profesora y aprendí mucho de ella. Cuando era niño mi pidió que la ayudara a llevar una cesta de naranjas a la escuela. No me gustaba la idea, porque yo quería jugar. Pero ella, cogía una naranja y hacía referencia a la esfera. Después cortaba alrededor y decía: "este es el círculo", cortaba por la mitad y hablaba de la "simetría" (...). (Escalante, 2007, párrafo 14).

\section{Lenguaje}

La matemática es el lenguaje con que interpretamos el mundo. La Matemática suministra un lenguaje adecuado para expresar las leyes de la naturaleza, porque las matemáticas son el principal lenguaje de la ciencia. La física, informática, biología, química es donde está el dinero, pero el lenguaje es la matemática (Escalante y Dirmann, 1990). El lenguaje simbólico matemático ha resultado ser en extremo valioso para expresar las ideas científicas sin ambigüedades (Escalante, 2008). En el programa de cálculo que diseñó y desarrolló en la secundaria de Garfield donde el cien por ciento de sus estudiantes aprobaron el examen de cálculo avanzado AP la mayoría con altas calificaciones, creó un lenguaje propio del grupo que cualquier extraño que entra a la clase de Escalante necesitaría un traductor. Además, los alumnos se sentían orgullosos de ser parte de un grupo especial. Aunque admite Jaime 
Escalante que la matemática tiene su propio lenguaje, signos y palabras claves (Escalante, 2008).

Durante años hemos aceptado sumisamente que hay un lenguaje matemático único pero ahora sabemos que no hay un lenguaje matemático para la Educación Primaria, ni para la secundaria, Jaime Escalante desde el principio de su carrera en la década de los cincuenta entendió que se debe incorporar un lenguaje apropiado para los alumnos. La dificultad de los alumnos con la matemática relacionaba con su experiencia que pasó del pueblo a la ciudad a la edad de diez años (Escalante, 2007). Le tocó vivir las dos Bolivia, la campesina y la citadina que existe un choque cultural. Este hecho le llevó pensar, que se necesitaba conocer el lenguaje para responder adecuadamente.

Para Jaime Escalante la matemática es un lenguaje que permite expresar el pensamiento humano y explorar el universo. La matemática tiene una simbología propia y especial. Para Escalante (2008) la matemática tiene muchas sorpresas: rompecabezas, trucos e ideas interesantes en el arte de enseñar y en el proceso aprender esta ciencia... pero, no sorprende cuando uno no entiende algunos términos". Para esto hemos tomado una foto publicado por ARCOS, ${ }^{16}$ donde muestra las diferentes notaciones 0 simbologías de las derivadas:

$$
\begin{gathered}
\frac{d y}{d x}=f^{\prime}(x)=m=\tan \alpha=\operatorname{Lim}_{\underline{\Delta x \rightarrow 0}} \frac{\Delta y}{\Delta x} \\
\operatorname{Lim}_{\Delta x \rightarrow 0} \frac{f(x+\Delta x)-f(x)}{\Delta x}
\end{gathered}
$$

Como ya fue indicado que los signos matemáticos permiten ir más allá de lo que la mente puede cuantificar. Sin exagerar decimos que los símbolos matemáticos están en segundo lugar después del alfabeto y son instrumentos del progreso humano.

\footnotetext{
${ }^{16}$ Foto publicada de Jaime Escalante en Garfield High School por ARCO.
} 


\section{Procedimiento}

Sostiene que la matemática es una ciencia en continua evolución, por lo que, implica un proceso tanto en su desarrollo como ciencia y su aprendizaje.

\section{"CALCULUS IS SOMETHING VERY DIFICULT TO DEFINE, BUT I} KNOW IT WHEN I DO IT"

Esta imagen fue tomada del periodico, The Washington Times del 12 de enero de 1990.
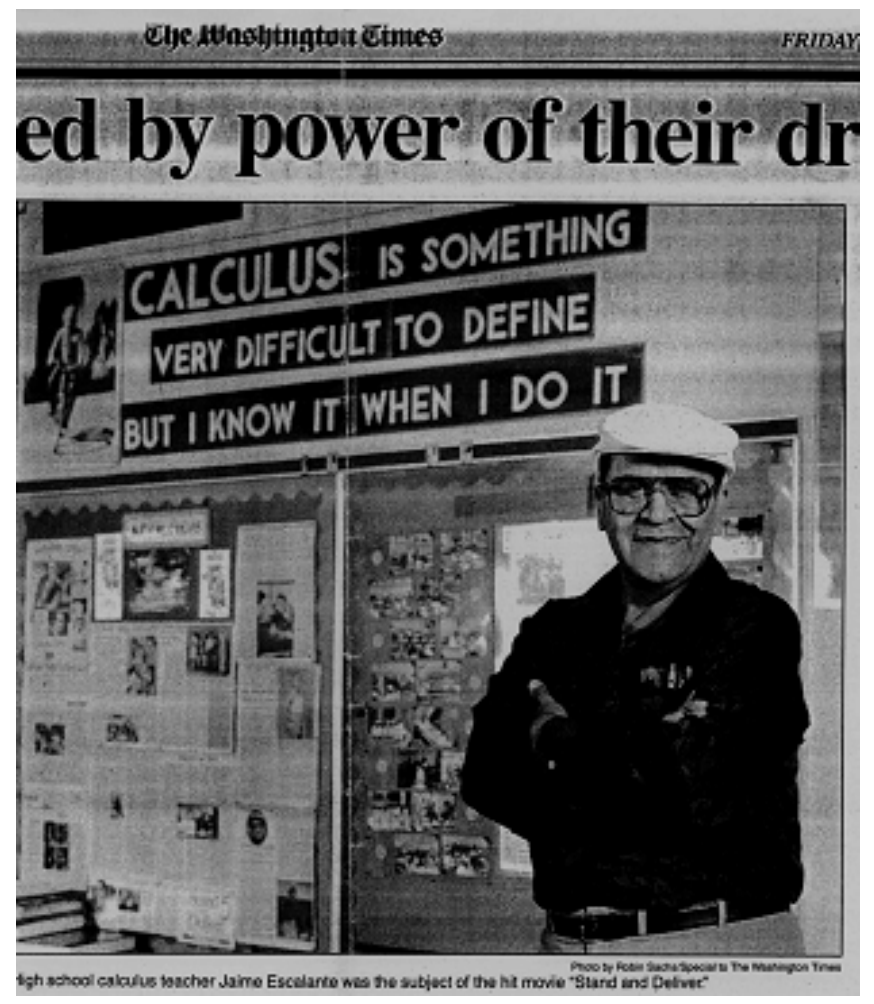

A Escalante, le gustaba hacer las cosas a su manera, analizar todo el proceso, resolver los ejercios antes de leer la teoría (Mathews, 1988), aunque no le motivaban todas las asignaturas:

No todas las asignaturas me motivaban. Aquello que yo podía hacer bien eran las que incluían las prácticas como la Física y algo de Química. Esto es lo que he dicho muchas veces. Yo me acuerdo de todos mis profesores en Bolivia, en Estados Unidos y en otros lugares donde he estudiado. Yo te puedo indicar todos los nombres de mis profesores, posiblemente pasan de doscientos, pero de algunos de ellos me he olvidado, de aquellos que no han hecho ningún impacto. No todos los profesores tienen el mismo impacto. Los profesores de 
geografía e historia, para mi eran un martirio, porque ellos querían que memorizaran. Venía el profesor y decía la consecuencia del golpe de estado de mil novecientos.... Uno se quedaba en la luna, era el test de complementación. "Que está hablando éste" yo decía. Tantos golpes que hubo en Bolivia y uno no sabía de quien estaba hablando. La otra parte, también memorística, la historia de Europa y otras cosas, no me fascinaban tanto, porque cada año iba al desquite, (recuperación). Para la recuperación me dedicaba a leer más cosas, pero después me gustó y me dediqué a la historia, a la historia de la matemática, no a la historia de Bolivia ni otra cosa parecida. Más para ver como empezaron los números y el lenguaje, y quienes fueron los primeros que inventaron las letras. Ahí descubrí que el hebreo no tiene alfabeto (Escalante, 2007, párrafo 15).

A sus alumnos pedía que en la solución del problema, siguieran paso a paso: entender el problema, buscar las palabras claves, anotar los datos, interpretar objetivamente, resolver el problema y escribir el resultado o la conclusión. Este proceso esta relacionado con el libro que usó su abuelo cuando Jaime tenía cinco años.

\section{Aplicación}

La matemática tiene aplicaciones útiles en los negocios, la industria, la música, la historia, la política, los deportes, la medicina, la agricultura, la ingeniería y las ciencias naturales y sociales. En los congreso celebrados por la Sociedad Boliviana de Matemáticas (SoBolMat), he escuchado más de una vez decir "si la matemática no tiene aplicación, no sirve". Refiriéndose a las matemáticas presentadas de manera abstracta. Aunque, para muchos matemáticos la mayor aplicación de los conceptos matemáticos lo encuentran en la misma ciencia. Sin embargo, Escalante se refiere a la aplicación de la vida diaria o la relación con cocas concretas, "la matemática debe tener una aplicación a la vida real". Una de sus frases era: "Hay que enseñar al alumno lo que va a utilizar en la vida" (Escalante, 2007). Para que nuestros jóvenes tengan éxito en la vida, tienen que aprender las matemáticas, haciendo matemáticas de una manera lúdica y atractiva. Para esto la persona sólo 
necesita ganas. La imagen que se muestra acontinuación fue tomada de NEA Today de Junio 1983.

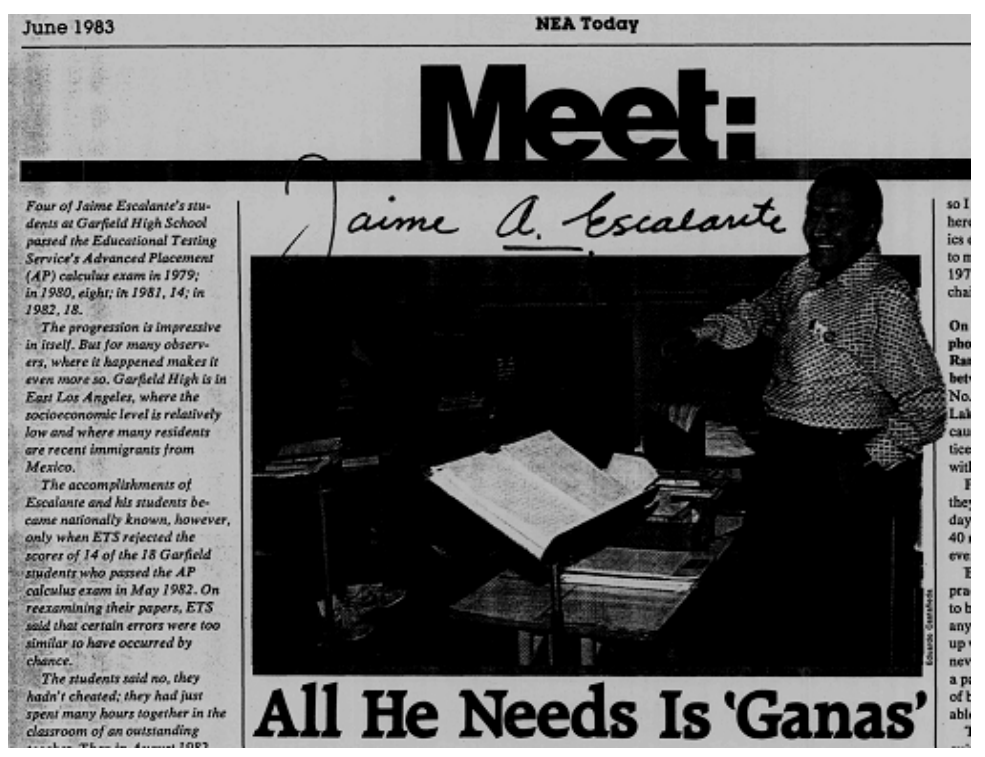

En consecuencia, en la medida en que los educadores matemáticos, entendidos estos como personas que pretenden formar o instruir a otras, mediante las matemáticas, es decir, consideran las matemáticas, en todo o en parte, como objeto de educación para las personas a cuya formación y desarrollo están contribuyendo (Rico y Sierra, 1991), han venido tomando conciencia de que el contenido matemático, acotado en lo que hoy conocemos como matemáticas escolares, no se considera aislado del medio cultural, ni de los intereses y actividad del niño, que esto no es sólo objeto de apropiación, sino una base importante para el desarrollo de la personalidad en todos sus aspectos. Las matemáticas han dejado de concebirse ya, como un objeto acabado que hay que dominar y se ha comenzado a considerar como una actividad humana, con margen para la creatividad, la intuición y el pensamiento lateral o divergente, especulativo y heurístico, que es necesario cultivar y desarrollar la individualidad y el ritmo de cada uno de los estudiantes.

Dentro de esta perspectiva sólo empleamos los método tradicionales y los método activos. Ciertamente, no son las únicas clasificaciones porque existe una variedad de criterios intereses para estudiar y clasificar los métodos de enseñanza de la matemática. En esta investigación se toma la clasificación 
de métodos tradicionales (pasivos) y los métodos innovadores (activos): Jaime Escalante dice mi metodología es muy sencilla y está basada en el criterio de "aprender haciendo" (Escalante, 2007). Parece tener una cierta influencia del Filósofo Educador norteamericano John Dewey. Jaime Escalante parte de un principio que los estudiantes tienen una imagen negativa.

Como ya se mostró en la historia de vida, Escalante es conocido por su forma de enseñar matemáticas en educación secundaria. Barack Obama, presidente de EE.UU, mediante un comunicado, destacó que Jaime Escalante, no sólo enseñó matemáticas a sus estudiantes sino que también les ayudó a encontrar la pasión y las ganas de alcanzar su potencial. También dijo, el mandatario, el profesor Jaime Escalante, durante toda su carrera abrió las puertas de éxito y la educación superior a cada uno de sus estudiantes, y demostrando que la procedencia de la persona no determina el éxito que pueden lograr.

En Garfield Higg School ubicada en el interior al Este de Los Angeles, California, en 1978, Escalante dijo a sus primeros cinco estudiantes de Cálculo que "yo les enseñaré matemáticas y ese va a ser su lenguaje. Con eso van a triunfar en la vida. Van a ir a la universidad y se van a sentar en la primera fila, no en la ultima, porque ustedes van a saber más que nadie." (Escalante, 2007; Mathews, 1988).

La metodología de Jaime Escalante no fue patentada, pero tiene su propia dinámica. El método ha sido denominado "Enriquecimiento de Matemáticas - Método Escalante". (Escalante, 2007). Jaime Escalante se ha hecho especial gracias a su particular estilo de enseñanza de las matemáticas con ejemplos de vida cotidiana, el humor y sobre todo estimulando la autoestima de sus alumnos que aprobaron el examen de AP una prueba de cálculo de admisión académica (Mathews, 1988). Parte de las cosas concretas o más conocidas por los jóvenes. 


\section{Opiniones y testimonios de exalumnos de Jaime Escalante}

Al respecto mencionamos algunos testimonios de sus alumnos de diferentes etapas: René Fernández Araoz, exalumno de Jaime Escalante y promoción 1962 en San Calixto. Un año antes de que Escalante emigrara a los Estados Unidos ${ }^{17}$ :

Un día de febrero de 1962, el tercer lunes para ser exacto, el profesor Jaime Escalante entró en nuestra clase del segundo piso (Planta) de la sección de secundaria del Colegio "San Calixto"...

En todo caso, aquel día propuso a nuestra clase, fiel a su método de enseñanza, un problema de física. Era en torno a la mecánica y tenía que ver con pesos, fuerzas velocidad, aceleración y la fuerza de gravedad. Usualmente, al comenzar las clases, Jaime Escalante, proponía algún problema simple, de rápida solución, el cual puede ser completado en muy corto tiempo, y nos hacía competir, asignando porciones de la nota final del mes, cada vez que uno acertaba con la respuesta en los primeros 5 a 10 lugares (nuestra clase tenía 52 alumnos).

Otras veces, como aquel día, nos proponía un problema más complejo, con muchas variables y esperaba que lo resolviéramos hasta la clase siguiente... El problema era:

“¿cuál es la fuerza necesaria, en Newton, velocidad y aceleración suficiente, en metros por segundo, para enviar un objeto de $5,610 \mathrm{~kg}$ de peso fuera de la atracción gravitacional de la Tierra y hacer que se sitúe en una órbita elíptica entre 250 y $300 \mathrm{~km}$ de altitud?....

Al día siguiente, el profesor solicitó a quien haya encontrado la respuesta, pasar a la pizarra y demostrar la solución....no recuerdo bien si fue Juan Ballon, Iván Finot, Gonzalo Vega, Gonzalo Velásquez, o Abelardo Zapata (los más aventajados en Matemática y Física en mi curso) quienes salieron al pizarrón, la memoria ya no es tan fiel. En todo si recuerdo alguien se acercó bastante a la solución, pero no en su totalidad. Escalante felicitó a quienes

\footnotetext{
${ }^{17}$ http://isabelvelascoc.blogspot.com/2010/04/querido-profesor-jaime-escalante-tus.html
} 
habían intentado resolver el problema y se acercaron al objetivo, y paso a dar la respuesta.

El problema propuesto tenía que ver con algo de mucha actualidad en esos momentos. La puesta en órbita de la nave espacial Friendship 7 (Amistad 7), del Proyecto Mercury de la NASA, piloteada por el astronauta John Herschel GlennJr. Primera misión orbital de los Estados Unidos (previamente hubieron dos mis suborbitales de los astronautas Alan Sheppard y Virgil Grissom, respectivamente).

El 20 de febrero de 1962, el astronauta John Glenn, piloteando su nave espacial impulsada por un Cohete Atlas LV-3B, lanzado desde el Complejo 14 de Cabo Cañaveral (hoy Cape John F. Kennedy Space Center, Florida, en homenaje al presidente que propuso a su nación "poner un hombre a la luna, antes del cierre de esa década"), completó exitosamente su viaje de tres órbitas a la tierra, alcanzando una altitud máxima de $264 \mathrm{~km}$ a una velocidad promedio de 17,500 millas por segundo (aproximadamente 7, 840 metros por segundo). El Cohete Atlas, la nave "friendship 7", el astronauta y su torre de rescate pesaban en conjunto $5,610 \mathrm{~kg}$ de peso que mencionó el profesor Jaime Escalante en su problema a resolver.

Jaime Escalante era un profesor informado y actualizado, esta vez él había propuesto que resolvieran los alumnos el mismo problema que tuvieron que encarar los científicos de la NASA.

\subsection{Concepciones y creencias sobre la matemática como objeto de enseñanza}

Sobre las concepciones y creencias de la matemática como objeto de enseñanza de Jaime Escalante se ha obtenido las siguientes:

- Quitar el velo y gozar de su encanto y su belleza de la matemática.

- La educación (educción matemática) es el billete a la excelencia.

- El profesor necesita tres cosas: dominio del tema, saber motivar y conocer las relaciones humanas.

- Involucrar a los padres en la educación de sus hijos

- Si enseñamos a pensar y comunicar, el futuro está arreglado. 


\section{Quitar el velo para gozar de su encanto y su belleza de la matemática}

Para Jaime Escalante, la matemática como objeto de enseñanza es quitar el velo y gozar de su encanto, escritura, concepto, evolución, historia, que todo esto revela la belleza de la matemática. Al respecto señala como sigue:

La matemática, como objeto de enseñanza es quitar el velo y gozar de sus encantos, su escritura, (símbolos) conceptos (lenguaje) preguntas y porque no decir su evolución, su historia, todo esto la belleza de la ciencia del pensamiento. Le digo a mis alumnos - Muchas de las cosas que nos rodean pueden ser descritas matemáticamente, aun conceptos matemáticos son inherentes en la estructura de células vivientes.

Las matemáticas tienen sorpresas: rompe-cabezas (puzzles), trucos e interesantes ideas en el arte de enseñar y el proceso de aprender esta ciencia es imperativo leer despacio, no sorprende cuando uno no entiende algunos términos, adquirir el hábito de tener a mano el lápiz y el papel, encontrar la palabra clave y tratar de visualizar el problema haciendo un skech o graficando para entender mejor. Tratar de entender lo que lee. (Escalante, 2008, p. 3).

Coincido ampliamente con Perkins (2003), Jaime Escalante tenía pasión por la matemática y la enseñanza. En una conversación con los alumnos de la Universidad Adventista de Bolivia en 2005 dijo: "que no podía estar sin resolver problemas de matemáticas, pero si cogía una novela para leer se queda dormido al instante".

\section{La educación es boleto a la excelencia}

Escalante creía que la educación (educación matemática), es el billete a la excelencia, por eso, en el primer año de estudios en Pasadena City College (PCC), Jaime Escalante se inscribió en 12 materias, incluyendo inglés, matemáticas y electrónica, y recuerda de la siguiente manera: "los primeros días y semanas de ese semestre fueron los más difíciles de mi vida." Después de clases se quedaba en la biblioteca hasta que se cerrara la puerta.

Era el único tiempo que tenía para las tareas" (Santana, 2003). Escalante, hizo ese esfuerzo porque creía, que el único camino era yendo a la universidad. 
Yo busco la excelencia en educación. Déjeme definir lo que es excelencia. Es una definición estúpida, pero funciona. Excelencia quiere decir: "Hágalo bien a la primer vez". Usted pasa el examen la primera vez. Bang. Usted se pone de pie y lo dice correctamente. No es excelencia cuando usted dice, "voy a hacer primero un prueba de mentirijillas de ellas," como suelen hacer los profesores. La segunda cosa es la anticipación. Anticipación quiere decir estar en el lugar correcto en el momento correcto. $Y$ cuando hago mis tareas sé lo que voy a hacer. Y la última es la innovación. Yo soy innovador. Innovación es la luz de la competencia. Esta es la única manera. (Escalante, en Hanson, 2003).

Al inicio de su trabajo en Garfield, se desilusionó por el bajo rendimiento de sus alumnos, llamó a la Burroughs Corporation y dijo: "me he equivocado. Quiero volver a trabajar donde trabajaba antes, me retiro, porque estos analfabetos no están en condiciones de aprender, no saben que la educación es el boleto al éxito" (Escalante, 2007, párrafo 38).

Jaime Escalante fue un profesor con compromiso social que vió en la educación no una simple formalidad, sino que una eficaz herramienta para sacar de la marginalidad a las personas. Por otro parte, con expectativas altas del rendimiento de sus alumnos, lo cual les motiva a ellos y ayuda a reafirmar su autoestima, que en algunos casos estaba muy deteriorado. Trataba de dar ejemplos pertinentes y significativos para sus alumnos.

Realizó una intervención estratégica. Se planteó un objetivo muy concreto: preparar a un grupo de alumnos para el examen de cálculo. Lograr esto, significaba el primer paso para derivar el mito de que los estudiantes no están motivados y/o posibilitados de aprender. Por otra parte, ayudaría a que los demás profesores, de otros departamentos se planteen altas expectativas también. Esta intervención estratégica llegó a generar una multiplicidad de eventos con un cambio de creencias en el sistema escolar.

A medida que el número de los estudiantes del Programa de Matemática de Escalante ha crecido en la escuela secundaría de Garfield, también ha explotado en otros temas técnicos como la Física, Química, Biología y Computadoras. (Escalante y Dirmann, 1990). 


\section{El profesor necesita tres cosas:}

Dominio del tema, saber motivar, entender las relaciones humanas

Escalante y Dirmann (1990), indican: "si estudiáramos a un centenar de profesores muy eficaces, creo que encontraríamos sus enfoques sencillos y directos con muchos denominadores comunes.

Para poder enseñar, usted necesita tres cosas. Número uno, el conocimiento del tema. Usted debe tener el dominio de lo que va a enseñar. Yo no tengo capacidad para enseñar biología. No puedo hacerlo porque no sé casi nada de eso. Debo tener en mi cabeza el modelo a seguir.

La segunda cosa es que debo motivar acerca de los conceptos que voy a enseñar. Por ejemplo, puedo introducir el concepto de la defensa ilegal, lo que en matemática sería la división por el cero. Para que quede claro pongo el cero en el divisor, y toda la clase grita: "iDefensa ilegal!”. Luego les pregunto si me van a ayudar a resolver. Si alguien viene y pregunta: “¿Qué es defensa ilegal?” le responderán: "Es cuando se divide por cero" y así con cualquier otro concepto hago lo mismo, debo usar algún juguete o algo para explicar los conceptos de algo. De ahí se debe partir.

Tercero, se debe entender las relaciones humanas. Usted debe ver a los chicos como personas y respetarlos. De esta manera los puede motivar y puede desarrollar gradualmente durante todo el semestre o en dos o tres semanas una buena relación. Si así lo hace, cuando tenga la retroalimentación del estudiante, hablando matemáticamente usted sabe que esta aprendiendo.

Yo suelo usar el basketball para cada concepto de las matemáticas. Los tiros de tres puntos: Una parábola. La violación de los tres segundos: valor absoluto, mayor que, menor que o igual al rebote, tiros bloqueados: paréntesis, quitar exponentes, etc. (Escalante, en Hanson, 2003).

\section{El dominio del tema}

El dominio del tema se consigue con la experiencia, el estudio formal, lectura y reflexión personal, e interacción con sus colegas. (Wilson, Cooney y Stinson, 2005). Escalante, siempre ha señalado que "la experiencia es el mejor maestro que uno tiene" (Escalante, 2007). "Yo no soy teórico yo tengo experiencia en el salón de clases y mi primer compromiso está con mis 
estudiantes." (Escalante, Dirmann, 1900). Además, en Garfield High School le pidió una oportunidad al Director para implementar su programa de matemáticas. La respuesta fue: "no hay libros", pero Escalante respondió: "No te preocupes de los libros yo conozco la materia y puedo enseñar"

En cuanto al estudio Formal, Jaime Escalante señala que la capacitación docente es muy importante, y como estudiante en Bolivia, ganó el apodo de genio. En Estados Unidos, un examen de dos horas lo hizo en 25 minutos y consiguió el primer lugar en la selectividad para los cursos pedagógicos que le permitieron conseguir la credencial de profesor de matemáticas.

En cuanto a la lectura y la reflexión personal, de joven cambió las travesuras por los libros e ingresó a la Escuela Normal Simón Bolivar, de donde salío profesor de matemáticas, y se definía como autodidacta.

Cuando vino los concursos de Matemáticas y Física, sobre todo los de Física, yo ocupaba el primer lugar. Yo no necesitaba prepararme, porque trabajaba con el padre Descottes, que era el encargado del sismógrafo San Calixto, existente hasta el día de hoy. Yo iba investigando por mi cuenta. Y vi que realmente era importante investigar y prepararme para la vida de manera autodidacta. (Escalante, 2007, párrafo 12).

Jaime Escalante nos dice, que el contenido depende del objetivo que nos propongamos los profesores. Luego nos cuenta cómo elabora los contenidos:

El análisis de contenido depende del objetivo que nos proponemos los profesores. Primero reviso las definiciones y conceptos de los diferentes libros que tengo a mi alcance. Pero no me quedo con ninguno de ellos, yo elaboro el mío. Segundo busco la aplicación que tiene este tema en la vida cotidiana, relacionándolo con algo que conoce el estudiante en su medio y trato de mostrar objetivamente el concepto. Por ejemplo, si tengo que enseñar las funciones y nos detenemos en las funciones cuadráticas. Asocio con el casco, (una taza artesanal para beber la chicha en Cochabamba). Utilizo los vasos de champán para mostrar los contractotes y el vaso del Melgarejo para mostrar los amplificadores. El movimiento del vaso de champán con la mano para el brindis, tanto vertical como horizontal. Así, el alumno no lo olvida. Debemos de aprovechar la memoria visual. (Escalante, 2007, párrafo 47). 
Nos explica a través de un ejemplo, cómo la enseñanza de las funciones y particularmente las funciones cuadráticas, que son ampliamente presentados en sus modelos de clase.

Todo esto que nos dice, lo hemos confrontado con las actividades que hemos observado en los seminarios y talleres para profesores. Evidentemente, no se ciñe al libro de texto del colegio o alguna editorial, ni amplia con algunos ejercicios, sino que el presenta su propio material. El mismo que nos ha proporcionado algunos tópicos.

\section{Saber motivar}

Para Escalante la motivación es la parte más importa en la enseñanza de la matemática.

Las matemáticas deben ser enseñadas con motivación y el profesor tradicional no debe tener un comportamiento reacio hacia sus estudiantes para enseñar la base de su futuro (Escalante, 2007).

Para motivar, el maestro debe ser innovador y Escalante se autodefine como motivador y no creador.

...soy un profesor innovador, por ejemplo, la forma cómo motivo está relacionado con las cosas que el alumno conoce o sabe. Si hay algo que el alumno conoce, el foquito verde y ve. Le despierta interés, pero si hago lo contrario, entro directamente a la definición y digo el teorema tal, todo se queda ahí. El alumno no lo ve porque no entiende, ni sabe por qué, entonces poco va poder definir el teorema. En cambio, si se empiezo por una cuestión que él conoce, aprende. Por ejemplo, en primaria podemos empezar con: “¿cuándo es tu cumpleaños?" el niño sabe cuándo es su cumpleaños porque sabe que va soplar 2 velas o 3 velas, etc. Entonces le damos el almanaque y me muestra donde está su cumpleaños, de ahí sale unas ideas muy interesantes.

\begin{tabular}{cc|ccccc}
\cline { 3 - 5 } 1 & 2 & 3 & 4 & 5 & 6 & 7 \\
8 & 9 & 10 & 11 & 12 & 13 & 14 \\
15 & 16 & 17 & 18 & 19 & 20 & 21 \\
22 & 23 & 24 & 25 & 26 & 27 & 28 \\
29 & 30 & 31 & & $\ldots$ &.. &..
\end{tabular}


La suma de una diagonal y la otra diagonal son iguales, y esto lo usará cuando esté llevando el concepto de matrices. Luego eliminas una columna y una fila y sale un número, además de muchas cosas que hice en la Universidad Adventista. A partir de ahí se puede sacar los conceptos que necesita. La derivamos en una forma que el alumno ha tragado la píldora exactamente (Escalante, 2007, párrafo 68).

Hay que hacer ver al muchacho que la matemática no es difícil y puede hacerlo, que adquiera confianza y esto influye mucho en la autoestima. Yo les digo: "No hay otra persona mejor que tu, tu eres único, así que tienes que responder a tu Yo Personal y ese Yo Personal consiste en la responsabilidad, personalidad y actitud"

Responsabilidad es lo que haces y tercero la actitud. Con tu actitud vas a poder conseguir cualquier tipo de trabajo. Las tres cosas: responsabilidad, personalidad y actitud.

Toma dos minutos decirles eso, ahora que ni siquiera dan Educación Cívica con la Reforma Educativa. (Escalante, 2005, Comunicación personal).

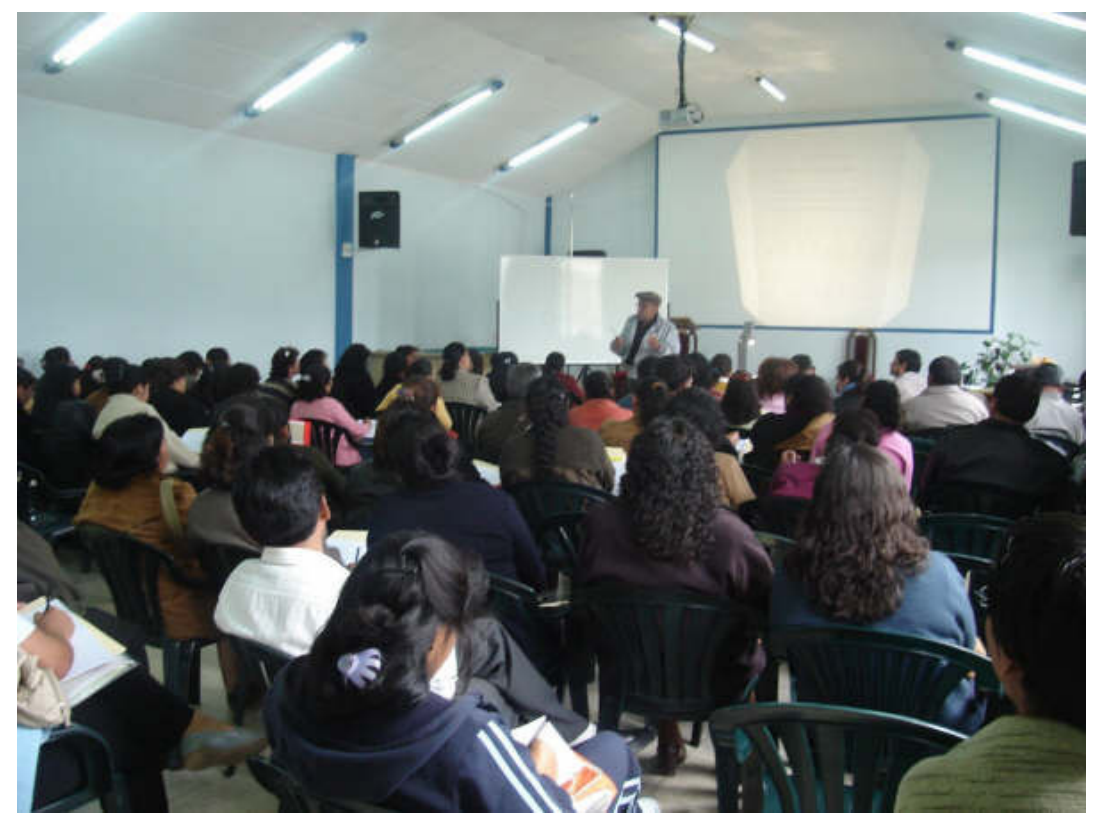

Coliseo Amasias Justiniano de Universidad Adventista de Bolivia Seminario para profesores del Distrito Escolar Vinto, 2009

Por otro lado, Escalante siempre estaba dispuesto a colaborar y ofrecer su ayuda para todo aquel que lo solicitara. En la foto de arriba se observa una 
de sus conferencias en la universidad Adventista de Bolivia. Muchos profesores quedaron maravillados por la clase del profesor Jaime Escalante. Con términos sencillos y una explicación emotiva y didáctica, se ganó el cariño y el aplauso de los asistentes. Escalante terminó la clase con la siguiente frase:

El profesor tiene que tener energía de un volcán, la precisión de la mejor calculadora y la inteligencia de un elefante.

Escalante les hacía creer a sus estudiantes que "la matemática no es difícil, cualquiera puede aprender". Uno de sus alumnos que hoy presta servicios en la NASA (National Aeronatic Space Administration), al destacar su forma de enseñar señala que Jaime Escalante "tiene la simpleza de los genios que hace sencillo lo que parece tan difícil”.

En una investigación que le llevó cinco años a Jay Mathews, y publicó en 1988, señala que había un lema en un lugar bien visible del aula, que decía:

No hay necesidad de facilitar el cálculo porque ya es fácil.

(Calculus need not be made easy; it is easy already)

Este lema aparece en el aula de clases de matemática del Instituto de Garfield, la institución donde llevó acabo su programa de Cálculo. Sin embargo, cuando enseña otra asignatura, va colocando el nombre particular de la asignatura, que puede ser Cálculo, Álgebra, Geometría, Trigonometría, etc.

Según Kolpas (2002), la multiplicación con los dedos fue popularizado en el filme Stand and Deliver. Edward James Olmos, personificó al profesor de matemática Jaime Escalante.

La preparación para este tipo de enseñanza requiere una inmersión personal, seria y profunda. No se trata de saber unos cuantos trucos superficiales, sino adquirir nuevas actitudes que calen y vivan profundamente. Jaime Escalante realmente tenía pasión por la enseñanza de la matemática. Escalante (2007) decía: "constantemente estoy buscando el clic (hacía sonar sus dedos) muchas veces no he encontrado, pero al final he conseguido. 


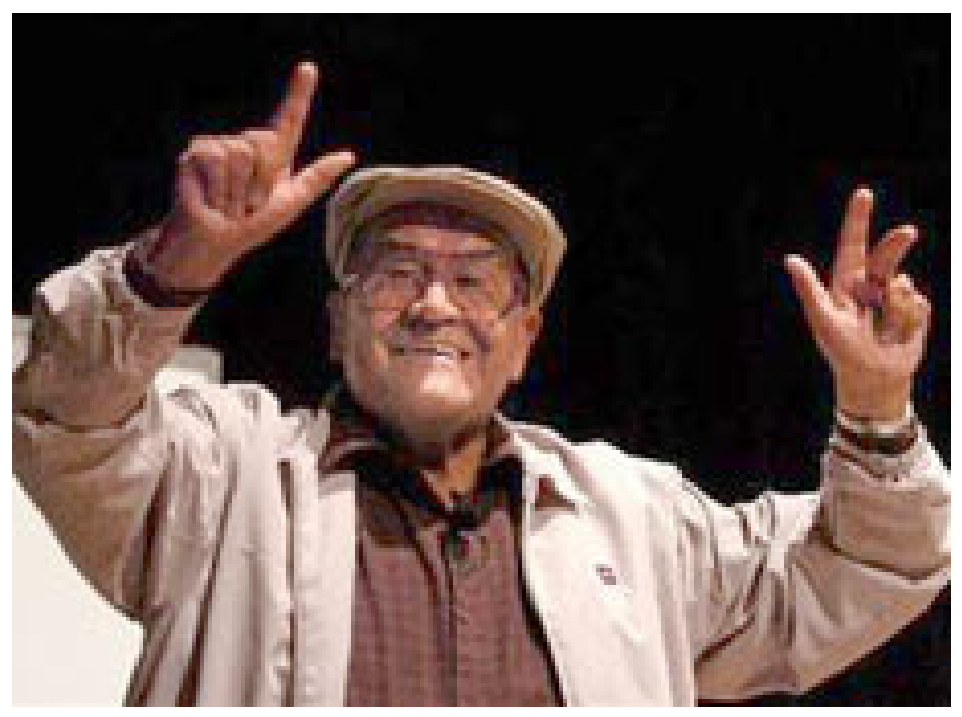

Are you The Finger Man? I am the Finger Man, too. I know how to multiply by nine!

He asistido a más de una decena de veces a las clases del profesor Jaime Escalante entre conferencias, seminarios y talleres para profesores de matemáticas. He visto y oído decir de que "las matemáticas son fáciles, cualquiera lo puede hacer" a veces con sentido del humor decía: "cualquier hijo de vecino, lo hace". Posiblemente el lector pueda pensar que es algo muy decorativo, la creencia de Jaime Escalante sobre la matemática como objeto de enseñanza. Sin embargo, uno de los asistentes a la conferencia del profesor Jaime Escalante del día 25 de julio de 2009 en el Texas Hall Auditorium, de la Universidad de Texas en Arlington, Tony Pérez dice:

Enseñar matemáticas es algo que el profesor Jaime Escalante sabe hacer muy bien, como pudimos darnos cuenta los que estuvimos en la plática organizada por AHETEMS. "Las matemáticas son tan fáciles que cualquiera lo puede hacer" nos dice, mientras nos nuestra mágicamente lo que tantas veces ha hecho. Son sus trucos mágicos los que logran que pongamos la atención en lo que dice y en lo que muestra, nos asombramos al descubrir la tabla del nueve de una manera que nunca antes habíamos mirado; las multiplicaciones, las divisiones, las restas, la raíz cuadrada, todo es tan fácil cuando el nos enseña y no sólo eso, sino que nos deja con la sensación de querer aprender mas, y de saber lo que nos está mostrando es sólo una pequeña parte de lo que él conoce. (Perez, 2009). 
Porque las pautas y su estilo de enseñanza, no son uniformes o predecible en términos sencillos. Reacciona de manera flexible ante la dificultad y el carácter de la materia tratada, las capacidades de los alumnos (que pueden variar incluso en el espacio de un solo curso), y sus propios objetivos educativos. No sólo puede dirigir su orquesta desde el podio, sino que además, se puede sentar en el fondo del aula y ver tocar a los músicos por sí solos con virtuosismo.

Según Perkins (2003), "Jaime Escalante es un gran promotor y comunicador su destreza fue única, y en ese aspecto nadie ha podido igualarlo."



Como ya señalamos, no había dos clases iguales, aunque se tratara del mismo tema. En ese sentido Cerda (2004) señala: "El exitoso profesor de matemáticas Jaime Escalante, asegura que las matemáticas son fáciles. Recurre a todo para enseñar, cartulinas, palitos y cuadrados con lo que explica el Algebra". Escalante estuvo en Santiago explicando su método de enseñanza a los participantes en el seminario Éxitos Educativos, organizado por Inacap"

A los profesores chilenos, Jaime Escalante sorprendió con la forma de enseñar matemáticas. Al respecto Cerda (2004) relata su forma de introducir razones y proporciones:

Una de las cosas que ha hecho especial a Escalante es la forma de enseñar matemática, algunas de las partes más concretas y más conocidas por los 
jóvenes. "Si quería enseñar lo que se entiende por razón y proporción, preguntaba cosas como cuantos dedos tienes en una mano. El muchacho sabe y responde cinco. Esa es una razón. Cuántos dedos tienes en dos manos, el muchacho decía diez. Eso es otra razón y comparación entre dos razones es una proporción. Y así empezaba. (Cerda, 2004).

Estamos de acuerdo con Perkins (2003), que indica: Jaime Escalante no solo aportó conocimiento, sino un arsenal de estrategias para motivar a los alumnos.

\section{Entender las relaciones humanas}

Jaime Escalante indica: "Usted debe ver a los chicos como personas y respetarlos. De esa manera, los puede motivar y puede desarrollar gradualmente durante todo el semestre o en dos o tres semanas una buena relación" (Escalante, en Hanson, 2003), y en sus conferencias, siempre instaba a los profesores a considerar las relaciones humanas.

El profesor tenía pasión por las matemáticas, y sabía cómo hacer la materia interesante para sus alumnos. Inspiraba en ellos el deseo de saber. Mostraba que las matemáticas eran relevantes. $Y$ sobre todas las cosas, les repetía que confiaba y esperaba lo mejor de ellos: "lo único que necesitan es tener ganas". Demandaba excelencia, pero también mostraba cómo llegar a ella. Escalante (2007, párrafo, 22), menciona la evaluación como una de los punto importantes en su práctica de enseñanza de la matemática.

\section{Involucrar a los padres en la educación de los hijos}

Para Jaime Escalante, la escuela sola no educa, necesita el apoyo de los padres. Es difícil cuando los dos padres trabajan para sostener la familia.

De regreso a Bolivia, Escalante habló con BBC mundo sobre la educación y uno de los puntos fue respecto al rol de los padres frente a la educación de sus hijos: "La función de los padres es guiar a los hijos, porque la primera escuela que uno tiene es el hogar" (Escalante, en BBC Mundo, 2003). 
Algunos padres se han olvidado de la casa, o no tienen una creencia personal sobre la importancia del valor de la educación de sus hijos. Sin embargo, tuve la gran fortuna de movilizar la mayoría de los padres de mi comunidd con el propósito de ayudar en la educación de sus niños (Escalante y Dirmann, 1990).

Escalante sólia decir: "Este hijo te pertence a ti, no pertence al Estado ni al colegio. Dile a tu hijo que le quieres, tócale, dale un abrazo, dedica tiempo a tu hijo." Las transparencias estaban en inglés y se trataba de las tres Ts (TTT): Tell, Touch and Time.

Jaime Escalante poseía la capacidad de formar equipos de trabajo, no sólo entre estudiantes, sino con una triada de "Profesor - Padres - Alumnos". Jaime Escalante es una persona apasionada, motivada por lo que hace, tiene gran compromiso y vocación de servicio social, es creativo, de ideas claras (visión), sabe donde quiere llegar, es un buen estratega porque elabora un plan para dirigir a sus alumnos hacia la meta formando un equipo de trabajo "Profesor - Padres - alumnos". Es un líder innato les muestra las altas expectativas y sabe entregar a sus alumnos la confianza para que desarrollen su autoestima y habilidades cognitivas.

\section{Enseñemos a pensar y comunicar}

Como ya señala la cita anterior, Jaime Escalante tenía una visión clara y sus creencias también lo eran. Sostenía que si nosotros pudiéramos enseñarles a nuestros niños a pensar y a comunicar, tendríamos el trabajo hecho. Eso es lo que necesitamos.

Jaime Escalante fue asesor de Educación Latinoamericana de George H. W. Bush (Escalante, 2006). Manifestó su preocupación acerca de los estudiantes en general de Estados Unidos. Además, los estudios nacionales que se publicaban sobre el aprendizaje de temas importantes como la matemática y las ciencias, muestran que los estudiantes en los Estados Unidos han dominado los hechos aritméticos simples, pero sólo un porcentaje pequeño era capaz del razonamiento complejo de matemática (Prawat, 1989). 
El Hudson Institute había publicado en 1987, que en los próximos 20 años, el crecimiento de las áreas de empleo, exigirían a los empleados altos conocimientos de matemáticas, idiomas y capacidad de razonamiento. Sin embargo, Jaime Escalante en el Garfield High Schol, ya lo había puesto en práctica entre los años 74 y 82.

Jaime Escalante afirma que el éxito se debe a las normas claras e inequívocos que escogen como metas para esos estudiantes, aceptar el desafío como aprobar el examen de Cálculo de AP: las normas claras ayudan mucho a los maestros y estudiantes a desarrollar este sentido de "ganas" para tener éxito, en la matemática, en la escuela y la vida. Escalante no mencionó nada del proyecto PISA, pero estaría completamente de acuerdo.

Para Escalante, la edad apropiada de los estudiantes para que un profesor pueda enseñar las matemáticas está entre los 10 a 15 años. Esta conclusión es el resultado de haber trabajo en diferentes niveles:

Yo no quería dejar el colegio, pero encontré un poco raro el ambiente. Cuando enseñaba en la universidad, lo podía hacer porque tenía la maestría. Descubrí que era mejor trabajar con los ignorantes, (me refiero a los que ignoran la matemática), porque se les puede conducir por el camino al sendero que uno desee. Llegué a entender que el periodo de la pubertad entre los 10 y los 15 años era la mejor edad para poderlos cambiar, porque estos muchachos estaban expuestos a diferentes actividades, así el profesor podía moldearlos y darle la vuelta a la situación; conducirlos por el camino que uno quería: la matemática es el lenguaje, es el camino con el que ellos iban a conseguir el éxito. Pero en la universidad me sentía frustrado, no podía hacerlo. Ellos ya iban con esa formación, y con la idea en mente de que tenían que sacar la nota mínima para aprobar y se acabó. Estos sólo iban para cumplir con los requisitos. En cambio, en secundaria, yo les hacía creer otras cosas enteramente distintas. (Escalante, 2007, párrafo 54)

Jaime Escalante señala tres puntos que ponen en riesgo la educación de niños y jóvenes: "alcohol, drogas y sexo," según su visión, a tierna edad empiezan a consumir bebidas alcohólicas y estupefacientes. Los orígenes de estos factores estan en el entorno familiar, círculo de amigos y la escuela, donde aprenden o pierden el interés en su aprendizaje. En contrapartida, 
destaca los valores que deben ser cultivados: la experiencia, responsabilidad, y actitud. "De los tres, la última es la mas importante, porque cuanto más tiempo pasa, más me doy cuenta, que una pesona deja un impacto en sus quehaceres cotidianos, la actitud es un factor más importante que el dinero, la educación, el éxito o el fracaso."

Los pilares fundamentales de la educación que imparte a sus alumnos son la honestidad, disciplina y la actitud positiva.

\subsection{Concepciones sobre el aprendizaje de la matemática}

En esta sección se presentan las concepciones y creencias de Jaime Escalante acerca de cómo los estudiantes aprenden matemáticas:

- Aprendizaje como juego o reto.

- Enfoque de equipo,

- Fijar metas a través de la orientación vocacional.

- Velocidades de aprendizaje.

- Partir desde los problemas y nunca desde la definición.

- Cualquiera puede aprender matemáticas, solo se necesita ganas.

- Aprovechar la memoria visual.

\section{Aprendizaje como juego o reto}

Para Jaime Escalante los alumnos aprenden mejor, cuando el aprendizaje es divertido, cuando se trata de un juego o un reto. (Escalante y Dirmann, 1990). Esta concepción de cómo aprenden los alumnos fue la que utilizó a través de su carrera. Como él mismo señala, lo comprendió al inicio de su carrera profesional. Desde que era estudiante de la Escuela Normal Simón Bolivar, sintió la obligación de hacerse un buen profesor y sacar provecho de sus errores. En 1952, cuando empezó a trabajar sin ningún título para enseñar, estuvo bajo los ojos críticos de un profesor experimentado, abandonó varias ideas inviables y llegó a comprender la importancia de ser comunicativo con los alumnos y no simplemente trabajar en la pizarra durante el día. En Escalante (2007), nos dice: "para enseñar, hay que tener un juego". 


\section{Enfoque de equipo}

En base a la concepción anterior, le dió un enfoque de equipo. El profesor como técnico y los estudiantes como equipo, quiso llevarlos a la disciplina de un equipo atlético y a la devoción por la práctica. Orientó a los estudiantes a convertirse en estrellas y adquirir la autodisciplina, un rendimiento excepcional, voluntad de ganar, la persistencia en la práctica de sus habilidades y otras cualidades. Las paredes del aula de clases estaban llenas de carteles de figuras deportivas: Jerry West, Wiilt Chamberlain, Magic Johnson, y otros, que eran la pasión de los estudiantes. Por otro lado, los conceptos matemáticos fueron enfocados desde metáforas deportivas y les proporcionó el uniforme que consistía en chaquetas, gorras y camisetas (Ver foto No. 8), para que los estudiantes se sientan parte de un equipo. Escalante se muestra como un profesor tolerante con alto grado de madurez para responder a los problemas en el aula sin confrontación, sino por el contrario integrándose como un ente más en el grupo, sin descuidar su rol de conductor.

\section{Fijar metas a través de la orientación vocacional}

Escalante planteaba a sus alumnos metas de corto (exámenes diarios), medio (examen de cálculo) y largo plazo (Universidad).

Como él mismo dice, se dió cuenta que sus alumnos necesitaban metas, que todo depende del alumno, pero no se puede esperar que venga un cambio violento de la noche a la mañana. El alumno tiene que elegir qué va a hacer, tiene que tener una orientación. Cuando está en segundo o tercero de secundaria, tiene que tener definida ya su vocación y enfatizar las clases que necesita.

Escalante (2006), nos explica cómo realizaba la orientación vocacional para sus estudiantes de nivel secundario de Garfield High School:

Invitaba a profesionales de todo tipo a dar conferencias los sábados. Ellos explicaban cómo habían llegado a ser médicos, industriales o policías, etc. Pero además es muy importante, por ejemplo en la transición de tercero a cuarto de secundaria, preguntarles en la clase qué quieren llegar a ser. Según las respuestas, uno debe orientarles a estar expuestos a las oportunidades que 
les de la vida para que se apliquen en esas áreas. Si dice periodista, entonces rescomendarle que escriba a diario oraciones; si dice ingeniero, pedirle que se concentre mucho en resolver ejercios de matemática y los relacione a la física y a la química, etc. El colegio debe ofrecer un buen ambiente pedagógico que le responda al alumno sobre lo que quiere y va a ser. Si el profesor sólo se concentra en su materia y no orienta, entonces no está educando. De lo contrario, poco después aparecen los psicólogos y dicen que el jóven tiene un bloque. Le piden que haga esto o lo otro, pero puede ser tarde. (Escalante, en Jara y Sagárnaga, 2008, Julio 6).

Según Escalante, la edad apropiada para trabajar mejor la vocación es en la pubertad.

En la pubertad uno tiene como una masa para darle la forma que uno quiere. Como yo daba clases cada día, tenía que combinar las actividades de enseñanza con música y películas para no hacer la matemática odiosa. El profesor tiene que inspirar confianza, decirle al joven que nada es difícil y que lo que está aprendiendo se puede relacionar con cuestiones objetivas. Yo no comulgo mucho con los psicólogos porque hacen teorías, la prática es la clave. Yo les enseñaba a multiplicar con los dedos o les daba geometría en base a la Puerta de Sol, y les explicaba además que era una sola piedra y también la cultura de Tiwanaku. La matemática no es estar, como en derecho, todo el día sobre un libro. La matemática inspira y orienta para múltiples vocaciones a cualquier carrera. (Escalante, en Jara y Sagárnaga, 2008, Julio 6).

\section{Velocidades de aprendizaje}

Según Jaime Escalante, en la clase tenemos alumnos con tres velocidades de aprendizaje: uno que aprende fácilmente a la primera explicación, el segundo que tiene un movimiento lento y necesita un poco de ayuda, y el tercero que es flojo. Recomienda a los profesores de la manera siguiente:

Tenemos que concentrarnos un poco más en aquellos que son flojos. No es que no puedan, es que no quieren seguir las instrucciones, no tienen la determinación de ser algo y aceptar con disciplina las instrucciones del maestro. (Escalante, en BBC Mundo, 2003). 
Es fácil que los profesores tengan expectativas sobre los alumnos que tienen la facilidad de aprender, pero Jaime Escalante tenía la capacidad de transformar estudiantes que no tenían ninguna expectativa en los estudios. Escalante les ayudaba a encotrar amor por el conocimiento, la matemática y la excelencia.

\section{Partir de problemas y nunca por la definición}

Escalante (2007, párrafo 60), recomienda: "nunca entrar por la definición del tema que uno va a hablar", sino que siempre se debe relacionar con algo que el alumno conoce o sabe, de ahí enlazar y sacar el concepto que uno quiere. En 1993, señaló que se debe preparar a los estudiantes en diferentes aproximaciones.

Las primeras diez semanas, no uso ningún libro. Realizo algunos experimentos que muestran la aplicación del cálculo, y desarrollo las cosas que los alumnos necesitan conocer. Porque para hablar un idioma, usted tiene que conocer el alfabeto; si uno conoce el alfabeto puede escribir las cartas. (Escalante, en Novak, 1993).

Escalante (2007), comprendió que debe enseñarse entre 10 a 15 minutos y luego pasar hojas de trabajo, que lo nominó laboratorio, y organizar a los alumnos en grupos. Vió que era importante hacerles trabajar en mesas de grupos de a cuatro, hacer que colaboren entre ellos. Escalante pensaba, "cuando éstos sean profesionales, un día van a trabajar juntos en las compañias donde vayan. Necesitan esta relación". Indica: "sólo los exámenes eran individuales y diferentes para que no usen su mirada diagonal."

\section{Cualquiera puede aprender matemáticas, solo se necesita ganas}

Escalante había hecho popular el cálculo en Garfield High School (Mathews, 1988, p. 184). El número de estudiantes por clase creció más allá de los 35, que era el límite fijado por el sindicato de profesores. (Jessness, 2002). Para Escalante, el hombre tiene la capacidad ilimitada de aprender, y dice: "el hombre aprende desde que nace hasta que muere, desarrolla múltiples facultades y posee una capacidad ilimitada de aprender" (Congreso Nacional de Ingeniería Civil, 2006), el profesor agrega: "los maestros no terminan su 
carrera cuando reciben su diploma, tienen que continuar aprendiendo, trabajar y mejorar".

Jaime Escalante públicamente promueve que "las matemáticas no son difíciles, cualquiera puede aprender"

Según Mathews (1988, p. 14) Escalante entregó sentencias cortas para justificar el sacrificio:

Usted quiere hacer orgullosos a sus padres y a su escuela. Piensa, que bien se sentirán si usted va a la universidad y sabe que hizo el AP del Cálculo. No cualquiera puede hacer eso. ¿No sería bueno que las personas reconozcan que el Este de los Angeles está produciendo tan buenos estudiantes? (Mathews, 1988, p. 14).

Cuando nosotros estamos en una banda, se socializa y se hacen amigos. Ellos estaban escuchando, usted se asocia a un club y usted hace algo bueno para algunas personas, ellos van a comprender. Ellos van a recordarlo si hace algo positivo. Eso es lo que estoy intentando hacer, algo positivo. (Mathews, 1988, p. 101).

Para Escalante, la experiencia es el mejor profesor que uno tiene, con el trabajo de varios años en el Colegio Bolívar, Gualberto Villarroel y San Calixto y alguna experiencia en Puerto Rico, vió que era necesario desarrollar la habilidad personal de los alumnos, interpretarles y aprovechar todo lo posible lo que ellos podían dar.

Consiste en crear la conciencia en los mismos estudiantes, las potencialidades que ellos tienen. Deben estar seguros de lo que ellos pueden hacer, sólo se necesita ganas. Yo no creo en superdotados, creo en los jóvenes que ponen un poco de ganas, en los que tienen la voluntad y el deseo de hacer las cosas bien. (Escalante, 2008).

Según Mathews (1988), Jaime Escalante les decía: "Usted tiene que estar a tiempo, usted no pude llegar tarde." Así lanzaba sus cinco minutos de conferencia en las limitaciones de los adolescentes americanos, particularmente en la persona mayor de la secundaria, entonces reanudaba su clase. 


\section{Todo lo que se necesita es Ganas}

Otra creencia de Jaime Escalante sobre el aprendizaje de las matemáticas se basa en el principio: se aprende más fácilmente cuando se está motivado. Nadie aprende cuando se siente cohibido o aburrido, o siente que el maestro no tiene interés.

Todo lo que necesita una persona para tener éxito son las "ganas".

Hoy en día, la palabra "ganas" es muy común en el idioma español (Martínez, Vázquez y Rosales, 2001). Todos los hispanohablantes sabemos lo que significa. Para Jaime Escalante, “ganas”, quiere decir "deseo”. Las ganas son el inicio de la motivación.

En mi clase yo tengo un letrero que dice "ganas". Esto quiere decir "deseo" $Y$ usted debe tener un deseo. Las ganas son el inicio de la motivación. Esta palabra es muy fuerte en mi idioma nativo (español). Ganas reemplaza a la palabra "dotado" usada en Estados Unidos. Yo no acepto esto de "dotado". Sólo le mide a un alumno el coeficiente intelectual y yo digo que no. Cualquier estudiante, cualquier persona para mi es dotada. Todos tienen algo para lo que son dotados, y en especial a mis estudiantes les considero por lo que hacen. $Y$ ahí es donde se puede hacer la transformación para motivarlos con las matemáticas. Uno se vuelve "dotado" con la práctica. La práctica asegura el éxito. Si le doy una simple ecuación, y si usted la resuelve una y otra vez, puede entonces retener esta información.

Para entender mejor pruebe hacer una comparación con algo que le sea familiar. Por ejemplo, si usted le dice al mecánico: "Deseo que me revise el carburador o que me cambie la llanta", La primera cosa que él va hacer es buscar sus herramientas. Si no las tiene, no va poder hacer el trabajo. De esta manera es como funciona las matemáticas. Para cualquier problema que se le presente, usted va a encontrar una fórmula, una ecuación para resolverlo, va a tener que pensar. Y lo que estoy enseñando es cómo usar bien estas herramientas.

Ganas es donde comienza la motivación. Ganas es donde se adquiere la energía necesaria para jugar de defensa. Si yo deseo ampliar una foto y que quede clarísima, entonces debo tener primero una buena foto que me permita hacer esta ampliación. Si usted no tiene una buena foto, entonces olvídelo, porque usted no podrá hacer lo que quiere. (Escalante, 2003, en Hanson). 
Jaime Escalante afirma: "Mis habilidades realmente, son motivar a estos niños, hacerles aprender para darles ganas - el deseo de hacer algo - para hacerles creer que ellos pueden aprender".

Todo lo que el alumno necesita para aprender matemáticas es "ganas", "Nada es difícil cuando uno tiene ganas". Jaime Escalante había escrito una expresión en un cartel que colocó sobre la pizarra en el salón de clases.

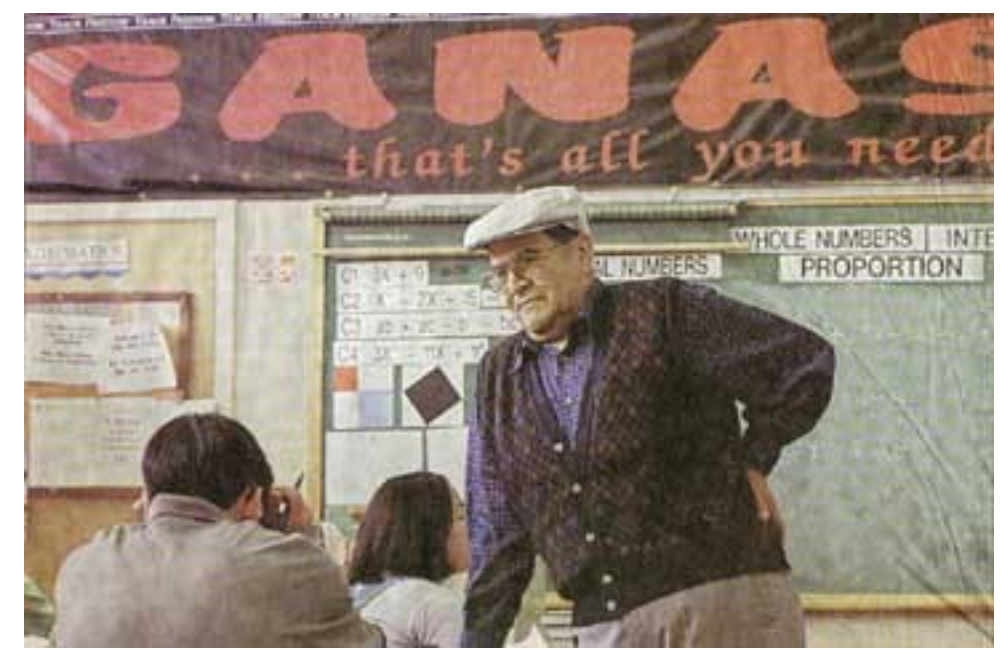

Una característica particular de Jaime Escalante es que él siempre mira desde su experiencia, y afirma que no es teórico, su experiencia está en el aula y su compromiso con los alumnos. Cree que ayudando a los estudiantes a encontrar las "ganas", un deseo que nace desde su interior, les permite superar todas las barreras ${ }^{18}$.

Jaime Escalante reconoce que tuvo muchas frustraciones y muchas veces estuvo en la lona, pero él solo cuenta las veces que uno se levanta y dice: "Tienes que imponerte y usar tu yo personal, esa es parte de tu responsabilidad. Cuando uno tiene ganas, se levanta, se sacude el polvo, y levanta la cerviz, sigue mirando hacia adelante y camina en pos del gran ideal que tiene" (Escalante, 2007, párrafo 35).

Otro factor importante en su experiencia fue la disciplina que su madre le enseñó, era cumplir y hacer las cosas bien. Terminar lo que había empezado. Además, hizo su formula:

\footnotetext{
${ }^{18} \mathrm{http}: / / \mathrm{www}$. Nthf.org/inductee/escalante.htm
} 


\section{Determinación + Disciplina + Trabajo duro = Camino al éxito}

La determinación la aprendió de su héroe nacional Eduardo Abaroa, la disciplina de su madre y el trabajo duro del Colegio "San Calixto".

Un equipo de profesores investigadores de la Universidad de Texas señala que hoy en día la palabra "ganas" es muy común en el idioma español y existe un amplio consenso sobre el significado. Casi todo es posible si hay ganas. Es decir, "los estudiantes pueden lograr todo si le ponen ganas al estudio" (Martínez, Vázquez y Rosales, 2001).

Según los autores citados, este concepto se popularizó con la película Stand and Deliver, basada en la vida del profesor objeto de esta tesis.

Esta metodología de las ganas fue aplicada por varios profesores en diferentes disciplinas y niveles. Como Nell G. Tiller, una instructora de español utilizó esta metodología inspirada por la película Stand and Deliver. Ella se centró en los carteles escritos sobre la pizarra en el salón de clases. Según Tiller $^{19}$ (2006), la expresión "tienes que tener ganas" es una expresión que no tiene una traducción fácil al inglés. "Tener ganas" va más allá de "You've got to want to". Implica algo más profundo. Yo quiero hacer esto más que cualquier cosa en el mundo. Ella, como instructora de español, adoptó este método.

Mientras que, Martinez et al. (2006), han hecho de GANAS un acrónimo: Gaining Access to Natural Habilitéis in Science (logrando acceso a las habilidades naturales en ciencias).

La premisa de esta metodología es sencilla: se aprende más fácil cuando se está motivado. Nadie aprende cuando se siente cohibido, aburrido o si siente que el profesor no tiene interés. GANAS exige que el educador sienta pasión por la enseñanza. GANAS dice que el educador tiene el deber de despertar el ánimo y la motivación de los educandos. Aprender haciendo y con ganas o voluntad; con motivación y entrega, ésa es la parte central del método GANAS.

1. GANAS significa hacer las cosas con optimismo, con motivación, interés y alegría.

\footnotetext{
${ }^{19} \mathrm{http} / / / \mathrm{www} .1 . \mathrm{brvccs}$. edu/tiller/worksheets_and notes fall\%202005.htm
} 
2. GANAS predica que la mejor manera de aprender es participando directamente en la materia que se enseña, es una metodología dinámica donde el alumno se vuelve protagonista.

3. Esta modalidad no requiere de presupuesto extra. Utiliza los recursos de la misma comunidad, los que el maestro tenga a su alcance.

Escalante, de entrada dice a sus alumnos, no habrá ningún paseo libre, ninguna excusa. Usted ya tiene dos factores en contra: su nombre y su color de piel. Debido a estos dos factores, hay algunas personas en este mundo que asumirán que usted conoce menos de lo que usted hace. La matemática es el gran igualador. Cuando usted va por un trabajo, la persona que lo va a contratar no querrá oír sus problemas; yo tampoco. Usted va a trabajar aquí más que lo que ha trabajado en la vida en cualquier otra parte. Y la única cosa que yo requiero de usted es "ganas". El deseo.

Para Jaime Escalante, la cosa más importante es que el niño tiene que estar listo para aprender, y aprenderá. Las mentes de los niños están en el baloncesto, la música, o copiando esos cortes de cabello cómicos, y así sucesivamente. Para motivarlos, nosotros tenemos que tocar esos puntos que ellos recordarán. Nosotros tenemos que usar eso para localizar a los niños en los grupos étnicos diferentes. Escalante señala como ejemplo: "Mira, tu futuro no es volverte Michael Jordan. Él es una superestrella en el baloncesto; usted no lo será. Tu futuro es hacerte una superestrella como ingeniero, técnico, volverse algo positivo en la vida. Y la educación es el boleto al éxito. La educación es tu vida. Así que tome esto como un ejemplo: este tipo dispara la pelota muy bien; tiene el concepto de matemática muy bien. Usa el concepto de matemática en tu cerebro para volverte un profesional - pero no jugador profesional del baloncesto; Yo uso algunos ejemplos de la comunidad hispana, de la comunidad negra, la comunidad anglo, dependiendo de los grupos étnicos de mis estudiantes".

\section{Aprovechar la memoria visual}

Jaime Escalante sostiene que se debe aprovechar la memoria visual en la enseñanza de la matemática. En el marco de esta perspectiva, desarrollaba 
en sus clases los conceptos matemáticos de forma lúdica y/o de laboratorio para llevar los conceptos matemáticos a través de actividades lúdicas. Jaime Escalante llevaba mucho material para las conferencias y seminarios.

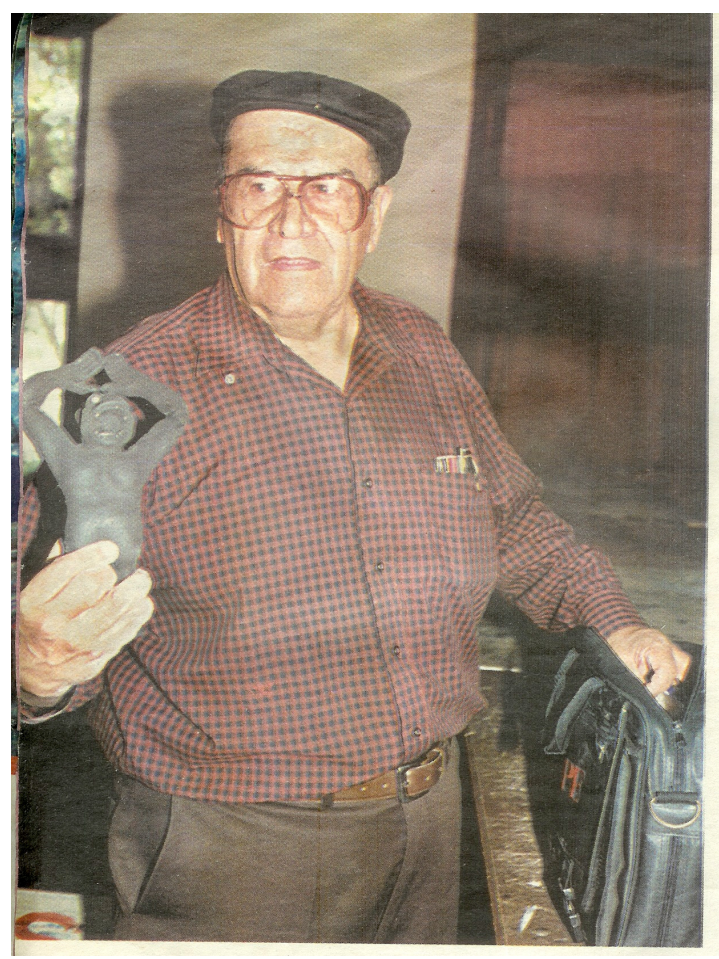

Jaime Escalante en Cochabamaba, 2002

Su objetivo era aprovechar la memoria visual para que el estudiante relacionara las cosas de modo que no las olvidara, a través de rompe-cabezas, trucos e interesantes ideas en el arte de enseñar y el proceso de aprender esta ciencia.

Para Jaime es imperativo leer despacio y entender los términos, de lo contrario no motiva. Adquirir el hábito de tener a mano el lápiz y el papel, encontrar las palabras claves y tratar de visualizar el problema haciendo un bosquejo o grafico para entender mejor. (Escalante, 2008).

Al visitar su biblioteca personal en Cochabamba, encontré que todos los libros eran de matemáticas o relacionados con historia de las matemáticas, y posiblemente ningún profesor de secundaria en Bolivia cuente con esa cantidad de libros, además la mayoría de los libros estaban en ingles. También pude observar los apuntes de clases muy organizados por asignaturas y por temas con los ejercicios resueltos y propuestos, la mayoría escritos a mano y algunos que había transcrito su hijo mientras estaba trabajando en Bolivia. 
Jaime Escalante tenía una gorra que le distinguía, y casi no se la quitaba porque cubría con ella los pocos pelos que le quedaban.

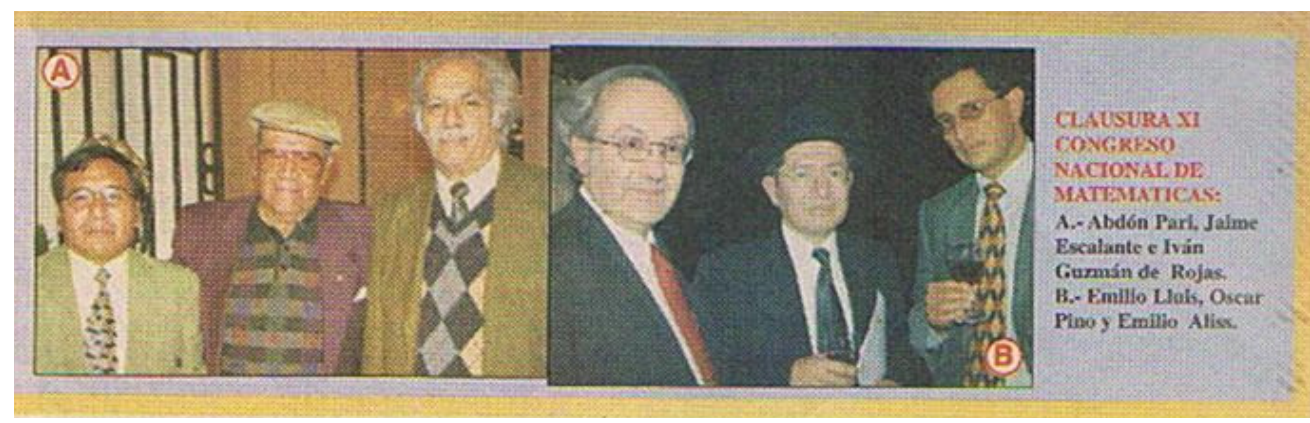

Cochabamba, 25 de febrero de 2005

Pero se distinguía más por su dinamismo, entusiasmo, su pasión por las matemáticas y por la enseñanza de las matemáticas (Mathews, 1988). No se cansaba de mostrarnos los problemas o ejercicios que estaba planteando y resolviendo por diferentes métodos.

Él mostraba interés por sus alumnos más allá de las aulas, se interesaba en el futuro de sus estudiantes. Y decía: "Tenemos que enfatizar la motivación de los estudiantes para hacer el trabajo (matemáticas), trabajar juntos, compartir ideas. Tenemos que enseñar en la clase lo que los alumnos van a usar en la vida real" (Escalante, en Novak, 1993). Hacía que la clase se vuelviera como un lugar de trabajo.

Para Jaime Escalante, la enseñanza de las matemáticas se puede resumir en una sola palabra: Diversión.

\subsection{Estrategias de la enseñanza de la matemática}

Coincido ampliamente con Perkins (2003), Jaime Escalante no sólo aportó conocimento, sino un arsenal de ingeniosas estrategias para motivar a sus alumnos.

Miencionaré algunas:

- Determinación + Disciplina + Trabajo duro = Camino al éxito

- Hay que introducir un lenguaje más cómodo para los alumnos, no simplemente enseñar los signos 
- Los carteles en el aula de clases como: "todo lo que se necesita es ganas", "No hay necesidad de facilitar el cálculo porque ya es fácil”, etc.

- Mensajes o pequeñas sentencias escritas para aumentar la autoestima

- El sentido del humor

- La música boliviana

- Su lengua nativa

- Jergas Bolivianas

- Trabajo en equipo

- Trabajo duro

- El juego

- Los retos

- La demanda y la exigencia

- El respeto a los estudiantes

- El apoyo de los padres

- Los uniformes como premio para los estudiantes del programa

- Las cenas en lugares lujosos de los famosos como premio

- Etc.

Según Jaime Escalante, un profesor para ser motivador tiene que ser innovador. La forma como motiva está relacionada con las cosas que el alumno conoce, entonces cuando hay algo que el alumno conoce, se le enciende la luz verde, y le despierta interés.

\subsection{Recursos didácticos}

En esta sección se abordan algunos de los recursos didácticos utilizados por Jaime Escalante en la enseñanza de las matemáticas. Como fue señalado por Perkins (2003), Escalante aportó un arsenal de estrategias, pero también contribuyó con muchos recusos didácticos desde lo más simple a lo más complejo. Los que se abordan en esta sección son los que he visto utilizar en sus clases y algunas conferencias para estudiantes de magisterio y profesores de matemática en Bolivia. Sin embargo, Escalante ha implementado muchos 
recursos didácticos a lo largo de sus años de experiencia. En uno de esos seminarios, me dijo: "lo que tengo en Bolivia es parte de lo que está en Estados Unidos".

Los materiales que utilizaba como recursos didácticos estaban elaborados con una variedad de materiales, desde lo más común hasta lo más extraño. Coincido con el periodista chileno Rodrigo Cerda en que el profesor Jaime Escalante recurre a todo para enseñar matemáticas: Cartulinas, palitos y cuadrados con los que explica el álgebra. Según Escalante:

Si le muestras con objetos que puede tocar lo que es una ecuación al cuadrado, inmediatamente el alumno la ve, la toca y reconoce lo que es esa ecuación. Luego, si le dices que al igual que las personas tienen un nombre y que se llama polinomio de tal grado, el alumno se entusiasma y empieza a tomarle cariño. (Escalante, en Cerda, 2004, Agosto 27).

El periodista opina en base a un seminario taller que dio el profesor Jaime Escalante en Santiago (Chile), en el año 2004. Sin embargo, yo he podido presenciar más de una decena de seminarios y talleres para estudiantes y profesores en diferentes ciudades en Bolivia, incluyendo las de la Universidad Adventista de Bolivia, y disertaciones en algunos Congresos de la SoBolMat que se celebraban en Cochabamba.

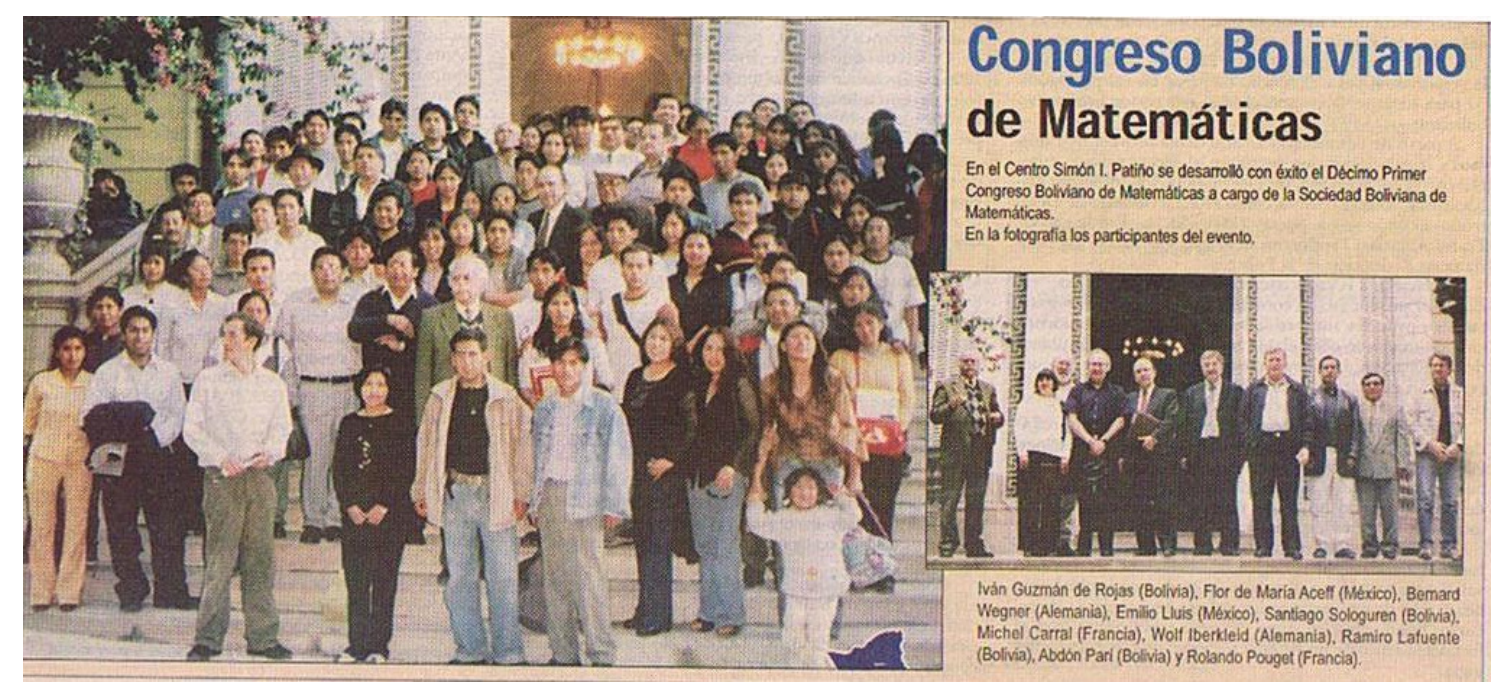

Cochabamba, 25 de febrero de 2005

La mayoria de sus disertaciones partían desde los dígitos numéricos y los relacionaba con los dedos, dicíendo: "con mis dedos puedo hacer todas las operaciones: la suma, la resta, la multiplicación." 


\section{La multiplicación con los dedos}

Según Kolpas (2002), Jaime Escalante ha usado muy bien el truco de la multiplicación con los dedos: la multiplicación del nueve, para captar la atención y el interés de sus alumnos. Este hecho es representado en la película Stand and Deliver, en la que Edward James Olmos personifica al profesor de matemáticas Jaime Escalante en Garfield High School.

Escalante. Ohh knows the times tables?

Chuco. I Know the ones...twos...three.

(On "three" Chuco flips the bird to Escalante)

Escalante. Finger Man. I heard about you. Are you The Finger Man? I'm de Finger Man, too. Do you know what I can do? I know how to multiply by nine! Nine times three. What you got? Twenty-seven. Six times nine? One, two, three, four, five, six. What yo got? Fifty-four. You wanna hard one. How about eight times nine? One, two, three, four, five, six, seven, eight. What do you got. Seventy-two. (Kolpas, 2002, p. 246).

En la siguiente imagen se observa a Jaime Escalante compartiendo la multiplicación con los dedos con los profesores de matemáticas de la ciudad de Santa Cruz, Bolivia.

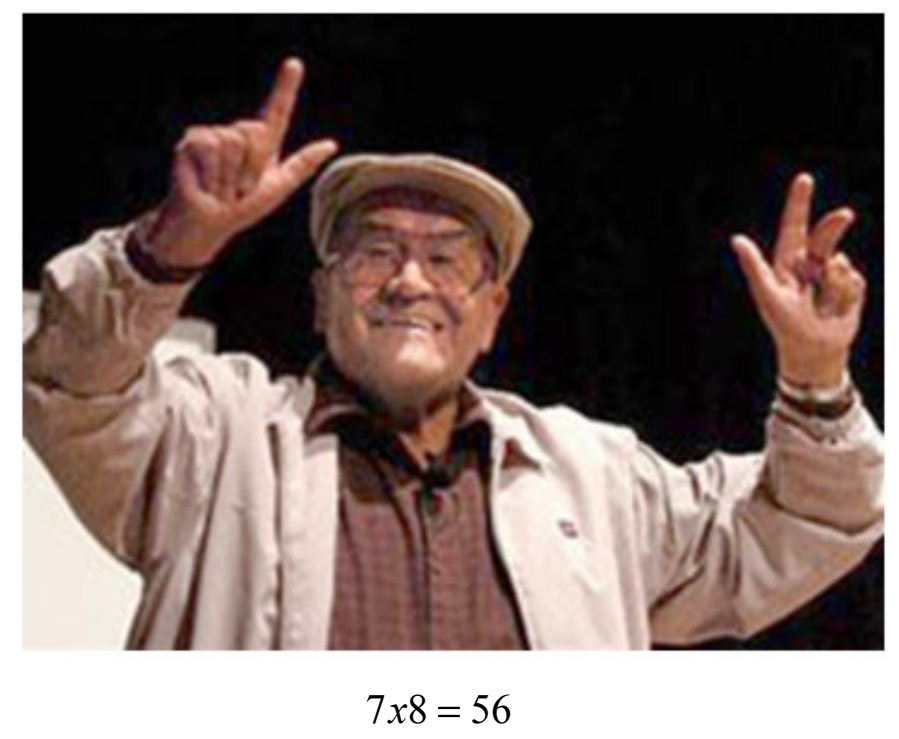


La multiplicación con los dedos es conocida en Europa (Kolpas, 2002), posiblemente ya fue conocida por los campesinos europeos, pero la multiplicación como el truco de Escalante fue popularizada por la película Stand and Deliver. Además, Escalante ha recibido la visita de muchos profesores de diferentes paises, incluso entre los chinos y japoneses, que han mejorado sus materiales, y se lo han entregado como un regalo (Escalante, 2005, comunicación personal).

\section{Pizarra metálica con imán}

Otro de sus recursos era la pizarra metálica, que le facilitaba adherir las fichas a través de un pequeño imán para que quedaran fijadas. En la parte izquierda aparece una pizarra metálica con los ejes coordenados, los números de los puntos estan hechos de goma y llevan un pequeño imán.

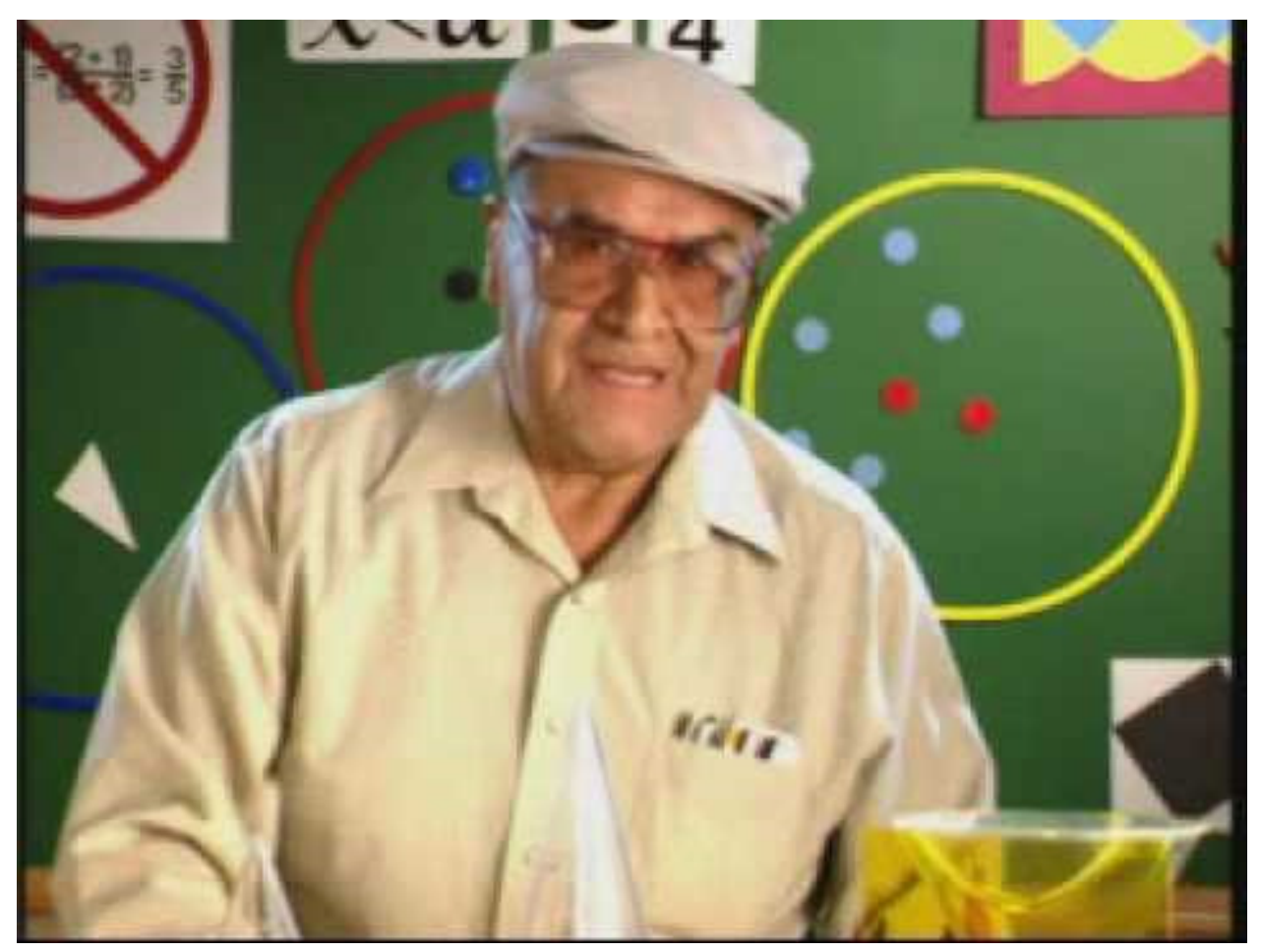

Jaime Escalante en Cochabamba, Bolivia

En la Universidad Adventista de Bolivia, en un Taller de la enseñanza de las matemáticas para estudiantes de Magisterio, utilizó la pizarra metálica para explicar el concepto del cero, la introdución de las fracciones y porcentajes, y la transición de la aritmética al álgebra. Además, tenía estos 
recursos en diferentes materiales, y podía utilizarlos de acuerdo a las circunstancias o las condiciones. Si la audiencia era grande, utlizaba las transparencias para proyectarlas en la pantalla. En el caso de los talleres, y si los alumnos podían trabajar en mesas de grupos de a cuatro, usaba las fichas de diferentes materiales y colores.

\section{Fichas de plástico}

Jaime Escalante llevaba una variedad de fichas de plastico y podía darles diferentes usos y aplicaciones. Una de las aplicaciones que vi, y describo a continuación, se refiere al concepto del cero. Jaime Escalante no se perdía en discusiones filosóficas, sino buscaba una aplicación práctica.

Para el profesor Jaime Escalante era muy importante que el alumno tuviera un concepto claro del cero. Esto facilitaria la entrada a los números enteros y al álgebra. El cero es un concepto bastante paradógico pero fundamental para el desarrollo de las matemáticas a través de la historia.

Al respecto, dice:

(...) pregunté a un alumno: ¿has estado en la playa?, ¿has jugado con la arena?". "Si", respondió el alumno. El hoyo que queda es negativo y la arena que sale es positivo, y le dije a uno de ellos: ¿menos uno mas uno? (Escalante, 2007, párrafo 39).

Escalante utilizó la pizarra metálica con una línea horizontal por el medio, arriba tenía un signo + (positivo) y abajo un signo - (negativo), cuyas las fichas eran de colores, cuacradas, de plastico e imantantadas por detrás, pero a los alumnos se les entregó un folio con el mismo diseño que la pizarra metálica y con cierto número de fichas plasticas circulares sin imán. El profesor hacía uso del retroproyector y los estudiantes los siguián desde sus mesas de trabajo distribuidos en grupos de cuatro 


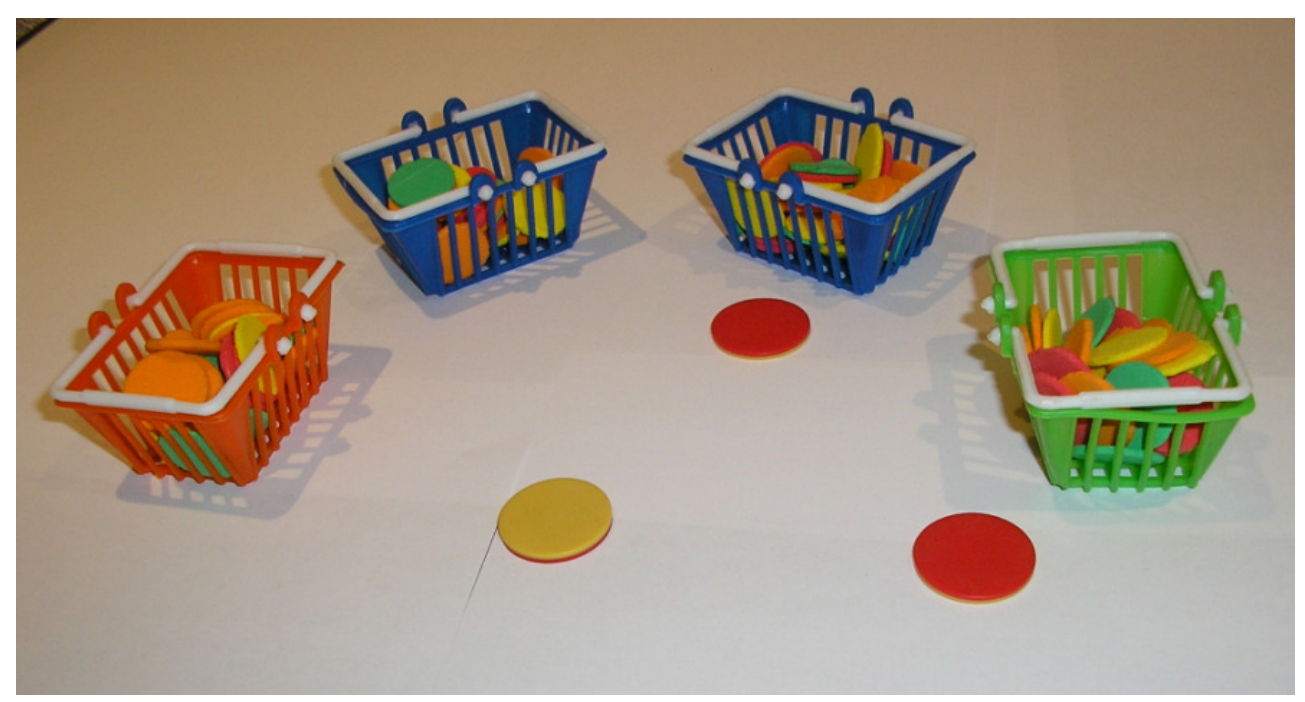

\section{Concepto de Cero}

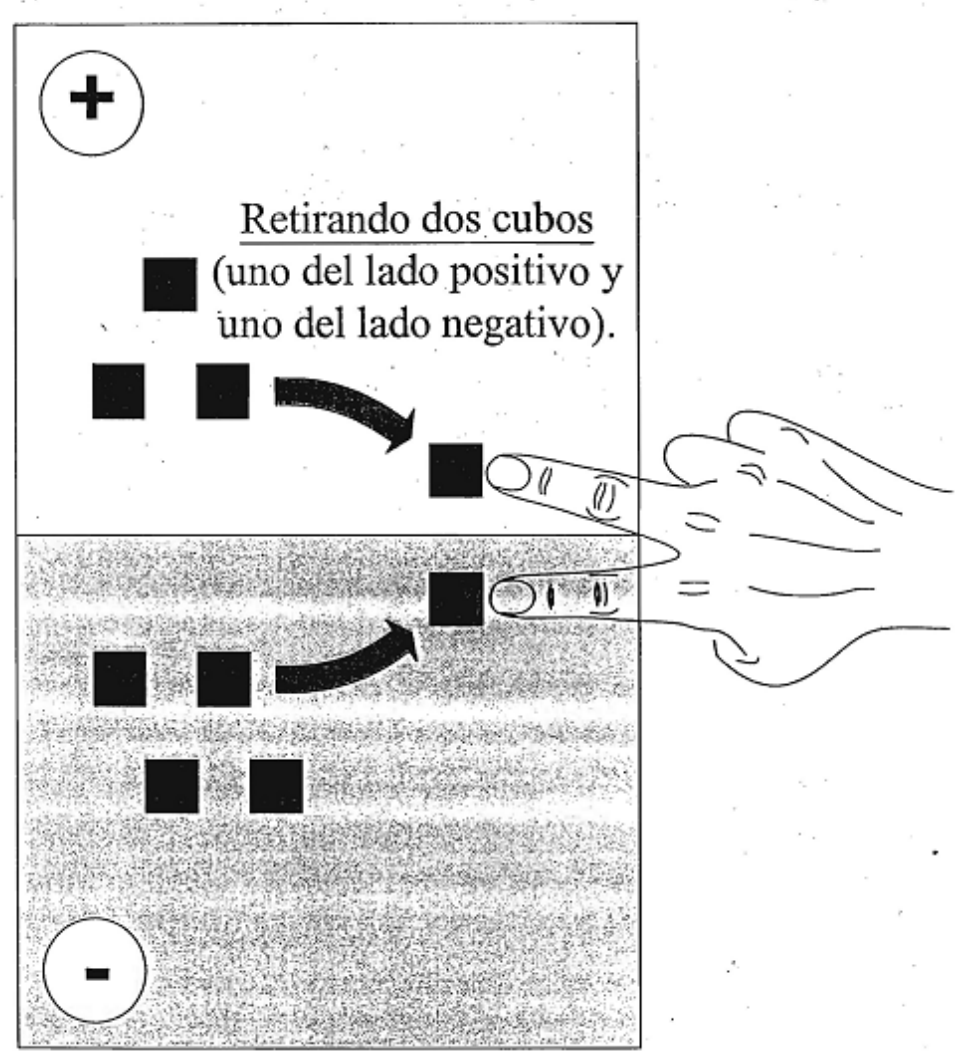

Cuando el profesor pide calcular: 4-5, el alumno hace la representación en el folio que está es su mesa, mientras que el profesor lo hace en la pizarra. Pueda ser que no tenga nada de nuevo, pero la actitud positiva del niño hacia la matemática es innegable, porque disfruta 
manipulando las fichas, además de comprender las operaciones con números enteros.

\section{El tablero de fracciones}

Para introducir al estudiante en los números racionales, Jaime Escalante comenzó por las fracciones. Sacó de una de las cajas una pelota de mano con algún dibujo encima, y un corte que pasaba inadvertido. Apretó la pelota con la mano y el corte formaba una boca, y el dibujo los ojos de una rana. Los alumnos quedaron sorprendidos y cada vez que apretaba la pelota, decía ¡fracción!, ¡fracción!, ¡fracción!

No siempre lo desarrollaba de la misma manera, a pesar de que el tema fuera el mismo. Algunas veces usó las fichas anteriores para explicar, otras veces llevaba frutas, como lo muestra la película Stand and Deliver, el actor le representa vestido de cocinero con su cuchillo para partir las manzanas en fracciones y lo hace con una destreza que sorprede a los alumnos. Mientras que, en un taller de la enseñanza de las matemáticas para estudiantes de Magisterio, impartido en la Universidad Adventista de Bolivia, parte desde la bandera nacional y luego presenta el tablero de fracciones, que fue construido por él mismo.

Con el sentido del humor que lo caracteriza, dice: "si el chico aprende bien las fracciones, le va a ir bien en el álgebra y en el cálculo por que Dios es Grande”. (Escalante, 2005, comunicación personal).

Escalante llegó con una hora de anticipación a la clase programada y con cinco maletas de materiales didácticos. Hizo la distribución de los materiales sobre las mesas antes de que los alumnos llegaran.

Escalante dijo: "hoy voy a hablarles de la bandera de mi país" y sacó la bandera tricolor. Todos los alumnos estaban atentos a los movimientos de Escalante, porque en cualquier momento saldría con otra sorpresa. 


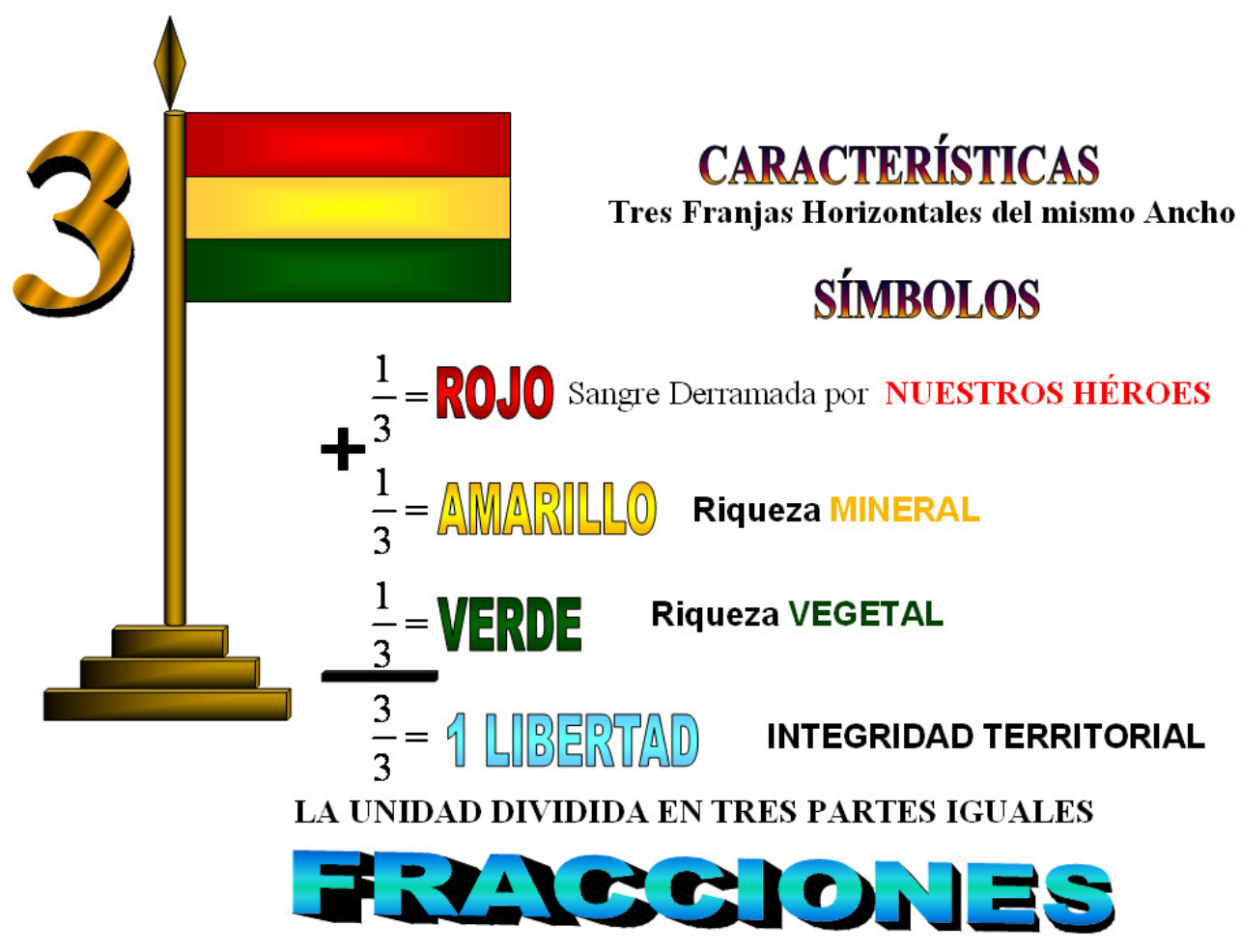

- Enfatizó la importancia del número tres, BO-LI-VIA.

- Al empezar a entonar el himno nacional se cuenta 1, 2 y 3.

- Al empezar una competición de las carreras de 100 ms. lisos, se dice: en su marcas, listos, ya.

- En el deporte: el ganador recibe 3 puntos, si es un partido de fútbol, y en básquet existe el tiro de 3 puntos.

- El hombre debe cuidarse del fuego, viento y agua.

- Nacimiento, vida y muerte

- Trabajo, descanso y muerte

- En el nombre del Padre, del Hijo y del Espíritu Santo.

- Buenos días, buenas tardes y buenas noches

- El monagillo en lugar de decir: Amén, Amén, Amén. Decía: Amor, Amor, Amor

Indicó que el alumno tiene dificultades en el manejo de fracciones (Escalante, 2005). Así , por ejemplo, no visualiza que: 


\section{$1 \frac{1}{3}=4+\frac{1}{3}$ \\ $4 \frac{1}{3}=4+\frac{1}{3}$ \\ 13 \\ 1

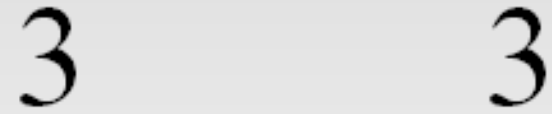

Puntualizó que el centro COMPLEJO de los Números Racionales son las FRACCIONES, que escritas simbólicamente representan muchos conceptos diferentes.

EI centro COMPLEJO de los Números

Racionales, son las FRACCIONES que escritas simbólicamente representan muchos conceptos diferentes.

1. Una fracción es parte de un ENTERO

2. Una fracción es una MEDIDA

3. Una fracción es un OPERADOR

4. Una fracción es una RAZÓN

5. Una fracción indica DIVISIÓN

Después de explicar cada uno de lo conceptos, solicitó a los alumnos que construyeran las representaciones gráficas. 


\section{ACTIVIDAD I}

\begin{tabular}{|c|c|c|c|c|c|}
\hline \multicolumn{5}{|c|}{ 1 ENTERO } \\
\hline \multicolumn{3}{|c|}{$1 / 2$} & \multicolumn{3}{|c|}{$1 / 2$} \\
\hline $1 / 3$ & \multicolumn{3}{|c|}{$1 / 3$} & \multicolumn{2}{c|}{$1 / 3$} \\
\hline $1 / 4$ & \multicolumn{2}{|c|}{$1 / 4$} & \multicolumn{2}{|c|}{$1 / 4$} & $1 / 4$ \\
\hline $1 / 5$ & $1 / 5$ & $1 / 5$ & $1 / 5$ & $1 / 5$ \\
\hline $1 / 6$ & $1 / 6$ & $1 / 6$ & $1 / 6$ & $1 / 6$ & $1 / 6$ \\
\hline
\end{tabular}

Mientras los estudiantes estaban absortos en las medidas de los materiales, tenian la libertad de elegir y recortar las figuras. Él sacó un tablero fraccionario de su propia elaboración en un material de goma, que llevaba por detrás unas piezas de imán que le facilitaba la adhesión a la pizarra metálica.

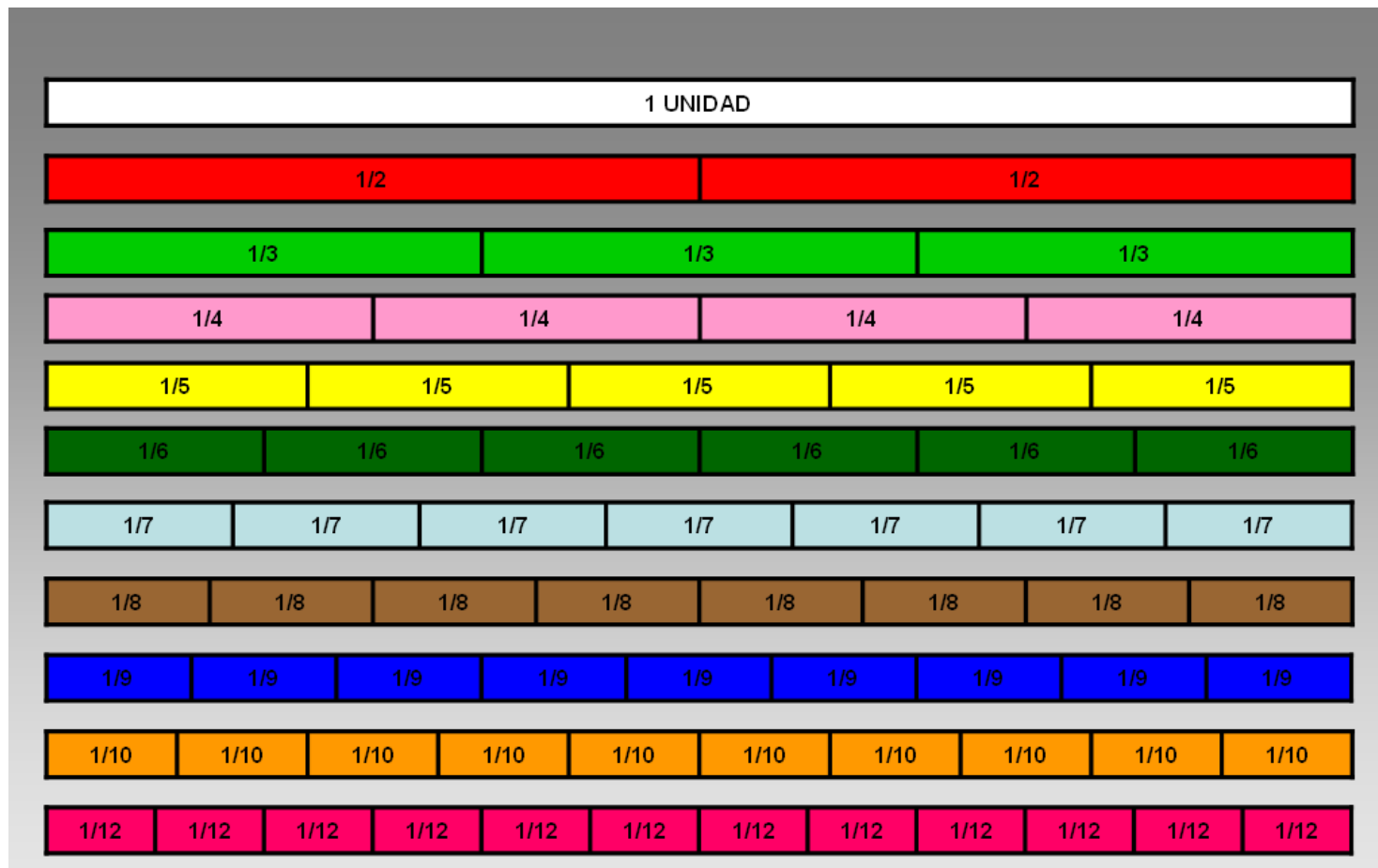

La unidad y fracciones equivalentes de la unidad 
Esto lleva relación con las regletas de Cousinaire. Aunque él señala que se inventó para ayudar a comprender las fracciones y las operaciones a los alumnos.

\section{ACTIVIDAD 2 \\ PRODUCTO DE UN ENTERO POR UNA FRACCIÓN}

PROPÓSITO: Construir la Tricolor

Nacional e ilustrar la multiplicación de un entero por una fracción.

\section{MATERIAL: Papel de color ROJO, y VERDE}

\section{PRIMERO:}

Seleccione el ancho (dos o tres centímetros) y pegue sobre una hoja de papel blanco.

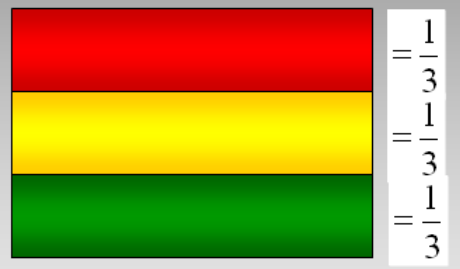

$$
\} 1 \times \frac{1}{3}=\frac{1}{3}
$$



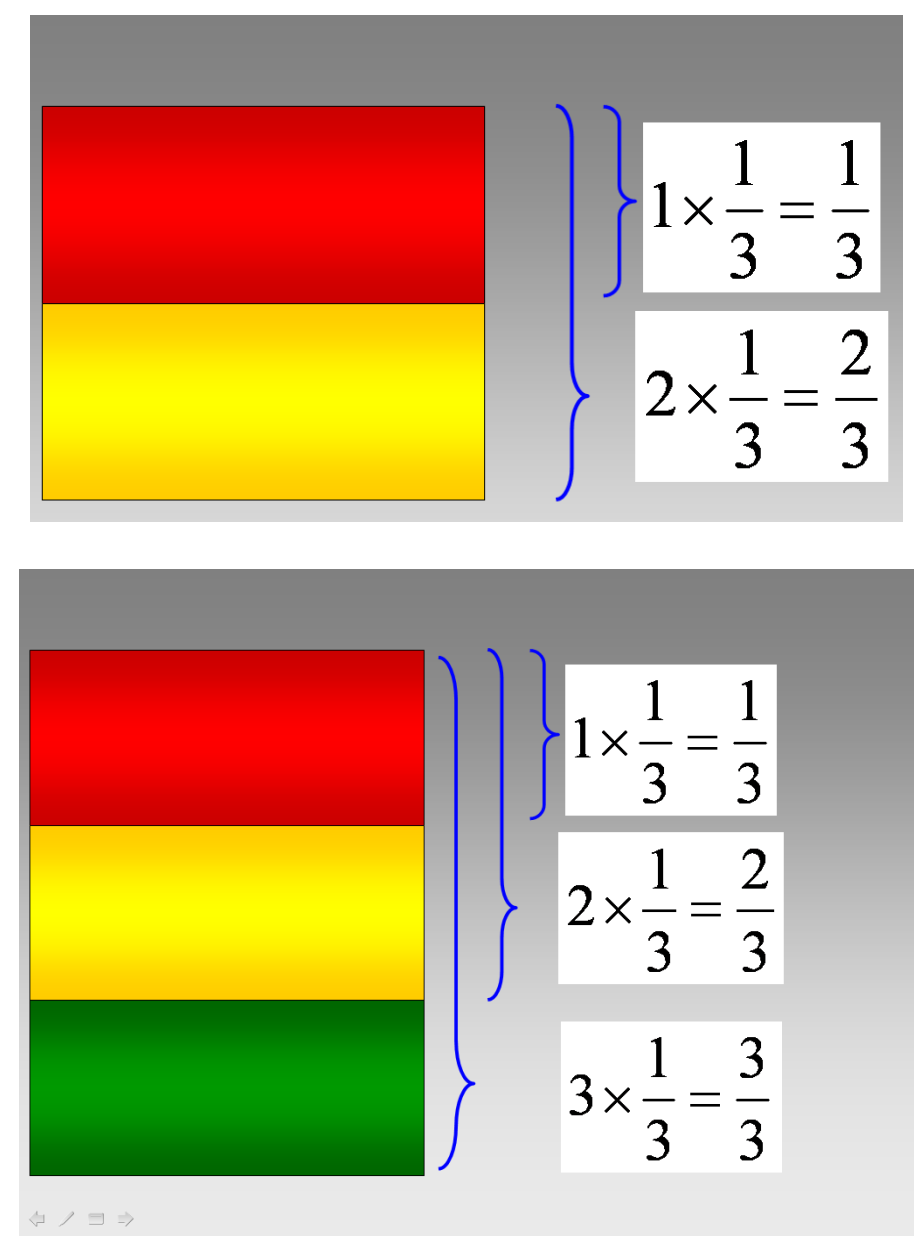

Ahora comienza a mostrar la multiplicación de una fracción por otra.

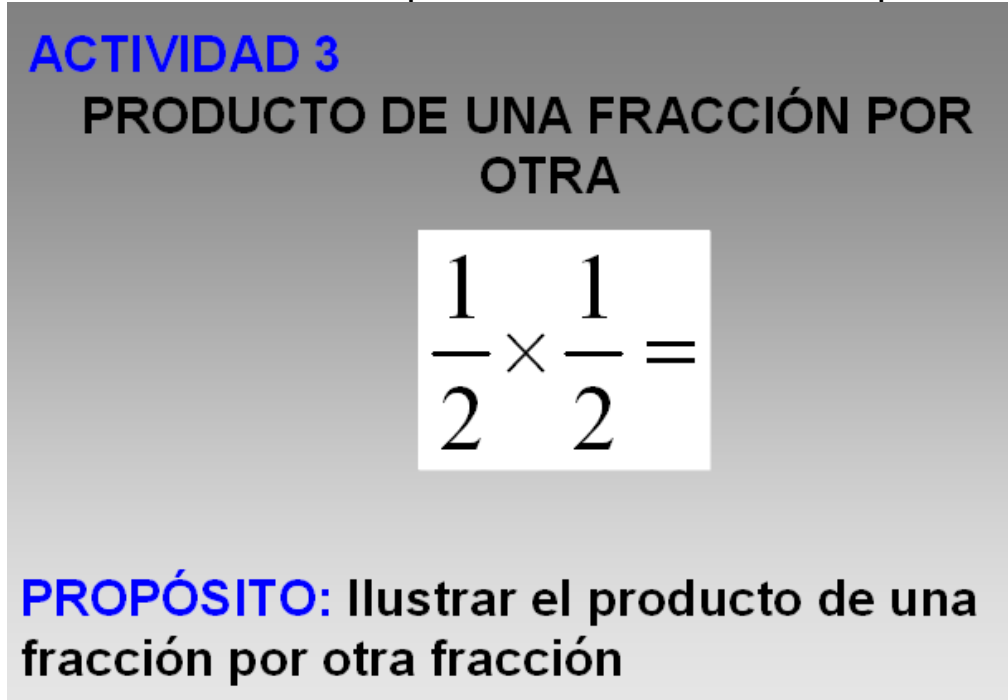

Frente a esta situación, los alumnos se preguntaban cómo puedían representar gráficamente esta multiplicación, y cada grupo discutía con sus integrantes, intentando analizar sus alternativas. Sin embargo se oyeron 
algunos comentarios: "esto es difícil". Se observa que algunos grupos lo intentan y muy pocos lo consiguen.

\section{MATERIAL: Papel Blanco}

Dibujar un cuadrado de lado $10 \mathrm{~cm}$.

Primero: Dividir o doblar el cuadrado en dos partes iguales e identificar esta fracción como indica la figura.

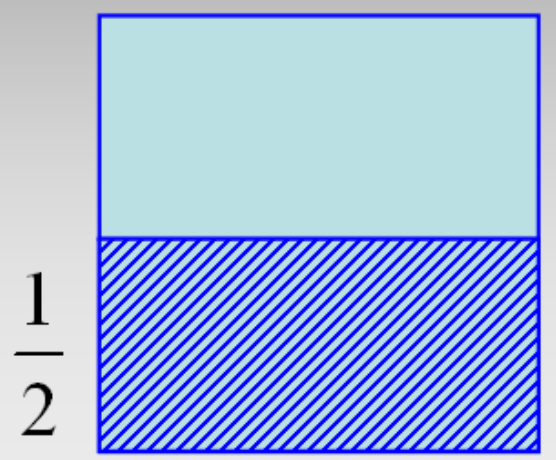

\section{SEGUNDO: EI mismo cuadrado doblar en} forma vertical como indica la figura.

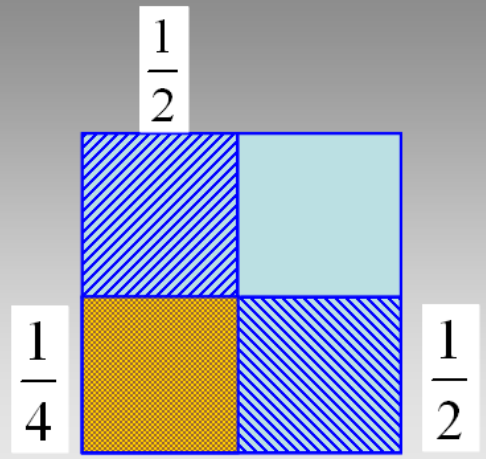



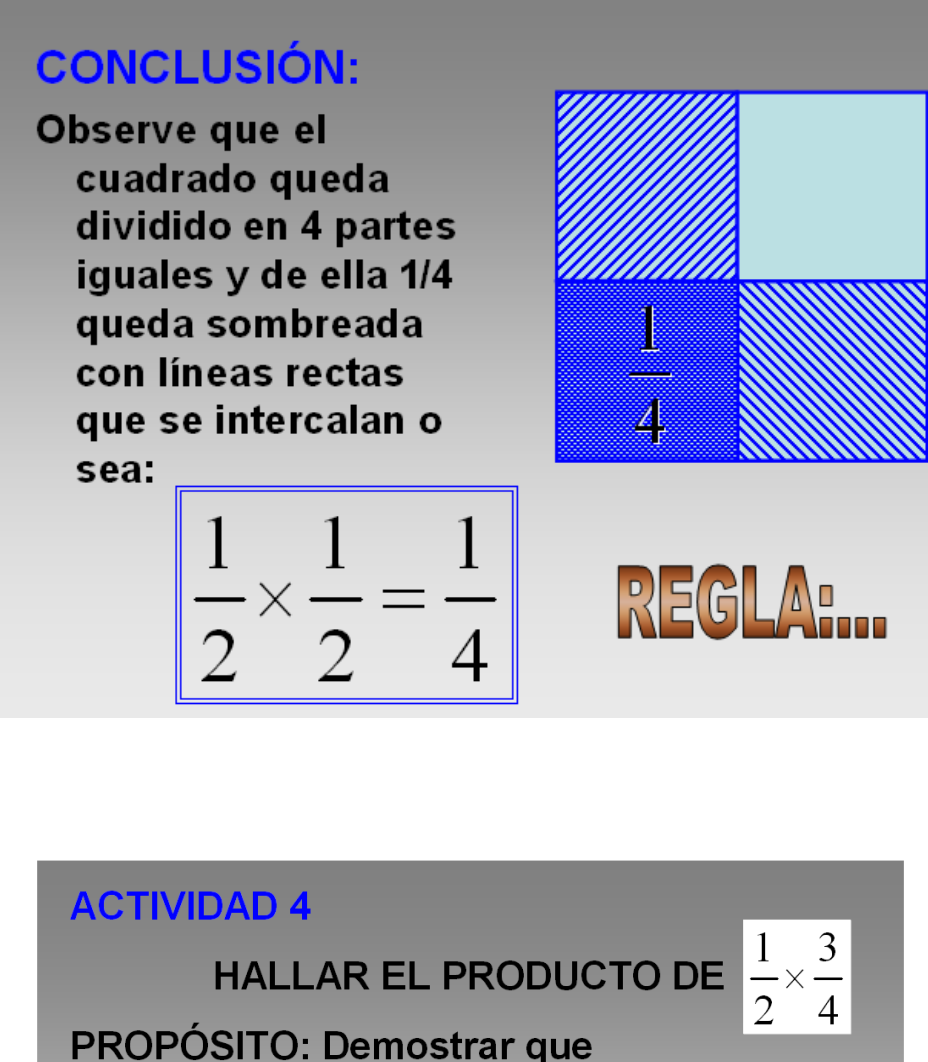

$$
\frac{1}{2} \times \frac{3}{4}=\frac{3}{8}
$$

MATERIAL: Papel Blanco

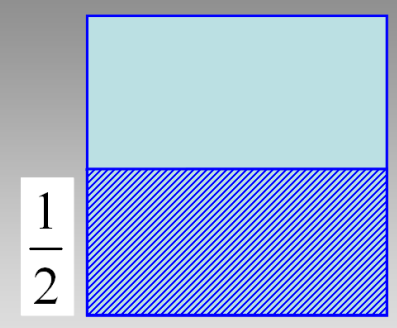




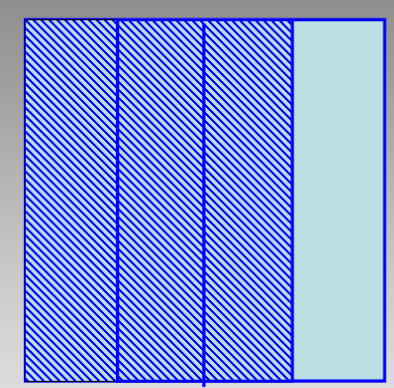

$\frac{3}{4}$

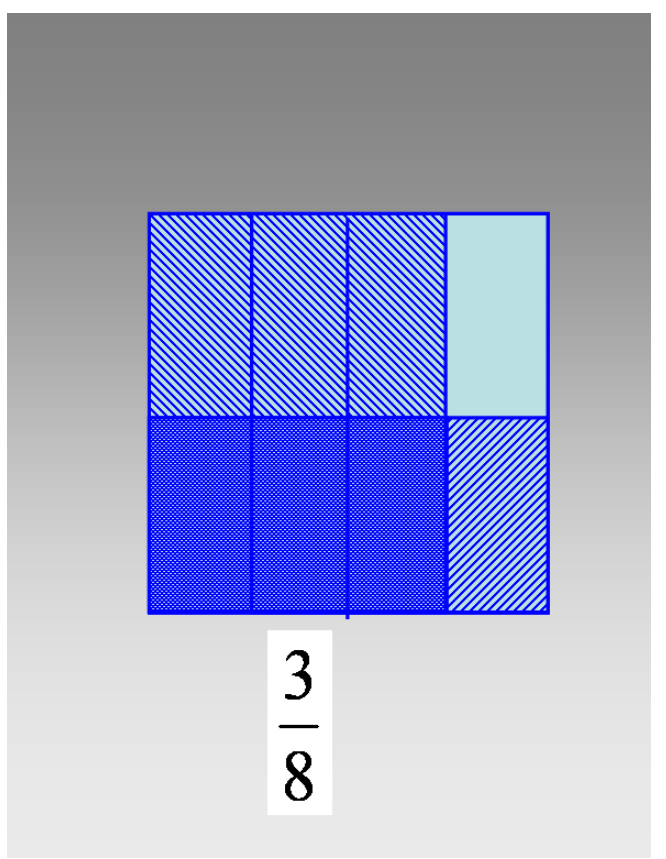




\section{ACTIVIDAD 5 \\ DIVISIÓN DE FRACCIONES \\ PROPÓSITO: Ilustrar la división de un ENTERO por una FRACCIÓN \\ MATERIAL: Una tira de papel, lápices de color. \\ Enrolle la cinta para dividir en tres partes iguales y pinte cada parte con los colores de la tricolor nacional. ¿Cuántos colores usó para pintar la cinta? Para ilustrar el concepto de

$$
1 \div \frac{1}{3}
$$

Observe que la unidad ha sido dividida en tres partes iguales. En suma

$$
1 \div \frac{1}{3}
$$

quiere decir cuantos tercios hay en una unidad.

$$
\begin{aligned}
& \text { CONCLUSIÓN: } \quad 1 \div \frac{1}{3}=3 \\
& 1 \div \frac{1}{3}=\frac{3}{1}
\end{aligned}
$$

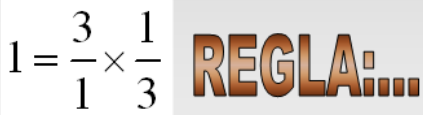

Usando esta actividad ¿Cuántos tercios hay en dos unidades?

Sabiendo que 3 tercios hay en una unidad en 2 unidades $2 \times 3=6$

$$
\begin{aligned}
& \begin{array}{ll}
\text { Otra interpretación es si } & 1 \div \frac{1}{3}=\frac{3}{1} \\
\text { Sustituyendo } 3 \text { por } \quad 1 \div \frac{1}{3} & \text { tenemos }
\end{array} \\
& 2\left(1 \div \frac{1}{3}\right)=2(3)=6
\end{aligned}
$$




\section{ACTIVIDAD 6

$$
1 \div \frac{2}{5}=?
$$

PROPÓSITO: Ilustrar el concepto de cambio de unidad.

MATERIAL: Tiras de papel.

Consideremos el ejercicio dado.

La pregunta es ¿Cuántos grupos de 2/5 caben en un entero? Para responder esta pregunta haremos la siguiente comparación.

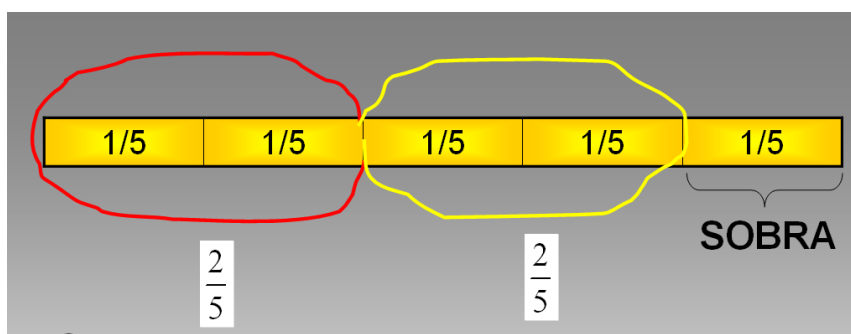

Caben 2 unidades de 2/5 de grupo y sobra $1 / 5$ comparada la sobra de $1 / 5$ con la nueva unidad

\begin{tabular}{|c|c|}
\hline $1 / 5$ & $1 / 5$ \\
\hline
\end{tabular}

Vemos que la sobra es la mitad de la nueva unidad.

$$
\begin{aligned}
1 \div \frac{2}{5} & =2+\text { la sobra } \\
& =2+\frac{1}{2} \\
1 \div \frac{2}{5} & =\frac{5}{2}
\end{aligned}
$$




$$
\text { ACTIVIDAD } 7 \quad \text { Hallar } \frac{3}{5} \div \frac{3}{10}=?
$$

PROPÓSITO: Ilustrar la división por otra donde el divisor es mayor que 0 y múltiplo del dividendo.

MATERIAL: Dos tiras de papel.

Considerando el ejemplo $3 / 5 \div 3 / 10$ y usando una actividad anterior examinemos $1 \div 3 / 10$ o sea ¿Cuántos $3 / 10$ caben en un entero.

$$
\begin{aligned}
& \text { AHORA REALCIONAMOS } \\
& \begin{aligned}
\frac{3}{5} \div \frac{3}{10} & =\frac{3}{5} \times\left(1 \div \frac{3}{10}\right) \\
& =\frac{3}{5} \times \frac{10}{3} \\
& =2
\end{aligned}
\end{aligned}
$$

\section{USANDO LAS TIRAS DE PAPEL}

\begin{tabular}{|l|l|l|l|l|}
\hline $1 / 5$ & $1 / 5$ & $1 / 5$ & $1 / 5$ & $1 / 5$ \\
\hline
\end{tabular}



12

Nueva unidad 


\section{ACTIVIDAD $8 \quad$ Hallar $\frac{3}{4} \div \frac{2}{3}=$ ?}

PROPÓSITO: Ilustrar la División de una Fracción por otra. Tanto el Dividendo como el Divisor no presentan ningún patrón.

MATERIAL: Una tira (Unidad) de papel para representar $3 / 4$ y otra para $2 / 3$.

Consideramos $\frac{3}{4} \div \frac{2}{3}=$ ?

Examinando: $\quad 1 \div \frac{2}{3}=\frac{3}{2}$ ó $1 \frac{1}{2}$

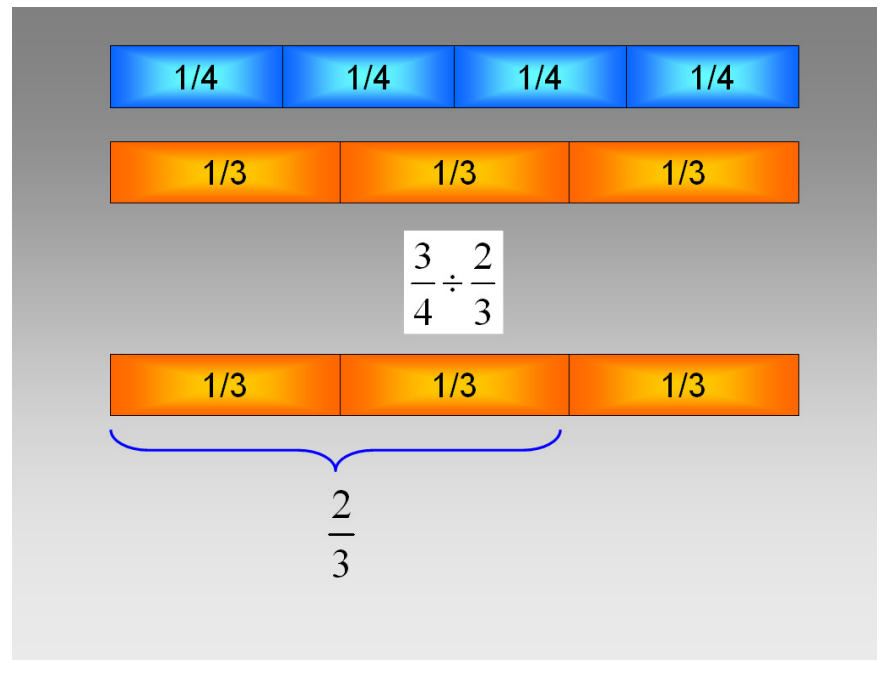

$$
\begin{aligned}
\frac{3}{4} \div \frac{2}{3} & =\frac{3}{4} \times\left(1 \div \frac{2}{3}\right) \\
& =\frac{3}{4} \times \frac{3}{2} \\
& =\frac{9}{8} \text { ó } 1 \frac{1}{8}
\end{aligned}
$$



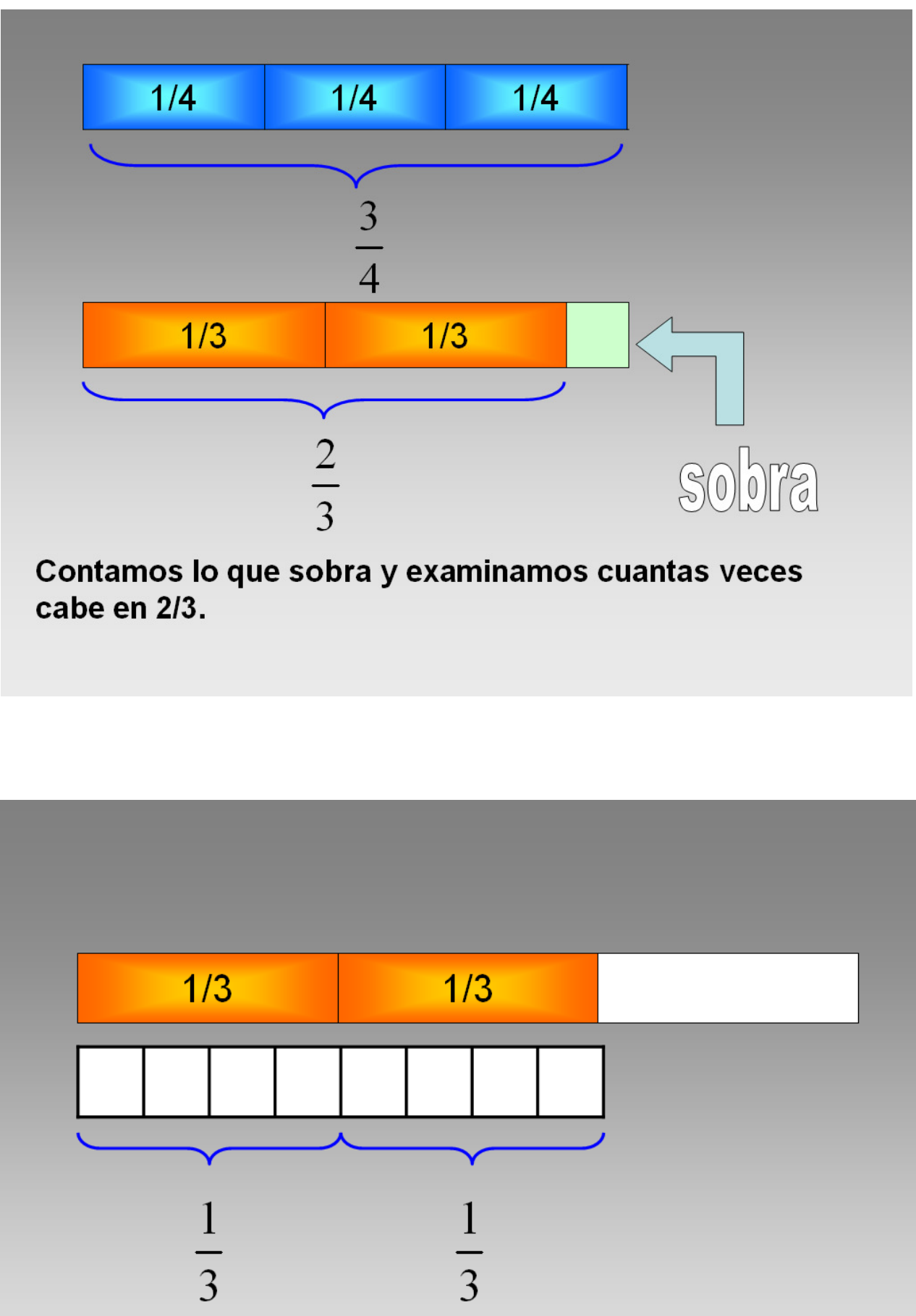

El pedazo que sobra cabe en $2 / 3$ ocho veces o sea lo que sobra es $1 / 8$ 


\section{El material de álgebra en vivo}

Jaime Escalante reconoce y trata a sus alumnos como personas, creando un ambiente cálido y de confianza, les enseña más de lo que ellos creen ser capaces de asimilar. Les da la oportunidad de responder confiando en ellos y motivándoles a seguir trabajando en su proceso de aprendizaje. Escalante (2007), dice: "Para ser motivador, el maestro tiene que ser innovador".

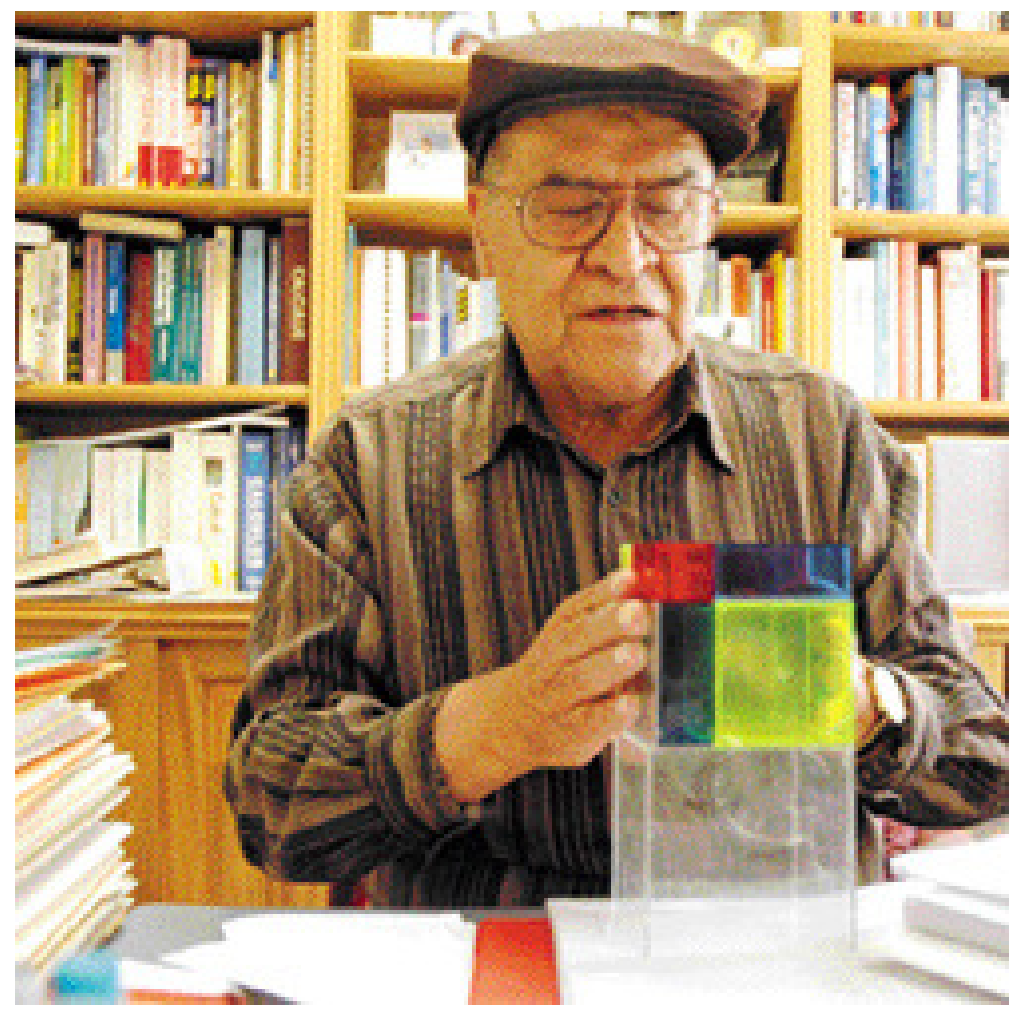

Jaime Escalante y los productos notables

La enseñanza y aprendizaje del álgebra a través del recurso didáctico que presentamos, se hace novedosa y atractiva. Jaime Escalante lo llama álgebra en vivo. Esta presentación se hace en base a una observación de un taller de enseñanza de las matemáticas para estudiantes de Magisterio en la Universidad Adventista de Bolivía (2004).

Escalante llevó mucho material didáctico para una clase de 20 alumnos y los distribuyó en grupos de a cuatro. El tema de la disertación se tituló: "Transición de la aritmética al álgebra". 


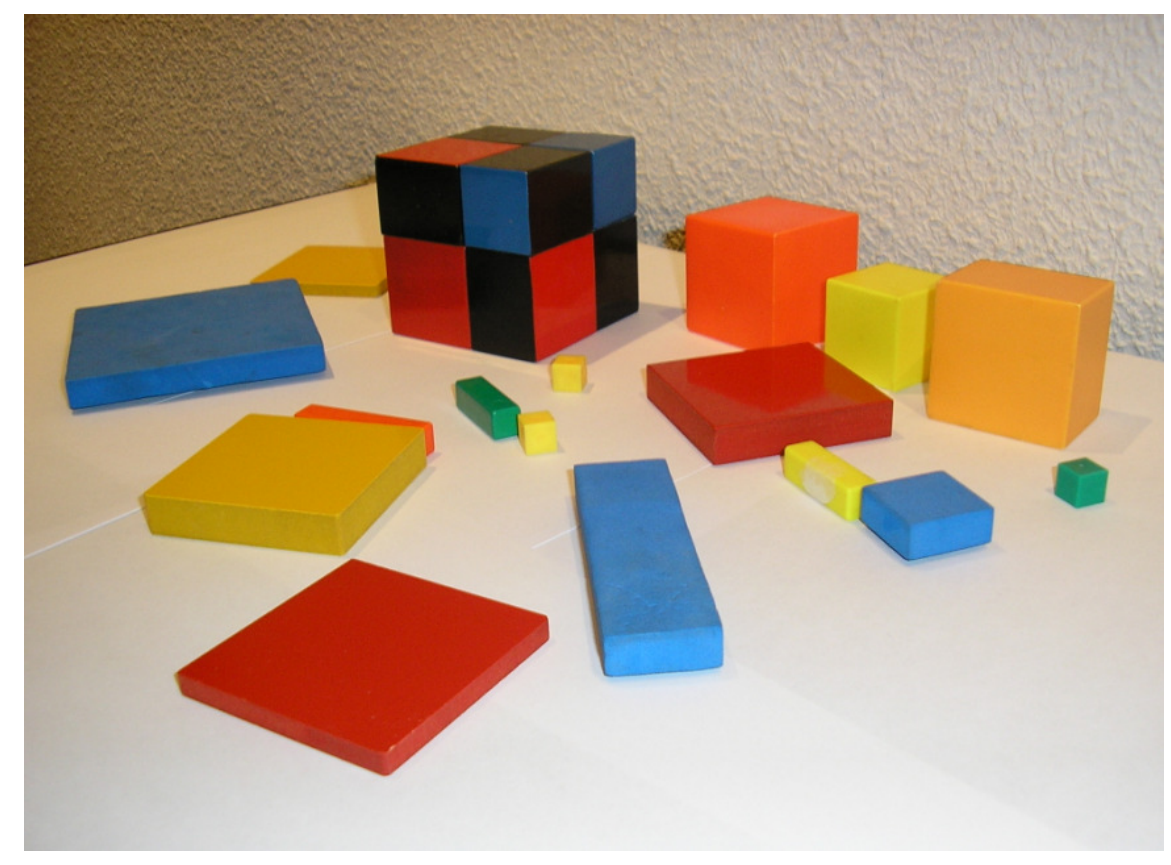

Las piezas pequeñas se consideran como la unidad (uno). Las barras son las variables porque no se sabe cuántas unidades caben en ellas. El color debe ser negociado con los estudiantes: un color para $x$, otro para $y$, etc.

Por ejemplo, la expresión algebraica $3 x+4$ es representada de manera siguiente:



Luego se introduce la variable al cuadrado, también de una manera objetiva. De esta manera, realizaba la transición de la aritmética al álgebra. Pero el estudiante lo encuentra atractivo porque lo puede ver y tocar.

En las imágenes siguientes tenemos el cuadrado de un binomio, suma y resta de polinomios. 

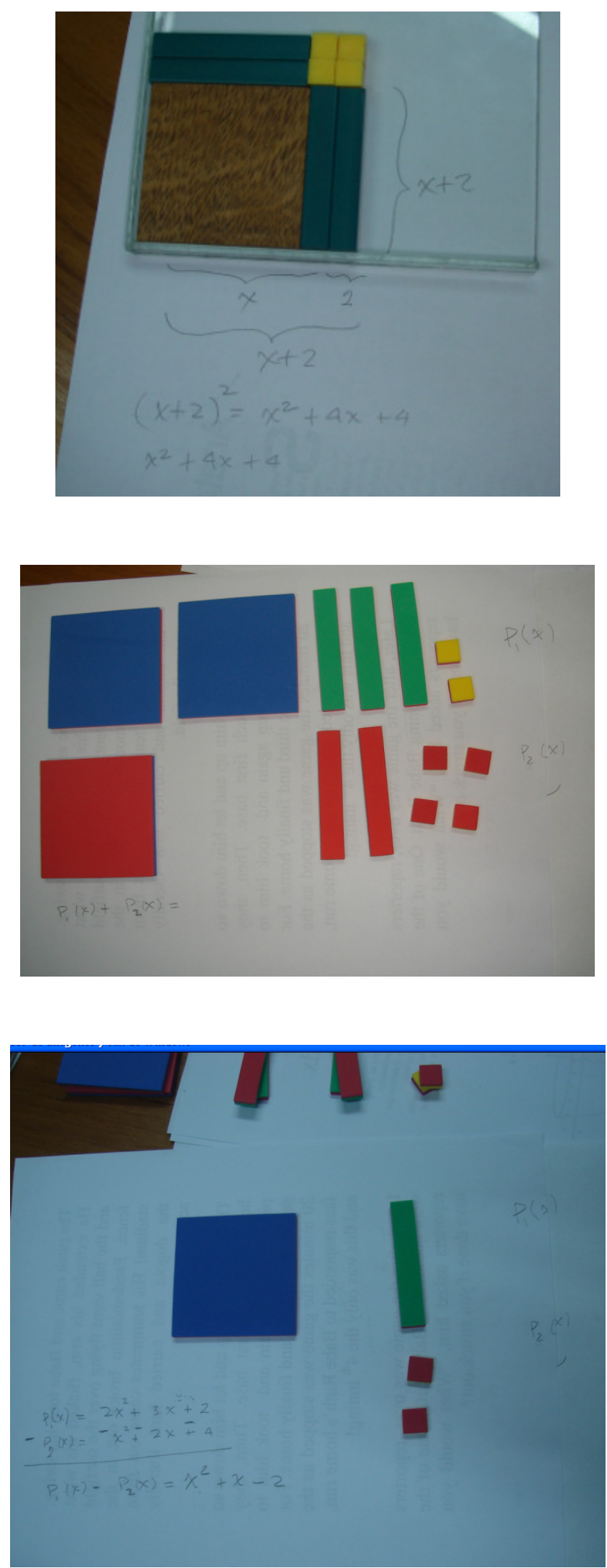


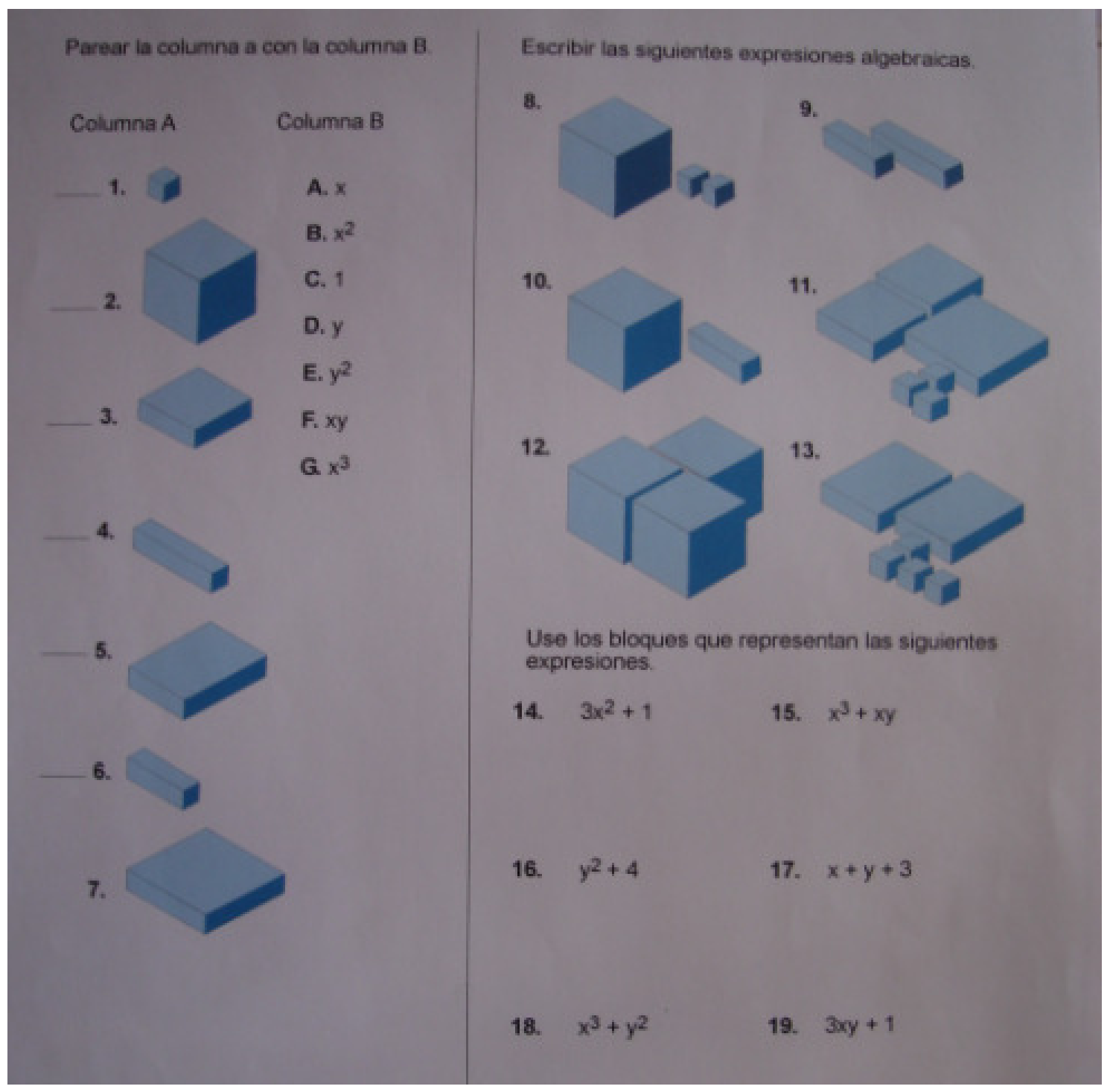

\section{La Tutuma}

La tutuma (también llamada casco), se utiliza en Cochabamba para beber la chicha (bebida típica del lugar), que tiene la forma de semiesfera. Inició la clase preguntando a los alumnos: "Dime una cosa hijo ¿fumas?", "No", de dicen. "Mejor porque si fumas, tus pulmones se van a volver negros y tu cara se va volver como chimenea. Eso es negativo porque va aumentando la caleta con la nicotina que te metes. Eso se llama $f(x)$, eso se llama función. Ahora, ¿chupas? ". "Si", me dicen. "¿Y usted?", me preguntan otros. "Yo tengo mi casco" y les muestro mi tutuma, cáncaba para arriba y convexa para abajo. La fórmula de esta ecuación es $a x^{2}+b x+c=0$ (escribe). Entonces el muchacho relaciona: "El casco es igual a una ecuación de segundo grado". 


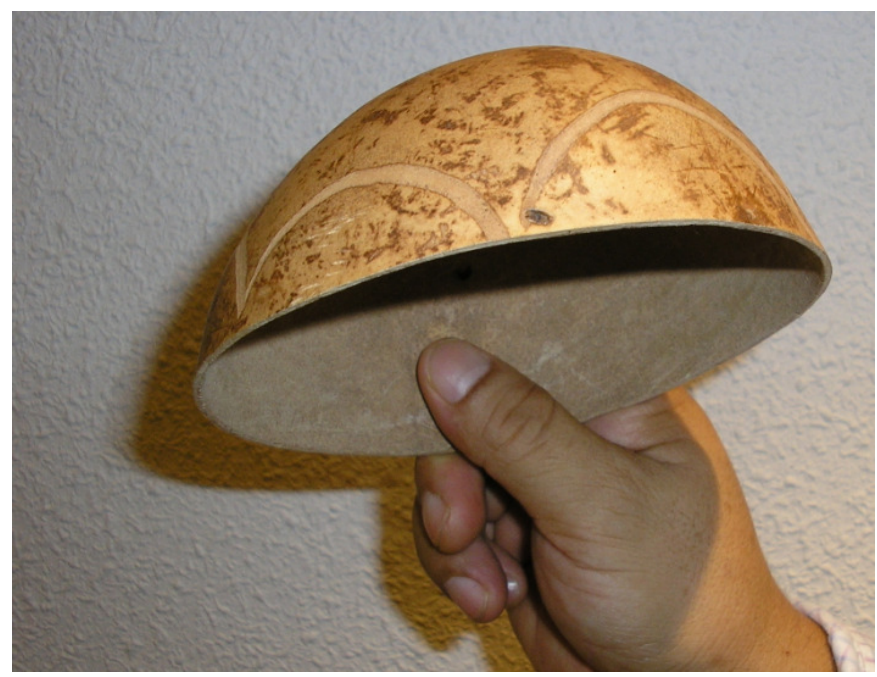

Luego puso en la pizarra, el título: "Ecuaciones de Segundo Grado".

Tenía una colección de vasos con formas parabólicas o paraboloides de diferentes materiales y tamaños. Explicó los contractotes, los amplificadores y las traslaciones de las funciones parabólicas.

También hemos pedido su plan de lecciones que está en la sección de los anexos (Escalante, 2006물

\section{Lenguaje del computador}

El nombre de este recurso didáctico respeta la nominación del profesor. En Escalante (2007, párrafo, 66), describe su forma de presentar el sistema binario.

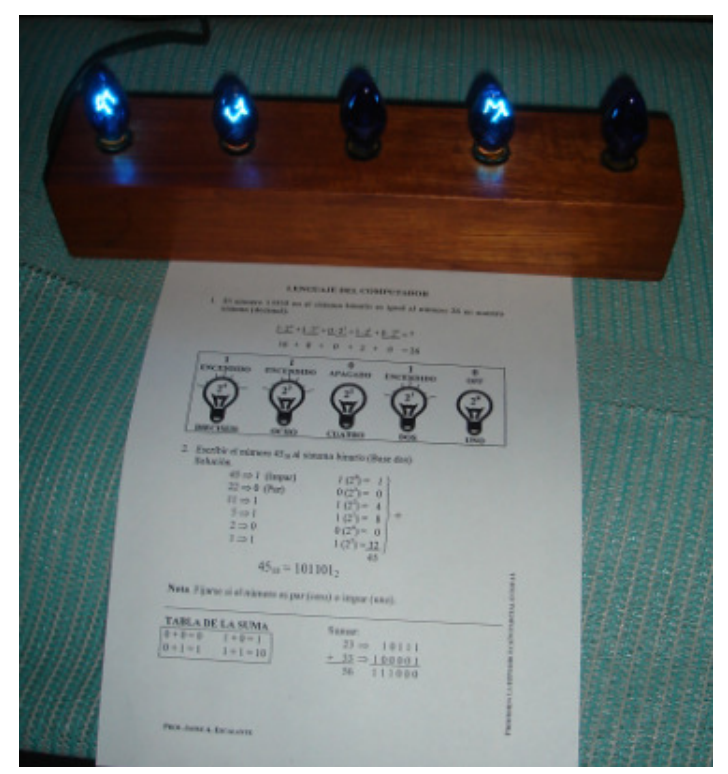




\section{LENGUAJE DEL COMPUTADOR}

1. El número 11010 en el sistema binario es igual al número 26 en nuestro sistema (decimal).

$$
\begin{aligned}
& \underbrace{1 \cdot 2^{4}}+\underbrace{1 \cdot 2^{3}}+\underbrace{0 \cdot 2^{2}}+\underbrace{1 \cdot 2^{1}}+\underbrace{0 \cdot 2^{0}}=? \\
& 16+8+0+2+0=26
\end{aligned}
$$

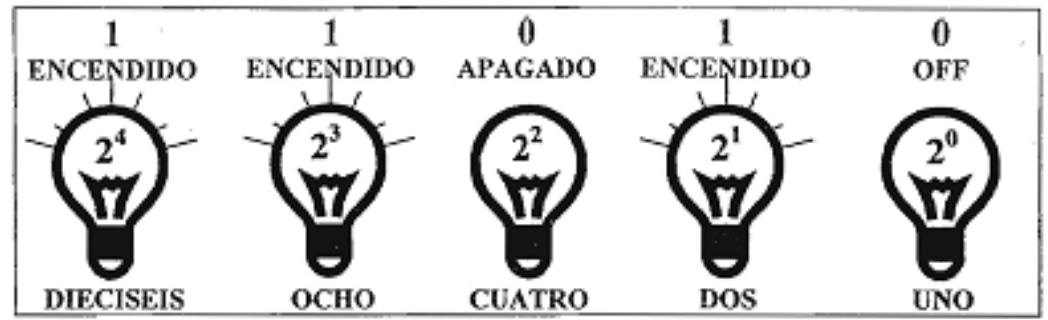

2. Escribir el número $45_{10}$ al sistema binario (Base dos) Solución.

$$
\begin{aligned}
45 & \Rightarrow 1 \text { (Impar) } \\
22 & \Rightarrow 0 \text { (Par) } \\
11 & \Rightarrow 1 \\
5 & \Rightarrow 1 \\
2 & \Rightarrow 0 \\
1 & \Rightarrow 1
\end{aligned}
$$

$$
\left.\begin{array}{l}
1\left(2^{0}\right)=1 \\
0\left(2^{1}\right)=0 \\
1\left(2^{2}\right)=4 \\
1\left(2^{3}\right)=8 \\
0\left(2^{4}\right)=0 \\
1\left(2^{5}\right)=\frac{32}{45}
\end{array}\right\}+
$$

$$
45_{10}=101101_{2}
$$

Nota. Fijarse si el número es par (cero) o impar (uno).

TABLA DE LA SUMA
\begin{tabular}{|ll|}
\hline $0+0=0$ & $1+0=1$ \\
$0+1=1$ & $1+1=10$ \\
\hline
\end{tabular}

$$
\begin{aligned}
& \text { Sumar: } \\
& \begin{aligned}
23 & \Rightarrow 10111 \\
+\quad 33 & \Rightarrow 100001 \\
\hline 56 &
\end{aligned}
\end{aligned}
$$

PROF. JAMEE A. ESCALANTE. 



\section{CAPÍTULO VI \\ APORTACIONES Y CONCLUSIONES}

\section{Introducción}

En Bolivia, el Sistema Educativo transita por una serie de Reformas Educativas carentes de visión, entusiasmo y metas. El expresidente Carlos De Mesa dijo: “... el Sistema Educativo Nacional está al límite del colapso por su ineficiencia, burocratización y sobre todo por los pésimos resultados académicos...". El país atraviesa por varios conflictos políticos-sociales y el Sistema Educativo no es ajeno a éstos. La Ley de Educación denominada "Avelino Siñani y Elizardo Pérez", se debate hasta el día de hoy.

Las universidades y las escuelas normales responsables de la formación docente hacen lo posible por cubrir las necesidades y expectativas de los profesores en cuanto a didácticas innovadoras.

Los profesores del país no consiguen alcanzar sus propias expectativas en la enseñanza de las matemáticas y otras materias afines, porque los estudios orientados a la didáctica de la matemática son escasos y casi inexistentes.

Esta necesidad de disponer de documentos que faciliten el acceso a la vida y metodología del profesor Jaime Alfonso Escalante Gutiérrez, no es simplemente percibida por el investigador, sino, también es manifiesta por parte de los profesores en general, y los profesores de matemáticas en particular. Este problema, impulsó la recopilación de información y documentación.

Bajo este contexto, considerando las necesidades y expectativas de la comunidad de educadores matemáticos, se plantea la siguiente investigación: "Historia de Vida y Metodología de Enseñanza de la Matemática de Jaime Alfonso Escalante Gutiérrez".

Esta memoria de investigación responde a la preocupación de elaborar una historia de vida temática de relato único acerca del profesor Jaime Alfonso Escalante Gutiérrez, centrado en sus concepciones y creencias sobre la matemática, su enseñanza y aprendizaje. 
En el marco teórico se ha hecho referencia a la línea de investigación correspondiente a las historias de vida y las creencias y concepciones de profesores de matemáticas.

A pesar del auge que está experimentando las historias de vida en el campo de la educación en estos últimos años (Bolivar, 2002; Gonzáles, 2008/2009), también ha ido progresando en su autonomía, de un método o técnica de investigación a una perspectiva de investigación educativa, cuando el centro de interés del estudio es una persona (Ferrarotti, 1981; Bolivar, 2002; Mallimaci y Gimenez, 2006). Para algunos autores las historias de vida tienen tres funciones: investigativa, formativa y testimonial (Gonzáles, 2008/2009). Además, las historias de vida definen una nueva línea de investigación en el campo de la Didáctica de la Matemática (Goodson, 2003).

Por otro lado, los estudios sobre concepciones y creencias de los profesores de matemáticas (Thompson, 1992; Flores, 1998; Martinez, 2003; Gil y Rico, 2003; Ponte y Chapman, 2006), han experimentado un aumento cuantitativ y cualitativo. Varios coinciden en que existe una relación entre las creencias y las prácticas docentes. En este sentido hemos tomado el modelo de Ernest (1989), para analizar las concepciones y creencias del profesor Jaime Alfonso Escalante Gutiérrez.

En base a la narración, la observación y la documentación disponible para fines de esta investigación, Jaime Escalante demostró que el origen de las personas no determina cuan lejos uno puede llegar y la capacidad de impacto que tiene un profesor sobre sus alumnos cuando tiene altas expectativas y le pone las ganas.

Jaime Escalante muestra una coherencia y entre sus discursos y sus acciones, no se interesa en las cuestiones filosóficas, sino en las representaciones concretas y vividas que hacen accecible los conceptos matemáticos y forja, en consecuencia, imágenes mentales lúdicas.

Gracias a su particular estilo de enseñar matemáticas con ejemplos de la vida cotidiana y sobre todo estimulando la autoestima de sus alumnos transformó la vida de muchos estudiantes. Como escribe Mathews, el autor del libro, Escalante: The Best Teacher in America, desde Washington: "Él cambió 
por completo la educación secundaria. Generó una serie de esfuerzos en miles de escuelas para que se acogieran a los alumnos de las minorías, a estudiantes pobres, para que tuvieran la oportunidad de acceder a la universidad de las que habían sido excluídos. Es lo más beneficioso que ha pasado en los últimos 30 años de la educación en Estados Unidos"20. Los cambios en la escuela de Garfield no se produjeron entre los estudiantes pertenecientes a la élite en matemáticas, también se produjo una baja en número de estudiantes que abandonaban la escuela, del 55\% en 1978 a solamente el $14 \%$ en 1988.

Enfoca los conceptos matemáticos desde metáforas deportivas, era un maestro en el uso de la imaginación, y tenía altas expectativas sobre sus alumnos.

Mathews cree que en Escalante había cuatro aspectos que tomar en cuenta, por la que fue capaz de transformar a cientos de estudiantes de la clase baja y enviarlos a la universidad como grandes promesas:

Primero, tenía grandes expectativas en cada uno de sus estudiantes.

Segundo, les dio tiempo extra, persuadiéndoles para que se quedaran después de clases o que tomen los cursos los sábados y durante las vacaciones de verano.

Tercero, se tomó las pruebas de admisión en serio e hizo que sean un objetivo a superar por sus alumnos.

Cuarto, creó un espíritu de equipo. Él y sus estudiantes tenían que superar las pruebas.

Estoy de acuerdo con los aspectos señalados por Mathews, pero el estudio me ha permitido incorporar otros aspectos. No se puede negar el impacto de sus creencias y concepciones sobre la matemática, su enseñanza y su aprendizaje en su práctica. Esto le facilitaba explicar de manera directa y sencilla los contenidos y no los complicaba con tecnicismos innecesarios, relacionaba con facilidad los conceptos matemáticos con objetos del entorno del estudiante.

\footnotetext{
${ }^{20}$ http://www.eldeber.com.bo/extra/2010-04-04/nota.php?id=100331180955
} 
En este contexto, el estudio presenta un aporte original a la historia de la educación boliviana, por cuanto Jaime Escalante es una figura destacada en el panorama educativo, dentro y fuera de su país, y ninguna investigación ha abordado un estudio sobre las concepciones y creencias sobre la matemática, su enseñanza y aprendizaje de Jaime Escalante.

La diferencia de otros documentos como Escalante: The Best Teacher in America y Stand and Deliver radica en el enfoque de investigación y aporta las creencias y concepciones sobre las matemáticas, su enseñanza y aprendizaje del profesor Jaime Escalante. Además, hace accecible al profesor hispanohablante.

\subsection{Consecución de los objetivos de investigación}

En este apartado analizaremos en qué medida han sido alcanzados los objetivos que nos habiamos planteado al iniciar este trabajo.

Objetivo 1: Describir la vida y obra del profesor Jaime Escalante.

En el capítulo IV, ha sido descrita su vida y obra, en tres epatas: La primera, su vida y obra en Bolivia (1930 - 1963). La segunda, en los Estados Unidos (1964 - 1998). Y la tercera, después de su jubilación (1999-2010).

El profesor de matemáticas de origen boliviano, emigró a los Estados Unidos, como muchos latinoamericanos lo hacen, tratando de mejorar su calidad de vida y hacer un aporte en lo que estaba a su alcance, y lo hizo con un instrumento muy valioso para una sociedad, se preocupó por motivar y enseñar matemáticas a un sector de una población que así lo requería. Utilizó la matemática como el motor para vencer las adversidades de la juventud de una escuela del Estado de California. Preparó en Cálculo a los estudiantes socialmente desaventajados en Los Angeles. Con su ejemplo, demostró al mundo, a ellos mismos, a los estudiantes de próximas generaciones de Garfield High School, y otras, que el origen de las personas no determina lo lejos que uno puede llegar. Todo esto se resume en la siguiente fórmula:

Determinación + Disciplina + Trabajo duro = Camino al éxito. 
Por lo que, consideramos que el primer objetivo ha sido conseguido en cuanto hemos descrito la vida y obra del profesor Jaime Escalante.

Objetivo 2: Establecer las creencias de Escalante sobre la matemática como disciplina científica.

En base al modelo planteado por Ernest (1989), Jaime Escalante se encuentra entre la concepción Platonista y Dinámica. Y se han establecido las siguientes creencias:

- La matemática se descubre y se inventa por la necesidad de resolver problemas.

- La matemática es una actividad antigüa y polivalente.

- La matemática está en todas las ciencias.

- La matemática es la ciencia del pensamiento.

- La matemática se define en cuatro palabras: concepto, lenguaje, procedimiento y aplicación.

Objetivo 3: Analizar las concepciones acerca de la matemática como saber transmisible, es decir, concepciones sobre la enseñanza de la matemática.

Jaime Escalante que se autodefine como el profesor de matemáticas, a pesar de ser ingeniero, pedagogo y con varios Doctores Honoris Causa. Como ya se dijo: lo que mejor sabe hacer es enseñar matemáticas. $Y$ se han establecido las siguientes creencias.

- Plantear metas de corto plazo (evaluaciones diarias), mediano plazo (examen de cálculo) y largo plazo (universidad).

- Enseñar matemáticas es quitar el velo y gozar de su encanto y su belleza de la ciencia del pensamiento.

- La educación (educación matemática) es el billete a la excelencia.

- El profesor necesita tres cosas: dominio del tema, saber motivar y conocer las relaciones humanas.

- Involucrar a los padres en la educación de sus hijos.

- Si enseñamos a pensar y comunicar, el futuro está arreglado. 
Determinación + Disciplina + Trabajo duro = Camino al éxito

Objetivo 4: Analizar las concepciones acerca de cómo los estudiantes aprenden matemáticas.

Se han encontrado las siguientes concepciones:

- Mezcla teorías de aprendizaje cognitivas (paso a paso), con conductual (ir tras una meta) y humanista (trabaja las emociones).

- El alumno aprende mejor cuando el aprendizaje es divertido, en forma de juego o reto.

- Se debe dar un enfoque de equipo, porque cuando salga de las aulas trabajará con sus colegas.

- Fija metas a través de la orientación vocacional.

- Respeta velocidades de aprendizaje.

- Parte desde los problemas y nunca por la definición.

- Cualquiera puede aprender matemáticas, sólo se necesita ganas.

- Aprovecha la memoria visual.

Determinación + Disciplina + Trabajo duro = Camino al éxito

Objetivo 5: Describir y analizar los recursos didácticos implementados para la enseñanza-aprendizaje de las matemáticas en el nivel secundario.

Jaime Escalante aportó un arsenal de estrategias, pero también, contribuyó muchos recursos didáticos desde lo más simple hasta lo más complejo. Los recursos didácticos que empleaba estaban elaborados con una variedad de materiales, él recurre a todo para enseñar matemáticas: Cartolinas, palitos, cuadrados, manzanas, deportistas,... médicos, ingenieros, artistas, etc. Su objetivo era aprovechar la memoria visual y quitar esa imagen negativa de las matemáticas. 
Se han descrito algunos de los recursos didácticos de Jaime Escalante que fueron utilizados en los seminarios y talleres en las diferentes ciudades de Bolivia, para estudiantes y profesores de matemática.

- El truco de la multiplicación de los dedos para captar la atensión de los alumnos.

- La pizarra metálica y las fichas con imán.

- Los recursos de álgebra en vivo elaborados de diferentes materiales.

- El tablero de fracciones que permite enseñar y aprender las operaciones con fracciones de manera visual objetiva.

- La tutuma y los vasos de champan.

- El lenguaje de computadores, que se aplican en matemáticas discretas, a los códigos binarios.

- Su lengua nativa.

Determinación + Disciplina + Trabajo duro = Camino al éxito

\subsection{Limitaciones del trabajo}

Señalamos las siguientes limitaciones del trabajo:

Entre el proyecto de la tesis y la presente memoria han quedado objetivos y algunas preguntas de investigación sin abordar, debido a las limitaciones.

Al tratarse de una historia de vida temática se han dejado de lado varios aspectos de su vida y por otro lado, en la etapa de la recogida de información, su hijo manifestó un poco de desconfianza, sin embargo, el profesor Escalante hizo la aclaración. El hijo indicó que muchos habían sacado información robando el derecho de autor.

A continuación enunciamos algunos asuntos indicados en el proyecto de tesis que han quedado descartados en este estudio.

- Ésta es una historia de vida de Jaime Escalante y no la historia de vida de Jaime Escalante para no pecar de pretencioso.

- No le hemos podido entregar un ejemplar de este trabajo como me hubiera gustado, solo hemos conseguido comentarle parte del 
trabajo. Esta limitación fue debido a su larga enfermedad, que finalmente Escalante a pesar de tener ganas no pudo vencer.

- Otra limitación fue de carácter económico, ya que no pude realizar varios viajes para comentarle los avances de la investigación y sólo se hizo a través del teléfono.

\subsection{Implicaciones para futuras investigaciones}

El presente trabajo de investigación ha permitido avanzar en la precisión de la perspectiva de la investigación de historias de vida temática de relato único, que pueden ser consideradas en sus tres funciones: investigativa, formativa y testimonial. La investigación como historias de vida, nos abre un enorme campo de investigación de la Educación Matemática.

Por otro lado, el estudio de las concepciones y creencias sobre la matemática, su enseñanza y aprendizaje en el nivel secundario, puede ser aplicado por otros profesores.

Cuestiones planteadas en el proyecto de tesis no investigadas en esta memoria son:

- La enseñanza de temás específicos de la matemática para el nivel secundario.

- Un estudio experimental de su método de enseñanza de las matemáticas en el nivel superior

Como reflexión final, el trabajo que se presenta en esta tesis doctoral, nos ha permitido comprender la utilidad de las historias de vida, tanto como herramientas investigativas y como herramientas pedagógicas en el campo de la educación matemática. Las historias de vida son una visualización y generación del saber pedagógico, que no se limita a ser un método o técnica de investigación, sino que proporciona una nueva perspectiva en la educación en general y educación matemática en particular.

Espero que mi trabajo haya contribuido a caracterizar y clarificar una parte conceptual de las historias de vida, y permitir el acceso a la vida y obra del 
profesor Jaime Escalante, para los interesados en el campo de la educación en general y particularmente en la educación matemática. 


\section{REFERENCIAS}

Albert, Mํ. J. (2007). La Investigación Educativa: claves teóricas. Madrid: McGraw-Hill.

Alsina, C. (2007). Educación Matemática e Imaginación. Revista Iberoamericana de Educación Matemática, 11, 9-17.

Alsina, C. (2008). El club de la hipotenusa. Un paseo por la historia de las matemáticas a través de sus anécdotas más divertidas. Barcelona: Ariel.

Bay, G. (1999). Jaime Escalante, 1999 Inductee. The National Teachers Hall of Fame, p. I, n.d. Recuperado el 5 de Agosto, 2006, de http//:www.nthf.org/inductee/escalante.htm.

BBC MUNDO (2003, Junio 03). "Determinación, disciplina y trabajo fuerte". Recuperado el 30 Julio, 2006, de http://news.bbc.co.uk/hi/spanish/specials/newsid 2944000/2944174.stm

Berteaux. D. (1980). L'approche biographique: sa validité methodologique, ses potencialités. Cahiers Internationaux de Sociologie. Vol LXIX, 197-225.

Berteaux, D. (1993). De la perspectiva de la historia de vida a la transformación de la práctica sociológica. En J. M. Marinas y C. Santamarina (Eds.), La historia oral: métodos y experiencia (pp. 19-34). Madrid: Debate.

Bisquerra, R. (1989). Métodos de investigación educativa. Barcelona: CEAC S.A.

Bisquerra, R. (2004). (Coord.), Metodología de la investigación educativa. Madrid: La muralla, S. A.

Bogdan, R. y Biklen, S. (1982). Qualitative research for education. An introduction to theory and methods. Boston: Allyn and Bacon.

Bolivar, A. (2002). “¿De nobis ipsis silemus?”: Epistemología de la investigación biográficanarrativa en educación. Revista Electrónica de Investigación Educativa, 4 (1). Recuperado el 3 de Octubre, 2006, de http://redie.uabc.mx/vol4no1/contenido-bolivar.html

Bolívar, A., Domingo, J. y Fernández, M. (2001). La investigación biográfico-narrativa en educación: enfoque y metodología. Madrid: La muralla S. A.

Carter, K. (1993). The place of story in the study of teaching and teacher education. Educational Research, 22 (1), 5-12.

Cerda, R. (2004). Maestro Boliviano explica cómo las matemáticas son fáciles. Santiago, Chile. Recuperado el 20 de Diciembre, 2009, de http://buscador.emol.com/noticias/Jaime+Escalante

Chapman, O. (2008). Narratives and mathematics teacher education. En D. Tirosh y T. Wood (eds.), Tools and Processes in Mathematics Teacher Education, 15 - 38.

Clandinin, D. y Connelly, F. (2000). Narrative inquiry. Experience and story in qualitative research. San Francisco CA.: Jossey-Bass.

Cockcroft (1985). Las matemáticas si cuentan. Madrid: MEC. Original 1982.

Cohen, L. y Manión, L. (2002). Métodos de investigación educativa. Madrid: Ibérica grafic, S.A. (edición original en ingles, 1989).

Conde, F. (1994). Las perspectivas metodológicas cualitativa y cuantitativa en el contexto de la historia de las ciencias. En J. M. Delgado y J. Gutiérrez (coord.): Métodos y técnicas cualitativas en ciencias sociales (pp. 53-68). Madrid: Síntesis.

Congreso Nacional de Ingeniería Civil (2006). Estudiantes quedaron maravillados con clase magistral de matemáticas. La Patria. Oruro, Bolivia, 21 de octubre.

Cook, T. y Reidchardt, C. (1986). Métodos cualitativos y cuantitativos en investigación evaluativa. Madrid: Morata. 
Corbalán, F. (2000). Galois Revolución y Matemáticas. La matemática en sus personajes. Madrid: Nivola.

Del Rincón, D. (1997). La metodología cualitativa orientada a la compresión. Barcelona: Ediouc.

Denzin, N. (1970). The research act. Chicago: Aldine

Denzin, N. y Lincoln, Y. (1994). Introduction: entering the field of qualitative research. En N. Denzin e Y. Lincoln (Eds.), Handbook of qualitative research (pp. 1-17). California: Sage.

Dollard, J. (1935). Criteria for the life history. New Haven, CT.: Yale University Press.

Durán, J. (2010). Escalante no fue profeta en su tierra. Recuperado el 17 Marzo de 2010 de http://www.iglesiaviva.net/-an\%C3\%A1 lisis---opini\%C3\%B3n/4915-duran-jaime-escalanteno-fue-profeta-en-su-tierra-.html

Elbaz, F. (1990). Knowledge and discourse: The evolution of research on teacher thinking. En C. Day, M. Pope y P. Denicolo (Eds.) Insight into teacher thinking and practice (pp. 15-42). London: Falmer Press.

Ernest, P. (1991). Philosophy of mathematics education. Londres: Falmer.

Ernest, P. (1989). The Impact of Beliefs on the Teaching of Mathematics. En Mathematics Teaching: The State of the Art (pp. 249 - 254). London: Falmer. Recuperado el 19 de Junio, 2007, de http://www.people.ex.ac.uk/PErnest/impact.htm.

Ernest, P. (1996). The nature of mathematics and teaching. En Philosophy of Mathematics Education Journal 9. Recuperado el 5 de Agosto, 2008, de http://people.exeter.ac.uk/PErnest/pome/pome9.htm

Escalante, J. (2005). Las fracciones. Trabajo presentado en el XI Congreso Nacional de Sociedad Boliviana de Matemáticas (SoBolMat). Cochabamba, Bolivia

Escalante, J. (2006a). Ecuaciones de Segundo Grado. Plan de clases. Manuscrito no publicado. Cochabamba, Bolivia.

Escalante, J. (2006b). Currículum vitae. Universidad Adventista de Bolivia. Cochabamaba.

Escalante, J. (2007). Entrevista a Jaime Escalante. Por A. Pari (Enero). Cochabamba, Bolivia.

Escalante, J. (2008). El primer día de clases. Manuscrito no publicado. Cochabamba

Escalante, J. y Dirmann, J. (1990). The Jaime Escalante Math Program. The Journal of Negro Education, Vol. 59, No. 3, 407-423. Recuperado el 10 de octubre de 2009 de http://www.thefutureschannel.com/jaime escalante/jaime escalante math program.php

Ferrarotti, F. (1981). On the Autonomy of the Biografical Method. En D. Bertaux (comp.), Biography and Society (pp. 19-27). California: Sage.

Ferrarotti, F. (1988). Biografía y Ciencias Sociales. Cuadernos de Ciencias Sociales No. 10. Historia oral e historias de vida. San José, Costa Rica: Flacso.

Ferrarotti, F. (2005). Historia de vida y ciencias sociales. Entrevista a Franco Ferrarotti. Por I. Montserrat Iniesta y C. Feixa. En Periféria, revista de recerca i formación en antropología, No. 5, Diciembre. Recuperado el 20 Junio de 2009 de http://www.raco.cat/index.php/Periferia/article/view/146549/198369

Ferrarotti, F. (2007). "Las historias de vida como método". Convergencia. Revista de Ciencias Sociales. No. 44, 15-45. (Traducción del italiano por J. M. Recillas). Recuperado el 10 marzo de 2010 de http://redalyc.uaemex.mx/pdf/105/10504402.pdf

Flores, P. (1998). Concepciones y creencias de los futuros profesores sobre las matemáticas, su enseñanza y aprendizaje. Investigación durante las prácticas de enseñanza. Granada: Comares.

Gil, F. y Rico, L. (2003). Concepciones y creencias del profesor de secundaria sobre la enseñanza y aprendizaje de las matemáticas. Enseñanza de las ciencias, 21 (1), $27-47$. 
González, J. (2008/2009). Historias de vida y Teoría de la educación: tendiendo puentes. Cuestiones pedagógicas, 19, 207 - 232: Secretaría de publicaciones Universidad de Sevilla. Recuperado el 10 de octubre de 2010 de http://institucional.us.es/revistas/revistas/cuestiones/pdf/numeros/19/12Monteagudo.pdf

Goodson, I. (2003). Hacia un desarrollo de las historias personales y profesionales de los docentes. Revista mexicana de investigación educativa, vol. 8, No. 019, 733 - 758. Recuperado el 10 de mayo de 2008 de http://www.oei.es/docentes/articulos/desarrollo historias personales profesionales docent es goodson.pdf

Goodson, I. (2004). Historia de vida del profesorado. En F. Hernández y M. Sancho (Eds.), Barcelona: Octaedro-EUB.

Hamilton, D. (1994). Tradition, preferences, and postures in applied qualitative research. En N. Denzin e Y. Lincoln (Eds.), Handbook of qualitative research (pp. 60-69). California: Sage.

Hanson, W. (2003). Entrevista a Jaime Escalante. Recuperado el 30 de agosto de 2006 de http://www.inacap.cl/tportal/portales/tp4964b0e1bk102/uploadlmg/File/pdf/748.pdf

Hornillo, E. y Sarasola, J. L. (2003). El interés emergente por la narrativa como método en el ámbito socioeducativo. El caso de la historia de vida. Portularia 3, 373-382. Universidad de Huelva.

Jara, E. y Sagárnaga, R. (2008, Julio 6). Jaime Escalante: "La Reforma Educativa tiene que mejorar no retroceder 500 años". Revista ;OH! Recuperado el 30 Agosto, 2009, de http://eduardojarafilosofiadelaeducacion.blogspot.com/2008/07/cuart-artculo-entrevista-jaime.html

Jessness, J. (2002). Stand and Deliver Revisited. California. Recuperado el 10 de Julio, 2007, de http://www.reason.com/news/show/28479.html

kaasila, R. (2007). Mathematical biography and key rhetoric. Educational Studies in Mathematics, 66, 373-384.

Kirk, J. Miller, M. (1986). Reliability and validity in qualitative research. Londres: Sage.

Kolpas, S. (2002). Let Your Fingers Do the Multiplaying. Mathematicas teacher, Vol. 95, No. 4, 246-251.

Kuhs, T. y Ball, D. (1986). Approaches to teaching mathematics: Mapping the domains of knowledge, skills, and dispositions. East Lansing: Michigan State University, Center on Teacher Education.

Langness, L. (1965). The Life History in Antopological Science. Nueva York: Holt.

LeCompte, M. (1995). Un matrimonio conveniente: Diseño de investigación cualitativa y estándares para la evaluación de programas. Revista electrónica de Investigación y Evaluación Educativa, I (1).

Lewis, O. (1971). Los hijos de Sánchez. México: Mortiz.

Llinares, S. y Sánchez, Ma. V. (1990). El conocimiento del profesor y la enseñanza de las matemáticas. En Llinares y Sanchez (Eds.), Teoría y Práctica en Educación Matemática (pp. 63-116). Sevilla: Alfar.

Llinares, S. (1996). Conocimiento profesional del profesor de matemáticas: Conocimiento, Creencia y Contexto en Relación a la Noción de Función. Departamento de Ciencias (Matemáticas), Facultad de Ciencias de la Educación, Universidad de Sevilla, España.

Lunenberg, M., Korthagen, F. y Swenne, A. (2007). The teacher educator as a role model. Teaching and Teacher Education 23, 586-601.

Mallimaci, F. y Giménez, V. (2006). Historia de vida y método biográfico. En I. Vacilachis (Coord.), Estrategias de investigación cualitativa. Barcelona: Gedisa

Mari-Klose, P. (2009). El nivel educativo de los padres es más determinante que el colegio en el éxito escolar. La Gaceta, Salamanca, 23 de septiembre de 2009. Col. 2, Sec. Sociedad. 
Marinas, J. y Santamarina, C. (1993). La historia oral: métodos y experiencias. Madrid: Debate.

Martínez, M. (2003). Concepciones sobre la enseñanza de la resta: un estudio en el ámbito de la formación del profesorado. Tesis doctoral no publicada, Universidad Autónoma de Barcelona, España.

Martínez, M. (2006). Ciencia y arte en la metodología cualitativa. Madrid: Trillas.

Martínez, J., Vázquez, J, y Rosales, M. A. (2001). Las Inteligencias Múltiples con GANAS en Ciencias. Talleres Pedagógicos. Primera Feria Hemisférico de Educación Indígena. Universidad de Texas en El Paso. Recuperado el 12 de Enero, 2008, de http://www.beps.net/publications/Partel.pdf

Mathews, J. (1988). Escalante: The best teacher in America. New York: Henry Holt and Company.

Mckernan, J. (1999). Investigación acción y currículum: Métodos y recursos para profesionales reflexivos. Madrid: Morata.

McMillan, J. y Schumacher, S. (2005). Investigación educativa. Madrid: Pearson.

McMillan, J. y Schumacer, S. (2006). Reaserch in education: evidence - based inquiry. Boston: Pearson.

Menéndez, R. y Musca, T. (1988). Stand and Deliver (Película). Estados Unidos: Warner Bros. Pictures.

Mesa, J., Gisbert, T. y Mesa, C. (2003). Historia de Bolivia (5ª ed.). La-Paz: Gisbert Cia. S. A.

Moliner, Mํ. (1984). Diccionario de uso del español. Madrid: Grecos.

Moreno, A. (2006). Historia de vida e investigación. En M. Martínez (Eds.), Ciencia y arte en la metodología cualitativa. Madrid: Trillas.

Muchmore, J. (2002). Methods and Ethics in a Life History Study of Teacher Thinking. The Qualitive Report, Vol. 7, № 4. Recuperado el 30 de Agosto, 2007, de http://www.nova.edu/ssss/QR/QR7-4/muchmore.html

Novak, C. (1993). "Interview with Jaime Escalante". Technos Quarterly, Vol. 2, No. 1. Recuperado el 30 de Agosto, 2007, de http://www.ait.net/technos/tq 02/1escalante.php

NCTM (1991). Professional standards for teaching mathematics. Reston: Va. National Council of Teacher of Mathematics.

Pajares, F. (1992). Teachers' beliefs and educational research: Cleaning up a messy construct. Review of Educational Research, 62 (3), 307-332.

Pérez, T. (2009, Julio 27). Jaime Escalante "Con ganas de Triunfar". Recuperado el 10 de Septiembre, 2009, de

http://www.nuestroportal.com/article/detail.php?article=iaime-escalante-con-ganas-de$\underline{\text { triunfar }}$

Perkins, D. (2003). La escuela inteligente: del adestramiento de la memoria a la educación de la mente. Barcelona: Gedisa (Original, 1992).

Plummer, K. (1989). Los documentos personales. Madrid: Siglo XXI.

Ponte, J. P. (1994). Mathematics Teachers' Professional Knowledge. En J. Ponte y J. Matos (Eds.), Proceedings of Eighteenth International Conference for the Psychology of Mathematics Education. Lisboa: International Group for Psychology of Mathematics Education

Ponte, J. P. (1999). Teachers' beliefs and conceptions as a fundamental topic in teacher education. En K. Krainer y F. Goffree (Eds.), On research in teacher education: From a study of teching practices to issues in education (pp. 43-50). Osnabrück:Forschungsintitut für Mathematikdidaktik. 
Ponte, J. y Chapman, O. (2006). Mathematics teacher'knowledge and practices. En A. Gutiérrez y P. Boero (Eds.), Handbook of research on the Psychology of Mathematics Education, 461-494.

Prawat, R. (1989). Teaching for understanting: Three key atribute. Teaching \& Teacher Education. Vol. 5, No. 4, 315-328.

Pujadas, J. J. (2000). El método biográfico y los géneros de la memoria. Revista de Antropología Social, 9, 127-158.

Pujadas, J. J. (2002). El método biográfico: El uso de las historias de vida en ciencias sociales ( $2^{\mathrm{a}}$ ed.). Madrid: Centro de Investigaciones Sociológicas.

Real Academia Española (1984). Diccionario de la real academia española. Madrid. Espasa Calpe. S. A.

Rico, L. y Sierra, M. (1991). La comunidad de educadores matemáticos. En A. Gutierrez (Ed.), Área de conocimiento: Didáctica de la Matemática. Madrid: Editorial Síntesis.

Rico, L. y Sierra, M. (1994). Educación matemática en la España del siglo XX. En J. Kllpatrick, L. Rico y M. Sierra (Eds.), Educación matemática e investigación. Madrid: Síntesis.

Rico, L., Sierra, M. y Castro E. (2000). Didáctica de la Matemática. En L. Rico y D. Madrid (Eds.), Fundamentos didácticos de las áreas curriculares, (351-445). Madrid: Síntesis.

Rocha, A. (2010). Jaime Escalante el mejor profesor de Estados Unidos. Recuperado el 17 de Marzo, 2010, de http://www.diario.com.mx/nota.php?notaid=c6d10c7e8b1bbe59cb56

Rodríguez, G., Gil, J. y García, E. (1996). Metodología de la investigación cualitativa. Granada: Aljibe.

Rojo, A. (1997). Los documentos personales en la investigación sociológica: Historias de vida, relatos, biografías, autobiografías. Su diferenciación y pertinencias. Revista General de Información y Documentación, Vol. 7, no. 2. Madrid: Servicio de Publicaciones Universidad Complutense.

Ruiz, J. (1976). El método histórico en la investigación histórica de la educación. Revista Española de Pedagogía. № 134, 449-475.

Ruíz, L. (1994). Concepciones de los alumnos de secundaria sobre noción de función. Tesis doctoral inédita. Universidad de Granada.

Ruíz, Olabuénaga, J. (1999). Metodología de la investigación cualitativa (2ª ed.). Bilbao: Universidad de Deusto.

Runyan, W. (1982). Life histories and psychobiography: Exploration in theory and Method. Nueva York: Oxford University Press.

Sabariego, M., Massol, I. y Dorio, I. (2004). Metodología de la investigación cualitativa. En R. Bisquerra (Coord.), Metodología de la investigación educativa, (pp. 293 -328). Madrid: La muralla S. A.

Saltalamacchia, R. (1992). La historia de vida: reflexiones a partir de una experiencia de investigación. CIJUP.

Sancho, J. Ma . y otros (2005). Explorando la posición de los investigadores en las historias de vida de profesores: implicaciones para el desarrollo profesional. Paper presented in European Conference on Educational Research (ECER2005). Dublin 7 - 10 September 2005. Centro de Estudios sobre el Cambio en la Cultura y la Educación Parc Científic de Barcelona: Universidad de Barcelona.

Sandín. M. P. (2003). Investigación Cualitativa en Educación. Fundamentos y Tradiciones. Madrid: McGraw Hill, Interamericana.

Santana, A. (2003). "Mr. Inspiration," PPC Spotlight, p. 2. Recuperado el 15 de Febrero, 2008, de http://www.pasadena.edu/about/history/alumni/escalante/escalante.cfm. 
Sanz, A. (2005). El método biográfico en investigación social: potencialidades y limitaciones de las fuentes orales y los documentos personales. En Asclepio - Vol. LVII - I -2005

Sarabia, B. (1985). Historias de vida. Revista Española de Investigaciones Sociológicas, 29, $165-186$.

Sarabia, B. (1993). Documentos personales: historias de vida. En M. Garcia, J. Ibañez y F. Alvira (Eds.), El análisis de la realidad social. Métodos y técnicas de investigación (pp. 205226). Madrid: Alianza.

Schoenfeld, A. (2000). Porpuses and Methods of Research in Mathematics Education. Notices of the AMS, Vol. 47, No. 6.

Schön, D. (1983). The reflective practitioner: How professionals think in action. New York: Basic Books.

Schön, D. (1992). La formación del profesor reflexivo. Barcelona: Paidós. MEC.

Schraff, A. (2009). Jaime Escalante: Inspirational Math Teacher. United States of America. Enslow Publishers, Inc.

Schuman, L. (1996). Perspectives on instruction. (On-line). Recuperado el 10 de Enero, 2009, de http://edweb.sdsu.edu/courses/edtec540/Perspectives/Perspectives.html

Shaw, C. (1930). The Jack- Roller: a delinquent boy's own story. Chicago: The University of Chicago Press.

Shulman, L. (1987). Konwledge and Teaching: Fondations of de New Reform. Harward Educational Review, 57 (1), 1-22.

Sierra, M. (1989) La Reforma de la Enseñanza de las Matemáticas después de la Segunda Guerra Mundial: aportación del Centre Belge de Pedagogie de la Matematique. Tesis doctoral no publicada, Universidad de Salamanca. España.

Sierra, M. (2004). Pensamiento de Miguel de Guzmán acerca de la Educación Matemática. Números, Vol. 59, 89-93. Recuperado el 8 Enero, 2010, de http://www.sinewton.org/numeros/numeros/59/Articulo09.pdf

Sillero, J. y Balmori, R. (2008). Metodología de Despliegue Didáctico de Enseñanza Activa para Diferentes Estilos de Aprendizaje en el Área de Ingeniería. Sixth LACCEI International Latin American and Caribbean Conference for Engineering and Technology (LACCEl'2008)

Smith, L. (2001). Life History as a Key Factor in Understanding Teacher Collaboration and Classroom Practice. Teacher Education Quarterly, 111-125. Recuperado el 8 de Mayo, 2008 de http://www.teqjournal.org/backvols/2001/28 3/v28n309.pdf

Sorando, J. M. (2005). Matemáticas e Historia. Suma 49, 125-137.

Souza, M. A. (2010, Abril 04). Jay Mathews: "Escalante cambió por completo la educación secundaria". Recuperado el 5 de Abril, 2010, de http://www.eldeber.com.bo/extra/201004-04/nota. php?id=100331180955

Thomas, W. y Znaniecki, F. (1958). The Polish Peasant in Europe and America. Nueva York: Drover (primera publicación, 1918-1920).

Thompson, A. (1992). Teachers' beliefs and conceptions: A synthesis of the research. En D. Grouws (Ed.), Handbook of research in mathematics teaching and learning (pp. 127-146). New York, USA: Macmillan.

Thompson, P. (1988). La voz del pasado. La historia oral. Valencia: Alfons el magnanin.

Thrasher, F. (1928). The Gang: A Study of 1313 Gangs in Chicago. Chicago: University Chicago Press.

Tójar, J. C. (2006). Investigación cualitativa comprender y actuar. Madrid: La muralla S. A.

Valles, M. (2000). Técnicas cualitativas de Investigación Social: Reflexión metodológica y práctica profesional ( $2^{\mathrm{a}}$ ed.). Madrid: Síntesis. 
Vidich, A. y Lyman, S. (1994). Qualitative methods: Their history in sociology and anthopology, en N. Denzin y Y. Lincoln (eds.), Handbook of qualitative research (pp. 23-56). California: Sage.

Wilson, P. Cooney, T. y Stinson, D. (2005). What constitutes good mathematics teaching and how it develops: nine high school teachers' perspectives. Journal of Mathematics Teacher Education 8, 83-111. 

ANEXOS 



\section{ANEXO 1: Transcripción de las entrevistas grabadas}

Jaime Escalante fue entrevistado por Abdón Pari en Cochabamba (Bolivia), en enero de 2007, en su propio domicilio. El esbozo general de la entrevista procura situar en una cronología estricta y detallada, las diferentes etapas de la vida del protagonista y hemos establecido una buena relación de confianza y amistosa cordialidad.

Se ha utilizado la técnica de grabación, con recursos como la cámara video y el mp3. Esta entrevista se fue realizada en cuatro sesiones, de variada duración entre una hora y media a tres horas cada una.

Una primera copia o registro original con la transcripción literal de la entrevista, de acuerdo en el mismo orden que hemos ido obteniendo el relato. La segunda copia en la que hemos ido ordenando y quitando algunas repeticiones, tratando de no cambiar el sentido y perder los detalles. Se ha visto conveniente, enumerar los párrafos para facilitar la referencia en el informe de la investigación.

\section{AP: Abdón Pari JE: Jaime Escalante}

\section{Primera parte: Jaime Escalante en Bolivia (1930 - 1963)}

$A P$ : ¿Cuál es el lugar de su nacimiento y qué recuerdos tiene de su infancia antes de ir a la escuela?

JE: (Párrafo 1). Yo, originalmente, soy de La Paz. Mis padres eran profesores destinados en la provincia de Umasuyos, cuya primera capital es Achacachi, donde pasé mi infancia. Me crié prácticamente con los indios. Mi tiempo transcurría en las fincas de mi tía junto a los aymaras. Yo no hablaba ni conocía el castellano, porque mi idioma original, en cierto modo, fue el aymara.

JE: (Párrafo, 2). Mi abuelo materno me enseñó las primeras letras cuando tenia cinco o seis años, con una pajita del altiplano y un libro que se llamaba "paso a paso." Aprendí el abc y más cosas útiles. Todas las mañanas aprendía con sus preguntas de ingenio y matemática.

JE: (Párrafo, 3). Mi madre, por alguna razón, se traslado de Achacachi a La Paz, para trabajar como profesora. En ese tiempo, yo tenía más o menos la edad de diez años. Al llegar a la ciudad de La Paz, empecé ir a la escuela elemental. Mi madre me matriculó en la "Escuela República de México" más conocido como la escuela "México". 


\section{AP: ¿En qué unidades educativas realizó sus estudios de nivel primario y secundario?}

JE: (Párrafo 4). La educación primaria la hice únicamente en la Escuela "México", de la calle Graneros. El nivel secundario lo cursé en el Colegio "La Salle", pero allí tuve inconvenientes, pues tuve una mala experiencia con el profesor de matemáticas por su vocabulario agresivo, al parecer, motivado por una mueca mía. Con el borrador que tenía en su mano, me lo lanzó a la cara, diciendo: "no te rías de mi". Me indigné, pues no creía haber hecho algo reprobable. Mi rebeldía hizo que agarrara el tintero y se lo lanzara al cura. Me echaron del colegio porque dijeron que era un insolente irrespetuoso y otros adjetivos. A raíz de esto, mi madre hizo un enorme esfuerzo para enviarme a estudiar con los jesuitas en el Colegio "San Calixto".

\section{AP: ¿Qué recuerdos más relevantes tiene del nivel primario?}

JE: (Párrafo 5). En la escuela estaba acomplejado. Primero por la vestimenta que llevaba, ya que estaba acostumbrado a la chaqueta y al pantalón de bayeta como lleva el indio de la tierra. Para mi era normal porque yo no había conocido otra cosa. Siempre calzaba abarcas del indio y no usaba zapatos. Segundo, porque los muchachos me miraban y se reían, diciendo: "éste es un indio, no sabe leer, no sabe escribir, no sabe nada". Y tengo que admitir que tenían razón. No cursé los tres primeros grados de educación elemental y pasé directamente al cuarto año con la consiguiente dificultad de entender lo que el profesor decía.

JE: (Párrafo, 6). Una cosa que me impresionó mucho fue cuando el profesor nos mandó hacer una carátula. No le entendí y le pregunté: “¿Qué significa la palabra carátula?" Entonces él me explicó y me dijo: "es lo primero que ves cuando abres una carpeta para saber de qué es y a quién pertenece. Puso en la pizarra unos dibujos con motivos Tiwanacotas del altiplano y le pedí que me dejara copiarlo. Me ofreció algunos modelos, de los cuales copié tres o cuatro y los adorné con colores. Al fijarme en el trabajo y los materiales de mi compañero de a lado, me dí cuenta de que yo no lo podía hacer mejor y no presenté ninguno. Mi intensión era hacerlo mejor, creando mi propio estilo con algunos arreglos y presenté mi trabajo. El profesor me dijo: "está muy bien, sigue adelante".

JE: (Párrafo, 7). El recreo era un sacrificio para mí, porque mis compañeros se burlaban. Un día, al llegar a casa le dije a mi madre: "no quiero volver al colegio", y ella dijo: “¿alguien se burla de tí?”, yo le dije: "no, y no quiero saber nada del colegio". La prima de mi madre le dijo: "cámbiale la ropa para que vaya como sus compañeros". Yo no sé que sacrificios hizo mi madre, me puso unos zapatos que no podía caminar, un pantalón de tela y una chamarra (cazadora) que le regaló la directora de su colegio. Con eso ya me identificaba con mis compañeros. Poco a poco, con el paso del tiempo, pasé al quinto grado de educación elemental y tuve un profesor muy bueno y aprendí el idioma, lo que me dio cierta confianza. 
JE: (Párrafo, 8). Cuando estaba en último curso de la escuela elemental me identificó el profesor, Humberto Bilbao (conocido como Bilbao la Vieja), y me dijo: "tienes habilidades y hay que explotarlas, pero tienes un problema, en primer lugar el castellano no lo hablas bien, pero eso se puede solucionar, con lectura y con otras cosas. La otra cuestión es un poco más peligrosa, y es que eres muy inquieto. No estas en un solo lugar, estas moviéndote y haciendo cosas y eso tienes que corregirlo. Primero, es parte de la disciplina. Segundo, no está de acuerdo con lo que se pide aquí. Quiero hablar con tu madre. Entonces lleve a mi madre y le aconsejó que me educara para no ser tan salvaje. Mi madre me llamo la atención.

JE: (Párrafo, 9). Cuando el profesor explicaba algo, yo terminaba junto con él. Un día me llamó y me dijo: "Aquí tienes una cartulina, corta dos de este tipo y tendrás un rectángulo, la recta que une, no me dijo vértice, este punto con este punto se llama diagonal; corta y traza las diagonales y cuando termines me avisas. Yo corté y acabé pronto, y le dije: "ya esta listo" y él me dijo: "te dije que cortaras y trazaras las diagonales, ¿has hecho eso?", "Si, he hecho eso". No miró ni el papel ni nada, y me dijo: ¿cuántas diagonales has trazado? Le dije "ocho". Él me dijo: “¿ocho?, cómo vas a sacar ocho, no sabes lo que dices. Haber, muéstrame, trae las cartulinas". Saqué las cartulinas y le dije: "aquí tienes dos y al otro lado dos, son cuatro por cartulina, entonces cuatro y cuatro son ocho", él quedó sorprendido con esta respuesta.

JE: (Párrafo, 10). Ese incidente se lo contó a mi madre y le dijo que tenía que ponerme en otro colegio, donde puedan ayudarle a desarrollar todo su potencial, porque tiene mucha creatividad y muchas otras cosas. Yo estaba escuchando. Luego mi madre se esforzó enormemente para enviarme al mejor colegio que había en aquel tiempo.

\section{AP: ¿Y qué recuerdos tiene del nivel secundario?}

JE: (Párrafo, 11). En el Colegio San Calixto, que está en la calle Jenaro Sanjinés, cerca del palacio de gobierno conocido como Palacio Quemado, estudié hasta terminar la secundaria. Los alumnos apreciaban mi sentido del humor.

JE: (Párrafo, 12). Cuando vino los concursos de Matemáticas y Física, sobre todo los de Física, yo ocupaba el primer lugar. Yo no necesitaba prepararme, porque trabajaba con el padre Descottes, que era el encargado del sismógrafo San Calixto, existente hasta el día de hoy. Yo iba investigando por mi cuenta. Y vi que realmente era importante investigar y prepararme para la vida de manera autodidacta.

JE: (Párrafo, 13). Después de terminar la secundaria en San Calixto, fui al servicio militar obligatorio, y al salir de cuartel fui a estudiar para profesor de Física y Matemáticas en la "Escuela Normal de La-Paz". 
AP: ¿Quiénes de su entorno familiar influyeron de manera positiva en su educación, especialmente en lo que respecta a las matemáticas?

JE: (Párrafo, 14). Mi madre era profesora y aprendí mucho de ella. Cuando era niño mi pidió que la ayudara a llevar una cesta de naranjas a la escuela. No me gustaba la idea, porque yo quería jugar. Pero ella cogía una naranja y hacía referencia a la esfera. Después cortaba alrededor y decía: "este es el circulo", cortaba por la mitad y hablaba de la simetría. Vengo además de una familia de educadores. Soy sobrino de Elizardo Pérez Gutiérrez, el fundador de la primera Normal Rural de Warisata, quien trabajó junto a su hermano Raúl. Ellos enseñaron allá a los campesinos aymaras que no conocían el idioma. Yo veía que tenían que enseñarles sonidos y buscar maneras de hacerse entender. Comprendí la paciencia que hay que tener. Y mi tía Candelaria hermana de Elizardo, inició los programas de desayuno escolar en Bolivia.

\section{AP: ¿Cómo estudiante, tenía rechazo por algunas asignaturas y motivación por otras?}

JE: (Párrafo, 15). No todas las asignaturas me motivaban. Aquello que yo podía hacer bien eran las que incluían las prácticas como la Física y algo de Química. Esto es lo que he dicho muchas veces. Yo me acuerdo de todos mis profesores en Bolivia, en Estados Unidos y en otros lugares donde he estudiado. Yo te puedo indicar todos los nombres de mis profesores, posiblemente pasan de doscientos, pero de algunos de ellos me he olvidado, de aquellos que no han hecho ningún impacto. No todos los profesores tienen el mismo impacto. Los profesores de geografía e historia, para mi eran un martirio, porque ellos querían que memorizaran. Venía el profesor y decía la consecuencia del golpe de estado de mil novecientos.... Uno se quedaba en la luna, era el test de complementación. "Que está hablando éste" yo decía. Tantos golpes que hubo en Bolivia y uno no sabía de quien estaba hablando. La otra parte, también memorística, la historia de Europa y otras cosas, no me fascinaban tanto, porque cada año iba al desquite, (recuperación). Para la recuperación me dedicaba a leer más cosas, pero después me gustó y me dediqué a la historia, a la historia de la matemática, no a la historia de Bolivia ni otra cosa parecida. Más para ver cómo empezaron los números y el lenguaje, y quienes fueron los primeros que inventaron las letras. Ahí descubrí que el hebreo no tiene alfabeto.

\section{AP: ¿Quiénes fueron los profesores y/o circunstancias que le motivaron en sus estudios y su formación como profesor de matemática?}

JE: (Párrafo, 16). Si, mi profesor de primaria, Humberto Bilbao. En el último curso de primaria, repitió la palabra carátula con motivos Tiwanacota, y me dijo que había hecho una bonito carátula y que íbamos a hacer un viaje imaginario a Tiwanacu. Le pregunté qué quería decir con imaginario. Él me dijo, piensa que vamos a salir de aquí y llegar a Tiwanacu. Nos llevó a un monumento que estaba en Miraflores, (ahora ha vuelto a Tiahuanacu), en la zona del estadio de 
fútbol Hernando Siles, que es el monolito de Vennet (en honor a su descubridor). Miré que tenía aproximadamente siete metros, y me dijo: "esto han hecho los Tiawanacotas, ¿crees que esta pieza tan grande lo han puesto ahí?, no, es una sola pieza. Si te fijas en los ojos, parece haber llorado. Yo le dije: "¿con que tipo de cincel hacían esto?, me dijo: "nadie puede decir, porque no había ningún instrumento". Te fijas en la proporción y la potencia. Yo quedé asombrado con lo que él me explicaba y me dijo, que realmente eran matemáticos y tenían el concepto de cero, pero yo no le daba importancia. Nada tenía para enseñar. Esto me impresionó y él me dijo: ¿qué forma geométrica tiene esto? Yo le dije: "prisma", ¿de qué base vas a decir? Yo le dije: "cuadrada" y el me dijo: "más o menos por ahí". ¿La mano también es prisma? Yo dije: "si éste es de una sola pieza, entonces tiene que ser prisma".

JE: (Párrafo, 17). Cuando estaba en la Escuela Normal, se organizó un viaje de clase. Dijeron que íbamos a ir a conocer Tiwanacu. En ese tiempo yo, ya conocía a mi esposa. Cuando llegamos a Tiwanacu, encontré las cosas que yo había visto en fotografía: la puerta del sol, los templos, la pirámide. ¡Esto es de lo que nos hablaba Bilbao la Vieja! Yo le escuchaba como si fuera un cuento. Dije, esto a lo que él se refería. Relacionaba la recta con la parte superior de la puerta del sol. Pero cuando lo vi objetivamente, dije: "aquí está la geometría". Decía, un día cuando tenga dinero voy a venir a sacar fotos. Y eso es lo que hice cuando vine de Estados Unidos, saqué muchas fotos para mostrarles todo lo que estaba relacionado con la geometría plana.

\section{AP: ¿Por qué decidió estudiar en la Escuela Normal?}

JE: (Párrafo, 18). Mi sueño era estudiar ingeniería en la universidad, pero al regresar del cuartel (milicia), me encontré con mi amigo Roberto Cordero, que se había inscrito para el examen de admisión (selectividad), en la Escuela Normal. De alguna manera, él me dijo: ¿por qué no haces la inscripción para el examen; a ti, que te gusta la física, la matemática y química, y estudiamos para ser maestros? Le dije que no quería ser maestro. Sin embargo, él insistió y me dijo: "date una oportunidad, y si no te gusta puedes cambiar". Entonces, por no contradecir a mi amigo, le dije: "de acuerdo". Por esa razón fui a inscribirme y me presenté al examen. Ciertamente no tuve dificultad en el examen. Aprobé y nos matriculamos para las clases de primer año.

JE: (Párrafo, 19). Cuando fui a la Escuela Normal, no estaba de acuerdo con la forma en la que los profesores daban las clases. La manera teórica de impartirlas me hizo pensar que no tendría utilidad en el terreno práctico. Así, pasaba de curso llevando mis equipos y materiales para mostrar de forma práctica lo que enseñaba. Pensaba que a mis compañeros les pasaba lo mismo que a mí en primaria. Si el alumno viene sin ninguna base de lenguaje ni preparación, no va responder, porque el alumno tiene que entender para responder. Pero los alumnos de este curso, no respondían bien, por no tener la preparación adecuada, o no tiene voluntad de hacerlo. 
JE: (Párrafo, 20). El profesor de didáctica de matemática, me dijo que le gustaría hacer las instalaciones para demostrar la fotosíntesis y otras cosas, y me pidió que le ayudara. Cosa que hice encantado.

JE: (Párrafo, 21). En el segundo año de la Escuela Normal, el profesor Humberto Bilbao me llamó para que enseñara, ya que era una autoridad en el Ministerio de Educación, y me dijo: "vas a ir a enseñar. Tú tienes una habilidad, sabes comunicarte y es lo principal. Te comunicas, no sólo con las manos, sino además con las figuras y otros materiales que traes, y eso te ayuda mucho". Yo comencé a trabajar como profesor cuando estaba cursando el segundo año; no tenía diploma ni nada. Me dio un Memorando de emergencia y empecé a trabajar ese año. Me llamaron del mismo Ministerio de Educación y me adjudicaron otro colegio donde enseñar. Así que tenía ocupado todo el día. Trabajé en los colegios de Nacional Bolívar y fundé el Colegio Gualberto Villarroel. En este último tenía la cátedra completa y mi acumulación de horas, (horas excedentes de la jornada completa), en el colegio Nacional Bolívar con dos paralelos de matemáticas. Ese año dejé de asistir a las clases de la Escuela Normal. Enseñaba aritmética siguiendo la orientación del profesor Bilbao la Vieja; él tenía una forma atractiva de enseñar los números. Llevábamos piedrecitas y otras cosas para enseñar las fracciones, es decir enseñaba a mi estilo. Pasó el tiempo y nos distanciamos, deje la normal y me dediqué a trabajar.

JE: (Párrafo, 22). Al siguiente año me dije que iba tomar solamente una sola cátedra y fui acumulando unidades. Después de 6 años, terminé la carrera. No necesitaba el certificado porque ya estaba trabajando, además, los que iban a hacer la práctica, (antes de ser maestro normalista), me consultaban y me preguntaban la forma como yo enseñaba. Les daba algunas sugerencias y les decía que el mejor plan de lección era:

Primero. Tienes que saber lo que tienes que enseñar. Tienes que estar bien documentado ante cualquier pregunta de los estudiantes. Tienes que saber lo que vas a enseñar, de lo contrario, no escribas algo que no vas a cumplir.

Segundo. Les decía que tenían que saber motivar lo que iban a enseñar, despertar el interés en el alumno de tal manera que puedan seguirles, que haya diálogo porque la matemática es tan simple y bonita que se hace agradable. Así, se puede convencer con algunas cuestiones como por ejemplo, como el juego del león y las ovejas. Yo les corregía y les decía que la parte más importante era la motivación, y como complemento, la evaluación para saber qué es lo que has enseñando y qué porcentaje de lo que has expuesto en el día, han asimilado.

El profesor Bilbao la Vieja me aconsejaba empezar siempre por lo más fácil: "enseña poco, pero enseña bien". No acumules contenidos de los que no tengas necesidad y que no te van a conducir a nada. Esa fue la primera instrucción. 
JE: (Párrafo, 23). Al terminar la normal, ya tenía el título. El Colegio Militar me contrató para ser profesor de Física y la Universidad también requirió mis servicios para ser profesor de matemáticas. Se me presentó la oportunidad de ir a trabajar al Colegio "San Calixto", con la cátedra de Física y Matemática, que es lo que yo quería: trabajar en el colegio donde yo me había educado. Las recomendaciones de mis profesores curas me orientaron a establecer la dinámica de mi trabajo. En ese momento empecé a ver los concursos de matemáticas, que me inspiraron con varias novedades. Allí anotaba cómo se podía innovar para mejorar.

JE: (Párrafo, 24). En esos años, el Colegio "San Calixto" ocupaba el quinto o sexto lugar en las competiciones. Los colegios que ocupaban los primeros lugares eran el Colegio Mariscal Braum y el Colegio Alemán. Tenían una instrucción de tipo francés y alemán. Los profesores venían de Francia y Alemania para enseñar en estos colegios. Un alumno del primer colegio me pidió que le ayudara en matemáticas, y pude ver cómo enseñaban. En ese momento me planteé empezar a innovar".

JE: (Párrafo, 25). Le dije al Director de San Calixto: "lo que tenemos que hacer es preparar a los estudiantes para estos concursos. No con dos o tres días de anticipación ni con dos semanas, sino con al menos tres años de anticipación y prepararlos desde base. Te garantizo que si el alumno tiene dominio de cancha, si domina las fracciones, te garantizo que le va a ir bien en el álgebra y va más allá del álgebra". Pero si no se pone la base, el alumno no lo conseguirá. Entonces llamamos a los padres de familia para que aportaran algo para el refrigerio para tener a los alumnos cuatro días a la semana. Yo me encargo de enseñarles lo elemental poco a poco. Comenzaremos con los de primero o segundo; cuando estén en tercero van a estar en condiciones de participar en cualquier concurso. Eso hicimos y resultamos ser el colegio que ocupamos los primeros lugares por cinco años consecutivos. En las competencias intercolegiales, luego en las interprovinciales, también entre los países del cono sur. Para nosotros era una cosa cotidiana sacar los primeros lugares. Me dediqué cien por cien a la enseñanza.

AP: ¿Qué actividades complementarias a los estudios realizaba en su época de estudiante?

JE: (Párrafo, 26). La necesidad me obligó a trabajar como zapatero y sastre, desarrollando mis habilidades, que aprendí gracias a que mi madre me mandaba a ver cómo lo hacían los que se dedicaban a ello. Yo tengo muchas cicatrices, me he cortado la mano muchas veces porque no sabía manejar el serrucho y otras herramientas; es por eso que tengo fracturas en el brazo, pues tenía que ganarme la vida. Empecé cosiendo botones a los chalecos. Luego me enseñaron a hacer el dorsal y la envoltura. Después, yo mismo hacía mis propios instrumentos y herramientas. En esa época había unos anafres (cocina), que funcionaban con queroseno. Yo arreglaba las bombas, buscaba los zapatos viejos y los cortaba para que sirvieran de gomas para la bomba. En 
aquella época se usaban los botines en vez de las zapatillas. En el Barrio era conocido como un muchacho que podía arreglar cualquier anafre, pero no era cierto. En aquella época, el charango utilizaba una cuerda de hierro, es decir metálico, no de nylon como ahora. Yo usaba la segunda cuerda, que era mas fuerte y de acero, la enrollaba en una lata y con eso lo destapaba tranquilamente. También hacía carretas, tenía una tabla y le puse cuatro ruedas. Mi hermana menor era mi ayudante. Íbamos a echar la basura de los vecinos por una barra de pan o un peso, y la llevábamos a unos ciento cincuenta metros donde estaba el basural.

$A P$ : ¿Qué experiencias negativas y/o positivas recuerda de sus primeros años de experiencia como profesor de matemáticas?

JE: (Párrafo, 27). Entre las cosas positivas, la invitación a trabajar en el segundo año de la normal y haber podido conseguir el apoyo del Director del colegio San Calixto para el proyecto de las olimpiadas y haber alcanzado el objetivo de ocupar el primer lugar en las olimpiadas. Las cosas negativas, El primer día de clases seguí el estilo que me habían enseñado y el Director me dijo que no traía ninguna planificación y la prepotencia de la persona que se sienta detrás de un escritorio, lo ven a uno como sino fuera persona. Me sacaba de quicio cuando me decían: "oiga, usted venga", y lo tomaba como algo ofensivo, pues no me llamaban por mi nombre.

\section{AP: ¿Qué logros considera haber alcanzado en ese periodo de su experiencia laboral?}

JE: (Párrafo, 28). Bueno, muchas veces he estado en la lona, pero no se cuentan las caídas, sino, las veces que uno se levanta. Yo tengo mi héroe nacional, es "Eduardo Abaroa". Él nunca se rindió. Una cosa que aprendí de mi madre es la disciplina. Mi madre nos decía que terminásemos lo que habíamos empezado, y otra cosa que aprendí en el colegio San Calixto era tener ocupado a los alumnos. Pasábamos casi 12 horas en el colegio. Eso es, lo que hice en los Estados Unidos con mis con mis alumnos de Garfield High School. Hice mi formulario y lo cumplía. Cuando estuve en los Estados Unidos, me dije, tengo que seguir una ecuación aquí. La ecuación que puse fue "determinación +disciplina + trabajo duro = camino a la excelencia". Esto es creación del que habla. Camino al éxito porque a veces hay muchas frustraciones, pero tiene que saber combinar esas frustraciones. Lo único que uno necesita es su yo personal, yo lo llamo "ganas", fundamental para poder eliminar frustraciones. La persona se hace grande cuando pelean esas frustraciones y sabe cuando se va a poner encima y cuando va estar abajo nunca hacerse doblegar, es como nuestro himno nacional, morir antes que esclavos vivir. (Himno Nacional de Bolivia). Pero en el buen romance es las ganas que uno le pone para poder seguir adelante. Nada es difícil cuando uno tiene ganas, hay frustraciones repito, pero tienes que aprender a vivir con ellas. Mi consejo ha sido para los alumnos que estaban allí en la universidad hay que seguir adelante. Ese mi principio me ha colaborado, esa es la fórmula que la he construido. 
AP: ¿Por qué decidió viajar a los Estados Unidos?

JE: (Párrafo, 29). La situación en Bolivia era muy deprimente. El presidente era el señor Víctor Paz Estensoro. Para comprar, uno tenía que anotarse en listas y hacer largas filas, porque no se conseguía nada. Me acuerdo bien, que había una tienda de zapatos cuyo dueño era argentino y había una fila enorme. Yo ya era profesor. Un día, haciendo fila para comprarme un par de zapatos. Cuando llegó mi turno, solo conseguí lo que se llama la chula, es decir, un solo zapato. Yo le dije al dueño: “qqué hago yo con un solo zapato?”, y me dijo: "busque al que tiene el otro par", entonces busqué y encontré, y le dije: "¿usted quiere este zapato?, yo soy profesor y tengo que estar bien presentable”. Me dijo: “¿por qué no me das tanto por el otro par?”, yo le dije: "encantado"; le pagué y se lo compré. A ese extremo estaba la situación.

JE: (Párrafo, 30). Mi señora tenía familiares en los Estados Unidos. Ella me dijo: "has estado en Puerto Rico, fuiste becado por el gobierno de los Estados Unidos que buscó a los mejores profesores de Física" y así fue. Me dijo: "aquí no tienes futuro, tu eres gran profesor y todos te conocen. Las cosas que haces aquí son papel mojado. Tienes que irte al norte". Yo le dijo: "no". Yo no quería ir, pensaba que yo podía enseñar algo mejor, pero la voluntad del Señor era esa. Le dije a mi señora que me iría, y así fue. Me recibió mi cuñado en California. Yo lo conocía, porque había vivido conmigo en La Paz. Su nombre es Samuel Tapia.

\section{Segunda parte: Jaime Escalante en los Estados Unidos}

$A P:$ ¿Con qué dificultades se encuentra al llegar a los Estados Unidos?

JE: (Párrafo, 31). Cuando llegué a los Estados Unidos, mi primer trabajo era lavar los platos, que para mi no era nada raro ya que lo había hecho en mi casa. Cuando empezaron a mostrar los diferente menús en la cocina, para mi no era nada difícil, pues yo veía el menú y podía prepararlos todos, por lo que acabé siendo el jefe de cocina. Así, el administrador me dijo aquel era mi puesto. Eso era lo que había aprendido cuando era niño.

AP: ¿Cuándo y cómo surge la idea de que puede triunfar como profesor de matemáticas en los Estados Unidos?

JE: (Párrafo, 32). Mi señora tenía familiares en los Estados Unidos. Ella me dijo: "has estado en Puerto Rico, fuiste becado por el gobierno de los Estados Unidos que buscó a los mejores profesores de Física" y así fue. Me dijo: "aquí no tienes futuro, tu eres gran profesor y todos te conocen. Las cosas que haces aquí son papel mojado. Tienes que irte al norte". Yo le dijo: "no". Yo no quería Me gustaba la física porque antes yo era físico y conocido por ser el encargado de dar la información de los movimientos sísmicos. Eso me ayudó mucho en la electrónica, porque cuando trabajaba en los Estados Unidos en la compañía Burroughs Corporation, yo no tuve dificultad en leer los planos, ni en usar los instrumentos de precisión que ellos usaban. Aprendí mucho de ellos, primero la 
organización, segundo, cumplimiento y tercero, en Estados Unidos le dan su mérito al que sabe, al que entiende y al que produce. Le ensalzan, le ayudan y le empujan. En cambio, en Bolivia, le pisan, y si le ven en el suelo no lo levantan.

AP: ¿Qué diferencias y similitudes encontró entre el sistema educativo de Bolivia y de Estado Unidos?

JE: (Párrafo, 33). Para nosotros los latinoamericanos, desde México, Centroamérica y Sudamérica haciendo una comparación, sobre todo latinoamericana, vemos la educación como un privilegio, porque debe tener ciertas oportunidades, ciertas ventajas para que el alumno pueda surgir en nuestro medio. Porque yo veía, que en mi pueblo no había un banco para sentarse ni folio blanco para escribir. En cambio, en Estados Unidos, para algunos alumnos la educación es un castigo, no les interesa mucho, porque a esa edad empiezan a ganar y disponer de dinero. Un adolescente de 15 años ya tiene un presupuesto para comprar su coche, comprar lo que quiera, porque reparte periódicos o ayuda a llevar algo. Sin embargo, en Bolivia, estamos viendo a los niños de 7 u 8 años trabajando en cerrajerías o cambiando llantas. Esa es la realidad de un país que tiene progreso.

JE: (Párrafo, 34). Yo tengo que reconocer que a mí, Estados Unidos me ayudó mucho. Me dio las oportunidades y yo no deje pasar ninguna; desde lavador de platos, administrador de la empresa donde trabajé, en la enseñanza de la matemática y la enseñanza de la electrónica en Guadalajara. Por lo que tengo que darle mucho, mucho mérito, mucho agradecimiento.

AP: ¿Qué pruebas y/o exámenes dio antes de incorporarse como profesor de matemáticas en los Estados Unidos?

JE: (Párrafo, 35). Uff, yo estuve en la lona más de 10 veces, He estado K.O. Muchas veces, tuve que pasar muchas dificultades, no sólo económicas, sino de otra índole, como el handicap del idioma y la arrogancia del gringo que si te ve en el suelo te pisa y no te levanta. Tienes que imponerte y usar tu yo personal, esa es parte de tu responsabilidad. Cuando uno tiene ganas, se levanta, se sacude el polvo, levanta la cerviz, sigue mirando hacia adelante y camina en pos del gran ideal que tiene. Así que yo he hecho eso, tengo mi héroe, que es Eduardo Abaroa, que nunca se ha rendido, y es el ejemplo más grande que ha habido de perseverancia y constancia. Más que todo es de mi misma sangre que nosotros.

\section{AP: ¿Cómo y por qué llega a trabajar en el Garfield School de los Ángeles de California?}

JE: (Párrafo, 36). Hay que cumplir muchos requisitos para ser profesor en los Estados Unidos. Es un poco difícil conseguirlo, sobre todo porque tienes que vencer el handicap del idioma, segundo porque tienes que tener un certificado 
o un documento de una de las universidades que está acreditada en el estado de California, que diga que uno ha terminado sus estudios en matemáticas y puede empezar en la escuela de educación. Entonces se empieza el curso de formación pedagógica que dura un año, y tenía que llevar pedagogía, didáctica, psicología, aunque para mi no tenía mucho valor. Pero tenía que hacerlo, aunque yo tenía mi propia pedagogía, mi propia psicología y más que nada toda mi experiencia de haber enseñado, no sólo, en Guadalajara, sino también en Puerto Rico y en Bolivia. No tenía temor a ese curso, así que cumplimos y pasamos todos los requisitos del examen de selección: examen de ingles, examen de la especialidad y examen de pedagogía; todo lo que se pedía en aquella época.

JE: (Párrafo, 37). Saqué la credencial y estaba en el primer lugar porque conocía realmente como se podía enseñar. Nos pusieron la práctica en un aula donde había un montón de forajidos que no dejaban hablar. Los postulantes tenían que explicar el tema que uno quería. Todos los que entraron a ese examen fracasaron y el único que les sorprendió fue el que habla, tenía la cara de latino, no tenía la cara de gringo. Entré y pasé unas hojas, cuando me preguntaron ¿para qué eran las hojas?, les dije: "para tenerlos ocupados haciendo algo". Segundo, hice la demostración en la pizarra, les pedí que escribieran un número de cinco cifras, luego restaran la suma de las cifras al primer número, que tacharan una de las cifras y que me dijieran la suma de las cifras del nuevo número. Capté la atención de todos. Tercero, todos empezaron a decir "uaoo, uaoo." Los tuve en la palma de mis manos en menos de cinco minutos, y ellos dijeron "este sabe lo que hace". Luego fui a la entrevista y me preguntaron de cómo se me ocurrió esto, el mejor profesor que usted tiene es la experiencia, eso he aprendido con personas que no responden y a estos forajidos les puse en su lugar en dos patadas.

JE: (Párrafo, 38). Yo elegí la escuela de Garfield, pero no sabía que estaba tan mal, porque vivía en otra ciudad. Cuando llegué a Garfield, al terminar la clase el primer día, llamé a mi compañía y le dije: "me he equivocado. Quiero volver a trabajar donde trabajaba antes, me retiro, porque estos analfabetos no están en condiciones de aprender, no saben que la educación es boleto al éxito. Yo me voy". Cuando me fui en mi coche Volkswagen, dije: "me voy, pero antes les voy a enseñar el respeto, respeto a las personas, respeto a la materia que es la matemática. También les voy a enseñar quien soy yo".

JE: (Párrafo, 39). Llegué por la mañana, como la película refleja, y pregunté a los alumnos: "¿ha estado usted en la playa?, ¿ha jugado con arena?". "Si”, responde el alumno. El hoyo que queda es negativo y la arena que sale es positiva. Por tanto, hay que completar, y le dijo a uno de ellos: "¿menos uno más uno?" Me miró sin responder, como quien dice qué me estas preguntando. Yo le dije: "yo sé que tu puedes. No eres tan bruto como se imagina la gente. “¿Menos uno más uno?” Él me seguía mirando sin responder. Yo le dije: "yo sé que tu puedes, piensa. Debes uno y pagas uno, ¿cuánto te queda?" Con rabia me respondió: "jcero!" "Ya ves que sabes, le respondí. Tú puedes tapar cualquier agujero". Se quedaron callados, y empecé 
a decirles que les iba a enseñar matemáticas. Mientras explicaba, me fijé en una alumna que copiaba con lápices de colores lo que yo escribía en la pizarra. Me acerqué y le pregunté: “¿te gusta las matemáticas? ¿Quieres algún sistema de matemáticas?" Me respondió: ¡sí!, y hablé con el director para enseñar álgebra en vez de aritmética elemental. El director se rió y me dijo: "estos vienen únicamente a perder el tiempo porque viven del sueldo que les da el gobierno y nada más. Usted está perdiendo el tiempo. Hable con el jefe del departamento de matemáticas". Cuando fui a hablar con él le dije que quería impartir álgebra en los cinco periodos que tenía de aritmética. "¡No te hagas muchas ilusiones!, no vas a poder porque estos son unos vagos, unos mal entretenidos que solamente se agarran a cadenas y a balas". Le dije: "¿no me das una oportunidad?" Me respondió que no había libros, y entonces le dije: "no te preocupes de los libros. Yo conozco la materia y puedo enseñar". El me contestó que lo hiciera sin molestar a nadie, y yo estuve de acuerdo.

(Párrafo 40). Ahí comencé la primera clase que tenía once alumnos, como vi que aprendían, decidí quedarme. En los siguientes años el número aumentó, y pasamos de Algebra I a Algebra II. Pasaron dos años y el profesor de biología me dijo: "hay unos concursos de matemática avanzada. Puedes participar con tus estudiantes, aunque dudo que ganen". Le dije: "vamos a conseguir, porque tengo la experiencia de San Calixto". Cuando llevé a mis alumnos al concurso, sacaron los primeros puestos dos mafiosos pandilleros. El periodista me dijo: "¿por qué usted no se viste como ellos para una foto?. La foto apareció en le periódico de la ciudad, diciendo que unos pandilleros habían ocupado los primeros puestos y explicaba una pequeña historia. Esto llamó la atención, haciendo que la gente se interesara. Ahí empecé a usar mi sistema que no es nada difícil, pues todo es fácil cuando uno pone ganas.

\section{AP: ¿Como empezó el programa de matemáticas que usted implementó en la escuela Garfield y cuál fue su motivación?}

JE: (Párrafo 41). No fue fácil hacer frente a un programa deficiente del Distrito Escolar de Los Angeles. Busque ayuda del East Los Angeles College (ELAC). El presidente de ELAC, señor Ávila, administradores George Madrid y Paul Powers, y el señor Villavicencio, maestro de la escuela Griffith Junior High School, fueron mis fieles colaboradores. Con respecto a la motivación, en mi concepto "Latino", no podía aceptar que Garfield High School ofrezca un programa insuficiente con requisitos mínimos en la preparación para nuestra gente. Por ejemplo: Solo 10 unidades en matemáticas (aritmética elemental equivalente a un tercero o cuarto grado de instrucción primaria), artes plásticas, imprenta, cerámicas, hojalatería, y carpintería. Con este tipo de instrucción secundaria engañamos y no preparamos a nuestros alumnos para un mejor futuro.

\section{AP: ¿Hubo alguna resistencia de parte de los administradores del colegio?}

JE: (Párrafo, 42). He peleado con muchos directores, con muchos consejos y con la mayor parte de los administradores porque me decían que estaba 
haciendo cosas que no tenían ninguna importancia en el campo de la matemática, debía dedicarme únicamente a enseñar lo que dice el programa y se acabó. Yo les dije: "el programa que tienen no sirve porque es teórico y ellos nunca van a leer. En primer lugar ese libro que usted tiene está bien para un barrio que tienen dinero, como Beverly Hill donde están los chicos de padres ricos, pero para estos que son de la escuela minoritaria donde todos hablan mitad ingles y mitad castellano, este libro no funciona, solo el hecho de ver los signos les lleva a poner a un lado. Tiene que ser un libro donde el alumno pueda entender lo que esta haciendo. Tenemos que escribir los planes de lección.

\section{AP: ¿Qué importancia tiene la planificación de la enseñanza del profesor para conseguir buenos resultados?}

(Párrafo, 43). Antes yo tenía que buscar una ayuda, necesitaba profesores que pudieran entender y seguir mi sistema. Luego teníamos que ver cómo íbamos a hacer el plan de la lección. Reuní a los profesores y les pregunté: "¿cuándo es la última vez que han escrito un plan de lección?" Algunos por mandarse la parte decían, que siempre lo hacian todos los días y otros más sinceros, reconocían que no lo hacían desde que salieron de la universidad. Seguían las instrucciones del libro y se acabó. Entonces les dije: "no señor. Vamos a hacer un plan de lección y cada uno hará independientemente". Alguien dijo porque no hacemos el mismo tema. Les dije: "elijan ustedes el tema y yo hago el plan de lección". Unos estuvieron de acuerdo y otros no. Yo les dije: "haremos una cosa simple: la suma" Pregunté a los profesores: “¿cómo introduce el concepto de la suma?" Uno dijo, yo escribo la definición, la demostración y ejercicios. Otro dijo, para mi la suma es decirles que es agrupar y poner de acuerdo a esto, mamá va al mercado y otras cosas. "No", les dije. "Se relaciona con lo que el alumno sabe, se comienza por ahí, luego se hacen las aplicaciones. La primera parte del concepto es motivar el tema del que usted va a hablar. Por ejemplo, agarramos un número, 25 y hacemos un juego. Voy a dividir por 5 porque $5 \times 5$ es 25 y de aquí, esto es tres y esto es 4 , esto es 5 esto es 6 y esto es 7. La suma te va dar 25.

$$
25=3+4+5+6+7
$$

Cómo ya han hecho esto en la primaria, el alumno conoce la suma cuando está en la secundaria, para ellos tienes que hacer aplicaciones. Vamos a tomar otro número $625=23+24+25+26+27$. Le pedía que den otro ejemplo, otros ejemplos. La tarea era que la siguiente reunión traiga cinco sumas. Al día siguiente los profesores traían la suma es asociar, esto y otro. Después de motivarlos iba al problema y lo que me interesaba era que aprendan a resolver problemas donde estaban involucrados la suma. Luego venía como motivar la multiplicación, algunos decían yo voy a usar números pares e impares. Yo iba usar el complemento, para esto les mostraba una película donde diga y ahora como complemento las palabras del profesor tanto. Complemento es lo que falta para 90 grados, ángulos complementarios son los que suman 90 grados. Complemento de 60 es 30 grados. Entonce voy indicando los diferentes ángulos para que ellos contesten y de esta manera establezco la relación con 
los alumnos. Entonces uno puede usar el complemento para lo que uno quiera. Por ejemplo uno puede complementar a nueve.



2- $1=1$ complemento a 9 es 8 , entonces $2 \times 9=18$

Estos señores, lo único que han puesto sombreritos para indicar el complemento. No avises a nadie.

JE: (Párrafo, 44). Voy a usar el mismo procedimiento en la multiplicación por 5, 25, 3575 y demás. Entonce requiero que pesquen la palabra complemento porque cualquier tema que uno está hablando es su palabra clave. Eso es lo que a uno le conduce. Para el alumno le quito uno, le quito uno, bien. No hay dificultad pero si dices le complemento, entonces ya no hay tal le quito, le dijo por ejemplo tengo 97 quiero complementar a cien ya no hay le quito sino tres en cierto modo es una resta. El que sabe matemáticas se da cuenta. Pero no puedo decirle resto. Sino complemento lo que le falta, voy a complementar a cincuenta. Entonces el complemente de 30 es 20.

JE: (Párrafo 45). Hicimos el plan de lección para diferentes tópicos: algebra, geometría, y así fuimos poco a poco. Me di cuenta de que necesitábamos comprender el concepto de trabajo en equipo. El equipo se prepara, entra a la cancha, mete el gol y gana. Al igual que un equipo como el "Bolívar", The Strongest" o el "Real Madrid" de España que me gustaba mucho por su forma de seleccionar. Les dije que les iba uniformar, a repartir chamarras, (cazadoras), con el nombre del alumno y les iba a dar unas mochilas para demostrar que lo que necesitaban eran ganas. Tercero, les iba a dar el material que necesitaban, y conseguir personas que colaboren económicamente para dar al alumno con problemas de la vista, gafas gratuitas. Semanalmente, comeremos juntos. Así nos iremos uniendo poco a poco, y yo me fuí adentrando en su terreno. Decidí visitar a cada uno, llevándoles chocolates o algo que les interesara, conseguir el apoyo de las madres, y así entrar en la vida familiar.

JE: (Párrafo, 46). Se organizó un equipo de trabajo y necesitaba dinero para los que iban a dirigir el equipo. Pedí a la administración que colaborara para que se reconozca lo que yo estaba haciendo. Conseguí una ayuda financiera de Richfield Atlántica, de una empresa que se dedicaba al negocio del petróleo. Ésta me dio dos mil dólares, después 20 mil y posteriormente 40 mil. Cuando tuve el éxito completo en Estados Unidos, el presidente Ronald Reagan reconoció mi labor, entregándome la medalla presidencial a la excelencia. Dio una ayuda económica de medio millón de dólares para que siga mi programa con estos muchachos. Con eso, ya estaba bien situado y pensé que no sólo necesito libros, sino que estos niños necesitaban estar en sitios diferentes, porque yo recordaba mi infancia. Me dije que deberíamos llevar a comer a estos niños a un restaurante cercano y el siguiente año a otro de mayor jerarquía. Y Así sucesivamente hasta el último año, que les llevaremos en donde comen los artistas, y el menú cuesta 50 dólares. Voy a vestir bien y 
prepararles para desenvolverse adecuadamente. Voy a demostrarles que la gente que acude a esos sitios tiene jerarquía. Pero ellos no son nada. Ellos llegarán a ser mejores que estos. Me podía permitir esto por las aportaciones que había recibido. Quería mostrarles a los diferentes grupos étnicos de California, que ellos podían cambiar su posición social.

AP: ¿De qué manera hace el análisis del contenido específico de un tema de la matemática para ser presentado en la clase?

JE: (Párrafo, 47). El análisis de contenido depende del objetivo que nos proponemos los profesores. Primero reviso las definiciones y conceptos de los diferentes libros que tengo a mi alcance. Pero no me quedo con ninguno de ellos, yo elaboro el mío. Segundo busco la aplicación que tiene este tema en la vida cotidiana, relacionándolo con algo que conoce el estudiante en su medio y trato de mostrar objetivamente el concepto. Por ejemplo, si tengo que enseñar las funciones y nos detenemos en las funciones cuadráticas. Asocio con el casco, (una taza artesanal para beber la chicha en Cochabamba). Utilizo los vasos de champán para mostrar los contractores y el vaso del Melgarejo para mostrar los amplificadores. El movimiento del vaso de champán con la mano para el brindis, tanto vertical como horizontal. Así, el alumno no lo olvida. Debemos de aprovechar la memoria visual.

AP: ¿Cuánto tiempo invertía en la preparación de la clase antes de realizar en el aula?

JE: (Párrafo, 48). Esto es lo que más cuesta. Hay que invertir mucho tiempo para que las cosas salgan bien en la clase. Los dos enemigos del maestro son la improvisación y la rutina. Buscaba las explicaciones de un tema de diferentes maneras y luego me quedaba con alguno de ellos que me resultaba interesante.

AP: ¿Qué factores considera importante en su experiencia con los estudiantes de Garfield High School?

JE. (Párrafo, 49). Hay varios factores, pero mencionaré algunos de ellos: la motivación, despertar el interés en el alumno, la disciplina en el estudio y proveerle de las condiciones necesarias, como materiales, instrumentos y sobre todo, el lenguaje apropiado.

\section{AP: ¿A qué atribuye el resultado conseguido con sus estudiantes de Garfield School en las pruebas de Advancedt Placement (AP)?}

JE. (Párrafo, 50): Consiste en crear la consciencia en los mismos estudiantes, las potencialidades que ellos tienen. Deben estar seguros de que ellos pueden hacerlo, solo necesitan tener ganas. Yo no creo en los superdotados, sino en los que tienen la voluntad y el deseo de hacer las cosas bien. 
AP: ¿Usted, no solo trabajó en la enseñanza del análisis, sino, también en otras áreas?

JE. (Párrafo, 51): Si. Trabajé en la universidad, pero nunca dejé el colegio. Yo iba como asesor porque tengo el nombramiento del presidente Reagan y Bush. Ocupaba el fin de semana para trasladarme, no podía dejar las clases, y ellos lo entendían. Además, ese puesto es honorífico, eso le sube 20 puntos en el Escalafón. Muy pocos tienen esa opción, son tantos Estados y muchos lo desean, pero yo nunca lo habia solicitado, sino que fue directamente como premio a lo que yo había hecho. Yo tenía mi actividad, primero no usaba el sustituto, nunca he faltado a la escuela, nunca he tenido ese problema de dejar la clase. Viajaba el viernes, el sábado y el domingo estaba con ellos, y el lunes ya estaba en clases. En vacaciones ellos se ajustaban a lo que yo quería.

\section{AP: ¿La clase a la que asistió Bush era una clase normal o era especial?}

JE: (Párrafo, 52). No. No fue especial, era la forma como yo entraba, con una llijlla, (manta hecha por los aymaras), que colgaba sobre el hombro, y les mostré unas postales. El indio en Bolivia conocía las fracciones mucho antes que los mayas o cualquier otra cultura. El indio del altiplano boliviano teje su frazada. Primero, hace la mitad, y esto es un medio; esa mitad la divide en cuatro partes, y resulta que la unidad esta dividida en ocho partes. Los colores se mostraban en la llijlla. También llevaba la chuspa, (una bolsa), tejido en Bolivia con muchos colores. Los matemáticos que teníamos allá en Bolivia eran los Tiwanacotas, no los aymaras ni los quechuas. Ese imperio ha desaparecido, ya no hay ninguno. Actualmente, dicen que son los aymaras, pero no lo son. Ellos son los invasores que lo han desplazado; esa es la historia verdadera.

JE: (Párrafo, 53). Después de presentar el problema, empecé a mostrar objetivamente las operaciones. Con cosas de goma o cartones, como has visto en Vinto. Esto me dió mucha creatividad. La creatividad depende del profesor y está en función de su conocimiento, de lo que él ha estudiado. Como yo he sido un tipo autodidacta, tenía muchos recursos. Ese tipo de actividad me ha hecho grande, eso es lo que al presidente Bush le llamó la atención. Esa forma de poner el problema en frente de los alumnos y resolverles desde la práctica. Solamente enseñar como una industria, de 10 a 15 minutos, y los alumnos empiezan a producir. Eso es lo que da resultado y evidentemente así fue. No es una clase común y corriente donde el profesor ocupaba los 45 ó 90 minutos. Yo usaba a veces un tercio, tal vez menos; el resto de los dos tercios trabajaban los alumnos. Tenían que demostrar lo que han aprendido. Ese tipo de comunicación me ayudó mucho. Sorprendió realmente cuando encontré que para dividir, se invierte una fracción. De un tercio dividido entre tres, se toman extremos y medios, pero en la suma no es lo mismo y en la resta tampoco. De ahí, que quería interpretar objetivamente, y encontré la forma como debía hacerlo. Hice mis papelitos, diseñé mi aparato para cortar cartones, y los alumnos cortaban porque haciendo se aprende. Nunca pensé que un presidente de un país tan poderoso llegaría a visitarme a mi clase. Ese día me 
sentí muy seguro porque estaba el FBI. Me preguntó que tenía que hacer para aprender matemáticas que todos temen. Le dije que debía asistir a clases, hacer sus tareas y confiar en el entrenador para dominar la cancha. Fue una sola broma.

\section{AP: ¿Después del éxito en el Garfield High School por cuanto tiempo permaneció?}

JE: (Párrafo, 54). Yo no quería dejar el colegio, pero encontré un poco raro el ambiente. Cuando enseñaba en la universidad, lo podía hacer porque tenía la maestría. Descubrí que era mejor trabajar con los ignorantes, (me refiero a los que ignoran la matemática), porque se les puede conducir por el camino al sendero que uno desee. Llegué a entender que el periodo de la pubertad entre los 10 y los 15 años era la mejor edad para poderlos cambiar, porque estos muchachos estaban expuestos a diferentes actividades, así el profesor podía moldearlos y darle la vuelta a la situación; conducirlos por el camino que uno quería: la matemática es el lenguaje, es el camino con el que ellos iban a conseguir el éxito. Pero en la universidad me sentía frustrado, no podía hacerlo. Ellos ya iban con esa formación, y con la idea en mente de que tenían que sacar la nota mínima para aprobar y se acabó. Estos sólo iban para cumplir con los requisitos. En cambio, en secundaria, yo les hacía creer otras cosas enteramente distintas.

JE: (Párrafo, 55). Como había sido un inmigrante que no dominaba el idioma y que tenía tanto éxito al final, algunos me veían como un ejemplo. Les decía: "todo depende de que sigas las instrucciones que te da tu mamá, lo que te dice tu entrenador y nada más". Me dediqué más a la secundaria y no quería dejarla porque los tenía por cuatro años seguidos conmigo, y tenía tiempo suficiente como para modelarlos. Es como tener una masa en la mano y ves que el ignorante vive en el desierto donde el agua es poca, el aire es impuro y un gramo le detiene al inseguro. Es mejor con estos antes que con los otros. Los de la universidad no te creían nada de lo que les decías. Yo les decía: que cumplieran y ellos me decían: "váyase, yo me cambio de clase y se acabó". No se podían formar matemáticos ni científicos, porque ellos ya tenían en mente para lo que necesitaban esa materia, para ser financieros, negociantes, cortador de carne o de lo que sea. Me quedé en secundaria hasta el último porque me gustaba más y tenía esa oportunidad, además tenía más experiencia. Sólo trabajaba después de las cinco de la tarde en la universidad, en lo que denominan "evening class", y algunas veces los sábados que teníamos que preparar algunos exámenes o exámenes de grados y otras cosas. Al principio yo estaba decidido a quedarme a enseñar en la universidad, pero no podía porque no se daban las mismas condiciones, el ambiente y los alumnos ya venían con la mentalidad definida. Sólo querían sacar la nota mínima y se acabó, y al margen de esto tú no podías verlos el próximo año. Ellos podían cambiar de profesor. No podía tenerlos como lo hacia en la secundaria. Cálculo 1, Cálculo 2, Ecuaciones diferenciales y otros. No podía seguir mi propio programa. Muchos me decían: "usted podría formar a muchas 
personas", y yo les decía: "no creo, porque ya están formados y son muy viejos".

\section{Tercera etapa: Jaime Escalante después de su jubilación (1999 - 2010)}

AP: ¿Qué actividades realiza después de haber dejado la docencia en los Estados Unidos?

JE: (Párrafo, 56). Después de haber terminado, llegada la jubilación, lo primero que hice fue reescribir todo lo que había hecho porque lo tenía en notas. Nunca he pensado en escribir un libro porque me planificaba en la parte social con los alumnos y los padres de familia, y esto me quitaba mucho tiempo. No disponía de tiempo, como ahora; que tengo la mañana o la tarde para escribir. Hemos puesto esos pequeños conceptos sobre la enseñanza del álgebra o la matemática en general. Tu has visto cuando hice en la Universidad Adventista las fracciones, la transición de la aritmética al algebra, la trigonometría, la factorización, y otros, cómo se visualiza. Esas cuestiones me tienen entretenido. El único problema es que no puedo estar mucho tiempo frente al ordenador. Toda mi vida he escrito sobre el papel en mi escritorio. Pero ahora la vista ya no funciona para esto.

JE: (Párrafo, 57). Por ejemplo, si voy a enseñar la línea recta, tengo que tener un juguete; aquí está, (saca otro juguete), con solo decir la palabra mágica: pendiente, pendiente. Aquí está una línea recta y cuelga un péndulo. Éste muestra cómo sube el péndulo a medida que varía el ángulo. Siempre va a subir cuando cambia el ángulo. Esto me ayuda para hacer entender a los estudiantes desmotivados porque capta la atención del alumno. ¿La palabra pendiente en cualquier momento puede usarse? No. La pendiente está en función de lo que se está haciendo. Hay un dibujo con el tobogán, que es lo que he mostrado en la Universidad Adventista. Las gradas, serían pendiente positiva y la bajada pendiente negativa cuando empieza a balancearse.

JE: (Párrafo, 58). Tengo toda la geometría analítica de esta manera. Paras las cónicas tengo el cono hecho de diferentes materiales. Pero eso me lleva por lo menos dos meses para enseñarlo. Sin embargo, a lo que voy yo, es que esto tiene que ser en una forma en la que el alumno conozca y sepa lo que está haciendo, sino no va a poder. Yo parto de ese principio, que el alumno siempre tiene que relacionarlo con algo que él conoce.

\section{Parte IV - Método Escalante}

$A P$ : ¿En qué consiste el método Escalante de la enseñanza de la matemática?

JE: (Párrafo, 59). No he patentado el método, pero tiene su propia dinámica. Muchos profesores lo han adoptado, sobre todo en Texas y en California. Ellos vieron primero la parte humana, la parte pedagógica de este maestro, y ellos adoptaron y pusieron en marcha estos mismos principios: Primero, si vas a suspender a un alumno que tiene condiciones, tienes que contar 10 antes de 
colocar la calificación mala. Para que veas que está suspendido, tienes que averiguar por qué no puede. Tal vez son factores económicos. Segundo, tal vez son factores sociales o de familia: la madre y el padre están peleados, no colabora el padre, es decir, no hay colaboración en el hogar. Tercero, a lo mejor tiene un complejo el alumno, o una idea flaca de las matemáticas, es decir, odia la matemática y por consiguiente te odia a ti también. Entonces tienes que acercarte, es como cuando uno va al médico y le dice que está enfermo. Lo primero que el médico pregunta ¿de qué adolece? De acuerdo a eso le da prescripción, el mismo principio vamos a seguir. Es eso, lo que yo hacía del Yocalla, (muchacho), que no puede, hay que saber si está metido en pandillas. Saber qué es lo que hace, entonces lo primero que yo hacía al entrar a las clases, era preguntarle si fumaba. "Ah, eso mata a las hormonas, no vas a pasar de curso, es temprano, muy temprano para empezar. Usted chupa, le tira al trago, eso es peor, porque el alcohol va directamente al cerebro, no pasa por la digestión, te embrutece, te quita toda la posibilidad de tener la memoria retentiva que necesitas, porque cuando yo ponga algo en la pizarra tienes que sacar una fotografía y eso se llama memoria visual". Segundo, respeto al estudio y aprovecha todas las oportunidades que te ofrece este país. Pocos ofrecen eso.

\section{AP: ¿Usted podría mencionar y explicar algunas estrategias que utilizado en su experiencia de la enseñanza de la matemática?}

JE: (Párrafo, 60). Primero, nunca entrar por la definición del tema que uno va a hablar. Siempre relacionar las cosas con algo que uno conoce o sabe. De ahí, enlazar y sacar el concepto que uno quiere. Después comprendí que se debe enseñar unos diez minutos y luego pasar hojas de trabajo, lo que llamábamos el laboratorio, y organizar a los alumnos en grupos. Vi que era importante hacerlos trabajar en mesas de a cuatro, hacer que colaboren. Me decía: "cuando éstos egresen un día, van a trabajar juntos en las compañías donde vayan. Necesitan esta relación". Sólo los exámenes eran individuales y diferentes para que no usaran su mirada en diagonal.

JE: (Párrafo, 61). Me permitía darles la forma de un equipo. Los uniformaba, les compraba chamarras, mochilas. Los mantenía en la clase. También me permitía usar la música, también música boliviana. Les decía, por ejemplo, que los pasos del caporal eran muy interesantes, les prestaba videos. Ellos así adquirían confianza. También, cuando ya hubo alumnos que se hicieron médicos, empezamos a hacer que a los nuevos les revisen la vista $u$ otros aspectos de salud. Así veían que uno se preocupaba por ellos. Desde luego he cambiado el sistema de educación en los Estados Unidos. Hice una innovación completa donde los niños, podían aprender algebra al cuarto o quinto año de primaria. Ha hacer el álgebra con los cuadraditos que me has visto.

JE: (Párrafo, 62). El secreto era tener a los alumnos por cuatro años, más cuatro vacaciones de verano, con el mismo profesor o con el grupo de profesores que había entrenado. Así los jóvenes tenían éxitos en los exámenes de admisión o las competencias. Hay que llevarlos a trabajar en equipo, 
motivar al estudiante, que relacionen los conceptos con las cosas que el estudiante conoce, conseguir la disciplina en el estudio, convencerle que él es el mejor, y no hay otro.

Para darle el sentido de equipo, entregábamos a los alumnos los materiales y les decía: "todo lo que se necesita es ganas y si no tienes ganas, yo soy experto en darlas"

Aquí está la chaqueta de Grafield High School. Stand and Deliver. Ponte de pie y entrega. El alumno la recibía como superdotado:

1. El primer curso recibía chaqueta color blanco

2. El segundo curso recibía chaqueta de color azul

3. Tercero curso recibía chaqueta de color rojo

4. Los del último curso usaban chaqueta negra, ellos eran mis ayudantes.

Estos últimos tenían la obligación de reclutar más gente para mi equipo. A estos, cualquiera podía preguntarles cualquier cosa de matemática y ellos respondían. Éstos ganaban 10 dólares a la semana y trabajaban conmigo una vez a la semana, rotaban de un grupo a otro. Tenían que depositar el dinero en un banco y me tenían que mostrar la cuenta. El propósito era que este dinero aumentara para cuando ellos egresen, y les sirva cuando vayan a la universidad porque iban a necesitar más dinero. Entonces todos querían llegar a vestir la chaqueta negra y era una manera de estimularlos.

JE: (Párrafo, 63). Puede ser el de la factorización, o lo que presentamos en Vinto: las fracciones de manera objetiva. Siempre he buscado explicar las cosas de una manera que el alumno relacione las matemáticas con las cosas que conoce. El profesor sólo habla 15 minutos y el resto del tiempo los alumnos trabajan en grupos de cuatro. Yo les doy una hoja que contiene los ejercicios o problemas para que discutan entre ellos y resuelvan. Observo las dificultades o problemas comunes entre los grupos, para explicarlos posteriormente. La evaluación debe ser continua y permanente.

\section{AP: ¿Cuáles son los reconocimientos más significativos que recibió en su trayectoria profesional?}

JE: (Párrafo, 64). Son muchos, ya no tengo espacio para colocarlos. Algunos las tengo aquí y otros en los Estados Unidos. Un ratito voy a traer, (Sale para buscar los documentos y trajo dentro de una mochila de Garfield High School) como te dije, una parte lo tengo aquí y otra parte lo tengo en Estados Unidos.

\section{AP: ¿Hablando acerca de la matemática, para usted la matemática se descubre o se inventa?}

JE: (Párrafo, 65). La matemática es una actividad antigua y polivalente. Las diferentes culturas han desarrollado su noción de Matemáticas. Por ejemplo, el Chasqui en el imperio del Inca, era uno que tomaba el morral, (el bolso), echaba las cartas en él y corría llevándolas de un pueblo a otro. Entonces éste era el primer maratonista que hubo en el mundo. Este indio, que recibía el nombre de Chasqui, era el correo. Luego apareció el sistema Morse. Este 
código fue inventado por Samuel Morse en 1838. De este modo se inició la comunicación a larga distancia durante la segunda mitad del siglo pasado. Este sistema eliminó al Chasqui. Desde entonces se usó el telegrama para la comunicación. Pero había que usar palabras cortas. Al respecto, hay un cuento. Había un comerciante que iba con sus mulas de vender y comprar sal y lo demás. Le dió algunos tragos y perdió o le robaron las mulas; y le puso un telegrama a su madre: "madre querida, mula perdida me quedé por animal", indicando que se le había perdido las cosas. El inventor del sistema Morse es el verdadero fundador del sistema Braille para los ciegos. Louis Braille (18091852). Después se ha descubierto el teléfono y su inventor: Alenxander Graham Bell (1876), era sordo y estaba buscando un aparato que le permitiera oír porque no oía bien. Beethoven murió sordo, mientras Bell buscando resolver su problema consiguió el teléfono. Éste reemplazó todo y lo echó afuera. Las indicaciones por medio de luz prolongada y colores y demás cosas se eliminaron por completo, eso ya es historia. Hoy nos comunicamos con la mayor parte del mundo con Internet.

JE: (Párrafo, 66). Internet o correo electrónico se comunican en cualquier lado. Pero entendiendo que el computador solamente usa el 0, (cero), y el 1,(uno). El cero lo usa como número par, evidentemente es un número par, y el uno como número impar. Yo enseñaba el código binario de manera objetiva y para mostrárselo tengo un reloj donde esta el sistema quinario, binario, decimal y los demás. Lo que el computador hace es simplemente esto.

Ejemplo: el número 29

$$
\begin{aligned}
& 29 \rightarrow 1 \\
& 14 \rightarrow 0 \\
& 7 \rightarrow 1 \\
& 3 \rightarrow 1 \\
& 1 \rightarrow 1 \\
& 29=11101(2)
\end{aligned}
$$

El computador sólo reconoce los números enteros expresados con el cero y el uno. Al 29 quita por la mitad porque es sistema binario, 14,5 pero no entiende decimales, entonces sólo queda 14, de 14 dice 7, del 7 dice 3 , del 3 queda 1. Luego lo clasifica, el primero es impar y equivale a 1, el segundo es par y equivale a 0 , y los otros son impares. Lo que quiere decir es que 29 es igual a 11101 en base dos y ahí muere.

JE: (Párrafo, 67). Esa habilidad que encuentra el profesor es su pedagogía, y no como enseñan; hay que dividir, hay que hacer esto, hay que cambiar, etc. Entonces son cuatro foquitos que se prenden nada más. Uno es la unidad 2 elevado a cero, y los otros a 1, 2, a 3, etc. Al que le toque par o impar. Ese tipo de habilidad es la pedagogía. 


\section{AP: ¿Usted se considera creador o innovador?}

JE: (Párrafo, 68). Yo diría que soy un profesor innovador, por ejemplo, la forma cómo motivo está relacionado con las cosas que el alumno conoce o sabe. $\mathrm{Si}$ hay algo que el alumno conoce, se le enciende el foquito, el foquito verde y ve. Le despierta interés, pero si hago lo contrario, entro directamente a la definición y digo el teorema tal, todo se queda ahí. El alumno no lo ve porque no entiende, ni sabe por qué, entonces poco va poder definir el teorema. En cambio, si se empiezo por una cuestión que él conoce aprende. Por ejemplo, en primaria podemos empezar con: “¿cuándo es tu cumpleaños?" el niño sabe cuándo es su cumpleaños porque sabe que va soplar 2 velas 03 velas, etc. Entonces le damos el almanaque y me muestra donde está su cumpleaños, de ahí sale unas ideas muy interesantes.

\begin{tabular}{cc|ccccc}
\cline { 3 - 5 } 1 & 2 & 3 & 4 & 5 & 6 & 7 \\
8 & 9 & 10 & 11 & 12 & 13 & 14 \\
15 & 16 & 17 & 18 & 19 & 20 & 21 \\
22 & 23 & 24 & 25 & 26 & 27 & 28 \\
29 & 30 & 31 & &.. &.. &..
\end{tabular}

La suma de una diagonal y la otra diagonal son iguales, y esto lo usará cuando esté llevando el concepto de matrices. Luego eliminas una columna y una fila y sale un número, además de muchas cosas que hice en la Universidad Adventista. A partir de ahí se puede sacar los conceptos que necesita. La derivamos en una forma que el alumno ha tragado la píldora exactamente.

AP: ¿En qué consiste su innovación?

JE: (Párrafo, 69). En introducir un lenguaje un poco más cómodo para el alumno y no simplemente en enseñarle los signos menor que, mayor que, sino el lenguaje. Decirle por ejemplo: tres $x$ sobre dos, más $x$ sobre tres, igual a un cuarto. Qué es una ecuación. Tienes que indicar por qué es ecuación, entonces él dice, es ecuación porque hay un signo igual.

$$
\frac{3 x}{2}+\frac{x}{3}=\frac{1}{4}
$$

Si no hubiera un signo igual y tuviera $\geq$, mayor o igual, entonces sería una inecuación o desigualdad. Luego te fijas si la ecuación es con denominadores o sin ellos, es decir, si es racional o irracional. Apenas veas un denominador, es el peor problema que tienes en tu vida. Hace una recta vertical y esto significa que vas ha hacer desaparecer el denominador. Esto es magia. Tomas el número menor, nada de estar hallaando el mínimo común múltiplo o máximo común divisor, lo vuelves loco al Yocalla. Te fijas en el número menor y comparas con el mayor, el 2 cae exactamente o entra exactamente en el cuatro, es dos veces, entonces este dos no lo necesitas y lo eliminas porque está incluido en el cuatro. El tres no entra, entonces te queda multiplicar tres por cuatro. Tres por cuatro es igual a doce y se acabó. Luego haces las divisiones o multiplicaciones etc., etc. 
JE: (Párrafo, 70). Lo didáctico es esto, ahora introduces variable en el denominador, porque en el caso anterior no había variable en el denominador:

$$
\frac{2 x}{x-1}+\frac{3}{x}=5
$$

En esta ecuación hay variable en el denominador, entonces tienes que aplicar esto. No puedes dividir por cero, porque si divides por cero te condenas, y ellos tiene miedo porque en la religión les dicen esto, si tu no hace tu primera comunión a los 7 años va ser tarde, te vas a condenar, es el miedo porque el cura le dice eso. Lo asusta, y tiene miedo a condenarse, es decir, esto no va tener salida, está prohibido dividir por cero, te puedes condenar. Este sistema o esta forma de hablar, de decirle al ñato algunas palabras que el conoce. Lo primero que puedes decir $x$ no puede ser cero, $x$ no puede ser 1 , entonce ya tiene la solución. Esa habilidad de crear y de innovar no la tienen los profesores de matemática porque yo lo he visto a mis colegas. Están repitiendo y dando la parte que es tan abstracta que el alumno no lo ve y no le despierta el interés.

JE: (Párrafo, 71). Y otras cosas que van descubriendo y planteando algunos problemas. Por ejemplo: En la parte donde tiene que razonar con lógica de una forma que esta escrita, tomo ejemplos con los alumnos de la clase. Señalando a los alumnos Juan y Pedro, Juan hace un convenio con Pedro. Le dice que le va a pintar la casa y Pedro acepta; y le plantea la modalidad de pago de la siguiente manera: te pago mil bolivianos más un televisor si me lo pintas todo. Cuando Juan está ya en la tercera parte del trabajo total de la pintado, viene Pedro y le dice: "me encanta el trabajo y te voy a dar anticipado estos 70 bolivianos más el televisor", o sea, le quedaban las dos terceras partes para terminar. La pregunta es, ¿Cuánto costaba el televisor? Ahí, no va poder decir sea $x$ o sea y. No señor. Él va a usar fracciones nada más. Tienen que ser fracciones, y él piensa que por la tercera parte le está pagando 70 bolivianos más el televisor.

Pero si le ponen que Pedro tiene la edad de..., no, olvídate. No va a entender, sino quizás va a memorizar. En cambio, si se hace una cuestión relacionada con lo que conoce, si. Yo tengo ahí los problemas y si tu quieres te los puedo proporcionar. Los he copiado últimamente, no son problemas de física, son problemas de algebra elemental. Son bien simples. Pero son complicados al leer, por ejemplo, este del televisor es muy complicado. Pero sale en un plis plas. Entonces esa habilidad hace que se pueda descubrir a los genios y hacer que los alumnos se dediquen a las matemáticas porque lo han visto muy fácil, y les despierta el interés sin ir tanto a la parte teórica.

\section{AP: ¿En la película Stand and Deliver se reflejada todo lo que usted hizo?}

JE: (Párrafo, 72). Se puede usar la película. De lo que interpreta, un $90 \%$ de la película es verdad, pero el $10 \%$ es cine para llegar al público. Porque no se muestra mucha matemática en la película Stand and Deliver. 


\section{AP: ¿En el libro de Escalante: Best Teacher in America de Mathews?}

JE: (Párrafo, 73). Muy poco habla de matemáticas, muy poco, porque el autor que es un periodista, muy poco habla sobre las matemáticas, porque él, más está concentrado a la sorpresa que causa en estos jóvenes estudiantes que no tienen ningún futuro, ninguna esperanza y superaron las pruebas. El periodista, el escritor del libro quedó sorprendido por un joven que tenía más de cinco o seis hermanos vivía en un sólo cuarto y no tenía campo, dormían como sardinas y era sorpresivo que este muchacho que esté llevando calculo y se esté preparando para una competencia nacional o internacional, se esté preparando para un examen de Colocación Avanzada de Matemáticas, entonces quedó sorprendido, porque cuando lo ubicó y le formuló la pregunta ¿dónde haces tu tarea? Y le mostró y le dijo en la mesa de planchar, donde su mamá plancha la ropa para el vecino, ella gana así. Entonces, era una tabla y el hacía las tareas ahí. ¿Por cuánto tiempo vienes haciendo esto? Todo el tiempo decía. ¿Y no piensan cambiar esto algunas vez? Bueno será cuando sea profesional, mientras tanto no puedo exigir nada tengo que seguir con eso, entonces eso era lo que le llamó la atención al periodista, y el escritor dice como estos han llegado a tener ese amor, ese cariño, esa responsabilidad y ¿qué personalidad tenía éste profesor, para influirles esto?

JE: (Párrafo, 74). El periodista se aproximó y vino a la clase y me dijo: "yo he visto que algunos alumnos no tienen comodidades que otros tienen". "si" - le dije - de qué alumno me está hablando y me dijo fulano de tal. Y yo abrí la caja, porque estábamos así sentados como ahora. (En la sala de estudios de su casa de Cochabamba). El estaba sentado al frente de mi escritorio, yo abrí la caja y vio ahí un montón de latas. Latas de conservas, latas de Coca-cola, latas de jugos y la demás cosas. -Me dijo- ¿qué hace con las latas?- yo le dijeeso es lo que me traen los alumnos, algunas veces vienen a lo mejor no tienes para tomar tu desayuno cuando quieres comer o tienes sed aquí tienes las latas, sírvete. Así, las latas envasadas, eran de frescos que llamamos y el jugo de naranja, jugo de limón, jugo de uva. Justo entró un alumno y dijo ¿cómo está Kimo? Entró con toda confianza. Sírvete puso una lata en la mesa, gracias agarré y puse en la colección de latas, entonces me dijo -eso va a tomar - le dije- no, algunas veces uso con los mismos alumnos, después de haber trabajado por la tarde vienen dicen - voy a tomar agua o algo de jugo, entonces le invito, si de esa manera acumulo, entonces él quedó sorprendido y me dijo ¿que influencia tenia usted en este tipo de gente? y ¿como ha llegado a cambiarlos de esta manera? - Le dije- el trabajo constante, la práctica es la clave del éxito. Constantemente estoy buscando el clic (hace sonar con sus dedos) me ha fallado muchas veces, pero al final he conseguido después de un año o dos años.

JE: (Párrafo, 75). Cuando ya les tenía en el bolsillo no había nada más que jugar pin- pon con ellos. Eso era la forma, incluso veían los juguetes que yo usaba para enseñar, utilizaba estos para que ellos puedan entender. No es nada recomendable y te voy a hacer la demostración para que de sirve de algo. Porque tal vez no me vas a poder ubicar. Entras a la clase (Hace girar un 
huevo de plástico que se abre) estas formando el volumen. Te fijas es de rotación sobre el eje y (toma en posición vertical) del eje $x$ (ahora toma en posición horizontal). Pero forma una especie de copa. Has visto alguna vez un volumen así. Yo cuando era niño jugaba con esto un pedazo de tela o papel (sopla para hacer girar) así consigues el volumen. Tu no has visto a tu mamá cuando naciste te dio esto (saca un juguete y hace girar) ella te estaba enseñando el volumen. Este es el juguete de un niño (hace girar) y señalas al lado que tu querrás. Si tu no crees, ese es el volumen, ahora vas a entender lo que es el volumen (saca otro juguete) fíjate el disco que forma, entonces el primer método que voy a usar es el método del disco. Lo que buscamos es el disco, donde tu querrás el disco se va formar. Yo no sé si ustedes alguna vez han tomado el champán y algunos me decían si. Cómo abren, con el tirabuzón y saca el tirabuzón.

JE: (Párrafo, 76). Han inventado el tirabuzón viendo jugar a un niño- yo les hacía creer eso. Lo único que han inventado es esto y que al final es la altura y ellos lo han puesto otro nombre es el método del cilindro hueco, no se ve el disco y hace la explicación de cómo se puede sacar el corcho. Tiene que entrar hasta cierta altura eso es el radio si no entra hasta el medio yo no voy a poder sacar (y tira el tirabuzón con un sonido producido en su boca). Explica que en el cilindro hueco tienes que tomar el radio y si tú no lo pescas esto yo te voy a enseñar como hacer esto y saca otro objeto que tiene forma de $\mathrm{T}$. que lleva la letra $\mathrm{H}$ en un eje y indica que es la altura y el mango es el radio. $\mathrm{Y}$ tengo hechos de masa de papel y otras cosas. El arte está en que encuentres la altura y dibujas, y después te fijas el radio y es muy fácil ver que va rotar. Sólo un ejemplo y nada más y tiene 30 problemas de ahí del mismo dibujo (muestra sus leccionarios). La forma de innovar la enseñanza es con un poco de creatividad. La creatividad depende del profesor y está en función de su conocimiento a lo que el a aprendido, a lo que él a estudiado. Como yo he sido un tipo autodidacta entonces yo tenía muchos recursos.

\section{AP: ¿Puede mencionar algunas frases celebres de su autoría?}

1. La educación es billete al éxito

2. Ustedes entran al colego en pos de un gran ideal de triunfar de ser un gran profesional de ser positivo para la sociedad.

3. Pondero y alabo a la madre, la mamá es incomparable, la mamá sabe tu dolencia, sin que le digas que te duele, domina la cancha así que obedece a tu mamá. Obediencia.

4. Hay que seguir adelante, porque no está muerto quien pelea. La vida es diferente, una vez que has visto y has pasado el túnel y has visto la luz, cuidado está viniendo el tren, te puede atropellar. Refiriéndome tu vas a terminar tu trabajo y completar, pero alguien te va a poner la pared te va atropellar, entonces cuando ya has hecho todo lo que te han pedido, has cumplido con todo tus requisitos, viene un tren que te va atropellar, cuidado contemplación, tienes que estar preparado 
5. Ni te pongas, ni me preguntes la edad, la edad no se cuenta por los años que uno tiene, sino por las sonrisas que uno lleva.

6. Aquel que sabe, sabe y el que no sabe empleado público

7. Esto si tienes que saber, ponte la mano en el pecho y otro en cualquier lugar es muy fácil.

8. Hay muchos que entran a la escuela pero la escuela no les entra

9. Esto es tan sencillo que cualquier hijo de vecino sabe

10. En los conceptos, a los matemáticos voy haciendo algunos cambios introduciendo apelativos de acuerdo al tipo de problema que hacemos. Dividir por cero es pecado mortal te condenas, yo he visto por ahí muchos se han condenado.

11. Has todo lo posible para ser primero, porque el segundo cualquiera puede ser, todo el sacrifico que hacen es para ser el primero, la gente piensa que no puedes tienes que demostrar que tu si puedes y eso hace honor a tu nombre, a tu apellido, a tu barrio y a tu país, eso te va dar más y te vas a sentir orgulloso.

12. The day someone quits school he is condemning himself to a future of poverty. 


\section{ANEXO 2: Entrevista escrita de opinión}

Cochabamaba, 15 de junio 2008

\section{P. ¿Qué piensa usted de las matemáticas como ciencia?}

R. Los conquistadores que llegaron a América (1492) usaron: ESTIMACIONES (Matemáticas), CONSTELACIONES para orientarse, Colón Conocía o tenía principios matemáticos (estimaba) pero no usaba como CIENCIA, sustituyó este adjetivo con su habilidad y experiencia de ser un gran navegante.

- VALE UN POTOSI - dicho español que refleja la riqueza del CERRO RICO de Potosí que:

$$
1545<\mathrm{x}<1825
$$

Produjo la impresionante cantidad de $\mathbf{4 6 . 0 0 0}$ toneladas de planta pura suficiente para construir un puente desde Potosí (Bolivia) a Madrid (Espafia). Este es el valor y un poco más que tiene las matemáticas como ciencia.

El hombre primitivo no sabía leer no tenía un alfabeto pero si usaba matemáticas cuando con los dedos de la mano indicaba cantidades sin tener un sistema de numeración.

- Los PIELES ROJAS para contar usaban dedos de una mano y cuando llegaban a 5 usaban los dedos de la obra mano, y cuando llegaban a 10 usaban los dedos de los pies; cuando se les terminaba decían INDIO COMPLETO.

- En la civilización AYMARA el pastorcito llevaba una bolsita (chuspa) en la cintura y en ella estaban el número de piedrecitas igual al número de ovejas del rebaño. Al final de la jornada sacaba de la chuspita una piedrita cada vez que entraba una oveja al corrar, [1 - 1] (correspondencia de uno a uno) tal que entrando la última oveja él estaba sacando la última piedrita, lo contrario significaba que la ecuación no verificaba, había que buscar la oveja perdida.

- Estas referencias son testimonio de los inicios de la matemática como ciencia. 
En este tipo de análisis es facil ver en la cultura TLAHUNACOTA la puerta del sol presenta la geometria plana de Euclides, se observa el concepto de simetrib, el circulo, la circunferencia, el cubo, el cuadrado, las rectas paralelas, perpendiculares, los ángulos, etc. esto muestra que esta civilización conocía esta ciencia no se sabe si la puesta del sol y los palacios decorados con monolitos tallados a mano son contemporáneos con las piramides de Egipto pero si muestran la evolución de la ciencia del pensamiento.

Los INCAS seguian las posiciones del satélite Luna para sembrar mientras que Pitágoras contribuidor de esta ciencia en su secta vegetariana sacrificaba bueyes a los dioses para acelerar el descubrimiento de su teorema.

Euclides enfrentaba a su rey Ptolomeo por negarle atajos para la mejor comprensión del cálculo matemático. Newton y Leibniz disputaban la paternidad de la invención del Cálculo Diferencial ayudaban al progreso de la ciencia del pensamiento lógico. ¿Por qué prestar atención a remotos intentos que hoy dia han quedado ampliamente sepultados por el sistema binario y la conquista del espacio?

Simple, lo que es valioso en la matemática antigua ya five incorporado en la matemática actual, entonçes por qué no olvidarlo. No, no se puede, debemos recordar a los descubridores de esta ciencia, la influencia de los Indúes creadores o descubridones del CERO le pusieron la música y la letra a la NUMERACIÓN DECIMAL y los italianos pusieron en prbetica en la Física, Quimica, Biología. Recordemos que somos herederos de las culturas: Griega, Romana, Árabe para ellos posiblemente la matemática como ciencia no era esencial para nosotros es imposible hablar de ciencia sin mencionar a genios como Arquimides, Fermat, Descartes, Alkhwarizmi.

Hoy la ciencia de los números nos permite vivir la ERA DIGITAL. 
P. ¿Quéc es lo que piensa sobre la matemátiç como objeto de casếanza?

R. La matemática, como objeto de enserianza es quitar el velo y gozar de sus cacantos, su escritura, (simbolos) conceptos (lenguaje) preguntas y porque no decir su evolución, su historia, todo esto revela la belleza de esta ciencia del pensamiento. Les digo a mis alumnos - Muchas de las cosas que nos rodean pueden ser descritas matemáticamente -, aun conceptos matemśticos son inberentes en la estructura de cellulas vivientes.

La matemática tiene muchas sorpresas: rompe - cabezas, trucos e interesantes ideas en el arte de ensetar y en el proceso de aprender esta ciencia es imperativo leer despocio, no sorprende cuando uno no entiende algunos términos adquirir el bábito de tener a mano el lápiz y el papel, encontrar la palabra clave y tratar de visualizar el problema haciendo un skech o graficando para entender mejor. Tratar de entender lo que lee, asi Si n es un número entero mayor que cero y n es divisible por 5 . Demostrar que descomponiendo el quociente en 5 numeros consecutivos la suma de estos nos da n solución.

Las palabras claves están subrayadas.

Sea $n=625$

Entonces: $\frac{\mathrm{n}}{\mathrm{s}}=125$.

El truco esta en quitar 2 unidades al quociente $125-2=123$.

Finalmente sumas 5 numeros consecutivos a partir de 123. Es decir:

123

$+124$

125

126

127

625

Prof. Jaime A. Escalante 




- Los signos matemáticos permiten ir más allá de lo que la mente puede cuantificar.

- Sin exagerar decimos que los simbolos matemáticos están en segundo lugar después del alfabeto y son instrumentos del progreso humano.

- El desplazamiento de la luz en el espacio es mayor que el símbolo que se usa para describir la trayectoria que describe durante su viaje.

- Esta ecuación describe una copa de cristal. Así la ecuación $x^{2}-2 x-8=0$ intercepta el eje de $x^{2}$ 's cuando $x=4 y x=-2$. Observe:

$$
\begin{array}{r}
x^{2}-2 x-8=0 \\
x^{2}-2 x=8 \\
x(x-2)=8 \\
(x-0)(x-2)=8 \\
\text { Necesito un pn. }
\end{array}
$$

Reemplazando en (")

$$
x= \pm 3+1 \quad\left\{\begin{array}{l}
x=4 \\
x=-2
\end{array}\right.
$$

Graficando:

$$
\begin{gathered}
-2\left(\frac{1}{2}\right)=-1 \\
\text { Llamamos: } \\
u=x-1 \\
x=u+1 \quad(\bullet) \\
\text { pn: } \begin{array}{c}
(u+1)(u-1)=8 \\
u^{2}-1=8 \\
u= \pm 3
\end{array}
\end{gathered}
$$

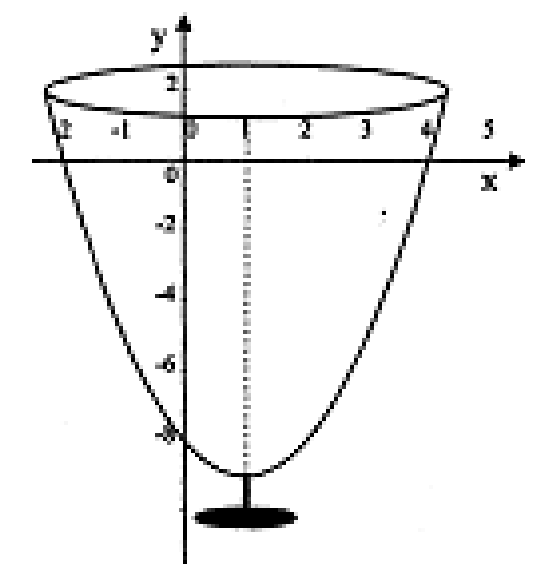




\title{
ANEXO 3: Premios y Reconocimientos
}

Medal Presidential of Excellence in Education

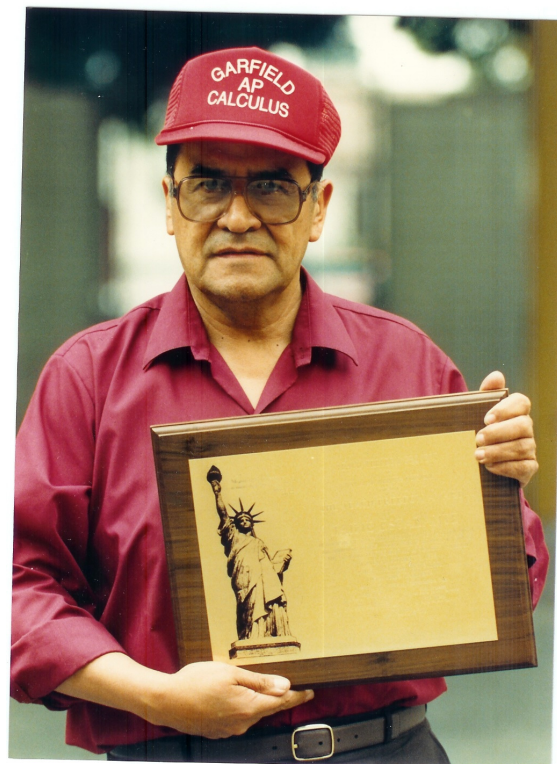

Premio Internacional de Educación "Andrés Bello"

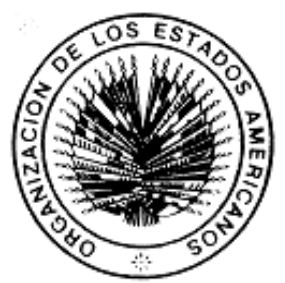

Premio Jnteranterícano đe êucación

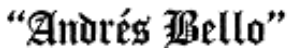

F] Consejo Interamericano para la Educación, la Ciencia y la Cultura de h Organitación de los tsilados imericanos olonga a

\section{Jaime $\mathbb{E}$ šalante}

\author{
Mención Hononifica \\ correspondiente al aio mil novecienlos noventa y uno \\ como reconocimicnto a la cficacia del mélodo por él creado \\ para la enscrianza de la malemálica \\ ce el nivel de ha coduceción sccundarie. \\ J beunfeanl \\ Ciganimatón de loe Pslados Anericonos

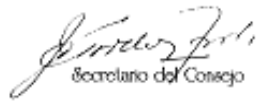 \\ Washington, D.C., 13 de enero de 1992
}


El Mural de Jaime Escalante y Edward James Olmos

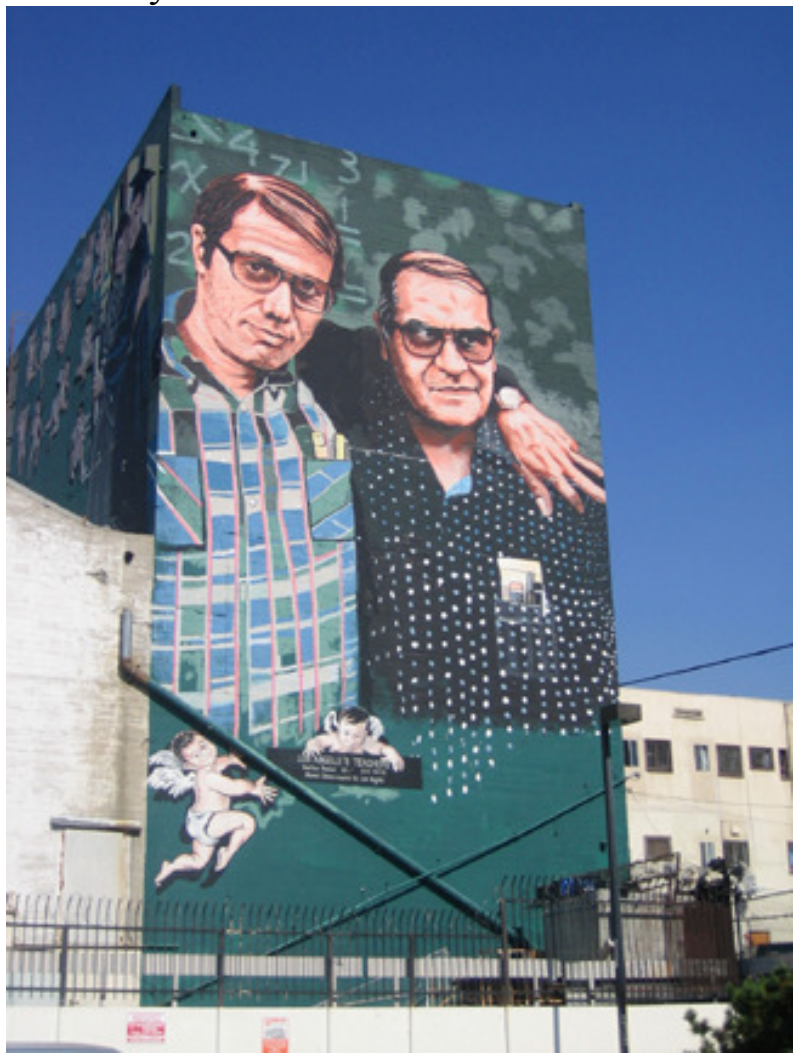

Un enorme mural de Escalante y Edward James Olmos, quien lo personificó en la película Stand and Deliver, en la intersección del Boulevard Willshire y la Calle Alvarado, en el distrito de Westlake justo al noreste del centro de Los Angeles.

\section{Escalante asesor de la NASA}

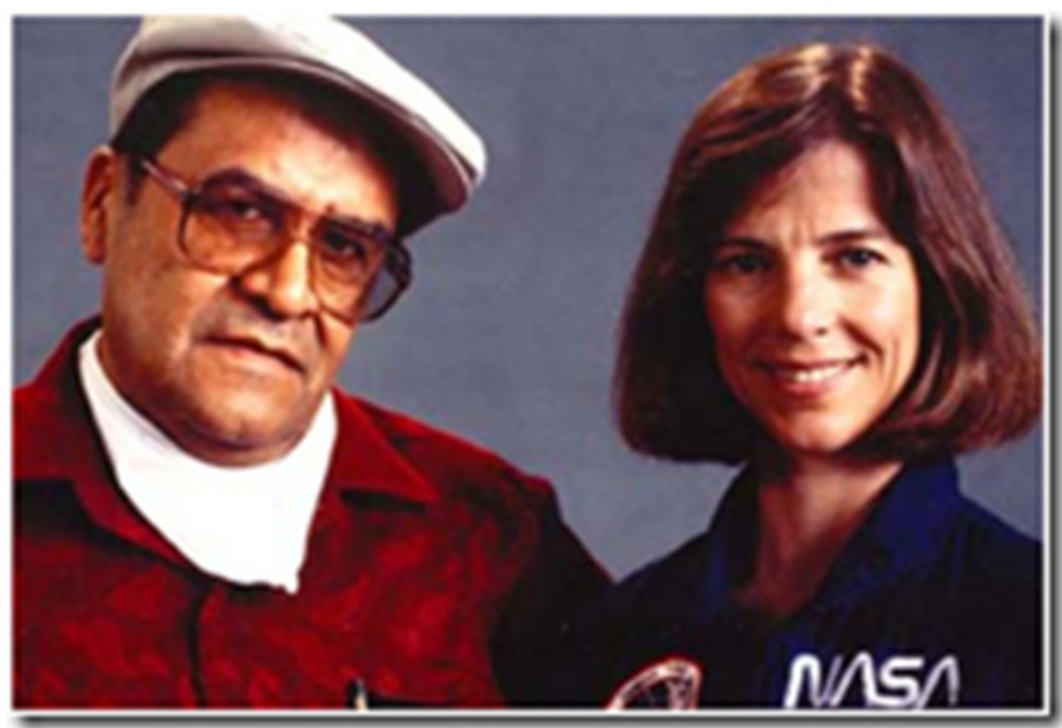

Figura: el maestro, en EEUU en los 80, junto a una astronauta de la NASA 


\section{ANEXO 4: Diplomas de Doctor Honoris Causa}

EMI Engineering \&Management Institute

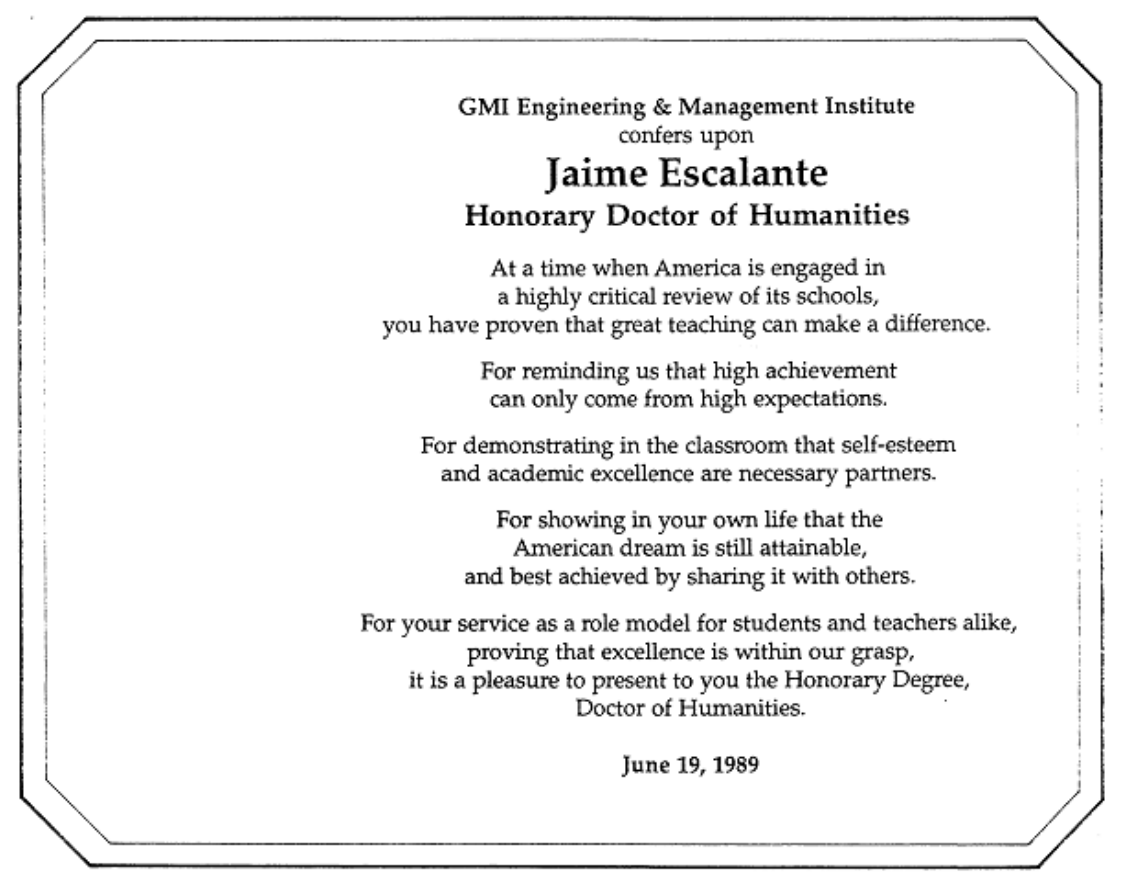

University of South Carolina

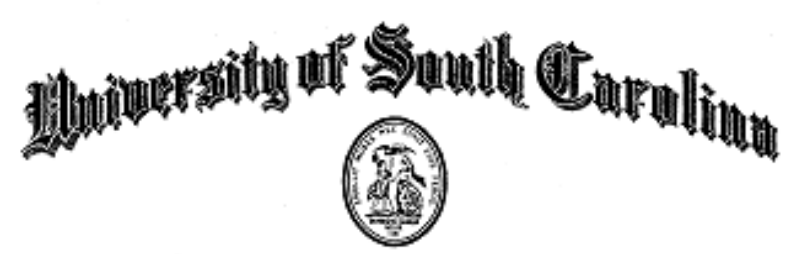

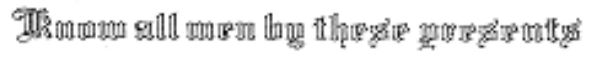

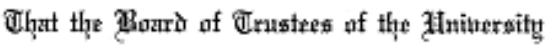

hुas conferrè upm

3) tatme Alfunsa Escalante Butierrey

the tegere of

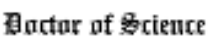

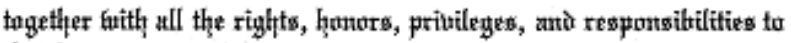
that Detgres appertainitg.

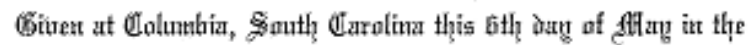

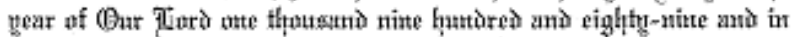

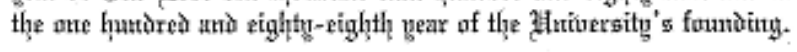
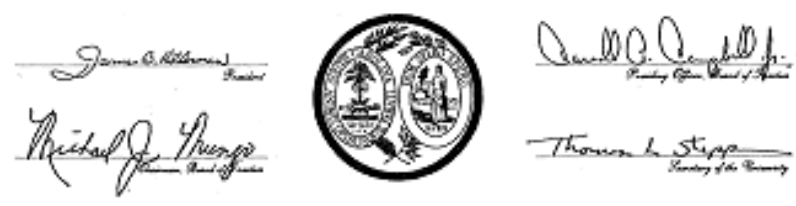
St. John Fisher College

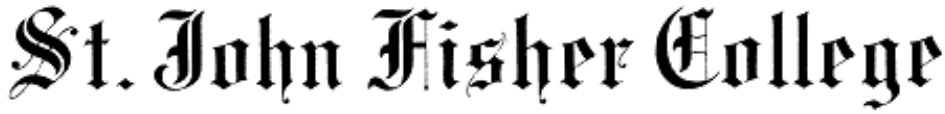

herehọ ronfers upon

\author{
Jaime 位rcalante
}

the tregree of

\section{但netor of Hhumane Tietters}

together frith all thie rights, prinileges and ḩonors appertaintung thereto.

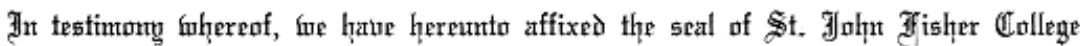
and the signtutures of the offiters therenf.

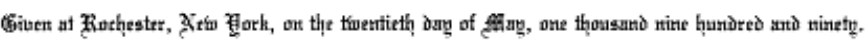
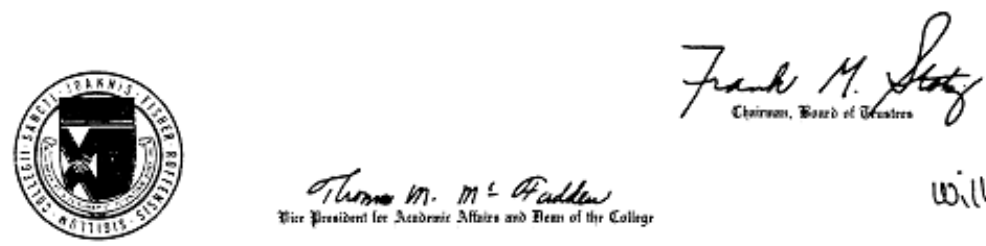



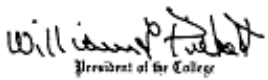

The Trustees of The California State University

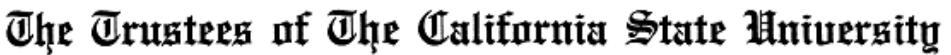

on recommendàtion of tḩe

herehty confer upon

\section{Jatame A. Ëratante}

Thye Humurary Begree of

\section{但actor af Humane Tietterg}

with all the rights. privileges and hanars pertaining thereto

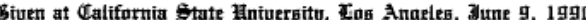

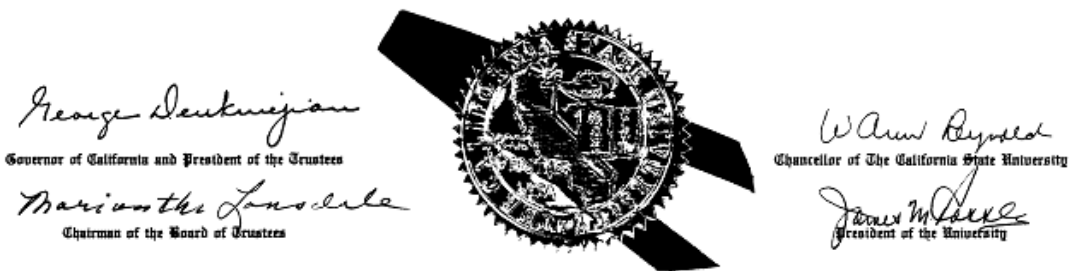


Concordia University

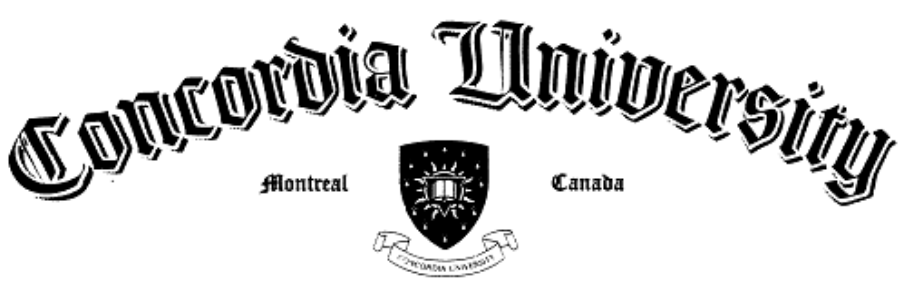

In all to whom thege presents mag come, greetings.

Whe the Chancellor, the Governors, and the Senate of the Tlowiversily assembled

in solomn convosation do hereby admit the eminent. learned. and distanguished.

Jainte Egralante

to the degree of

Burtur of Taums

with all the rights and privileges chereunto appertaining.

$3 n$ testimunn wherenf we have set our hands and the seal of this Olniversily

on this 12 th day of frome. 1990.

binngive Gandex Greece anat

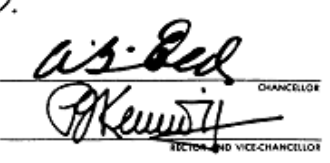

Wittenberg University

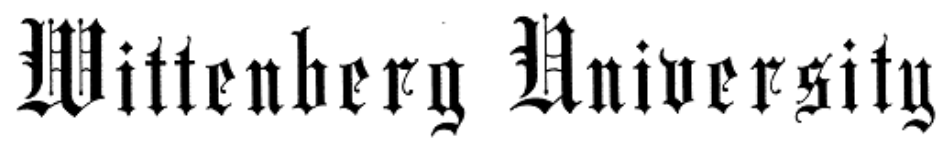

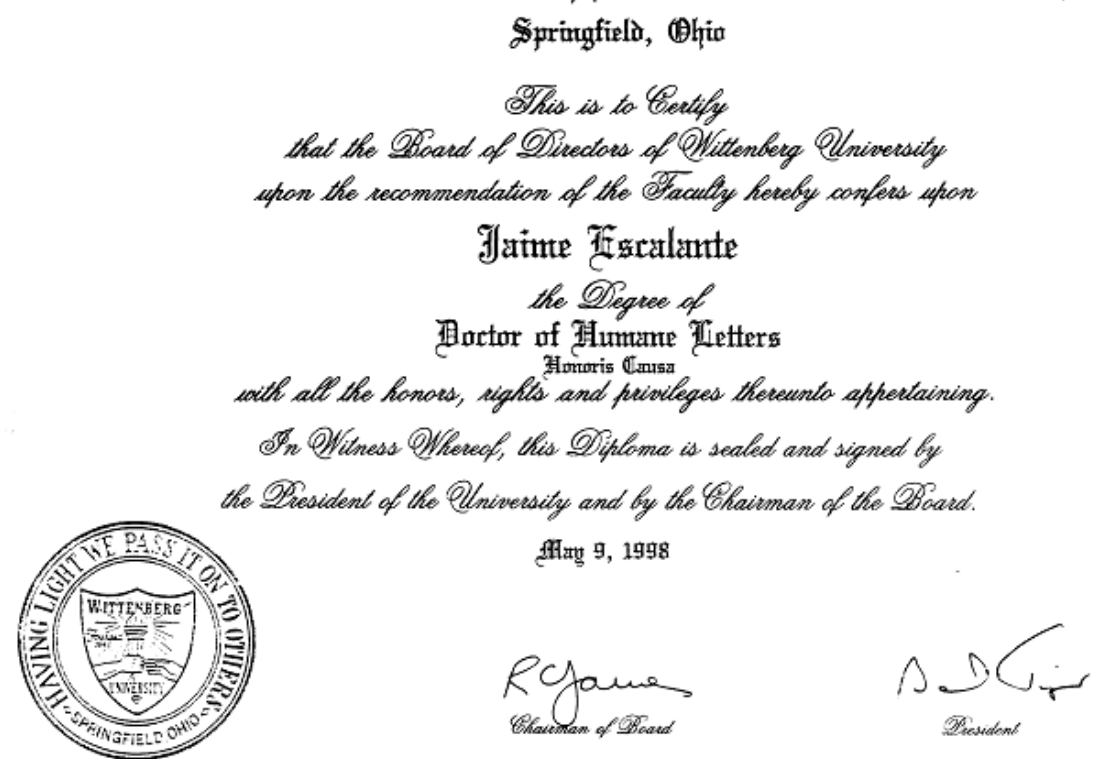


University of Northern Colorado

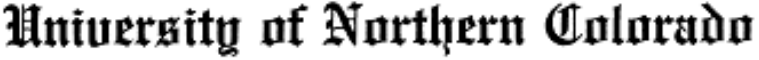

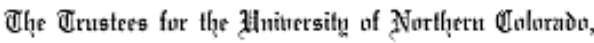

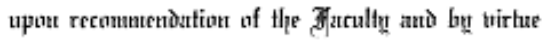

of the suthurityू in them uesteò, hạıe comferrè upon

\author{
Inantie Tiscalante \\ the 更egret of \\ Eactor of Jatus
}

fwith atll the rights, unto prinileges, tharreututo appertatinting.

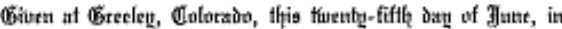

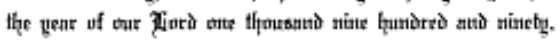

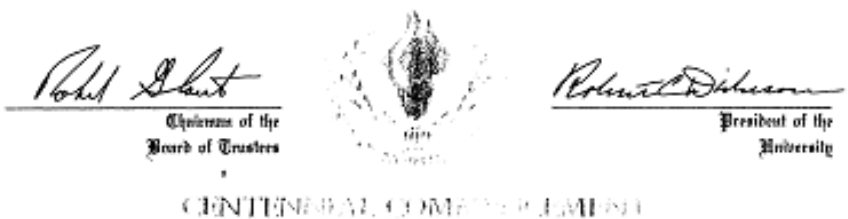

Susquehanna University

THE PRESIDENT AND DIRECTORS OF

\section{SUSQUEHANNA UNIVERSITY}

TO ALL TO WHOM THESE LETTERS SHALL CONE

GREETING IN THE LORD

BE IT KNOWN THAT WE RY VIRTUE OF AUTHORTY GRANTED BY CHARTER FROM THE COMMONWEALTH OF PENNSYLVANIA AND IN SOLEMN RECOCNTION OF DISTINGLISHED SERVICE DO HEREBY CONFER UNON

\section{JAIME FSCALANTE}

THE HONORARY DEGREE OF

DOCTOR OF EDUCATION

WTTH ALL THE RICHTS, PRIVILEGES AND IMMLNITIES THEREUNTO APVRTAINING; IN WITNESS WHEREOF WE HAVE CALSED THIS CERTIFICATE TO BE SIGNED BY THE DLLY ALTHORIZED OFFICERS OF THE UNIVERSITY AND SEALED WITH OLR CORPORATE SEAL.

GIVEN AT SELNSGROVE, PENNSYLVAIA. THIS FOCRTEENTH DMY OF XIN TV THE YEAR OF OUR, LOSD, TWO THOCSAND AND SEX AVD

OF TEE UNTVRSSTYY THE ONE GUNDRFD AND FORT:EIGHTH.
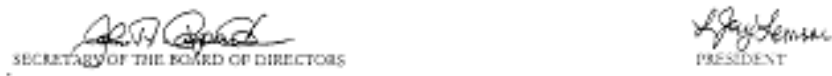


\section{ANEXO 5: Recortes de periódicos}








\section{$2 / \mathrm{de}$ cot 06}

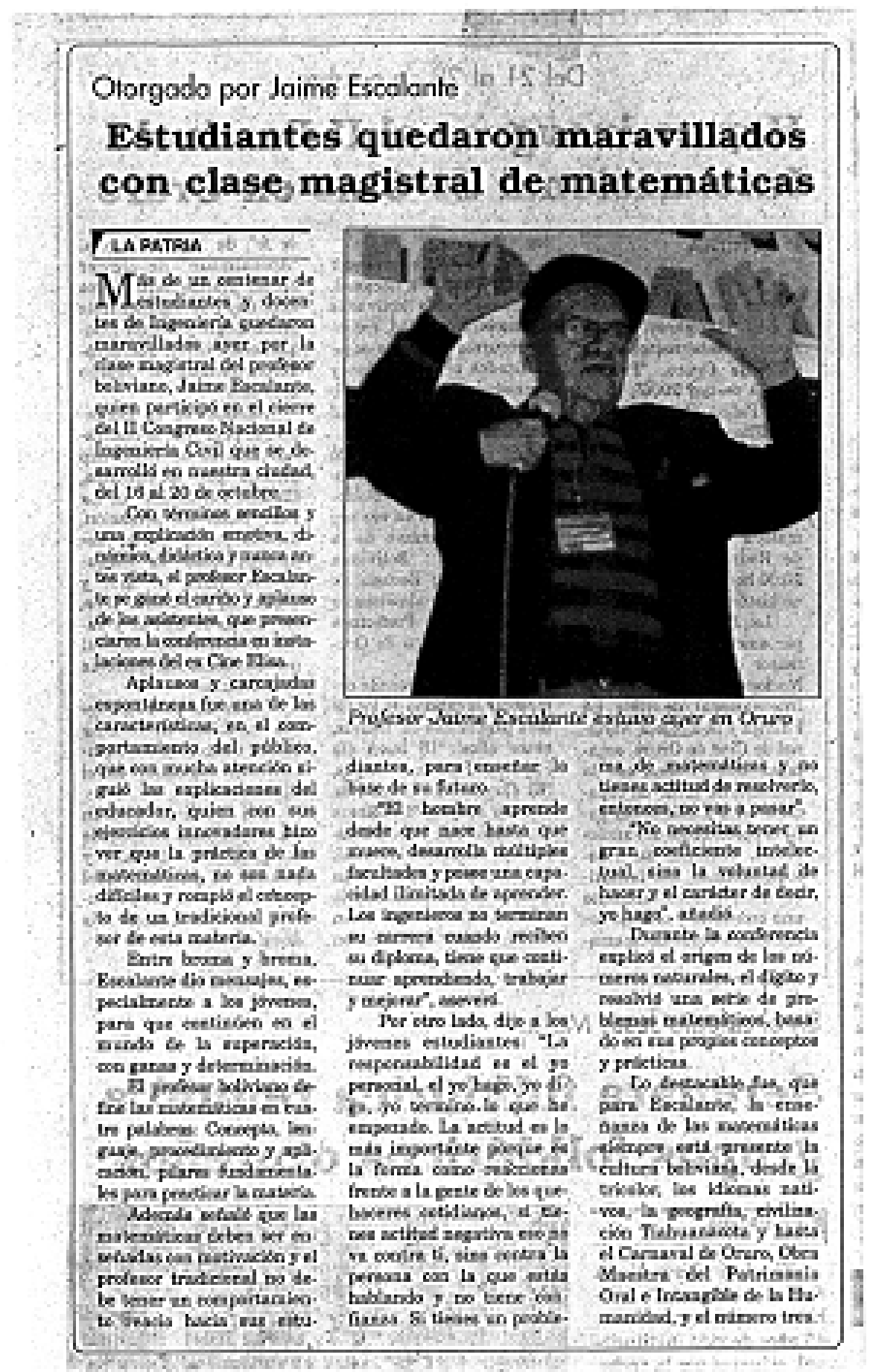




\section{ANEXO 6: Manuscritos}

\section{PRIMER DÍA DE CLASES}

No hay ninguna fórmula mágica a mano que te permita ver el camino y te lleve al ÉXITO en matemática, pero sí puedo sugerir que sigas cuidadosamente las instrucciones del profesor (Maestro), esto ayuda al estudiante que sólo tiene que practicar cada dia.

\section{LA PRÁCTICA ES LA CLAVE DEL ÉXITO}

Esto te ayuda académicamente, tal vez a pasado por tu mente que:

- Nunca he sido bueno en matemáticas.

- Todo un tiempo he odiado matemáticas.

- Las matemáticas me asustan, no me gustan.

- Con frecuencia me olvido las reglas, leyes de esta ciencia o no se cómo usarlas.

- Tengo dificultades en entender al instructor por consiguiente no hago las tareas, no quiero preguntar, tengo vergüenza.

A todo esto le llamo: "Ansiedad Matemática" que tu mismo creas, por eso te aconsejo y sugiero que elimines, estos pensamientos con un criterio positivo y para esto sólo necesitas

\section{GANAS}

Te vas a sorprender, ten en mente

\section{QUE NADIE ES MEJOR QUE TU}

Vivimos en la ERA DIGITAL, esto significa que no debes levantar las mano, no te rindas, aprovecha esta oportunidad, ten confianza, elige una carrera que va de acuerdo al avance de la tecnología con una mejor remuneración económica. LAS MATEMÁTICAS están en todas las otras ciencias. Recuerda que tu obligación y responsabilidad es beneficiarte con el aprendizaje de esta ciencia. 


\section{TU ERES LO MEJORCITO QUE TENEMOS}

Para esto necesitas:

- BUENA ASISTENCIA.

Como base primordial y con el objeto de alcanzar el éxito debe tener puntualidad, de acuerdo a mi experiencia estadísticamente se ve que las calificaciones en esta clase mejoran con una buena asistencia.

Cada que faltas a una clase pierdes información vital que te ayuda en la continuidad del aprendizaje, cuando faltas, pierdes el hilo de los conceptos básicos, las notas que te ofrece tu companiero sólo sustituyen las calificaciones bajas en la materia.

\section{- PARTICIPACIÓN EN LA Clase}

Tienes la obligación de ser parte activa en la clase, siéntate adelante, formula preguntas, contribuir en la solución de los problemas o solución de las tareas es tu responsabilidad, muestra interés en el trabajo en clase, no seas un simple espectador, tu participación aumenta tu conocimiento, hazte un favor a ti mismo participa y verás que

\section{SI SE PUEDE}

\section{- REPASO DEL NUEVO MATERIAL}

Cada día antes de entrar a la clase toma unos minutos para refrescarte de lo aprendido en la clase anterior (continuidad en el aprendizaje). Un vistazo a lo visto anteriormente para familiarizarse con lo aprendido te familiariza con la terminología y el lenguaje matemático.

\section{- LEER EL TEXTO O LOS APUNTES}

Paciencia, lee cuidadosamente el tópico o discutirse (estudiar), leer un texto de matemáticas no es lo mismo que leer una novela un libro de 
historia, psicología o sociología, leer un libro de matemáticas toma más esfuerzo y tiempo. La matemática tiene su propio lenguaje, signos y palabras claves.

\section{- TOMAS NOTAS}

Es importante tomar notas de la clase notas que tengan significado principalmente debes ser activo, escuchar bien lo que dice el profesor y estar listo para formular preguntas si algún concepto no esta claro. Escribe ideas importantes, fijate en los ejemplos que se resuelven. $\mathrm{Si}$ tratas de escribir todo lo que dice el instructor no ganes terreno, anota solo los conceptos que crees son importantes hazlo con letra legible. (Demostraré objetivamente).

\section{- BUSCA AYUdA}

Encontrar la ayuda correcta y en el tiempo indicado es el ingrediente de mucha importancia para el éxito en álgebra, un poco de esfuerzo por tu parte mejora tus habilidades en esta ciencia; presta atención especialmente en el trabajo de laboratorio y las ayudas audiovisuales que vamos a usar.

\section{- TAREAS}

Recuerda que desarrollas tus habilidades de aprendizaje cuando practicas matemáticas, es como aprender a tocar un instrumento musical o dedicarse a un deporte, debes asignar un tiempo exclusivamente para hacer tus tareas y ejercicios en matemáticas.

\section{LA PRÁCTICA ES LA CLAVE DEL ÉXITO}

$$
\text { EL FIN COAONQ } 2 \text { OBLA }
$$




\section{ANEXO 7: Planes de clase}

TÓPICO 5. ECUACIÓN DE SEGUNDO GRADO.

INSTRUCCIONES. Estudie los ejemplos, trabaje cada problema, verifique su respuesta, fijese en los errores, si usted tiene dificultades en entender pregunte y este seguro del tópico o concepto.

A. UNA ECUACIÓN CUADRÁTICA ES UNA ECUACIÓN CUYO TÉRMINO DE ALTO GRADO ES DE SEGUNDO GRADO TAL ECUACIÓN ES TAMBIÍN LLAMADA ECUACIÓN DE SEGUNDO GRADO O FUNCIÓN CUADRÁTICA.

- Ejemplo:

a) $4 x^{2}+5 x-7=0$

b) $\frac{3}{4} x^{2}=\frac{2}{3} x+4$

c) $x^{2}-9=0$

d) $f(x)=7 x^{2}-21 x$

Forma general o forma estándar.

$$
\left\{\begin{array}{l}
a x^{2}+b x+c=0 \\
a x^{2}+b x+c=f(x), \quad a \neq 0
\end{array}\right.
$$

donde $a, b$ y $c$ son $\mathbb{R}$.

Nota. Si $a=0$ y $b \neq 0$, entonces la función $f(x)$ es una función lineal $f(x)=b x+c$. Si $a=0$ y $b=0$ entonces la función es una constante $f(x)=\mathrm{c}$.

[ Ejemplo:

Si:

$$
(4-x)(x+2)=0
$$

Entonces:

$$
\begin{array}{cl|l}
\hline 4-x=0 & & x+2=0 \\
-x=-4 & \mid(-1) & x=-2 \\
x=4 & &
\end{array}
$$


Observación: Tiene que haber cero en el miembro derecho de la ecuación para resolver por factorización.

- Ejemplo:

Sea:

$$
4 x^{2}=2 x
$$

Volvemos a escribir como:

\begin{tabular}{r|r}
$4 x^{2}-2 x=0$ \\
$2 x(x-1)=0$ \\
\hline $2 x=0$ & $x-1=0$ \\
$x=0$ & $x=1$
\end{tabular}

Del 1 al 12 resolver por factorización.

1. $x(x-5)=0$

8. $x^{2}=2-x$

2. $x^{2}-3 x=0$

9. $2 x^{2}=5-9 x$

3. $7 x^{2}+14 x=0$

10. $x^{2}+x=6$

4. $6 x(x-1)=0$

11. $x^{2}+16=8 x$

5. $(x-3)(x+2)=0$

12. $6 x^{2}+7 x=3$

6. $(2 x+1)(3 x-2)=0$

7. $x^{2}-x-12=0$

B. CUANDO EL FACTOR COMÚN ES UN MONOMIO. ESTE CASO ES LA APLICACIÓN DE LA LEY DISTRIBUTIVA.

$$
a b+a c=a(b+c)
$$

Ejemplo:

$$
\begin{aligned}
(x-a)(x+b)^{2} & =(x-a)(x-c) \\
(x-a)(x+b)^{2}-(x-a)(x-c) & =0 \\
(x-a)\left[(x+b)^{2}-(x-c)\right] & =0
\end{aligned}
$$

Sea: $p=(x+b)^{2}-(x-c)$

$$
(x-a) p=0 .
$$

Donde $p$ se puede resolver completando cuadrados. 
Ejemplo:

$$
\begin{aligned}
(x+1)(x+3)^{2}+(x+1)(x-4) & =(x+1)\left[(x+3)^{2}+(x-4)\right] \\
& =(x+1)\left[x^{2}+6 x+9+x-4\right] \\
& =(x+1)\left(x^{2}+7 x+5\right) \\
& =(x+1) p
\end{aligned}
$$

Del 13 al 15 , hallar $p$ para completar la ecuación.

13. $(x-2)(x-1)^{2}-(x-2)(x+3)=(x-2)(p)$

14. $(x+4)(x-3)^{2}+(x-4)(x-3)=(x-3)(p)$

15. $(2 x-1)(x+1)-(2 x-1)^{2}(x+3)=(2 x-1)(p)$

16. $(x-1)(x-2)^{2}+(x-1)(x+1)=(x-1)(p)$

C. USANDO LA FÓRMULA:

$$
x=\frac{-a \pm \sqrt{b^{2}-4 a c}}{2 a}
$$

es importante interpretar la cantidad sub-radical $D=b^{2}-4 a c$. La interpretación gráfica de una ecuación de segundo grado es una parábola que depende del valor de $D$. Así:

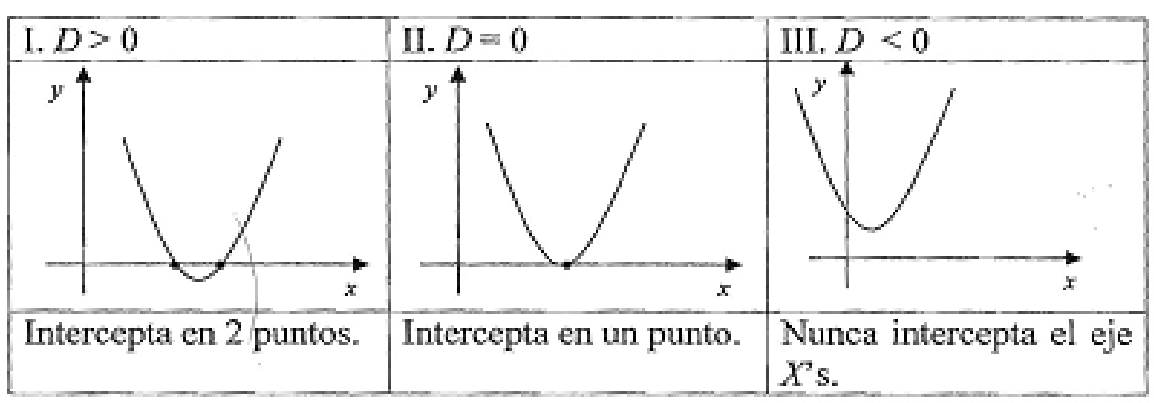

Por esta razón las soluciones de una ecuación se conocen como: ceros de función, raices de ecuación o simplemente soluciones. 
Del 17 al 22, halle el valor de $D$ para determinar el número de ceros de la función.
17. $f(x)=2 x^{2}-4 x-5$
20. $f(x)=4 x^{2}-8 x+4$
18. $f(x)=x^{2}+5 x+8$
21. $f(x)=3 x^{2}+2 x-7$
19. $f(x)=x^{2}+x+2$
22. $f(x)=x^{2}+4 x+4$
D. USO dE LA FórMULA PARA RESOlVER ECUACIONES QUE NO SON FACTORIZABLES.

Ejemplo:

$$
\begin{aligned}
& x^{2}+4 x+4=7 \\
& x^{2}+4 x-3=0 \\
& \quad A=1 \quad B=4 \quad C=-3 \\
& D=16-4(1)(-3)=28=4(7) \\
& x=\frac{-4 \pm \sqrt{4(7)}}{2}=\frac{-4 \pm 2 \sqrt{7}}{2} \\
& x=-2 \pm \sqrt{7}
\end{aligned}
$$

Así las dos raíces son:

$$
-2+\sqrt{7} \text { y }-2-\sqrt{7}
$$

- Ejemplo:

Las dos raices son:

$$
\begin{aligned}
& 3 p^{2}-2 p=3 \\
& 3 p^{2}-2 p-3=0 \\
& \quad A=3 \quad B=-2 \quad C=-3 \\
& \quad D=4-4(3)(-3)=4(1+9)=4(10) \\
& p=\frac{-(-2) \pm \sqrt{4(10)}}{2(3)}=\frac{1 \pm \sqrt{10}}{3}
\end{aligned}
$$

$$
\frac{1}{3}(1+\sqrt{10}) \quad \text { y } \quad \frac{1}{3}(1-\sqrt{10})
$$

Del 23 al 28, resolver las ecuaciones indicadas.

23. $4 y^{2}+4 y-2=0$

24. $3 x^{2}=5 x+4$

25. $3 n^{2}-8 n=-2$

Prof. Jatme A. Fscalante

$$
\begin{aligned}
& \text { 26. } x^{2}-4 x=7 \\
& \text { 27. } x^{2}+2 x=2 \\
& \text { 28. } 2 x^{2}+2 x=3
\end{aligned}
$$


E. INECUACIONES (DESIGUALDADES) CUADRÁTICAS.

Ejemplo:

Hallar la solución algebraica y geométrica de:

$$
x^{2}-4 x>-3
$$

Re-escribimos

$$
x^{2}-4 x+3>0
$$

Continuación.

Primero resolvemos la ecuación:

$$
\begin{aligned}
& x^{2}-4 x+3=0 \\
& (x-3)(x-1)=0 \\
& \hline x=3 \quad x=1
\end{aligned}
$$

3 y 1 son puntos criticos, buscamos $p>0$

Análisis:

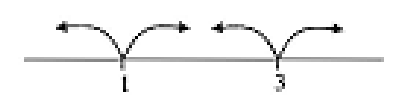

\begin{tabular}{c|c|c|c} 
& $x-3$ & $x-1$ & \\
\hline$x<1$ & - & - & + \\
\hline$-1<x<3$ & - & + & - \\
\hline$x>3$ & + & + & +
\end{tabular}

Solución:

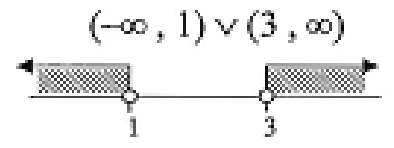

Del 29 al 34 resolver gráficamente y algebráicamente.

29. $x^{2}-x-6>0$

32. $x \geq x^{2}$

30. $x^{2}-2 x<0$

33. $2 x^{2}+x-1>0$

31. $x^{2}-2 x<-1$

34. $x^{2}-x+2>0$

F. Completar CuAdrados $(P)$

$x^{2}+b x$, será cuadrado perfecto (de un binomio) cuando se le suma un número c. 
Se halla $c$ si se divide el coeficiente numérico de $x$ por 2 y luego se eleva al cuadrado.

Así: $\quad c=\left(\frac{b}{a}\right)^{2}=\frac{b^{2}}{4}$

Entonces:

$$
\begin{aligned}
x^{2}+b x+c & =x^{2}+b x+\left(\frac{b}{2}\right)^{2} \\
& =\left(x-\frac{b}{2}\right)^{2}
\end{aligned}
$$

Ejemplo:

$$
x^{2}+5 x
$$

La mitad de 5 es $\frac{5}{2}$ y $\left(\frac{5}{2}\right)^{2}=\frac{25}{4}$, lo que se debe suma a $x^{2}+5 x$ o sea:

$$
x^{2}+5 x+\frac{25}{4}=\left(x+\frac{5}{2}\right)^{2}
$$

Ojo, si el coeficiente de $x^{2}$ no es 1 entonces es necesario factorizar.

Ejemplo:

$$
3 x^{2}-x=3\left(x^{2}-\frac{1}{3} x\right)
$$

mitad de $-\frac{1}{3}=-\frac{1}{6}$ y $\left(-\frac{1}{2}\right)^{2}=\frac{1}{36}$

asi: $\quad x^{2}-\frac{1}{3} x+\frac{1}{36}=\left(x-\frac{1}{6}\right)^{2}$

Finalmente:

$$
3\left(x^{2}-\frac{1}{3} x+\frac{1}{36}\right)=3\left(x-\frac{1}{6}\right)^{2}
$$

Para mantener la igualdad $\frac{3}{36}=\frac{1}{12}$, debe ser añadido a $3 x^{2}-x$ para completar cuadrados. 
Del 35 al 38 complete cuadrados e indique el término que se debe añadir.

35. $x^{2}-10 x$

36. $x^{2}+x$

37. $x^{2}-\frac{3}{2} x$

38. $2 x^{2}-8 x$

G. LA GRÁFICA DE UNA FUNCIÓN CUADRÁTICA ES UNA PARÁBOLA.

I. La gráfica de $f(x)=a x^{2}$

Si $|a|=1$, la parábola es unitaria $(0,0)$ es el vértice y el eje de y's es el eje de simetría.

Si $|a|<1$ la gráfica es gorda.

Con respecto a $f(x)=x^{2}$.

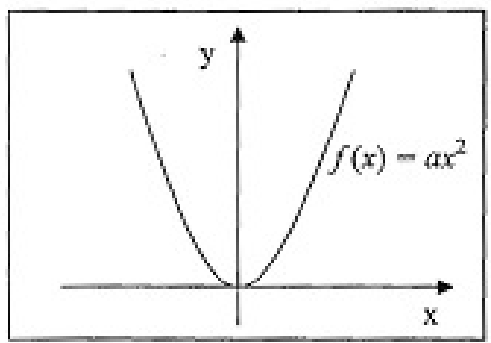

Si $|a|>1$ la gráfica es fiaca

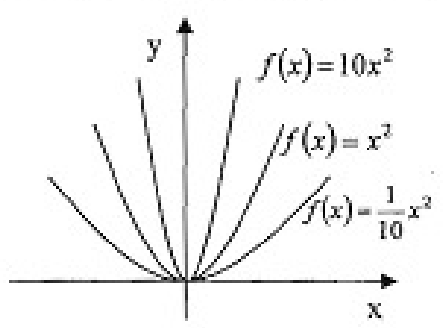

II. La gráfica de $f(x)=a x^{2}+h$, la parábola que representa esta función mueve el vértice abajo o arriba del eje de x's dependiendo del signo de $h$.

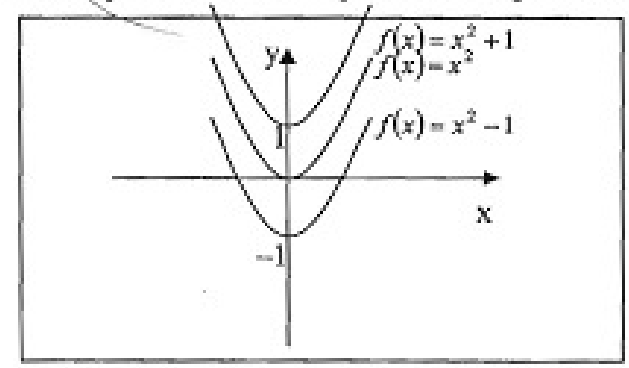


III. La gráfica de $f(x)=a(x-h)^{2}$, la gráfica de esta función es una parábola cuyo vértice se ha movido a la derecha o del eje de y's así.

a) $f(x)=x^{2}-6 x+9=(x-3)^{2}$

b) $f(x)=x^{2}+8 x+16=(x+4)^{2}$

c) $f(x)=x^{2}-2 x+1=(x-1)^{2}$

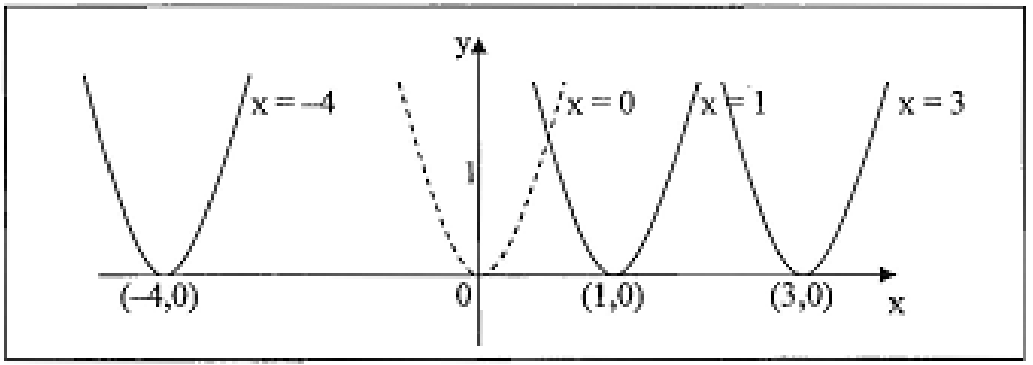

En general la gráfica de $f(x)=a(x-h)^{2}$ es la gráfica de $f(x)=a x^{2}$ moviendo $h$ unidades horizontalmente. Si $h>0$ el vértice de la gráfica se mueve a la izquierda. Si $h<0$ el vértice se va a la derecha.

IV.La gráfica de $f(x)=a(x-h)^{2}+k$. Esta función representa la combinación de los casos II y III.

$$
f(x)=a(x-h)^{2}+k
$$

Representa $f(x)=a x^{2}$ moviéndose $h$ unidades horizontalmente y $k$ unidades verticalmente. Así

$$
f(x)=(x-3)^{2}-2
$$

Representa mover el vértice 3 unidades a la derecha y 2 unidades abajo.

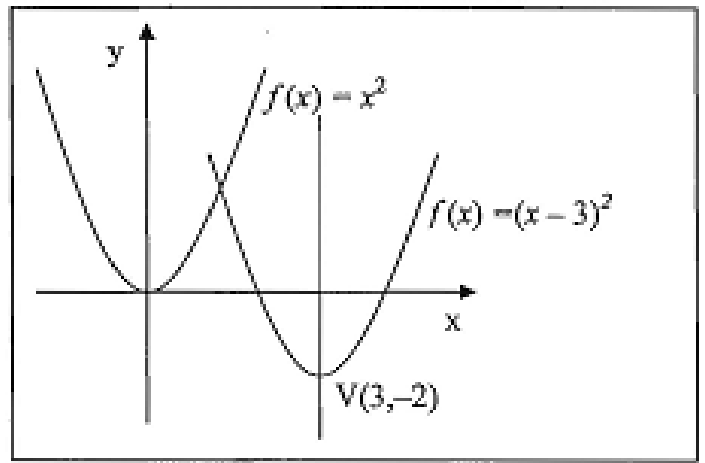


Del 39 al 46 se pide la gráfica, el vértice y la línea de simetría.
39. $f(x)=x^{2}$
$g(x)=(x-3)^{2}$
40.
$f(x)=\frac{3}{4} x^{2}$
42 .

$$
\begin{aligned}
& f(x)=\frac{1}{5} x^{2} \\
& g(x)=\frac{1}{5} x^{2}-2
\end{aligned}
$$

$$
\begin{aligned}
& g(x)=\frac{3}{4}(x+3)^{2} \\
& f(x)=x^{2} \\
& g(x)=x^{2}+2
\end{aligned}
$$
41. $f(x)=x^{2}$
43. $f(x)=\frac{1}{2}(x-3)^{2}+2$
44. $f(x)=4(x+2)^{2}+3$

Respuestas.

1. 1 y 5 .

2. 0 y 3 .

3. $0 \mathrm{y}-2$.

4. 0 y 1 .

5. -2 y 3 .

6. $\frac{2}{3} y-\frac{1}{2}$.

16. $x^{2}-3 x+5$.

17. 2 ceros.

18. No ceros.

19. No ceros.

20. 1 cero.

21. 2 ceros.

7. -3 y 4 .

8. $1 \mathrm{y}-2$

9. $-5 \mathrm{y}^{1 / 2}$.

10. $2 \mathrm{y}-3$.

11. 4.

12. $\frac{1}{3} \mathrm{y}-\frac{3}{2}$.

13. $x^{2}-3 x-2$.

14. $x^{2}+2 x-16$.

22. 1 cero.

23. $-\frac{1}{2}(1-\sqrt{3})$ y $-\frac{1}{2}(1+\sqrt{3})$.

24. $\frac{5 \pm \sqrt{73}}{6}$.

25. 2,39 y 0,27 .

26. 8,63 y $-4,63$.

27. $1+\sqrt{3}$ y $1-\sqrt{3}$

15. $-2 x^{2}-4 x+4$.

29.

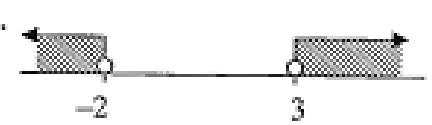

28. 0,33 y $-2,33$

30.



Prof. Jame, A. Escal.ante:

\section{No solución.}


32.

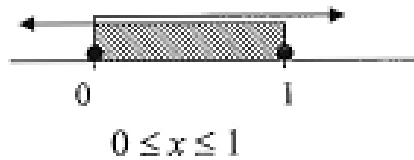

34. Todos IR.

35. $(x-5)^{2}$ sume 25 .

36. $\left(x+\frac{1}{2}\right)^{2}$ sume $1 / 4$.

39.

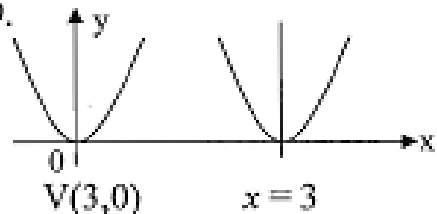

41.

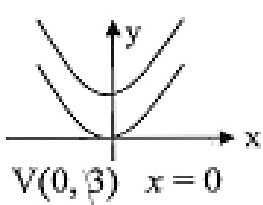

43.

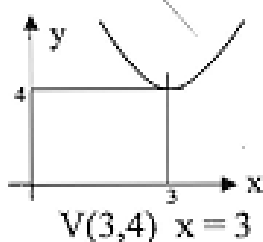

33.

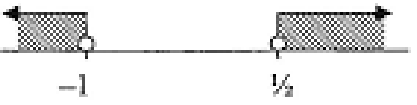

$(-\infty,-1) \vee(1 / 2, \infty)$

37. $\left(x-\frac{3}{4}\right)^{2}$ sume $\frac{9}{16}$.

38. $2(x+2)^{2}$ suma 8 .

40.

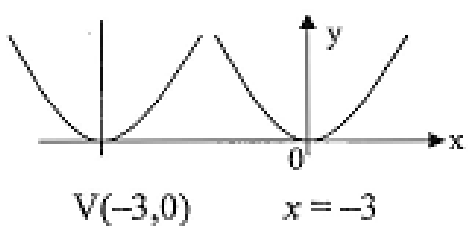

42.

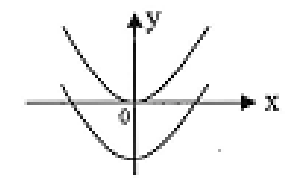

$\mathrm{V}(0,-2) \mathrm{x}=0$

44.

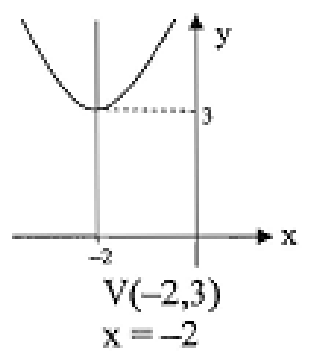




\section{ANEXO 8: Fotos de Jaime Escalante}

XI CONGRESO NACIONAL DE MATEMÁTICAS

Cochabamba, del 14 al 18 de febrero de 2005

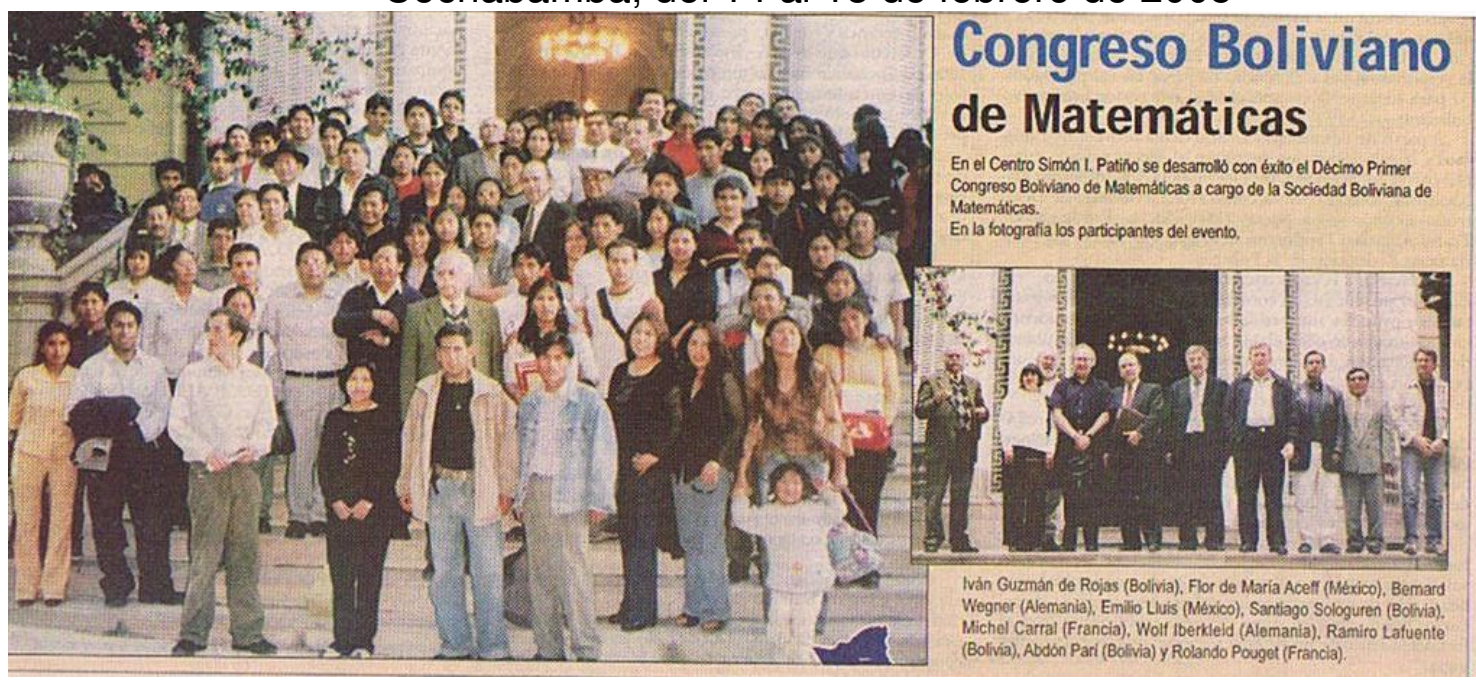

Jaime Escalante junto al presidente de la SoBolMat

Publicada el 25 de febrero de 2005 por el periódico Los Tiempos de Cochabamba.

Foto No 1

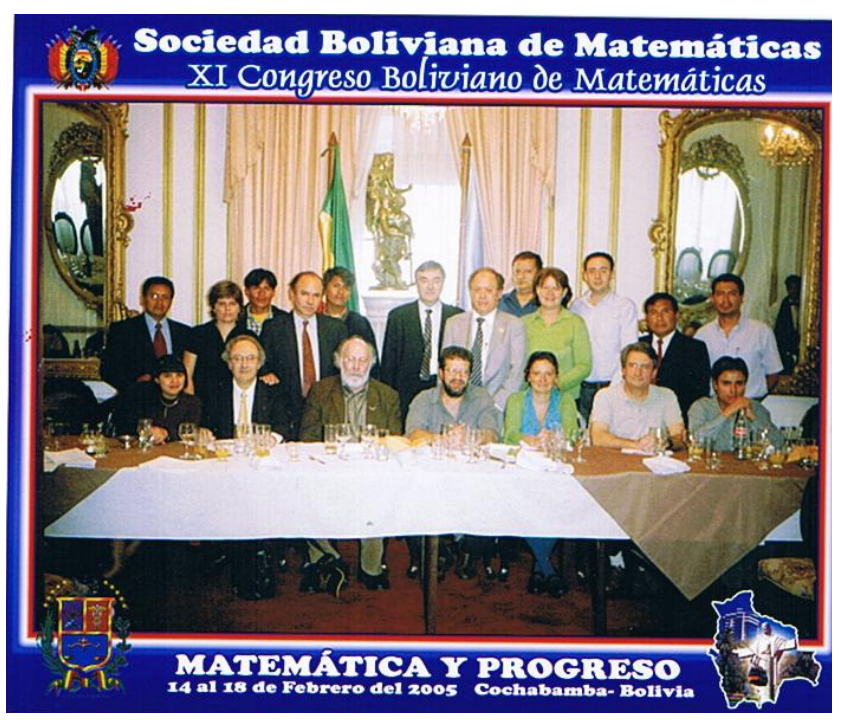

Foto No. 2

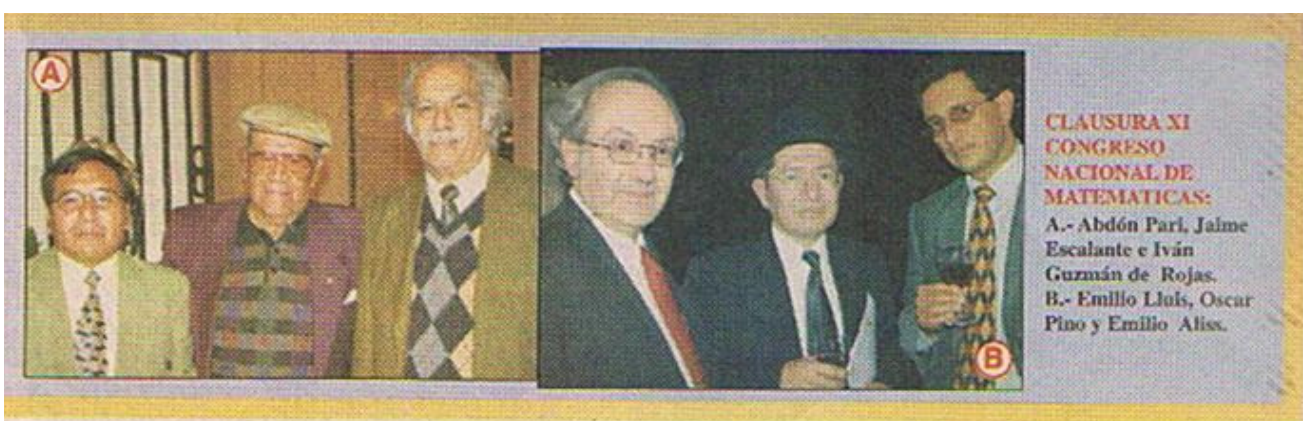

Foto No. 3 
Escalante en Garfield High School trabajó de 1974 a 1991

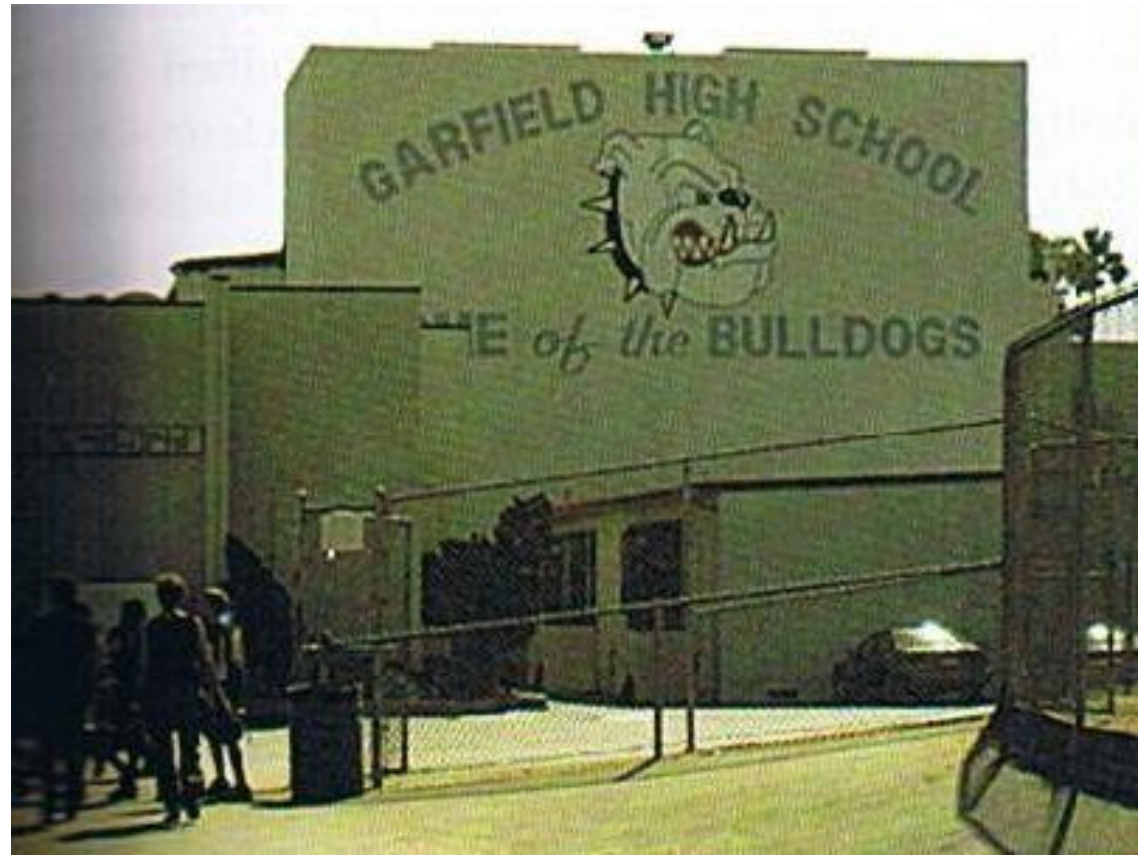

Foto No. 4

All He Needs Is Ganas. Escalante (2003) dice, en mi clase yo tengo un letrero que dice "ganas". Esto quiere decir "deseo". Usted debe tener el deseo. Las ganas son el inicio de la motivación.

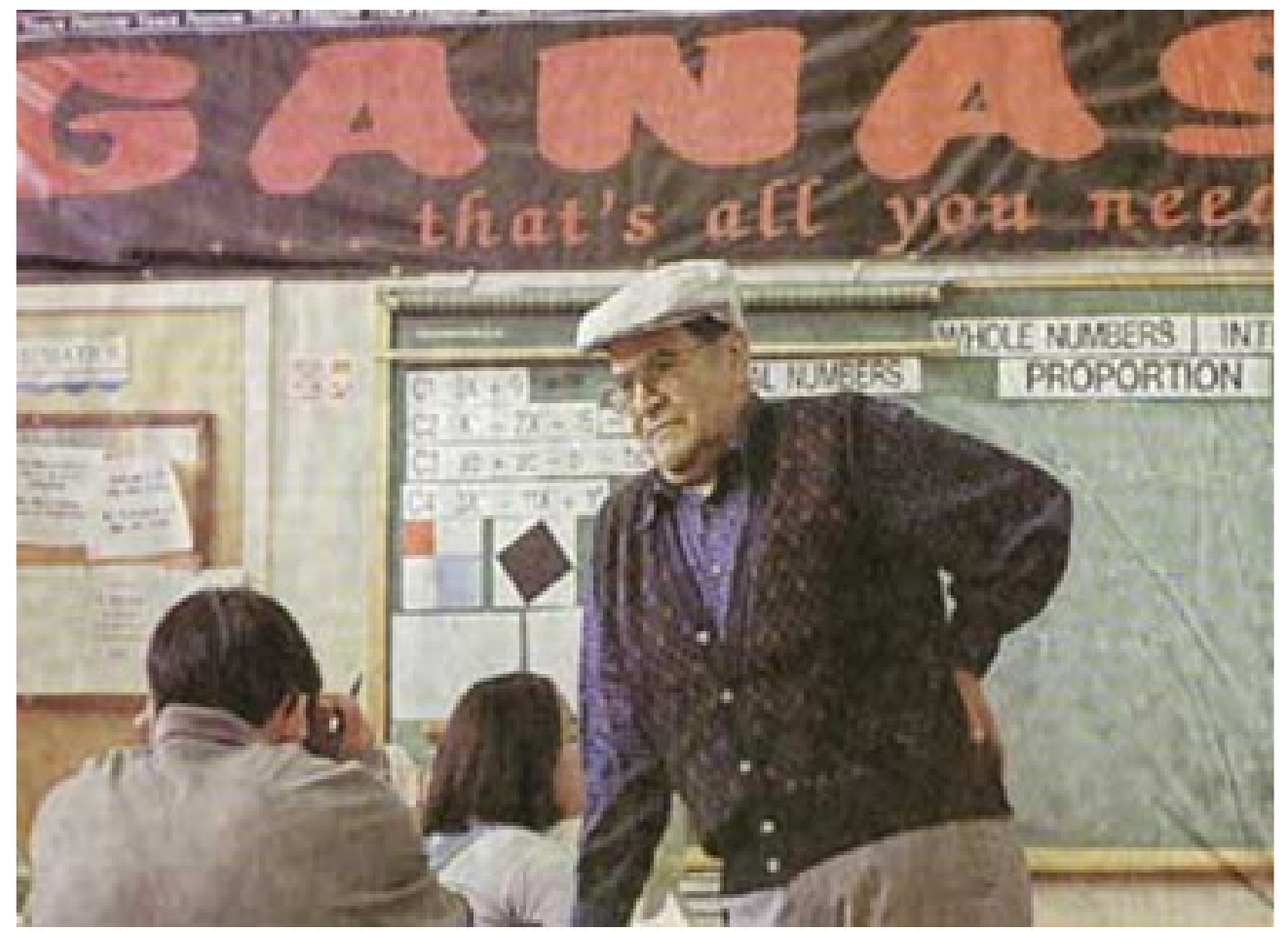

Foto No. 5 
Jaime Escalante preguntaba a sus alumnos, ¿qué vas a ser en la vida?, ¿Dónde está el dinero?, Él mismo daba la respuesta: "Está en la física, informática, biología, química y la electrónica. ¿Cuál es el leguaje que estos hablan?: "el lenguaje es la matemática"

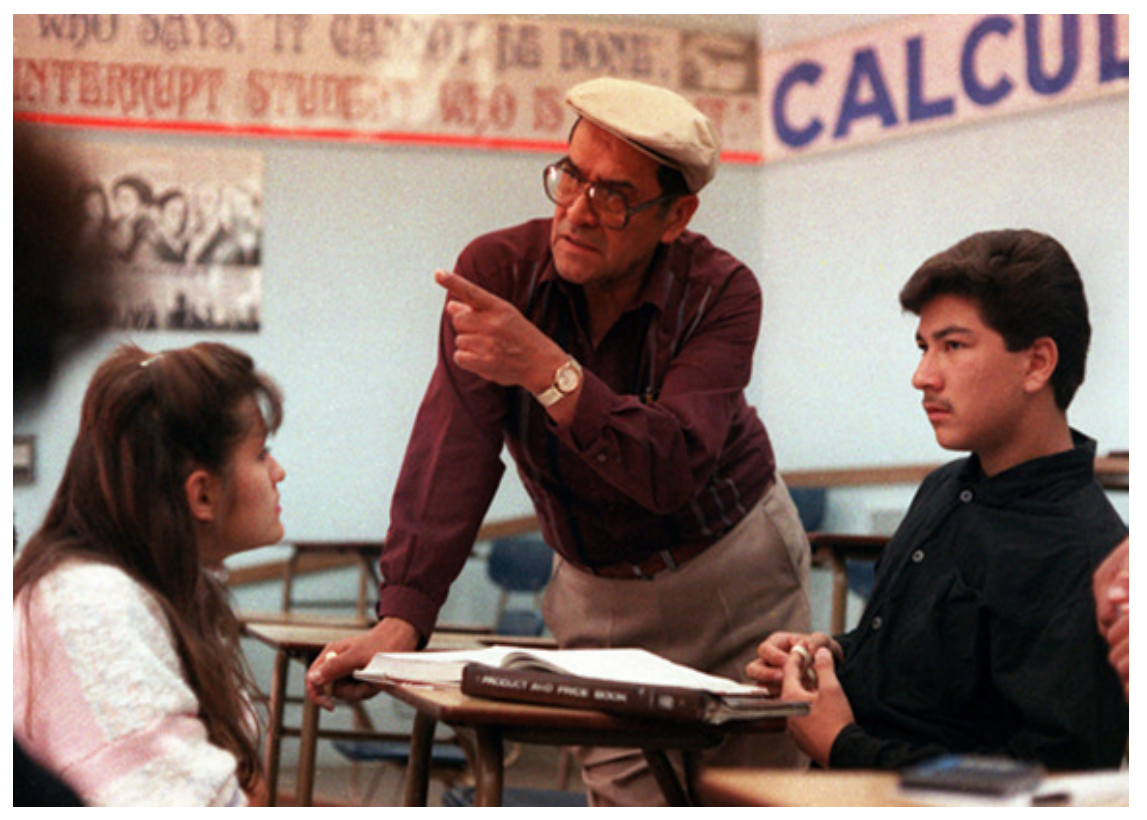

Foto No 6

Jaime Escalante usaba, un lema colgado en un lugar bien visible del aula y decía: "No hay necesidad de hacer facil el cálculo porque ya es fácil"

Método de integración Escalante.

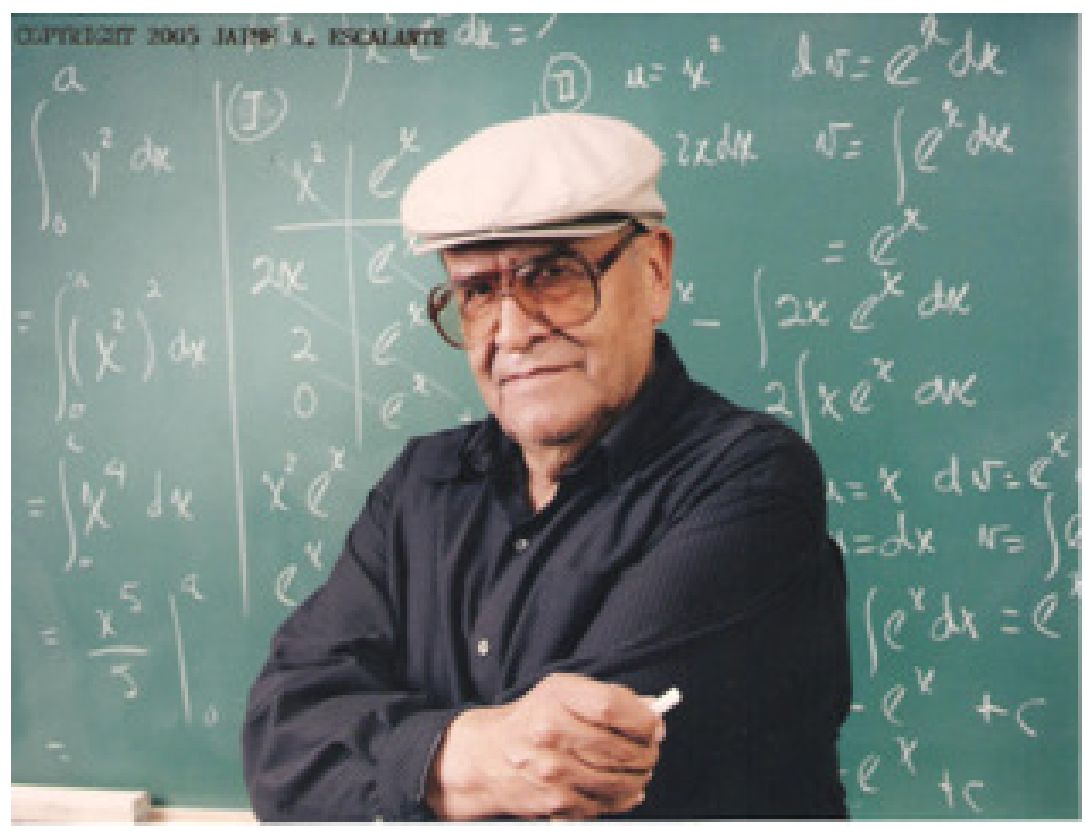

Foto No. 7 
Jaime Escalante ha dado a su metodología un enfoque de equipo, el profesor como el técnico y los estudiantes en papel de equipo. El rival eran los exámenes anuales o las competiciones como las Olimpiadas Matemáticas o el AP de cálculo.

Los estudiantes de primer curso, recibían chaqueta color blanco.

Los estudiantes de segundo curso, recibían chaqueta de color azul.

Los estudiantes de tercero recibían chaqueta de color rojo

Los estudiantes de cuarto que era el último, usaban chaqueta negra, y ellos eran los ayudantes de Escalante.

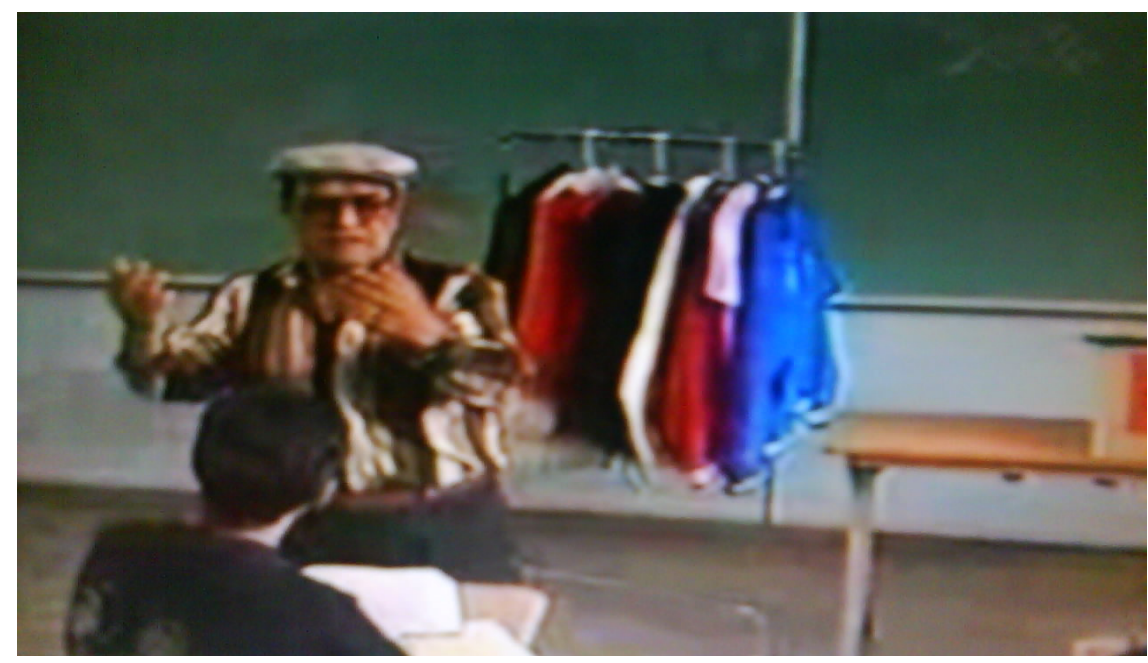

Foto No. 8

El equipo de profesores que formó Escalante en Garfield High School

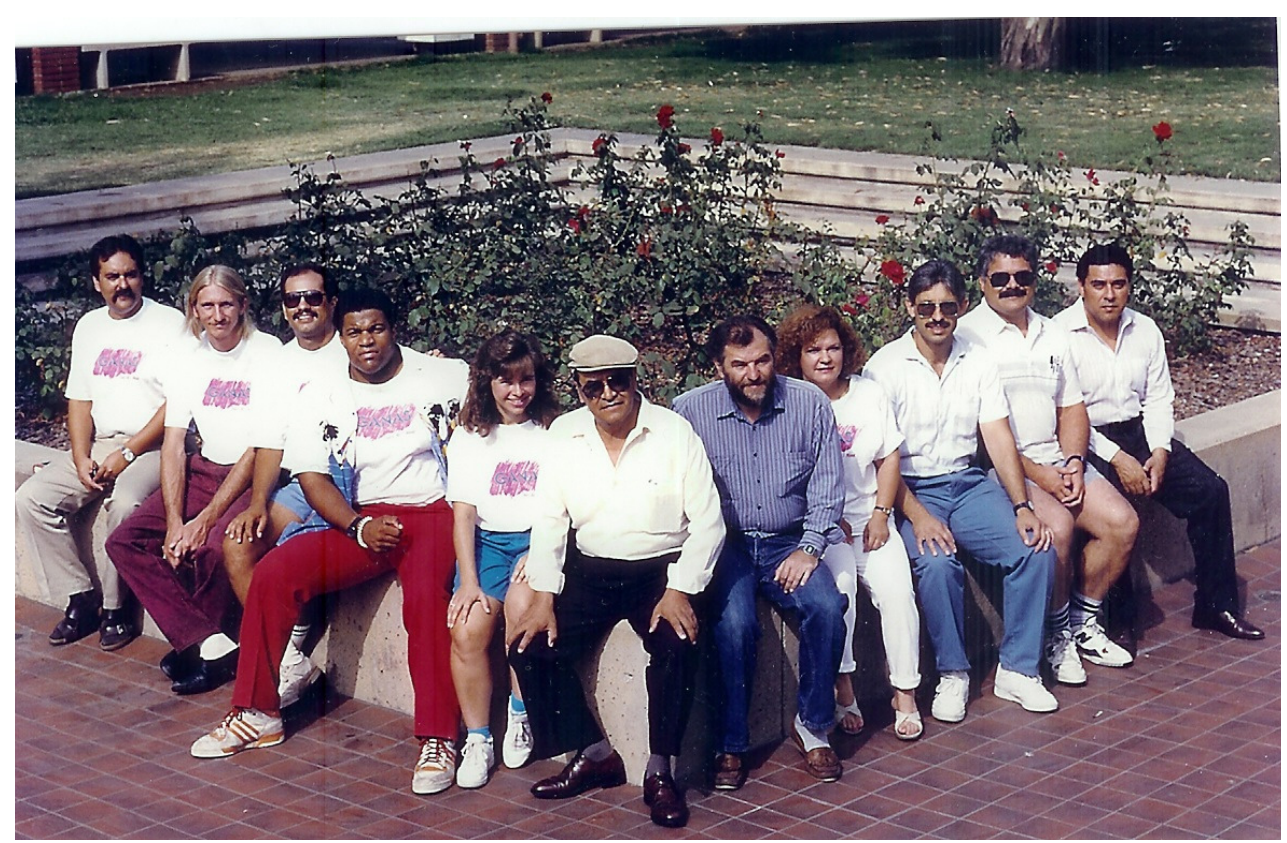

Foto No. 9 
Los estudiantes del Programa de Matemáticas de Escalante en Garfield High School.

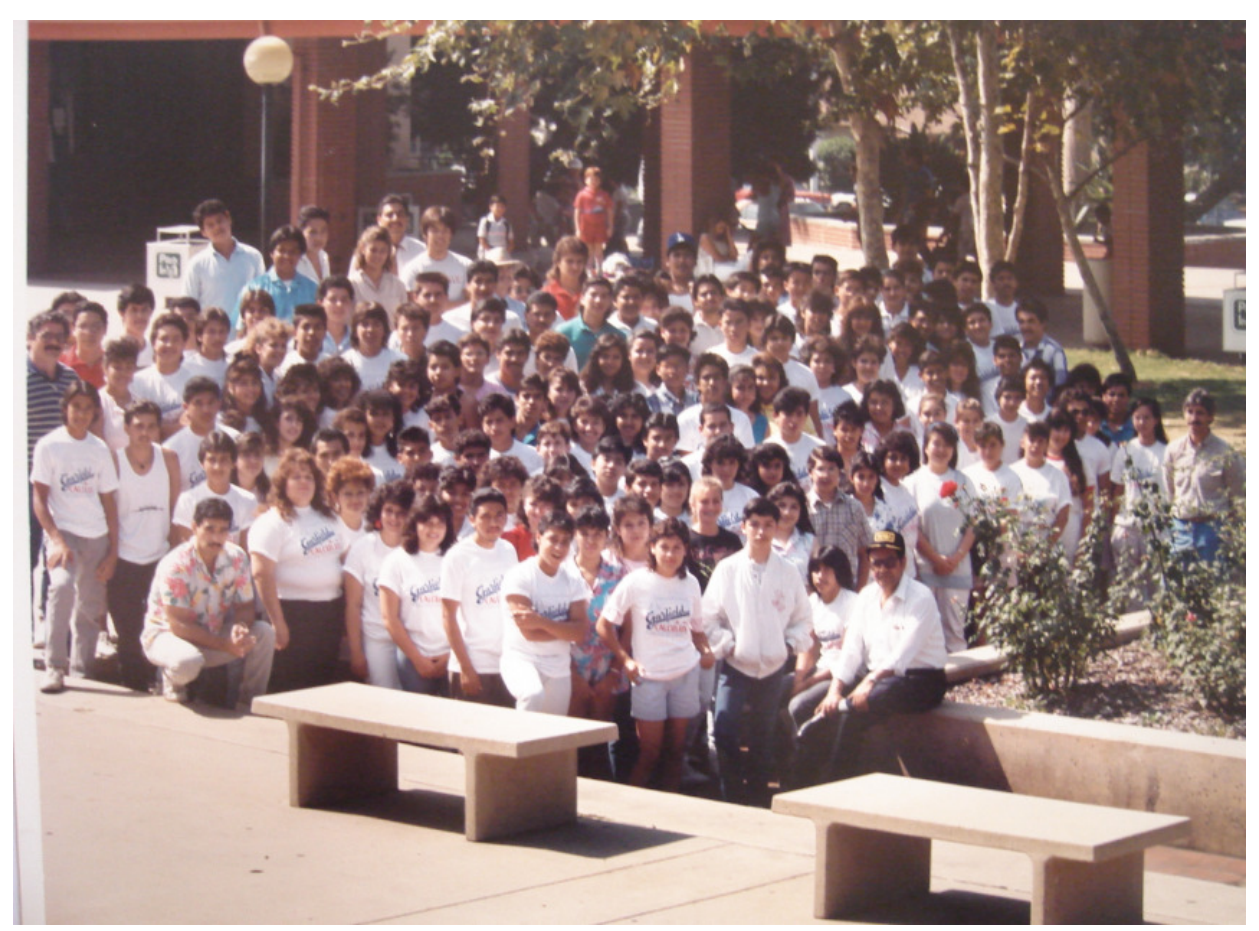

Foto No. 10

La capacidad de impacto del profesor testimoniada por sus exalumnos

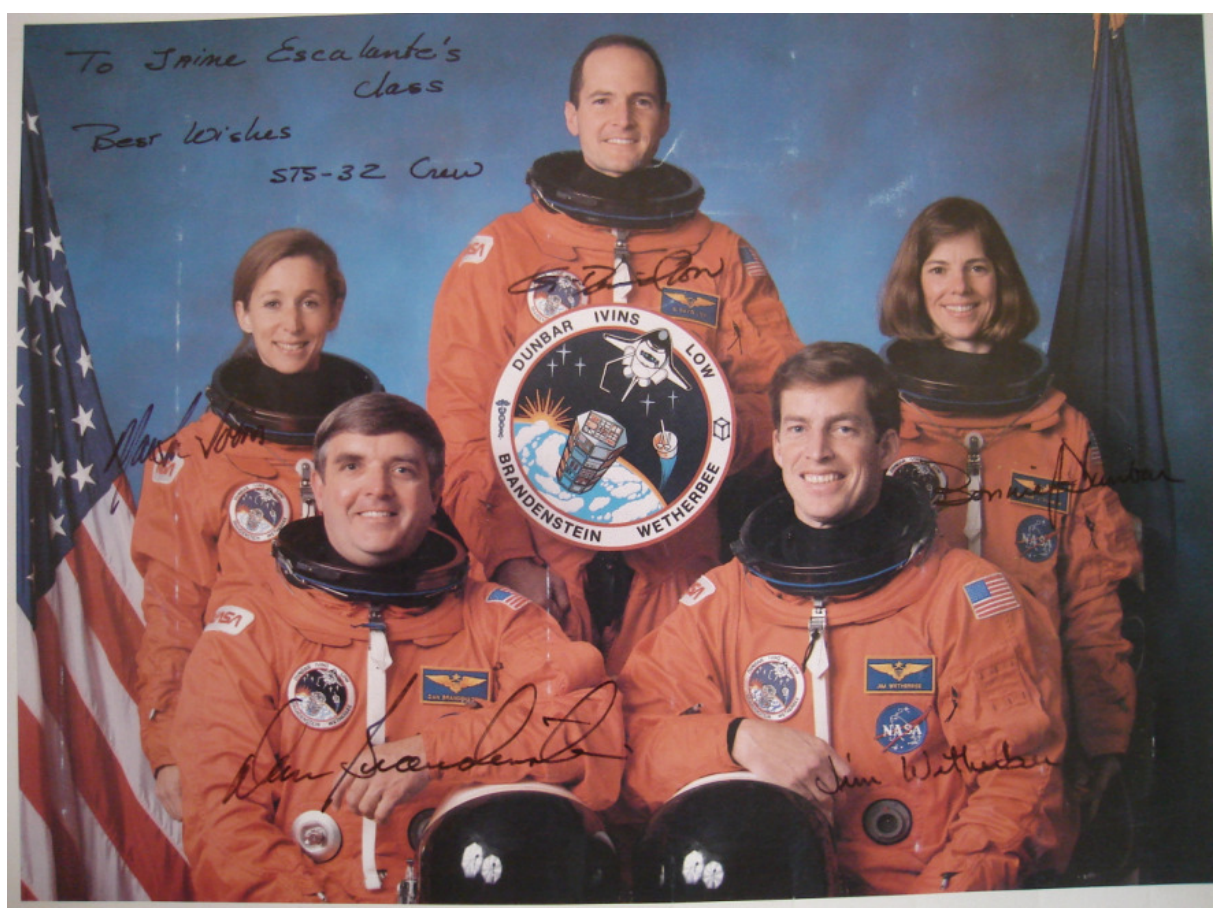

Foto No. 11 
Jaime Escalante Asesor de la NASA

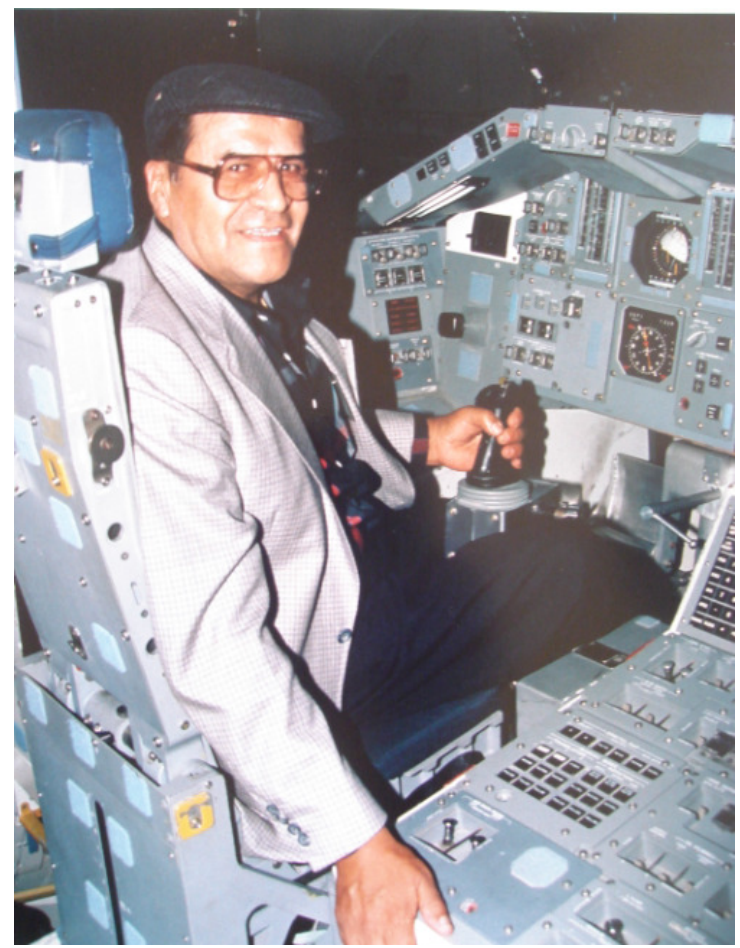

Foto No. 12

Jaime Escalante premiado con la Medalla Presidencial a la Excelencia en Educación del presidente Ronald Reagan

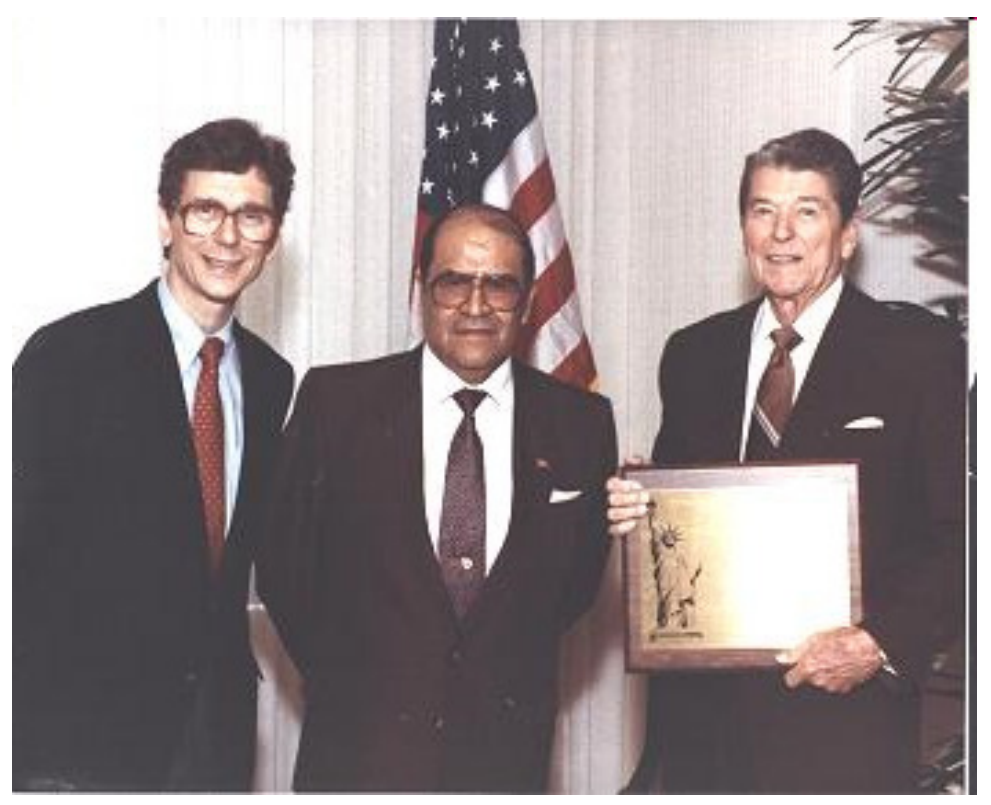

Foto No. 13 


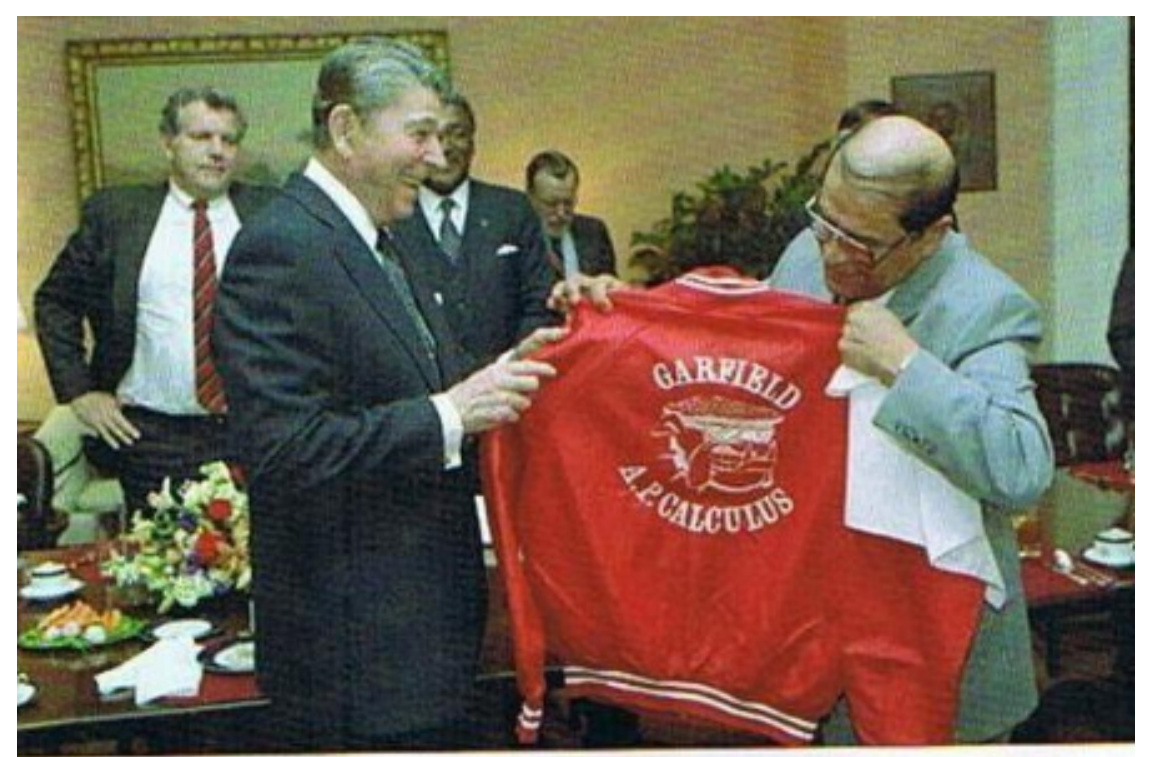

President Ronald Reagan welcomed Escalante at a teacher's Iunch in 1984.

Foto No. 14

Profesor Jaime Escalante con el presidente George H. W Bush en la Casa Blanca

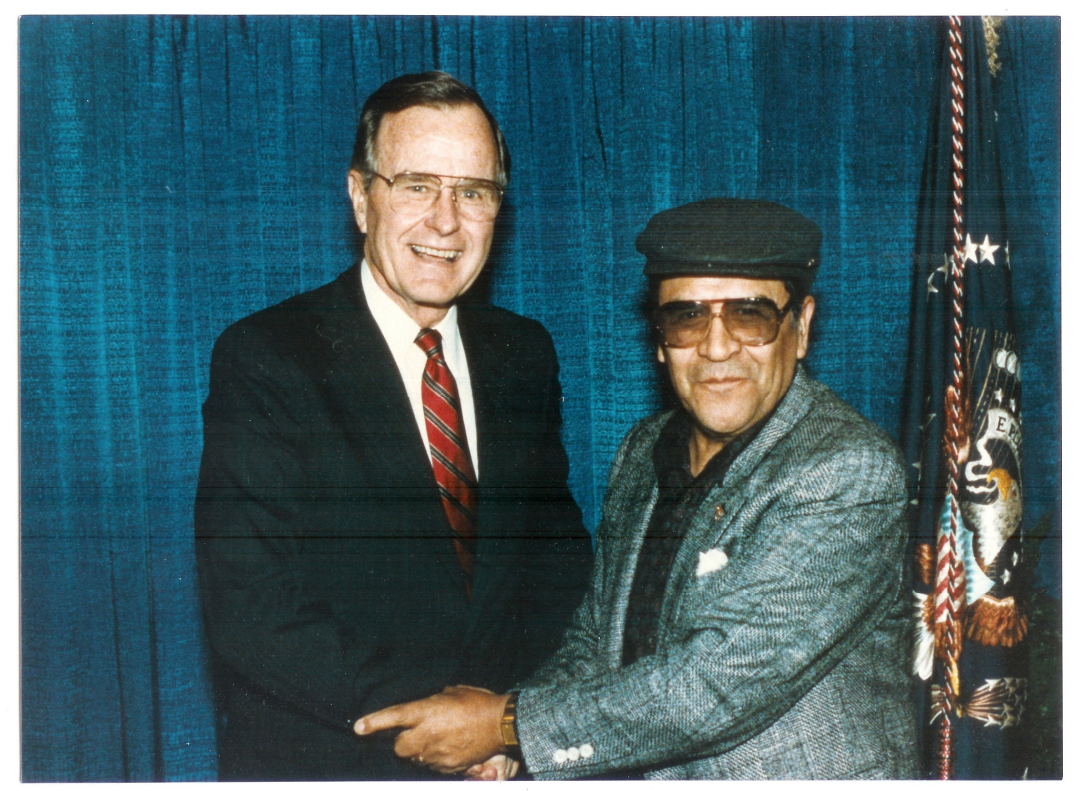

Foto No. 15 
George H. W. Bush en la clase de Jaime Escalante

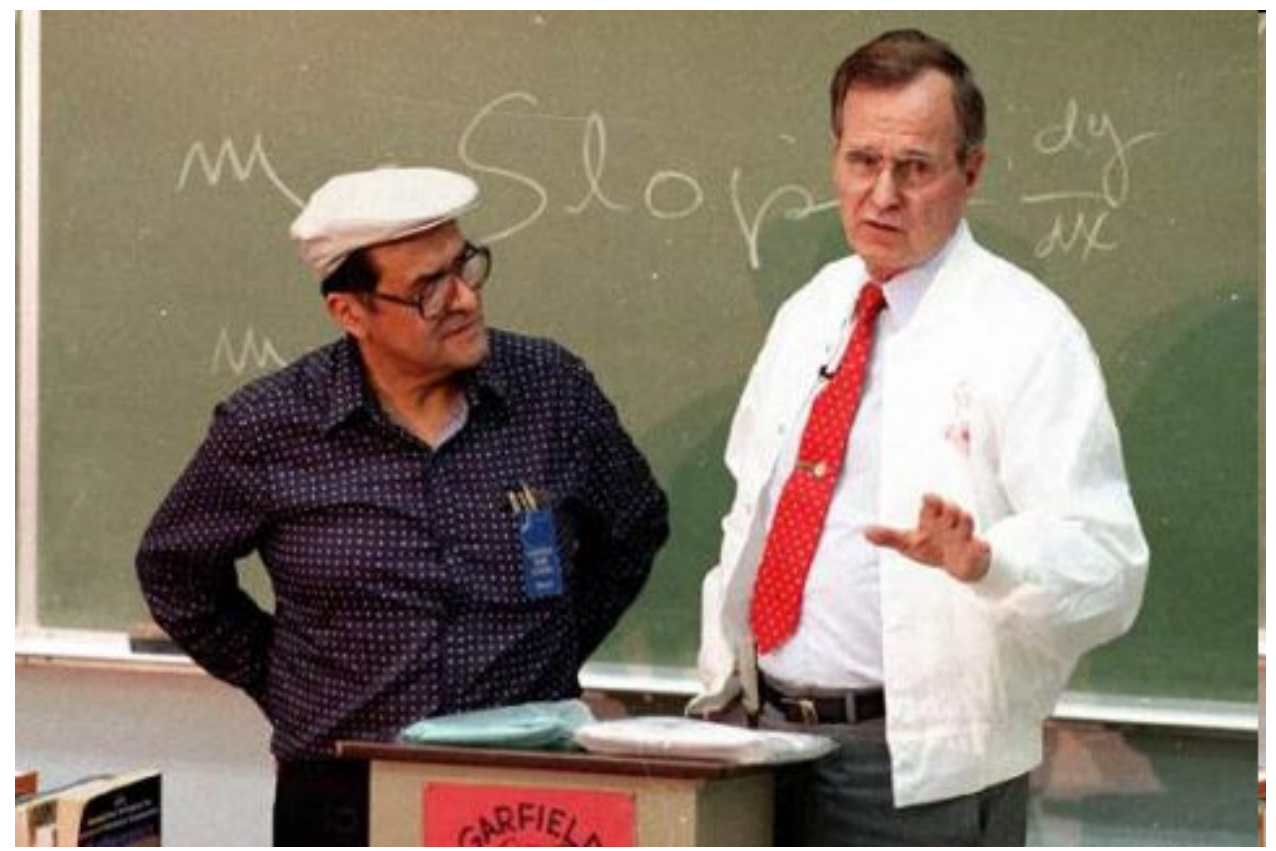

Foto No. 16

El profesor Jaime Escalante y el actor Edward James Olmos quien lo personificó en la película de Stand and Deliver conocido en Latinoamérica como "Con Ganas de Triunfar" y en España como "Lecciones Inolvidables".

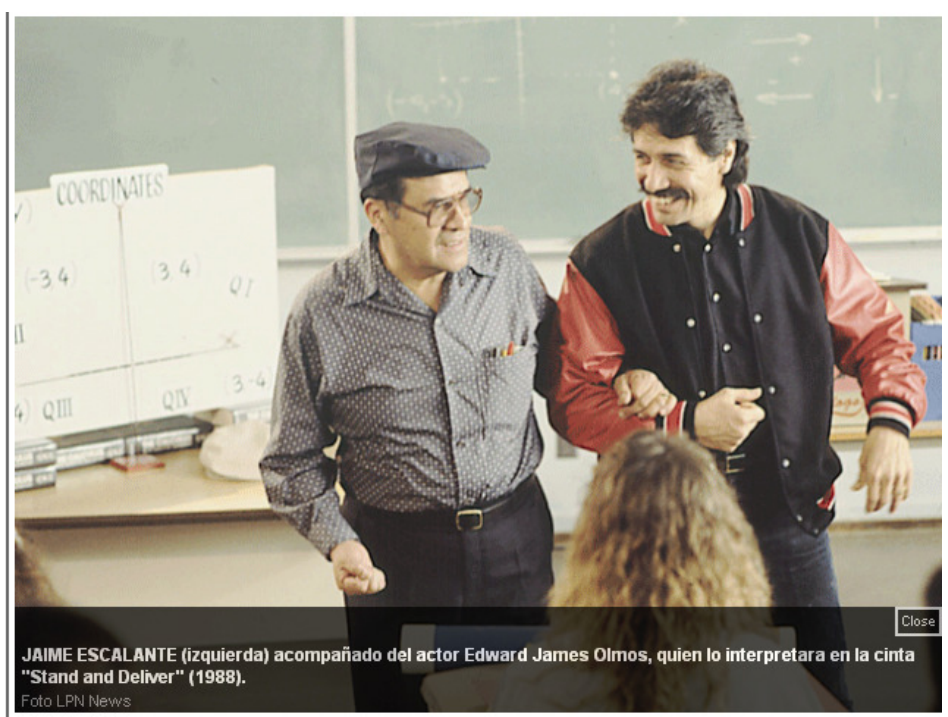

Foto No. 17 
Escalante con su gorra, explicando los trucos numéricos

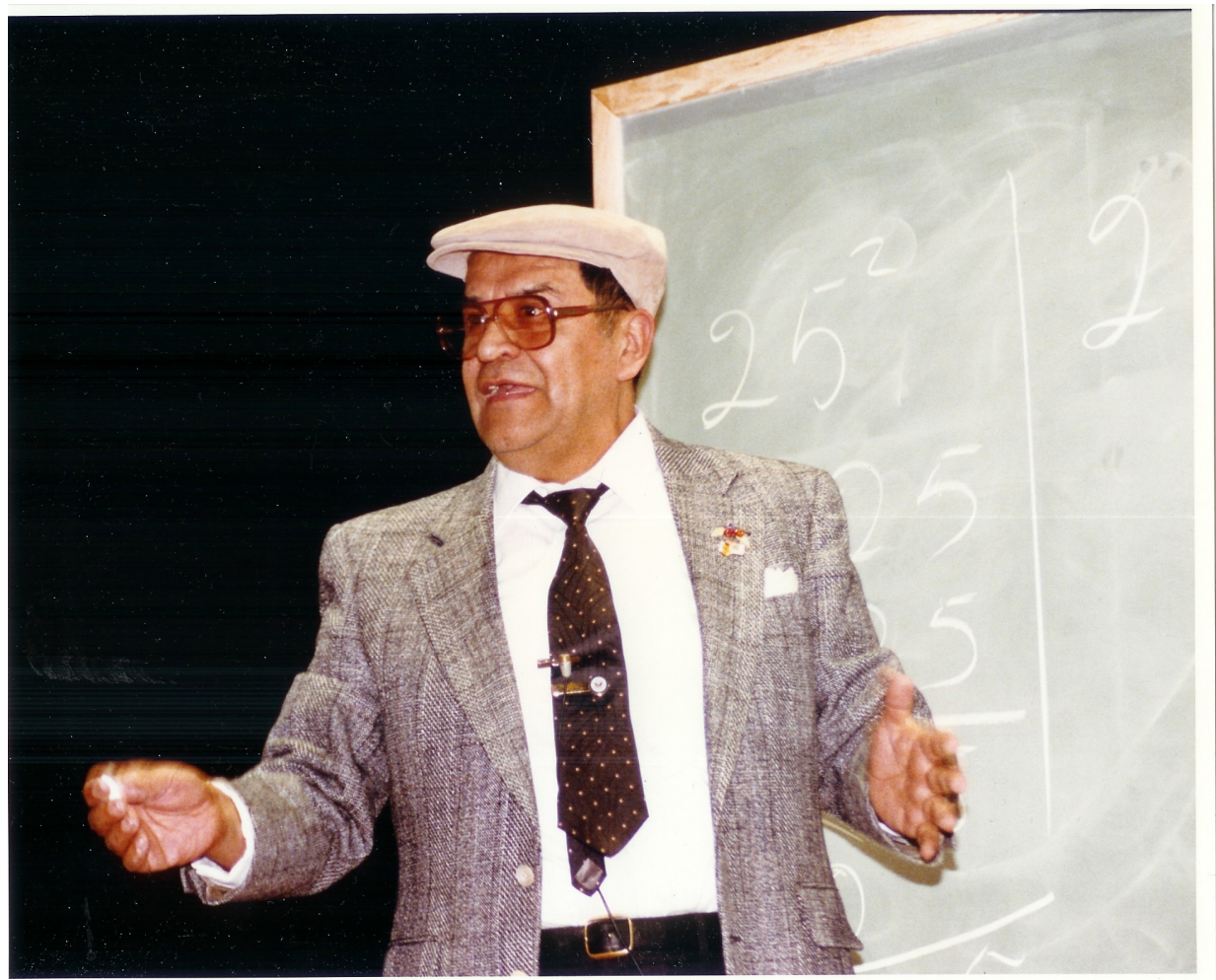

Foto No. 18

Escalante enseña a multiplicar con los dedos en sus seminarios y talleres para profesores de matemáticas y estudiantes.

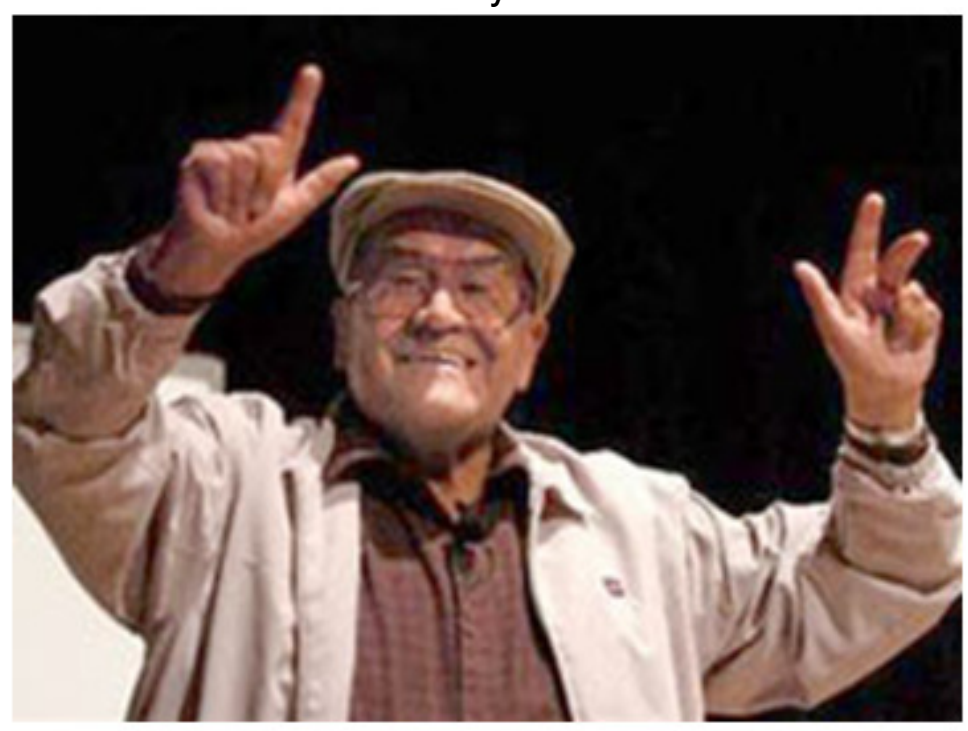

Foto No. 19 
Jaime Escalante recomienda, nunca entrar por la definición sino comenzar por lo que el alumno más conoce o sabe. Realiza una explicación a partir del cumpleaños de los alumnos usando el calendario para la suma de diagonales e introducir el concepto de la traza de matrices



Foto No. 20

Jaime Escalante realiza la demostración de la pendiente de una recta con un juguete en su sala de estudio en la ciudad de Cochabamaba, donde fue entrevistado por el investigador.

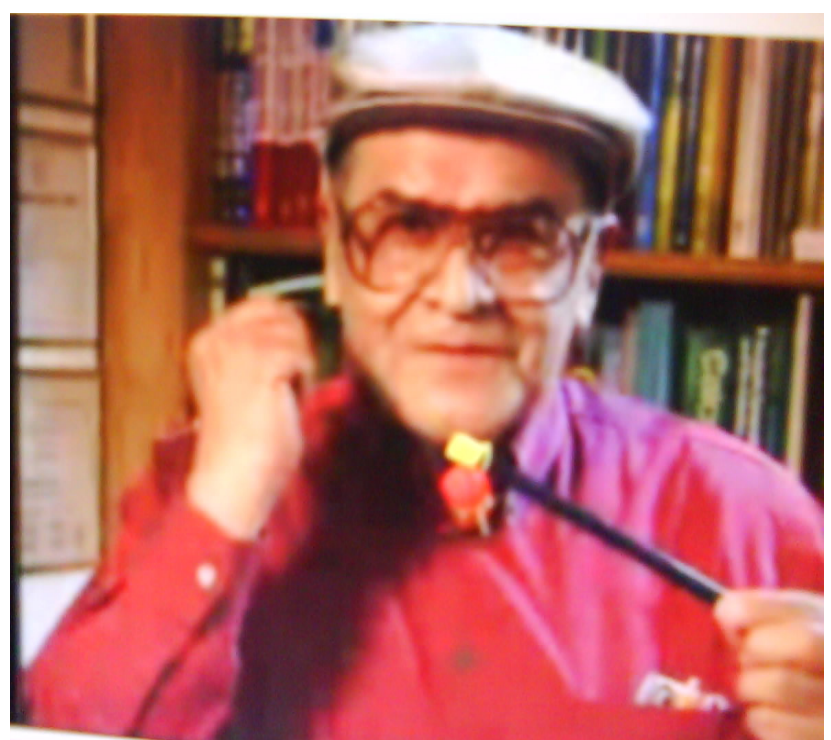

Foto No. 21 
Jaime Escalante realizaba la orientación vocacional y motivacional con la participación de sus exalumnos en el salón de clases

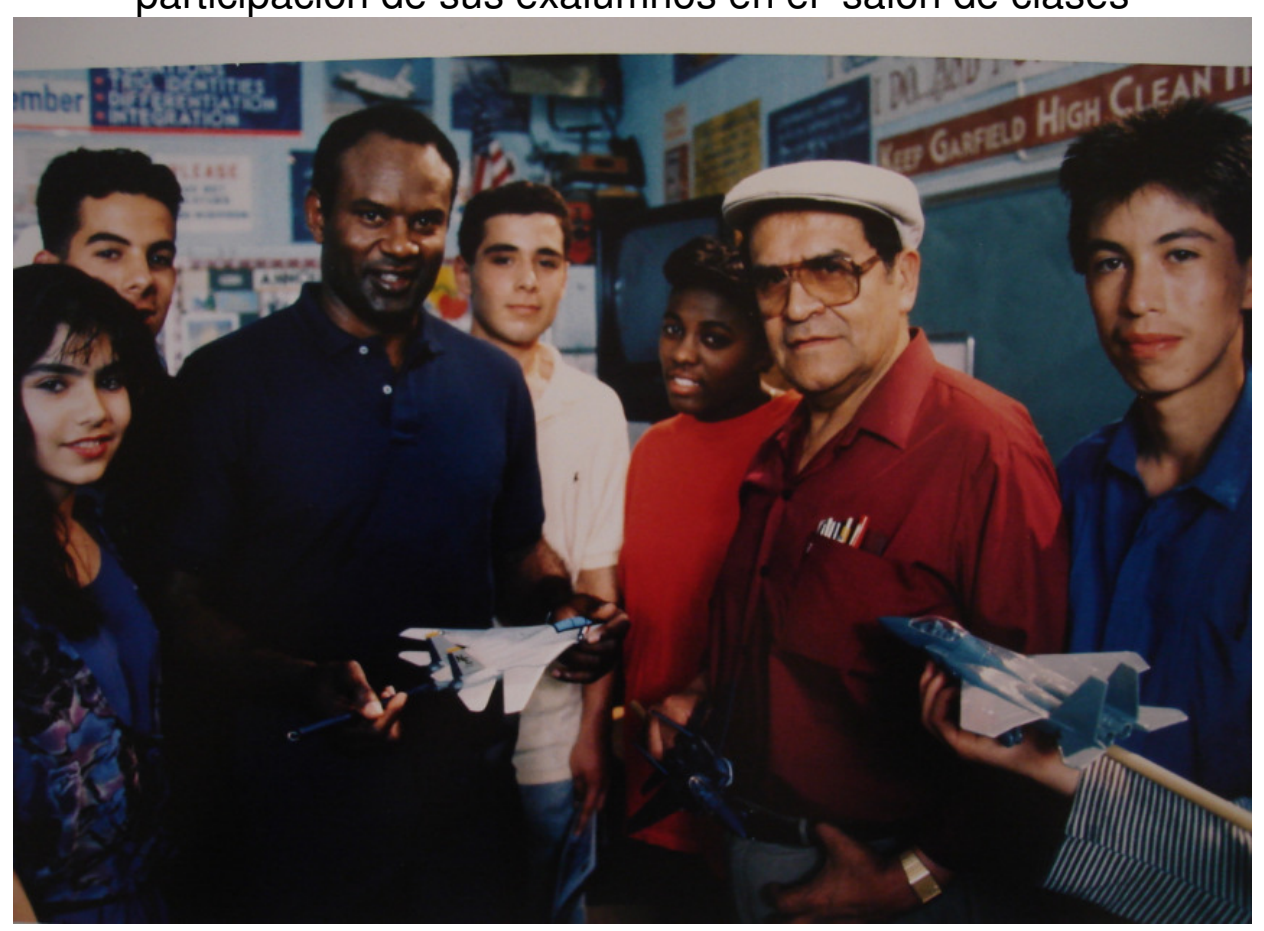

Foto No 22

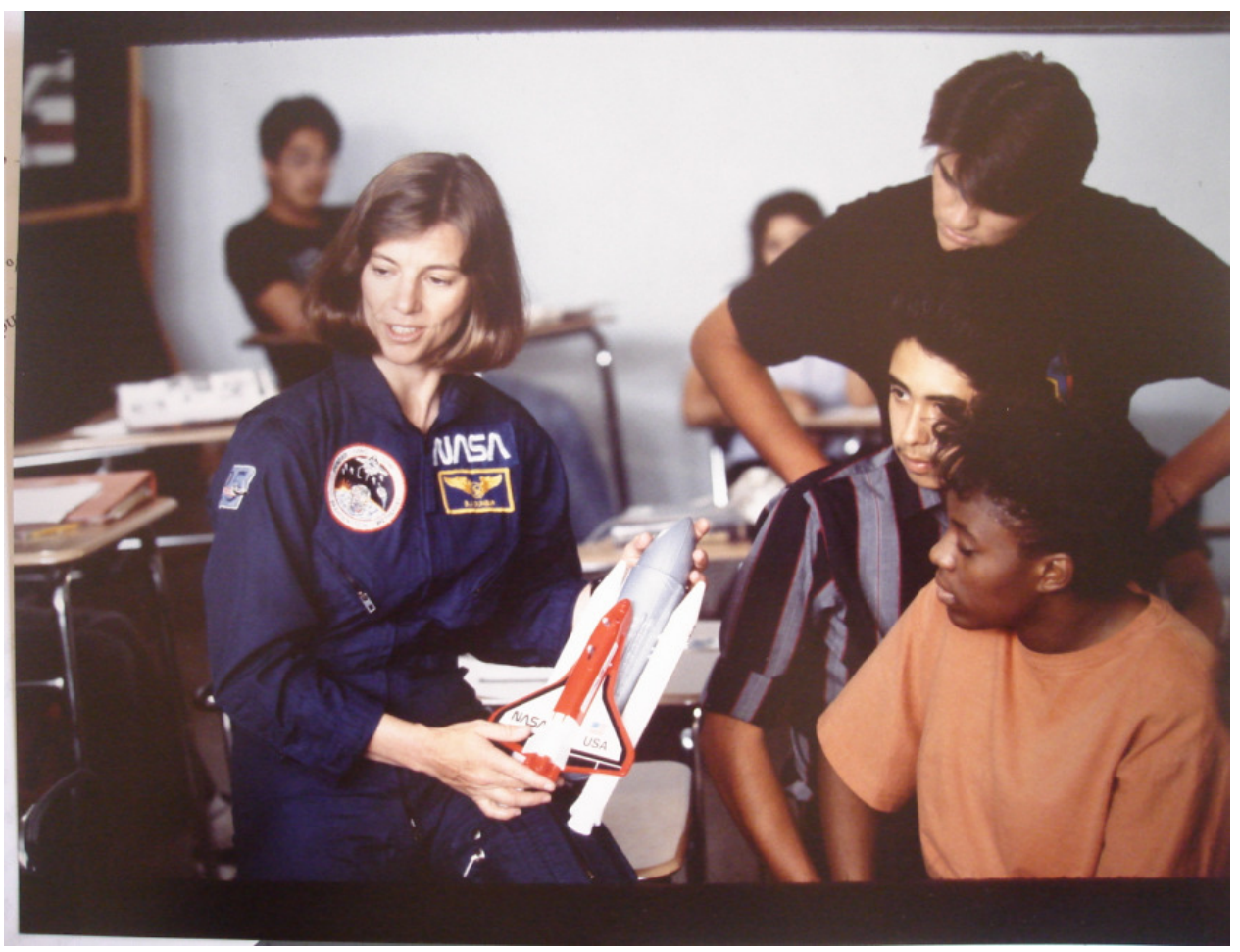

Foto No. 23 
Jaime Escalante dice: "para enseñar matemáticas tienes que llevar un juguete, para que los alumnos vean la matemática como un juego"



Foto No. 24

Jaime Escalante y Abdón Pari en el periodo de la entrevista. Cochabamba Bolivia

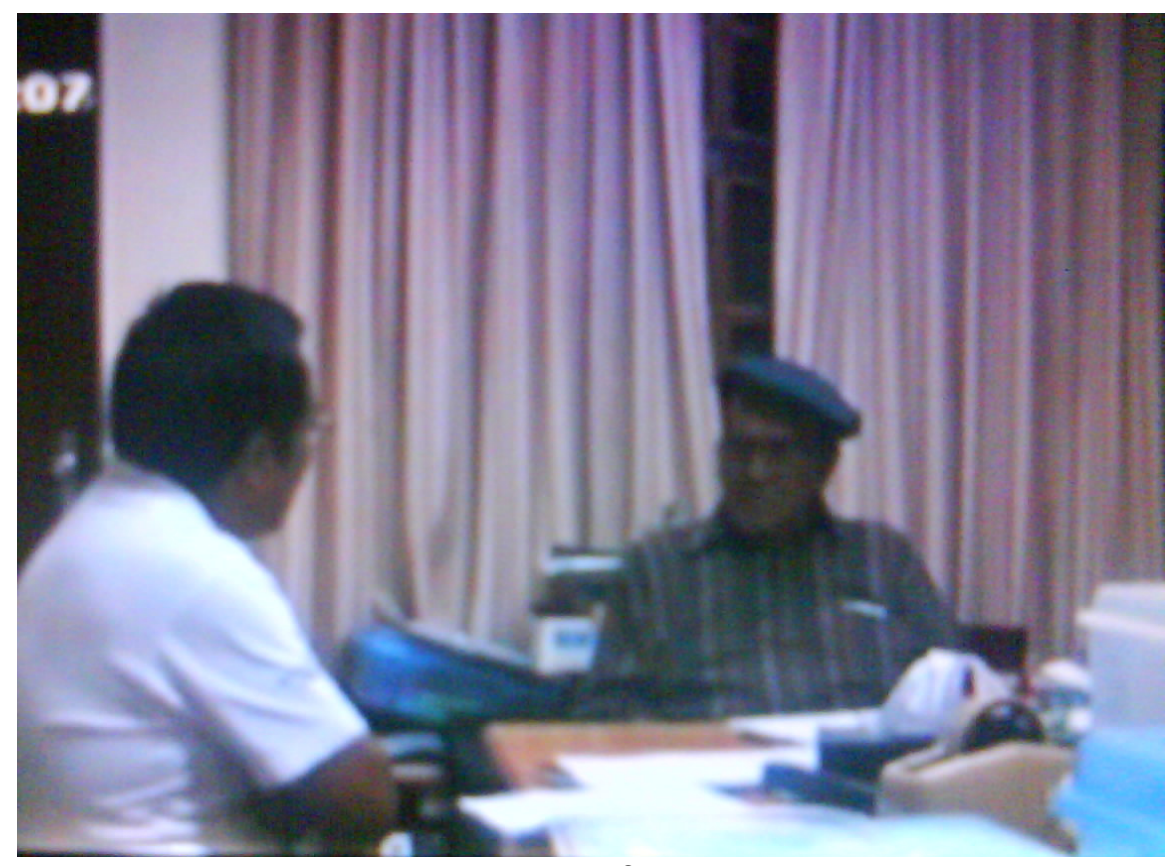

Foto No. 25 
Jaime Escalante en Bolivia



Foto No. 26

Escalante se gradua en San Calixto

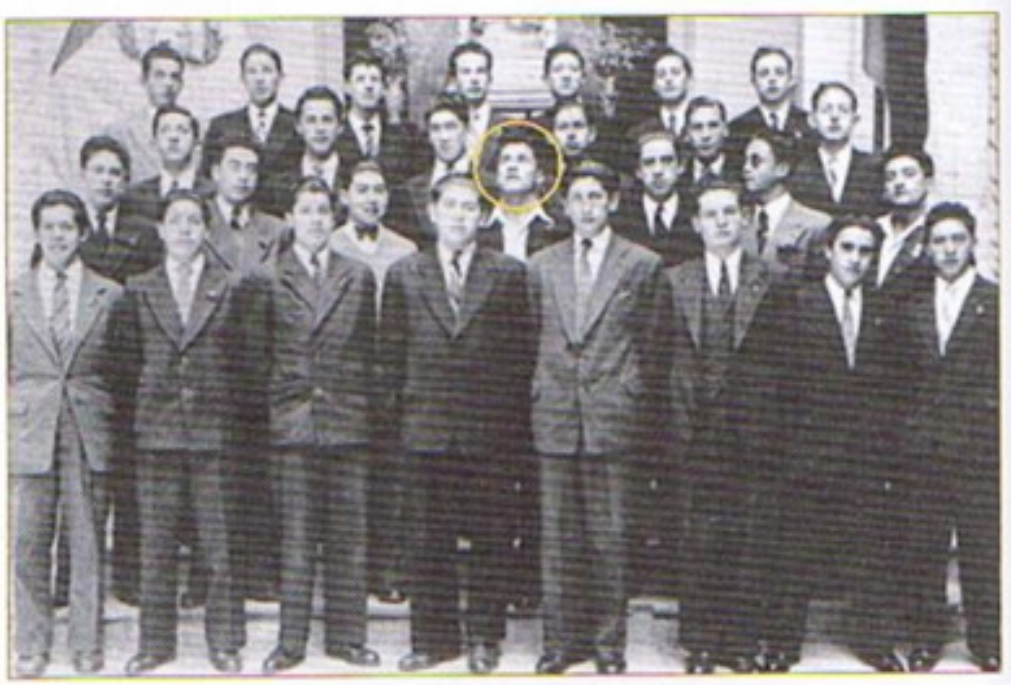

Escalante (in center, looking up) graduated from San Calixto Jesuit High School.

Foto No. 27 


\section{Escalante a sus siete años}

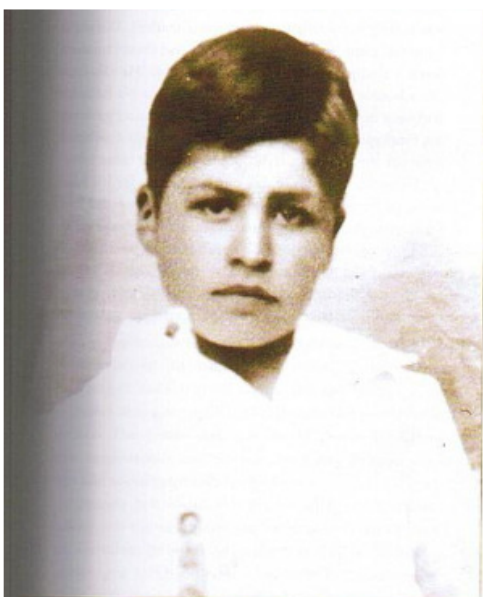

Foto No. 28

Jaime Escalante nació en Sopocachi, La Paz

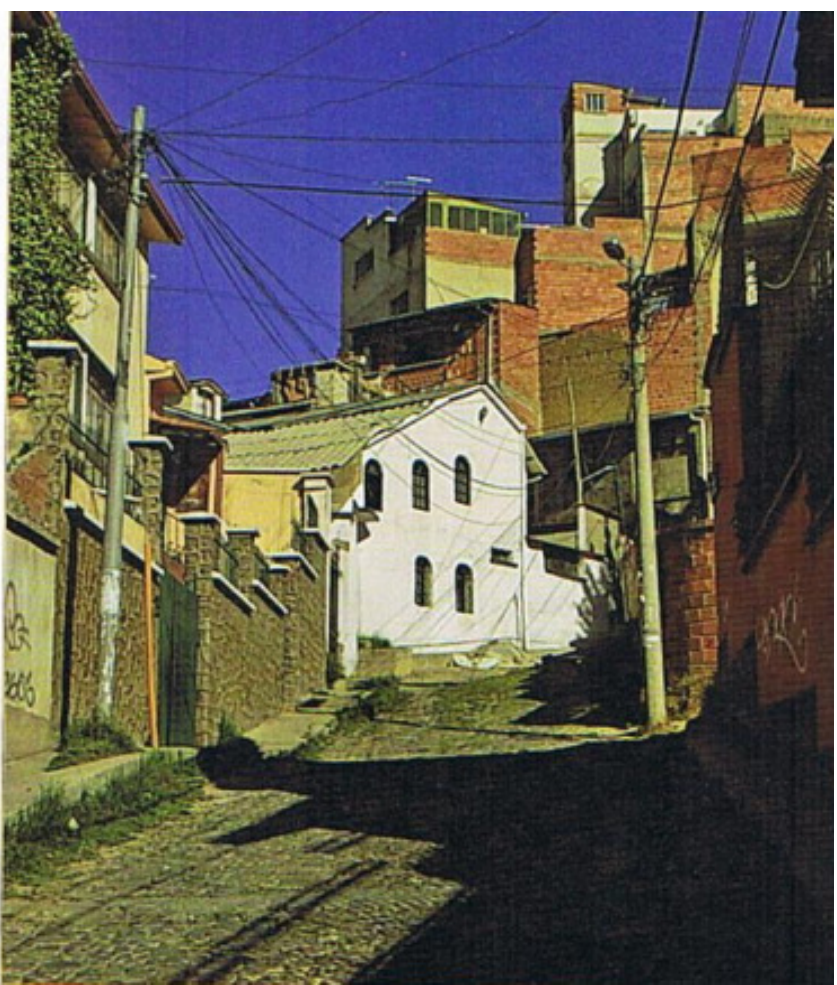

Foto No. 29

La mayoria de las fotos de la investigación fue proporcionada por el mismo profesor Jaime Escalante. 